UNIVERSIDAD NACIONAL DE LA PLATA

FACULTAD DE PERIODISMO Y COMUNICACIÓN SOCIAL

Trabajo de Tesis realizado como requisito para optar al título de Doctor en Comunicación

\title{
TÍTULO:
}

\section{Radio Sutatenza y Acción Cultural Popular en la era digital}

Producción de sentido y construcción de ciudadanías en las Escuelas Digitales Campesinas

AUTOR: Juan Carlos Pérez Bernal

DIRECTOR: Darío Gabriel Martínez 


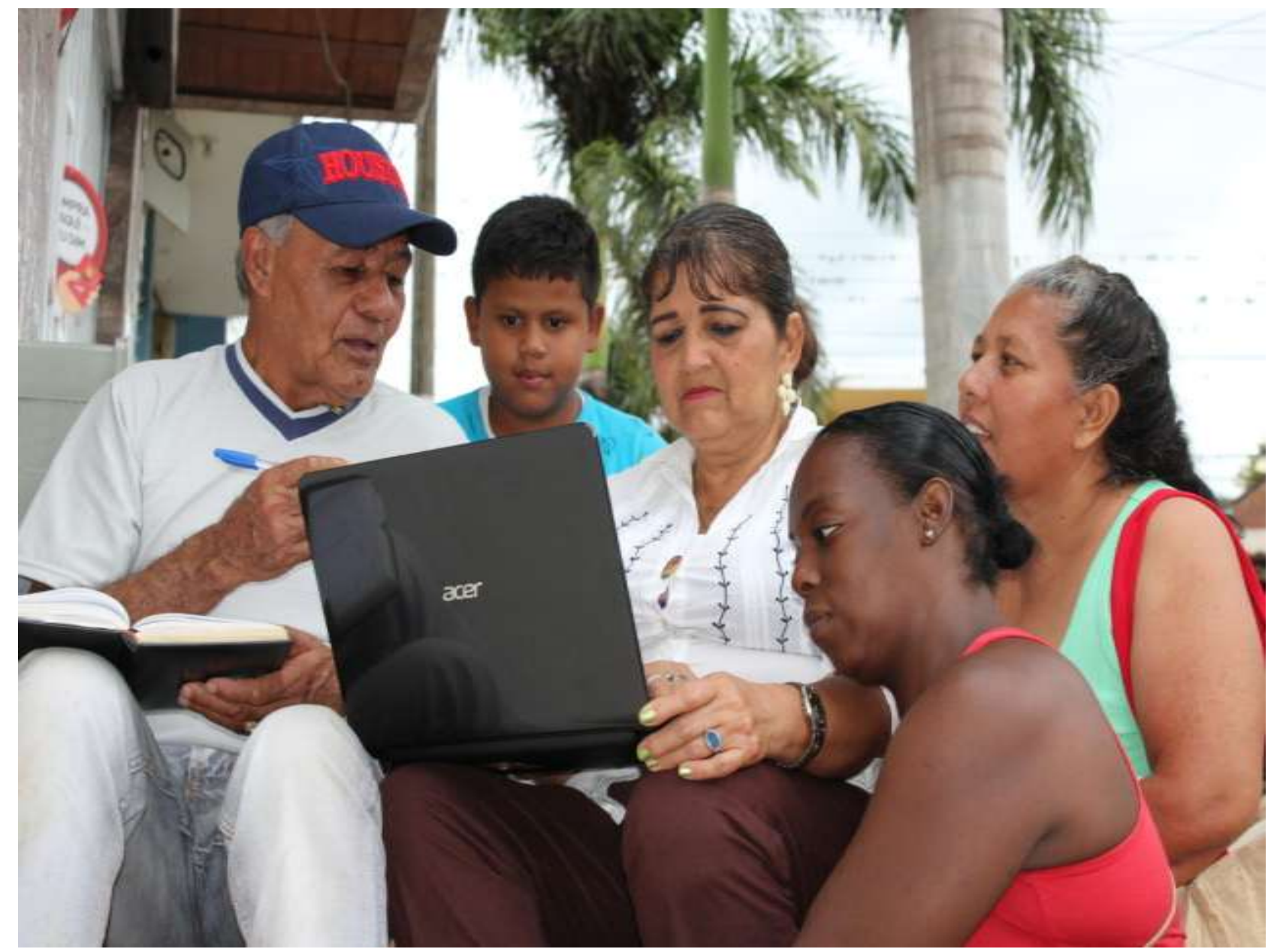

Foto cortesía ACPO-elcampesino.co 


\section{Agradecimientos}

Muchas gracias a Dios y a todas aquellas personas que me acompañaron en este proceso y, en especial, a quienes con su lectura crítica contribuyeron al propósito de lograr el mayor rigor posible en un trabajo lleno de sobresaltos y de incertidumbres, pero también de muchas satisfacciones.

Mi especial reconocimiento a los profesores Liliana María Gómez Céspedes , Darío Gabriel Martínez y Liliana Beatriz Irizar, por sus aportes generales y puntuales en materias tan complejas como la Comunicación/Educación, la democracia radical y el humanismo cívico. Y, por supuesto, a las campesinas, campesinos, indígenas y afrodescendientes, quienes en su calidad de estudiantes o facilitadores de las Escuelas Digitales Campesinas, son protagonistas de los relatos y análisis, inmersos en ejercicios de Investigación Acción Participativa (IAP), piedra angular de nuestra tesis.

A Edna, mi querida esposa, y a mis hijitas, María Alejandra y Juanita, gracias mil por su amor incondicional, el mismo que siempre tengo para ellas. 
Radio Sutatenza y Acción Cultural Popular en la era digital 


\section{Contenido}

Introducción

\section{Capítulo I}

Rutas para la producción de sentido en las Escuelas Digitales Campesinas, EDC (1)....15

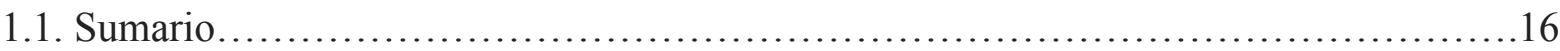

1.2 Introducción..................................................................

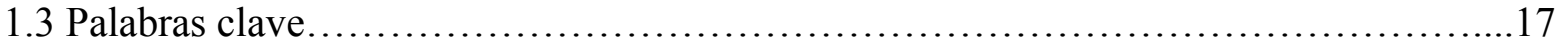

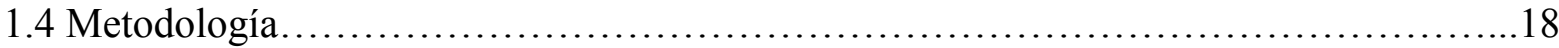

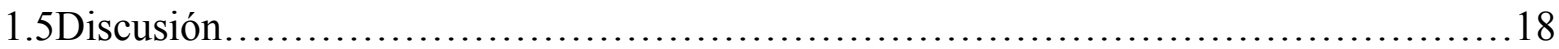

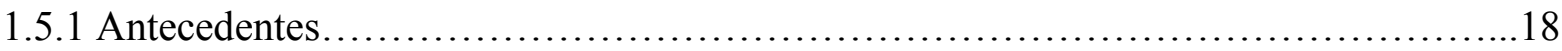

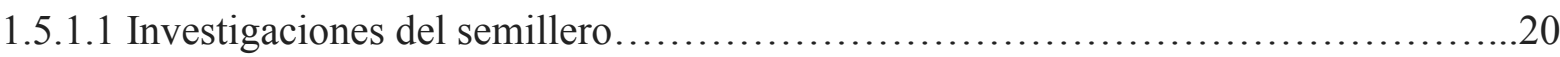

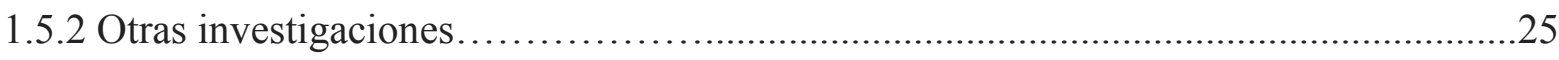

1.5.2.1 La investigación en comunicación popular....................................28

1.5.2.2 Construcción de identidades....................................................

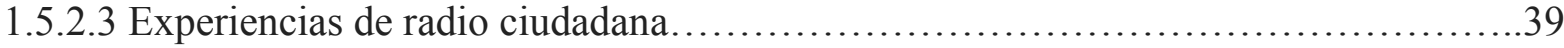

1.5.2.4 Lecciones de Radio Sutatenza................................................46

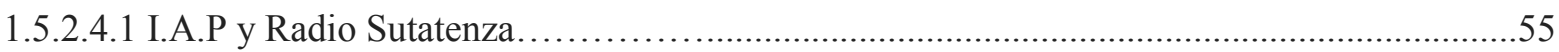

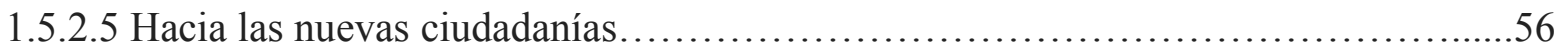

1.6 Conclusiones................................................................... 71

\section{Capítulo II}

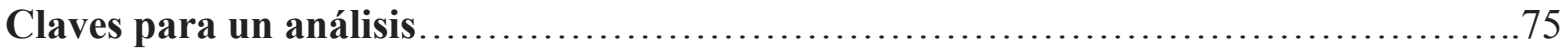

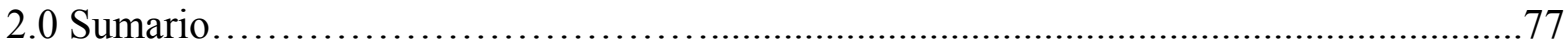

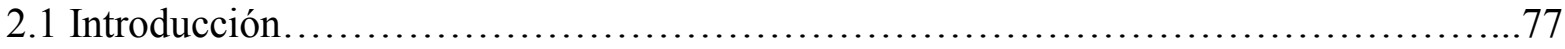

2.2 ACPO en clave de comunicación................................................. 79

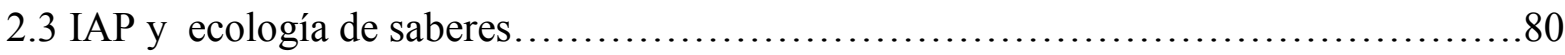

2.3.1 Participación e implicación.................................................. 82

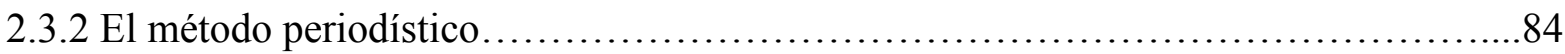

2.3.2.1 Polifonía de voces en clave periodística............................................. 86

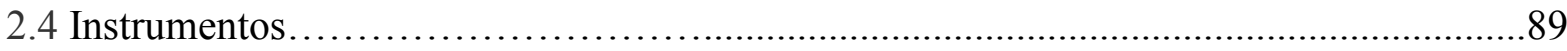

2.5 Producción de sentido en las EDC................................................. 
2.5.1 Comunicación/Educación..................................................91

2.5.2 El contrato de lectura .........................................................

2.5.2.1 El análisis de discurso, la prosodia y el tono.................................93

2.5.3 Técnicas participativas en las EDC …........................................

\section{Capítulo III}

Radio Sutatenza: Lecciones de radio popular para América Latina..................96

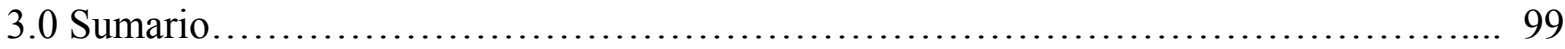

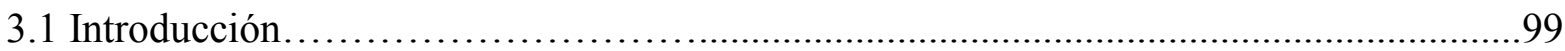

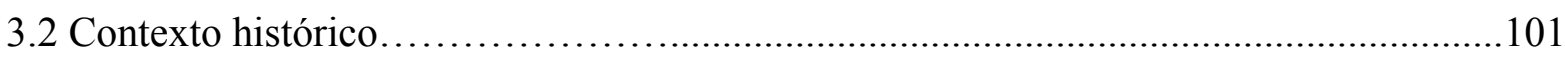

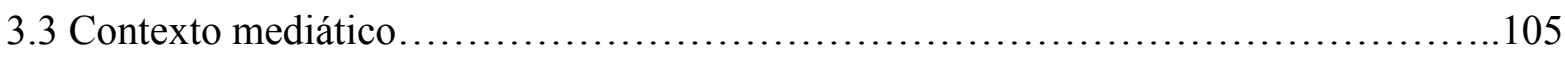

3.4 ACPO y la defensa del derecho a la comunicación............................107

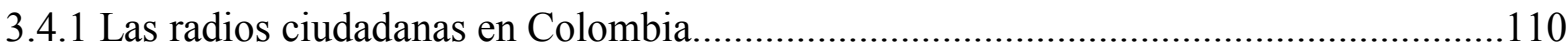

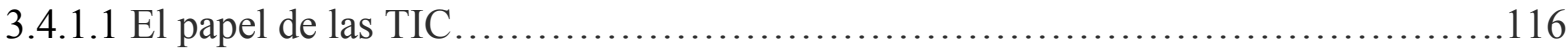

3.4.2 Las Escuelas Radiofónicas de ACPO...........................................119

3.5 ACPO y la EFI como estrategia de inclusión digital..............................125

\section{Capítulo IV}

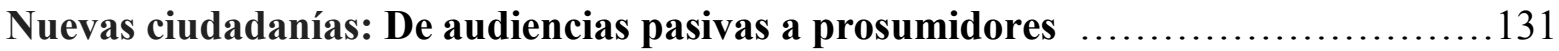

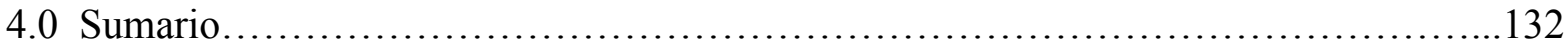

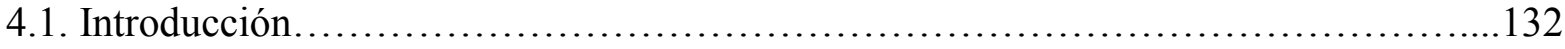

4.2 Democracia radical y nuevas ciudadanías........................................134

4.3 Comunicación y periodismo en clave de democracia radical........................139

4.3.1 El papel del prosumidor en la era

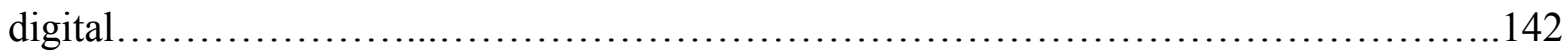

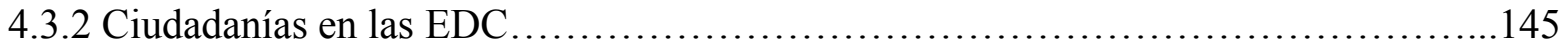

4.4 Significados de ser campesino.................................................. 147

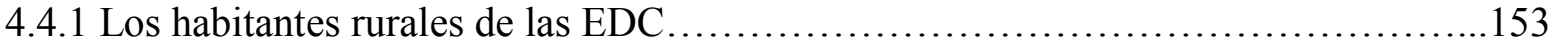

\section{Capítulo V}

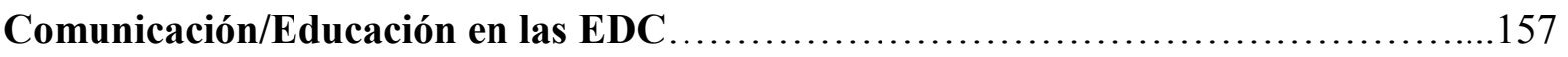

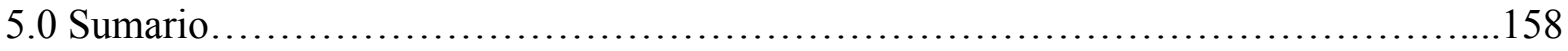

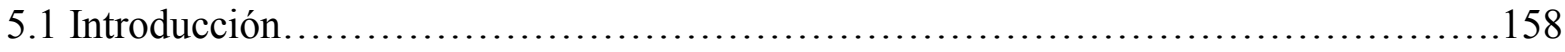




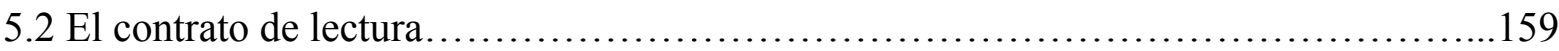

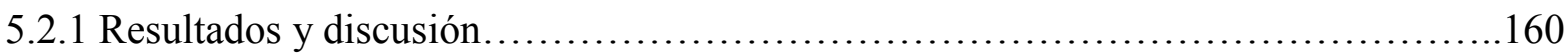

5.2.1.1 Las cartas y el auxiliar inmediato o facilitador....................................162

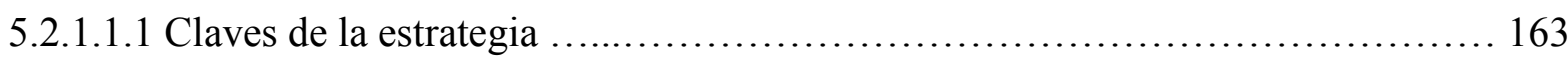

5.2.1.1.2 La Acpoeducación en la Educación Fundamental Integral.........................167

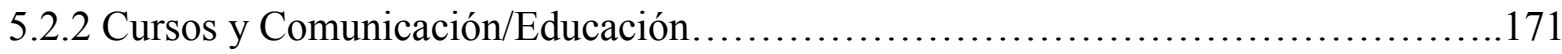

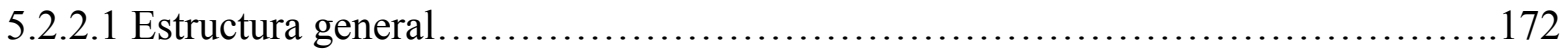

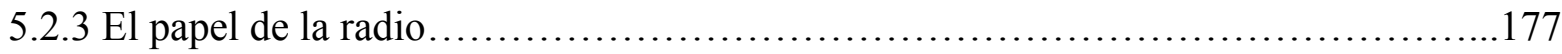

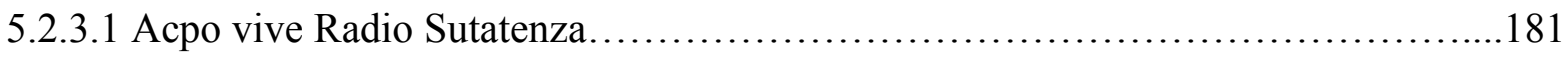

5.2.3.2 Asoacpo Sutatenza Medellín................................................... 183

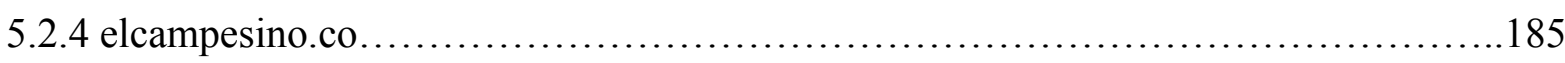

5.2.5 Retroalimentación en tiempos de las TIC .......................................187

5.2.6 El radioclip como dinamizador del diálogo social....................................189

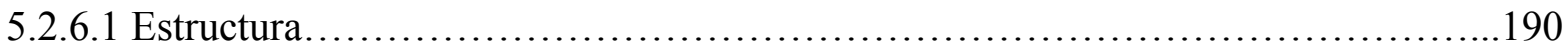

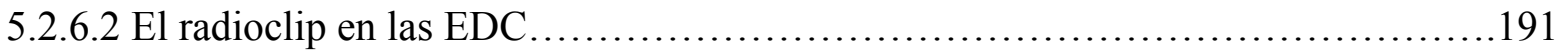

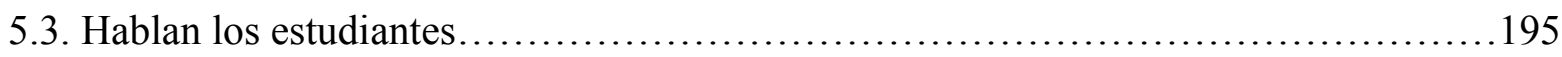

5.3.1 "La educación salva el país": Angelmiro Barbosa.....................................195

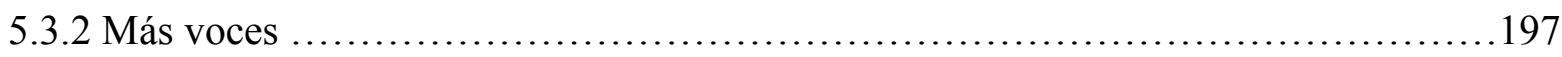

\section{Capítulo VI}

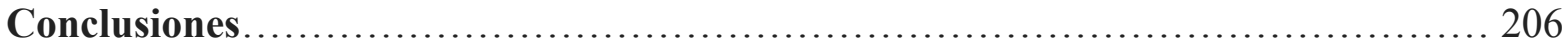

6.1 El diálogo: clave en las nuevas ciudadanías de las EDC.........................207

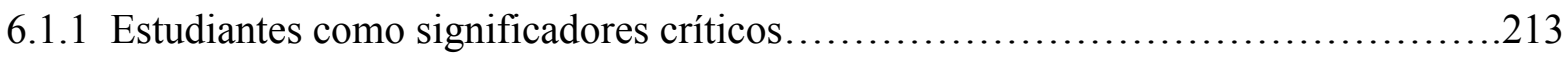

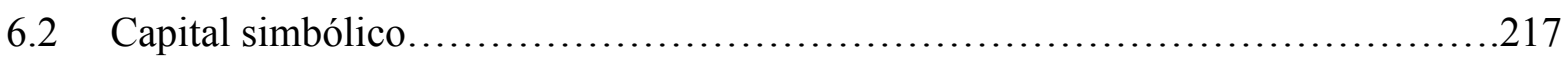

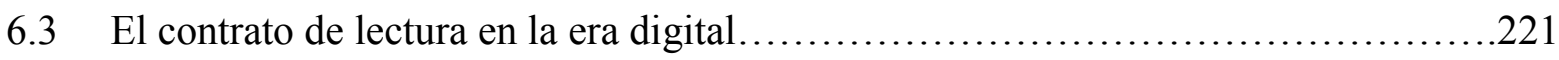

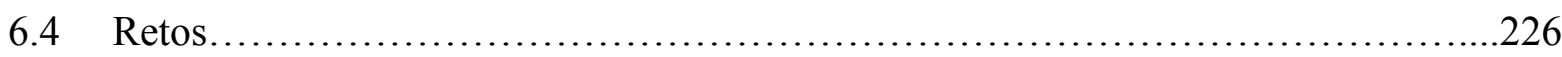

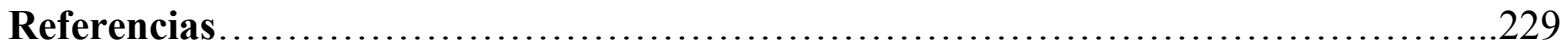

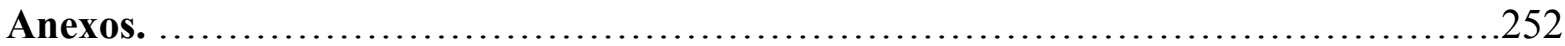

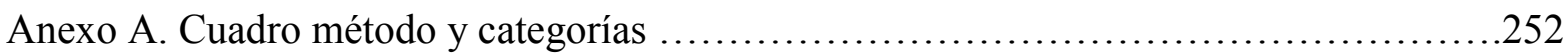

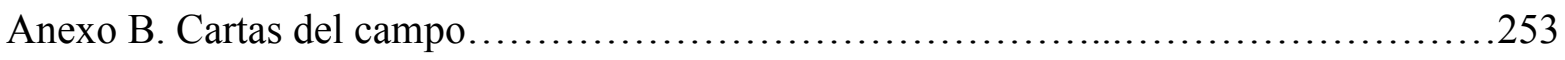

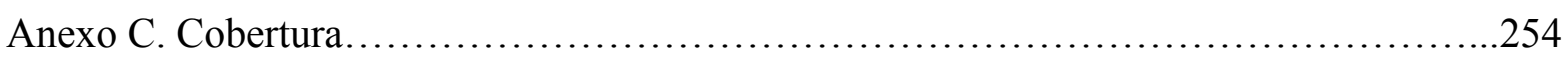

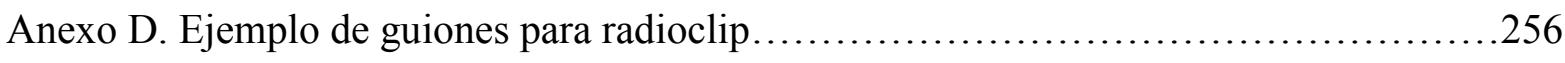

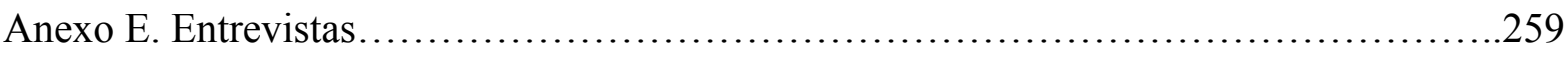


Radio Sutatenza y Acción Cultural Popular en la era digital

"El camino es fatal como la flecha pero en las grietas está Dios, que acecha"

J.L. Borges 


\section{INTRODUCCIÓN}

Esta tesis surge de la siguiente pregunta central: ¿Cómo se puede cualificar el ejercicio de las nuevas ciudadanías en las Escuelas Digitales Campesinas (EDC) de Acción Cultural Popular (ACPO)?

Partimos entonces del siguiente supuesto: se practican las nuevas ciudadanías en las EDC, pero es necesario mejorar su ejercicio.

En ese radio de acción, identificamos las siguientes apuestas esenciales:

a) En lo epistemológico: Se apoya en rutas de indagación o problematización que parten de otra forma de entender y de asumir la investigación, donde los actores sociales son protagonistas del proceso. Por lo tanto, no se cuenta la historia para ellos sino con ellos. Por ahí pasa el enfoque central de esta tesis: un ejercicio de polifonía de voces y de saberes, que se inscribe en los principios de la democracia radical con su propuesta de transformar el antagonismo (escenario de enemigos irreconciliables, dada la enorme distancia entre sus espacios simbólicos) en agonismo (escenario de adversarios, entendidos como aquellos con quienes se pueden construir acuerdos y hacer evidentes los disensos, gracias a que se mueven dentro del mismo espacio simbólico). En este enfoque es, por consiguiente, imposible la neutralidad del investigador, quien no se para desde afuera sino desde dentro del fenómeno investigado, en un ejercicio de investigación participante. Así mismo, los valores son esenciales en estas miradas, pues se apoyan en la intersubjetividad como fuente de interpretación, conocimiento y transformación de la realidad. Es una apuesta, entonces, por una metodología dialógica, emancipadora y transformadora.

b) En lo científico: Es un enfoque cualitativo, cuyo respaldo esencial está en los conocimientos y saberes diversos, esto es, complejos, no entendido lo complejo como lo difícil o intrincado sino como lo transdisciplinar, con una perspectiva política radical, enfocada hacia la comprensión de otros mundos, 
concebidos y contados por los propios actores sociales. Se trata, así mismo, desde la perspectiva de Comunicación/Educación, del interjuego entre interpelaciones y reconocimientos, una de las dimensiones analíticas centrales para que los sujetos actúen como significadores críticos de sus propias realidades.

Pretendemos, así, avanzar hacia reflexiones y propuestas frente al primer interrogante que planteamos arriba y frente a estos otros fundamentales: ¿Cómo perciben los estudiantes de las EDC su propio proceso? ¿Cómo se reconocen como actores en las Escuelas Digitales Campesinas? ¿Cómo se activa el diálogo y cómo se da ese diálogo en las EDC? ¿Cómo se vive el aprendizaje colaborativo entre los estudiantes, entre ellos y los facilitadores y entre la comunidad de las EDC con el resto de la sociedad? ¿Cómo participan de la deliberación pública? ¿Cómo han evolucionado en los últimos años, según ellos mismos, los significados de ser campesino? ¿Cómo se vive el ejercicio de la ciudadanía en las EDC? ¿De qué manera las campesinas, los campesinos e integrantes de comunidades indígenas y afrodescendientes se involucran en las que denominamos"constelaciones de sentido y de significados"? Y ahora, como productores activos, ¿qué significa para ellas y para ellos su ingreso a las plataformas digitales?

Así las cosas, el recorrido de esta tesis pasa por las lecciones que dejó Radio Sutatenza, tanto en sus postulados teóricos como en las prácticas de radio popular, no solo en Colombia sino en América Latina. Buscamos ver de qué forma los estudiantes de las EDC actúan y pueden actuar como sujetos radicales de la política, a la luz de los planteamientos de la democracia radical y del humanismo cívico; y analizar, tanto las formas como se activa el ejercicio de la Comunicación/Educación en la llamada Educación Fundamental Integral de ACPO, como las maneras y medios que se usan para producir sentido, desde los postulados de la semiosis social de Eliseo Verón, que tiene coincidencias con la Teoría de los Campos Sociales de Pierre Bourdieu.

Aunque se incluyen diversas disciplinas de la investigación social, hacemos énfasis en las miradas que surgen de los postulados de la Comunicación/Educación, perspectiva que concibe el proceso de aprendizaje como producto de la interacción entre educadoreducandos, en la que éstos últimos actúan como protagonistas del proceso.

Nos referimos, así, a diversas modalidades del diálogo que, para este trabajo, ha estado presente tanto en las entrevistas semiestructuradas y en los reportes directos de los estudiantes de las EDC, a través de la Red de Reporteros Rurales (R3), como en el programa 
de radio Mundo Rural y en el periódico digital elcampesino.co, con su sección denominada "Las cartas del campo". Así mismo, en los foros de discusión y en los conversatorios, que tuvieron como punto de partida el encuentro denominado "Las voces de la ciudadanía en la radio del Siglo XXI", realizado el 20 de marzo de 2013. Así mismo, el diálogo se ha extendido a otros escenarios, como el foro "Radio Sutatenza-ACPO 70 años: lecciones de la Educación Fundamental Integral", que tuvo lugar el 27 de abril de 2017. Y el "Encuentro intergeneracional de líderes campesinos: familias que cultivan paz”, que se llevó a cabo en Sutatenza (Boyacá) los 19 y 20 de agosto de 2017, para conmemorar los 70 años de Radio Sutatenza.

Queda claro que nuestros sujetos de investigación son las y los estudiantes de las EDC, otrora denominadas Escuelas Radiofónicas de Radio Sutatenza, a quienes se considera el centro y la razón de ser de ACPO. En efecto, hacer un viaje hacia la historia de Radio Sutatenza implica encontrarse con el protagonismo que jugaron desde su nacimiento las campesinas y los campesinos al escuchar el llamado que les formulara el entonces recién ordenado sacerdote católico José Joaquín Salcedo Guarín. La que después se conocería como Educación Fundamental Integral (EFI), es decir, la estrategia socioeducativa del modelo, no pasaba de ser entonces una vaga idea en la cabeza de Salcedo, que solo se empezó a concretar cuando los habitantes de Sutatenza (Boyacá) aceptaron su llamado. Ellas y ellos pusieron la primera piedra de una obra que en 1949 se inscribió oficialmente como la Fundación Acción Cultural Popular.

El nombre tampoco fue gratuito, pues trazó una línea de trabajo que nunca ha perdido su vigencia concreta. No se puede negar que es una obra de la iglesia Católica, pero no su sentido eclesiástico sino eclesial, es decir, de sus feligreses. Por consiguiente, la denominación ACPO va mucho más allá de una sigla institucional o de la organización jurídica, para asociarse con una forma de sentir, de pensar y, lo más importante, de actuar en la vida.

Son esos sujetos de carne y hueso, quienes trabajan en el día a día para hacer tangible los valores y principios de la EFI, los que le dieron nombre y renombre mundial a Radio Sutatenza, el centro de este trabajo. Vale decir también que en este ejercicio hay una implicación directa del titular de esta tesis con los propósitos y tareas de ACPO, ora como estudiante indirecto de las Escuelas Radiofónicas en Villarrica (Tolima); ora como integrante del Consejo Editorial de elcampesino.co; ora como co-realizador del programa de radio Mundo Rural o como voluntario facilitador del proceso emprendido por ex estudiantes de las Escuelas Radiofónicas con su emisora online "Acpo vive Radio Sutatenza". Lejos de verse 
esa implicación como una amenaza para el proceso de investigación, se considera una gran oportunidad de interaprendizaje, a la luz de las teorías y prácticas tanto de la Investigación Acción Participativa (IAP) como de la Comunicación/Educación.

Como señalamos, en ese contexto implicativo son concebidos los sujetos de investigación: mujeres y hombres, no solo campesinas y campesinos sino indígenas, afrodescendientes y un ejército de voluntarios de la cultura que se han encargado de mantener vigente el nombre Radio Sutatenza. De ahí que la esencia de esta propuesta -como lo anotamos en el libro Ser ciudadano en la radio (2012) - le apunte muy poco o nada al lenguaje monofónico y mucho al polifónico, característica esencial de una verdadera radio ciudadana.

En concordancia con esos postulados, el enfoque metodológico se inscribe en la Investigación Acción Participativa (IAP) que se concibe a la vez como método, como una filosofía de vida y como un proceso atravesado por la relación sujeto-sujeto, de cara a lograr la transformación de la realidad. Dentro de esa perspectiva metodológica y epistemológica, los instrumentos aplicados se enmarcan en los postulados de la Comunicación/Educación; la Ecología de Saberes; el periodismo literario y las lógicas o "marcas" de la producción de sentido definidas por Eliseo Verón en el "contrato de lectura" .

En ese marco de acción, el conocimiento no se concibe como algo abstracto, porque surge de las prácticas específicas de los actores sociales, es decir, ancladas a la cotidianidad, esto es, al contexto particular, en el que se viven las formas de conocer, reconocer y representar la realidad.

Con ese norte, el estudio que presentamos a continuación parte de historizar el proceso de las Escuelas Radiofónicas de Radio Sutatenza y de las actuales EDC; se detiene en el análisis de los hechos políticos que más lo han influenciado y se adentra en los soportes de la construcción de sentido, para ir en la búsqueda de significados, no de leyes.

Por su propia naturaleza dialógica, las discusiones que planteamos en esta tesis no buscan ofrecer respuestas contundentes sino conducir hacia nuevos interrogantes y sugerir nuevas rutas de acción. Es lo que, en nuestro caso particular, hemos promovido desde 2010 de la mano del semillero Radio y Ciudadanía de la Universidad Sergio Arboleda de Bogotá, a cuyos estudiantes es justo reconocerles su entusiasmo y aportes sobre las diversas formas de sentir, de pensar y de actuar en la comunicación, entendida como la relación o relaciones que se dan en contextos culturales específicos y conducen a la producción de sentido. En su calidad de coinvestigadores ellos también son actores y productores de muchos de los resultados que presentamos a continuación. Son miradas y análisis que hemos podido 
profundizar en el marco del doctorado en comunicación de la Universidad Nacional de La Plata, gracias a su larga tradición en los estudios culturales sobre las teorías y prácticas comunicativas en América Latina.

Estamos, entonces, ante sentidos, acciones y producciones insertas en un continuum simbólico y cultural llamado Acción Cultural Popular, más conocido en el mundo por su marca Radio Sutatenza y considerado por muchos investigadores como un proyecto pionero tanto en la práctica como en la investigación de la comunicación con un enfoque culturalista, donde el receptor deja su papel pasivo y pasa a actuar como prosumidor (Ver capítulo IV), elemento clave de las nuevas ciudadanías. Ello, en un país como Colombia, donde el conflicto armado sigue, en buena medida, marcando la agenda social, política y económica, con un especial impacto en las zonas rurales, significa apostar por el poder de las ciudadanas y los ciudadanos, como motor y razón de ser de una democracia aún en ciernes. En esa perspectiva enmarcamos los aportes de esta investigación. 
Radio Sutatenza y Acción Cultural Popular en la era digital 


\section{CAPÍTULO I}

\section{Rutas para la producción de sentido en las Escuelas Digitales Campesinas}

\subsection{Sumario}

En este capítulo serán presentados antecedentes de investigación, con el propósito de fortalecer el análisis sobre las principales dinámicas de producción de sentido y de construcción de ciudadanías que se han dado, primero en las Escuelas Radiofónicas de Radio Sutatenza y ahora en las Escuelas Digitales Campesinas, las dos como parte de la Educación Fundamental Integral (EFI), el modelo socioeducativo de Acción Cultural Popular (ACPO), más conocido por su marca Radio Sutatenza. Para dicho fin, partimos de la siguiente pregunta central: ¿Cómo se puede cualificar el ejercicio de las nuevas ciudadanías en las Escuelas Digitales Campesinas de ACPO? Es claro, como lo indicamos, que allí hay un supuesto implícito: se ejerce la ciudadanía en las EDC, pero es necesario fortalecer esa apuesta. Con esa perspectiva, se incluyen primero investigaciones que se enmarcan en el trabajo desarrollado por el semillero "Radio y ciudadanía", fundado en 2010 y después se hace referencia a investigaciones realizadas por otros autores. Diez de los trabajos consultados están relacionados directamente con el quehacer de las Escuelas Radiofónicas, desde su fundación, en 1947, hasta su declive y cierre, ocurrido entre 1989 y 1994. Los otros, aunque no tienen como eje a Radio Sutatenza, sí se han interesado por contribuir a profundizar el debate sobre las principales características y alcances de los medios ciudadanos, y por aportar a la teorización y problematización sobre el ejercicio de la ciudadanía y la producción de sentido en las EDC, otros de los objetivos de esta investigación. 


\subsection{Introducción}

Para este trabajo nos interesa ver de qué manera el modelo de Radio SutatenzaACPO, que incluyó, además, cartillas, el periódico El Campesino, correspondencia, cursos de extensión, libros y discos de acetato, entre otros, se puso y se pone hoy al servicio de la inclusión educativa, social y económica de las campesinas y campesinos beneficiarios. (Población que, como veremos, hoy también incluye a las comunidades afrodescendientes e indígenas). Esta revisión bibliográfica incluye autores de Alemania, cuya iglesia católica aportó importantes recursos para la expansión y consolidación de la EFI, así como de Bolivia, Argentina, México, Chile y, por supuesto, Colombia, cuyo interés investigativo confirma la importancia de Radio Sutatenza para entender el devenir de la radio popular y educativa en América Latina.

Buscaremos describir cómo se puede cualificar el ejercicio de las nuevas ciudadanías en las Escuelas Digitales Campesinas de ACPO y, para ese propósito, objetivar cómo se entiende y cómo se asumen las nuevas ciudadanías, en el marco de la democracia radical y del humanismo cívico; determinar cómo se pueden construir esas ciudadanías desde la comunicación y el periodismo; identificar las formas concretas como las EDC aportan a la inclusión de sus estudiantes en el mundo digital, y describir los elementos fundamentales que intervienen en la producción de sentido en las EDC.

En concordancia con los objetivos de esta tesis, se hará énfasis en la naturaleza y en las principales características de la investigación sobre la comunicación popular en América Latina y en la relevancia del campo de la Comunicación/Educación para la construcción de identidades. También haremos referencia a algunas experiencias de radio ciudadana que permitan leer el proceso de comunicación en prácticas concretas, esto es, objetivar cómo se asumen, cómo se encaran $\mathrm{y}$, en buena medida, precisar cuáles son sus principales características.

Así mismo, al subrayar la importancia de los aprendizajes y lecciones que dejó el proyecto de Radio Sutatenza, la revisión se concentrará en los aportes hechos por investigadores de la historia de ACPO y su modelo de Educación Fundamental Integral (EFI), en especial aquellos que han asumido su base metodológica desde la Investigación Acción Participativa (IAP). 
Ya en el apartado "Hacia las nuevas ciudadanías", las miradas se centrarán en la revisión y análisis de conceptos como democracia radical; liberalismo; humanismo cívico; comunicación participativa y ciudadanía comunicativa, a fin de encontrar rutas de acción hacia la búsqueda y promoción de nuevas prácticas políticas y de ejercicio del poder que permitan cualificar el ejercicio de esas nuevas ciudadanías en las Escuelas Digitales Campesinas.

En el recorrido propuesto se hará énfasis en las siguientes categorías de análisis: ACPO-Radio Sutatenza, entendida no como la organización institucional exclusivamente sino como los actores -campesinas, campesinos, afrodescendientes e integrantes de comunidades indígenas- que han participado o participan como estudiantes de las Escuelas Radiofónicas, hoy denominadas Escuelas Digitales Campesinas; Educación Fundamental Integral (EFI), la estrategia socioeducativa de ACPO, que gira alrededor de cinco áreas básicas, como lo son el alfabeto (hoy alfabetización digital); número; salud; economía y trabajo y espiritualidad. Allí también se inscribe el modelo de combinación de medios, hoy denominado convergencia de medios (que para esta investigación llamamos “Acpoeducación) con un mismo fin esencial: el interaprendizaje, que implica la propia acción y participación de los estudiantes, como protagonistas del proceso; Nuevas ciudadanías, las cuales se asumen para esta investigación desde el humanismo cívico y la democracia radical que coinciden en identificar a los ciudadanos como el el centro de la política. Como se puede apreciar, ese enfoque está planteado desde la formulación del problema de investigación,y se encamina a profundizar el ejercicio de Comunicación/Educación inserto en el universo vocabular de los estudiantes. Y Comunicación que, desde las teorías del contrato de lectura (Eliseo Verón) y de los campos sociales (Bourdieu) busca aprovechar y potenciar el ejercicio radiofónico como práctica significante. Ello implica ver a los actores de las EDC como participantes activos de la lucha/disputa por la construcción del sentido. Es un ejercicio que pasa por la representación de su propio mundo, como principio esencial para interpelar, reconocer e incidir en el cambio del estado de cosas que, según su propia lectura del mundo, les impide crecer como personas y como integrantes del colectivo social.

\subsection{Palabras clave:}

Nuevas ciudadanías; Comunicación/Educación; Escuelas Digitales Campesinas; radio ciudadana; I.A.P. 


\subsection{Metodología}

Para la construcción de los antecedentes se ha apelado a la revisión de libros, artículos científicos o académicos, así como de tesis doctorales. Con ese propósito, se ha acudido acudido también a bases de datos de Colciencias y otras de consulta abierta como Proquest, Scielo, Clacso, Dialnet y Google Académico.

De esa manera, se busca la necesaria confrontación y contrastación, a partir de miradas más o menos cercanas a nuestro objeto de estudio: Las Escuelas Digitales Campesinas de Acción Cultural Popular (ACPO), como continuación de las Escuelas Radiofónicas de Radio Sutatenza.

\subsection{Discusión}

\subsubsection{Antecedentes}

En esta primera parte se hará énfasis en los trabajos de investigación de los cuales ha participado el autor de esta propuesta, en el marco del semillero "Radio y ciudadanía", fundado en 2010 en la Universidad Sergio Arboleda de Bogotá.

Es importante tener en cuenta que en Colombia los semilleros de investigación nacieron a finales de la década de los 90, como estrategia para fortalecer la investigación formativa en la educación superior. Según los investigadores González, Oquendo y Castañeda, son

comunidades de aprendizaje nacidas en la universidades colombianas, que se caracterizan por su origen espontáneo, naturaleza autónoma y diversidad dinámica. Sus principios básicos están enfocados a promover una formación académica más investigativa e integral, contribuyendo a proyectar una educación participativa donde se elogie la pregunta, se aprenda a aprender y se fortalezca la capacidad de trabajar en grupo. (2001, p. 11)

En el caso de la Universidad Sergio Arboleda el semillero "Radio y ciudadanía" busca promover la cultura investigativa alrededor en la radio como escenario para el ejercicio de la ciudadanía ; fortalecer lo público desde la comunicación y el periodismo e identificar las lógicas de interacción/participación que aplican los sujetos, para aportar en la 
cualificación de las nuevas ciudadanías. Es necesario puntualizar aquí que concebimos lo público como la articulación entre el interés común, el espacio ciudadano y la interacción comunicativa, es decir, "lo común, el mundo propio a todos” (Rey, 1998)

Con esos propósitos, los estudiantes pertenecientes al semillero formulan proyectos inscritos en la línea "radio y ciudadanía" y trabajan con organizaciones no gubernamentales cuyo radio de acción sea alguna de las muchas poblaciones vulnerables del país, como víctimas de la violencia; mujeres cabeza de familia; niños, niñas y adolescentes de familias en situación de desplazamiento; personas con discapacidad o comunidades inmersas en programas de autoconstrucción de vivienda. Los docentes investigadores brindan el acompañamiento constante, mediante la realización de tutorías personalizadas, en las cuales se orienta el proceso en asuntos clave, como la información requerida para la metodología, bibliografía, uso de bases de datos y realización radiofónica con perspectiva transmediática.

En el marco de esa política, el semillero empezó su tarea con la investigación denominada "la radio y el ejercicio de la ciudadanía", que, como se verá, estuvo orientada a determinar cuáles fueron los principales aspectos que se tuvieron en cuenta para la construcción de ciudadanía, a partir de las experiencias de comunicación radiofónica del Colectivo de Comunicaciones Línea 21 de los Montes de María (Costa Caribe); Radio Andaquí y la Escuela Audiovisual Infantil de Belén de los Andaquíes (Caquetá) y el Sistema de Comunicación para la Paz, SIPAZ, que integraba entonces a colectivos de comunicación de 18 regiones colombianas.

Este campo de investigación busca potenciar los postulados del denominado periodismo público, encaminado a restablecer las conexiones necesarias entre la comunicación plena y la democracia. En otra palabras, se busca "fortalecer la construcción de lo público y lo ciudadano desde la comunicación” ( Miralles, 2002, p. 67).

Se apoya, además, en las perspectivas de responsabilidad y extensión social, tanto de la Universidad Sergio Arboleda como de su Escuela de Comunicación y Periodismo, y en el respaldo que le ha brindado a trabajos como el desplegado por la Fundación Víctimas Visibles a lo largo y ancho de la geografía colombiana, en favor de las víctimas de la violencia. 
Gracias a la creación de la cátedra electiva "Radio y Ciudadanía" y a la vinculación directa de estudiantes a las tareas de investigación formativa de la Escuela de Ciencias de la Comunicación, el semillero ha conseguido el objetivo fundamental de impactar el plan de estudios del programa de comunicación social y periodismo.

Desde 2013 la Universidad Sergio Arboleda suscribió una alianza con Acción Cultural Popular, ACPO -la antigua Radio Sutatenza- encaminada a fortalecer su apuesta educativa, que gira hoy en torno a las Escuelas Digitales Campesinas, EDC. El principal producto realizado por la universidad para las EDC es el programa semanal de radio "Mundo Rural", que se emite los viernes en la emisora Online Radio Virtual, y es retransmitido por 26 emisoras comunitarias en diferentes regiones del país. En el marco de este convenio, el semillero adelanta hoy (2017) su principal proyecto de investigación denominado "Significados de ser campesino en el marco de las EDC", cuyos objetivos son Identificar cómo se asume y cómo se ejerce el ser campesino en las Escuelas Digitales Campesinas de ACPO ; establecer cuáles son las principales necesidades de comunicación de las Escuelas Digitales Campesinas (EDC) ; identificar las principales lógicas de interacción/participación que se dan en las EDC. Y fortalecer la estrategia comunicativa de las Escuelas Digitales Campesinas, mediante el uso de narrativas transmedia.

\subsubsection{Investigaciones del semillero}

En el libro "Ser ciudadano en la radio. Experiencias exitosas de comunicación y de periodismo para la construcción de ciudadanía" (2012) se da cuenta de un trabajo implicativo realizado con los colectivos de comunicaciones Línea 21 de los Montes de María; Radio Andaquí y la Escuela Audiovisual Infantil de Belén de los Andaquíes (Caquetá) y el entonces llamado Sistema de Comunicación para la Paz, Sipaz (Hoy Corporación Sipaz). La investigación giró alrededor del siguiente objetivo general: determinar cuáles son los principales aspectos que se han tenido en cuenta para el ejercicio de la comunicación radiofónica en los colectivos Línea 21 de los Montes de María; Radio Andaquí y la Escuela Audiovisual Infantil de Belén de los Andaquíes (Caquetá) y los nodos integrados al Sistema de Comunicación para la Paz, Sipaz. Y partió de esta pregunta central: ¿Por qué es particularmente importante la radio para el ejercicio de la ciudadanía? En consecuencia la narración se construyó con los propios actores-sujetos, integrantes de los mencionados colectivos, como se le anticipa al lector desde la misma introducción, en los siguientes términos: "En este libro no se "escuchará" una sola voz ni se leerá una sola 
verdad, pues la mismas naturaleza y esencia de nuestra propuesta le apuntan muy poco o nada al lenguaje monofónico, y mucho al polifónico, a imagen y semejanza de lo que debe ocurrir en una verdadera radio ciudadana". (p.13). En consecuencia, son ellas y ellos mismos los que cuentan y comparten con nosotros cómo ejercer su derecho a la comunicación en entornos muy afectados por la violencia: "la mayoría de los reporteros de Sipaz se hace escuchar en medio del fragor del conflicto, sin poner en riesgo su propia integridad por ejercer el derecho a la comunicación. Ello es posible porque el Sistema puso en marcha y ha venido consolidando códigos informativos con los cuales marca una estratégica distancia de la guerra. Sin dejar de cubrir ni dejar de hablar del conflicto armado cotidiano, la agenda informativa busca privilegiar la narración sobre los incontables hechos a favor de la vida, muchos de los cuales se refieren al conflicto social y a las mediaciones y soluciones que se dan alrededor del mismo" (p.45) ¿Y cómo debe ser entonces una radio ciudadana? Aquí algunas de las conclusiones y retos construidos con la misma gente: - Debe ser una radio cultural, educativa y para el desarrollo. Por lo tanto, debe ser propositiva, que conozca muy bien su contexto y que hable con todos los actores sociales. -Debe ser plural y, por lo tanto, reflejar la diversidad de voces y palabras que hay en la comunidad. - Encontrar su propia identidad, es decir, entender en esencia que nuestros medios ciudadanos se deben caracterizar por estar al servicio de la misma gente, para que ella misma reconozca, intérprete y cuente su propia realidad, y no por el simple rechazo a los medios masivos. -Apoyar a las víctimas para que construyan su propia narrativa, gracias a la reconquista del lenguaje, y para que reconstruyan su propia memoria, que no es otra que la memoria de la sociedad. - Asumir la comunicación como un conjunto de procesos de circulación de sentidos y, como tal, trasciende a la misma radio. Así las cosas, la radio se vuelve un eficiente punto de encuentro por donde pasa la vida y, como tal, sirve para visibilizar anhelos, necesidades, dificultades y logros.

Otra investigación realizada en el marco del semillero dio lugar al texto "Sonoridades Bogotanas. Oportunidades para el ejercicio de la ciudadanía en las emisoras comunitarias de Bogotá"(2015). Este trabajo realizado en asocio con los investigadores de la Escuela de Filosofía y Humanidades de la Universidad Sergio Arboleda, Liliana Beatriz Irizar y Javier González Camargo, ofrece antecedentes clave, en relación con la experiencia educativa de Acción Cultural (ACPO) cuyo eje fue Radio Sutatenza. Así mismo, brinda reflexiones y propuestas de acciones de gran interés alrededor del humanismo cívico, enfocados hacia el ejercicio de lo que denomina "nueva ciudadanía".

Para la búsqueda de respuestas, se apoyó en los postulados de la Investigación, 
Acción Participativa ( IAP) según la cual los procesos de investigación o de desarrollo solo tienen trascendencia y sentido si asumen a sus beneficiarios como protagonistas de los mismos. (Pérez, 2016)

Como lo explicaba su propio creador e impulsor, el sociólogo Orlando Fals Borda, citado por Casado y Alonso:

el objetivo es generar un conocimiento liberador que parta del propio conocimiento popular y que explica su realidad globalmente (enfoque sistémico), con el fin de iniciar o consolidar una estrategia de cambio (procesos de transición), paralelamente a un crecimiento del poder político, destinados ambos a alcanzar transformaciones positivas para la comunidad a nivel local, y a niveles superiores, en cuanto que es capaz de conectarse con experiencias similares (redes). (2007, p. 30)

En esa línea de trabajo se inscribe el aporte de radio Sutatenza, destacada por Gumucio (2000, p. 43) como "uno de los programas radiales de educación de adultos más grandes del mundo", por su enfoque epistemológico que les permitió a las campesinas y campesinos ser protagonistas de su propio proceso de aprendizaje. Una de las grandes virtudes de la estrategia de Acción Cultural Popular, ACPO, -entre 1947 y 1994- consistió en entender que la radio trasciende a la misma radio.

Y como lo dice Hernando Bernal Alarcón ex director general de ACPO,

La gran innovación de ACPO no fue utilizar la radio para la educación, sino haberla complementado con una serie de mecanismos o elementos de apoyo educativo, entre los cuales el más sobresaliente fue la actividad de los miles de voluntarios de la cultura, deseosos de ayudar a los campesinos adultos a aprender por medio del simple seguimiento de las orientaciones que recibían del profesor que hablaba por la radio. (Pp. 2-3)

En esta misma dirección, el semillero Radio y Ciudadanía desarrolló la investigación titulada "El ejercicio de la ciudadanía en la convergencia de medios, a partir de la experiencia de Radio Virtual", la emisora online de la Universidad Sergio Arboleda (2014). El enfoque central de estas indagaciones giró alrededor de las teorías y prácticas de la comunicación/educación, un concepto que se ha abierto espacio en América Latina por su gran incidencia e impacto sobre las comunidades tradicionalmente marginadas de los procesos de desarrollo. Tal y como lo refiere Ismar de Oliveira Soares esta perspectiva solo cobra sentido cuando asume a las comunidades como protagonistas de su propio cambio: 
la comunicación pasa a entenderse como un modo dialógico de interacción del actuar educomunicativo: ser dialógico, según Freire, es no manipular, es no " esloganizar” el diálogo es el encuentro amoroso de los hombres, que mediatizados por el mundo, lo pronuncian, esto es, lo transforman y transformándolo, lo humanizan. (...) En esta dirección es igualmente oportuno retomar a Mario Kaplún, para quien la "comunicación educativa" existe para brindarle a la educación métodos y procedimientos para crear la competencia comunicativa del educando. Educar por la comunicación y no para la comunicación. Dentro de esta perspectiva los medios son reubicados en un proyecto pedagógico más amplio. (1998, p.8)

En el caso particular de Acción Cultural Popular (ACPO), un referente clave para esta investigación, fueron identificadas coincidencias importantes, tanto en la estrategia de convergencia de medios como en la apuesta de promover la construcción de ciudadanía. Así las cosas, se decidió aunar esfuerzos entre el semillero y ACPO para trabajar en la consolidación de la plataforma multimedia Mundo Rural -hoy denominada Escuelas Digitales Campesinas- a partir del programa de radio del mismo nombre.

Así se pudo comprobar que la radio es un medio que brinda herramientas para potenciar la convergencia como estrategia, las cuales apuntan a fortalecer el elemento clave de la interactividad. Entre las principales conclusiones están las siguientes:

La propuesta buscó ponerse al servicio de la experimentación, mediante la realización y difusión de piezas de comunicación que surgen de este proyecto . De esa manera, se pudo establecer cómo y con qué grado de efectividad los medios integrados le apuestan a la solución de problemas específicos que plantea el ejercicio de la ciudadanía, para encarar los retos del posconflicto, en un contexto fundamental para el futuro del país.

Ya en cuanto a los trabajos realizados por el autor de esta tesis, está el libro "Cómo escribir para radio", que se ocupa de temas de gran interés para esta investigación, en especial aquellos relacionados con las características esenciales de la radio y los recursos que ofrece ese medio para el mejor uso del lenguaje, como la voz, la música, el sonido ambiente y los efectos especiales, que se ponen al servicio de "la magia del dial" y de lo que Eliseo Verón denomina "contrato de lectura". Según la publicación, el lenguaje radiofónico se caracteriza por ser "vivo, seductor, claro y sencillo". Son elementos que -como se apuntó en esa oportunidad - cumplen la tarea de captar la atención de los interlocutores. Entre las principales recomendaciones está tener en cuenta que el lenguaje hablado tiene sus propias 
particularidades, las cuales demandan la "utilización de un vocabulario usual, comprendido por la mayoría de personas (...) hacer frases cortas, evitar las inversiones y las subordinadas y utilizar preferiblemente palabras con un valor descriptivo". (P. 26) En cuanto al manejo del tono se refiere, se plantea la necesidad de sacarle el mayor partido posible, para garantizar que los mensajes lleguen a los oyentes: "En nuestra experiencia como oyentes hemos podido comprobar que una noticia leída varias veces en tono magistral por un locutor no se quedó en nuestras mentes. En cambio sí captamos el sentido exacto de la información cuando esa misma noticia fue narrada en un tono más tranquilo, es decir más cercano, por un periodista que transmitiendo gran dominio y credibilidad, decidió contarnos lo que estaba pasando". (P. 29) Se privilegia allí, en consecuencia, la necesidad de, más que leer, interpretar, para lograr la necesario empatía con el interlocutor y conseguir, así, que fluya la comunicación. Otro aspecto que interesa destacar aquí, por su incidencia en la tarea de las Escuelas Digitales Campesinas, es la importancia que se le da al género dramático con fines pedagógicos, "que sigue más vigente que nunca (...) a la hora de despertar conciencia entre los oyentes sobre temas trascendentales como la protección y conservación del medio ambiente; sobre el mal uso de los servicios públicos o sobre la discriminación y la exclusión, entre muchos otros, este recurso se puede convertir en un gran apoyo". (P. 30)

Son discusiones que se complementan en el artículo denominado "De las Escuelas Radiofónicas a las Escuelas Digitales Campesinas: El regreso de ACPO y la experiencia de Radio Sutatenza en la era de las TIC (2017). Publicado en la revista Interacción de Cedal con ocasión de los 70 años años de Radio Sutatenza y Acción Cultural Popular, ACPO destaca, en primera instancia, el valor que tiene esta experiencia de comunicación, como antecesora de la radio comunitaria, no solo en Colombia sino en América Latina. El investigador Luis Ramiro Beltrán (2005, p.58 ) la exalta como una experiencia que se anticipó en por lo menos diez años a la teoría de la comunicación para el desarrollo y el cambio social en estas latitudes. Así mismo, en el artículo se subraya que ahora el gran reto de ACPO, que retomó sus actividades en 2012, con las Escuelas Digitales Campesinas (EDC) es promover la “ciudadanía rural”, para que las campesinas, campesinos, comunidades afrodescendientes e indígenas participen de la Sociedad de la Información y el Conocimiento. Esta experiencia se empezó a escribir el 23 de agosto de 1947, día en que llegó a Sutatenza (Boyacá) el entonces novel sacerdote católico José Joaquín Salcedo, quien llevaba entre su equipaje un proyector de $16 \mathrm{~mm}$ y un radio receptor de onda corta. Cuenta la historia que desde su primera misa Salcedo prefirió el diálogo al sermón. Y en esa interacción con las campesinas 
y campesinos supo que unos de los problemas que más los afectaban eran el alcoholismo y el analfabetismo. Muy pronto llegó a una contundente conclusión, inspiradora de la obra que un poco después se enmarcó en la Educación Fundamental Integral, EFI: “El subdesarrollo está en la mente del hombre". (Bernal, 2012, p.36) Y como su vocación por la radio lo acompañó desde siempre, quiso saber de qué manera ese medio que tanto entretenía y encantaba se podía usar en la noble tarea de educar. Gracias entonces al apoyo de su hermano, el también sacerdote Antonio José Salcedo, ensayó un rudimentario transmisor de 1 kilovatio, cuya audición escucharon tres campesinos de la vereda Irzón, quienes no lograban entender cómo, de esa especie de cajón de madera, salía la voz de un sacerdote de carne y hueso. Pero del susto inicial pasarían a la fascinación, materia prima clave para hacer de Radio Sutatenza, en muy poco tiempo, no solo "la potencia del pueblo colombiano", su slogan durante muchos años, sino todo un referente para las radios populares, tanto en América Latina como en África y en Asia. Allí se insertaría la historia de las Escuelas Radiofónicas de ACPO que durante sus 45 años de funcionamiento -1949-1994- capacitaron a más de cuatro millones de campesinas y campesinos, para que jugaran "un papel activo en su propio desarrollo (...) y pudieran pasar de ser 'el hombre marginado 'a una posición participante de la sociedad en general”. (Bernal: 1978).

\subsubsection{Otras investigaciones}

\section{Comunicación y producción de sentido}

Como se ha señalado, en la producción social de sentido, que implica tratar a las audiencias como sujetos activos y no como simples consumidores o replicadores de mensajes pre elaborados, está el centro de las discusiones que se busca plantear en esta tesis.

Así las cosas, a continuación se pondrá el énfasis en los estudios culturalistas, también enmarcados en la perspectiva crítica, para la cual "lo que interesa 'no es el efecto de la comunicación sobre alguien', sino retomar el concepto de cultura, observando su aspecto dinámico, la comunicación”. (Brandolin y Rosboch, 2003, p.35).

Autores como Eliseo Verón (1985) le conceden especial valor al uso del lenguaje con sus cadenas significantes, inmersas en las estrategias o modos de comunicación usadas para estar en sintonía con los lectores, oyentes o, en una palabra, cibernautas. Uno de los fundamentos de esta perspectiva analítica está en la convicción de que el impacto de los discursos no se puede entender solo desde las naturaleza y/o condiciones del emisor; es indispensable, además, escudriñarlos desde las lógicas de quien o quienes reciben el mensaje, en relación con quien o quienes lo producen. Así, como lo dice el propio Verón, “el análisis 
del contrato de lectura permite de este modo determinar la especificidad de un soporte, hacer resaltar las dimensiones que constituyen el modo particular que tiene de construir su relación con sus lectores". (p.6)

Como se puede apreciar, la razón de ser de este método está en que la lectura de la producción de sentido como hecho sociocultural se considera una "actividad significante". Es así, porque, según Roman Jakobson, citado por Verón, "los procesos de producción de frases y los de su recepción, no son de la misma naturaleza”. (Ib, p. 1). El planteamiento de Verón se centra, entonces, en la pregunta por el "funcionamiento social de los textos", en su afán por comprender no solo qué lee la gente sino, lo más importante aún, cómo lee y por qué, con frecuencia, no lee lo que le proponen los medios. Como lo señala el mismo autor, en este enfoque hay "vocación translingüística", al incluir la semiótica y la teoría social. (Fernández, 2009). Fernández encuentra coincidencias entre estos planteamientos de Verón y la "Teoría de los campos sociales" de Pierre Bourdieu, para quien en el "sistema total de relaciones" está la explicación sobre el sentido de las acciones "más personales y más transparentes" de los sujetos. La afirmación de Verón (1993) es categórica: "No se puede describir ni explicar (...) un proceso significante sin explicar sus condiciones sociales productivas"( P. 126). Por su parte, Bourdieu propone tener presente para el ejercicio analítico la tensión que subyace entre los usos oficiales o formales y las posibilidades del decir, condicionadas por el habitus lingüístico, a su vez constituido por lo "social incorporado" y tejido por aquellas relaciones de poder que son asumidas o internalizadas por los individuos, en un contexto sociocultural específico, pues, como lo plantea Favela Rodríguez,

Esto es más manifiesto por el hecho de que, según la afirmación de Bourdieu y Passeron, el contenido de la enseñanza y las formas de autoridad que se encuentran en un sistema de enseñanza están determinadas por las relaciones de fuerza entre las clases o los grupos de la sociedad. (2010, p. 148)

También se puede expresar así: lo que decimos y lo que callamos está íntimamente permeado por la estructura social a la cual pertenecemos. Y allí se genera la "relación comunicativa" de la que habla María Cristina Mata (2012) en la cual son tan importantes los emisores como los receptores, cuyos papeles se intercambian permanentemente, pues, según indica, "ambos tipos de sujetos, emisores y receptores, cumplen la misma función de 
productores de sentido aun cuando ocupen posiciones o lugares diferentes y no simétricos dentro del proceso". (Ib., p.3)

Así, en coincidencia con el método de análisis cultural que propusiera el antropólogo estadounidense Clifford Geertz en su "enfoque semiótico de la cultura", la idea es orientarse por la búsqueda de significados en contextos específicos. Para Geertz, hay que ir tras pistas muchas veces ínfimas e inadvertidas a primera vista, pero inmersas en las mismas sociedades analizadas que suelen contar con "sus propias interpretaciones", razón por la cual, se trata de buscar explicaciones, “interpretando expresiones sociales que son enigmáticas en su superficie" (2003, p.20). Ahí está la tarea que sugiere: no ir en la búsqueda de leyes, sino de significados, pues, como lo afirmara con Max Weber, el hombre es "un animal inserto en tramas de significación que él mismo ha tejido". O, en palabras de la educadora ambiental Lucie Sauvé (2012, pp. 12-23), “un valor no tiene sentido sino en el universo de significación en que se sitúa, en la visión del mundo en el que se inscribe".

Con esos mismos enfoques han trabajado autores como Valerio Fuenzalida, para quien "la significación no se agota en el proceso de emisión, ni en el análisis semiótico: es una construcción del sujeto inmerso en su contexto". (Aparici, 1996, pp. 262-263)

Desde esa perspectiva de producción de sentido se podrá ahondar en los recursos que usó Radio Sutatenza con su modelo de Educación Fundamental Integral, para configurar su audiencia, a partir de claras "propuestas identitarias y comunicativas". (Vaca Gutiérrez. 2011) Vaca Gutiérrez, en la investigación denominada "Procesos interactivos mediáticos de Radio Sutatenza con los campesinos de Colombia (1947-1989)" hace una diferenciación entre los procesos interactivos mediáticos y los interactivos conversacionales. Mientras los primeros, sostiene, pertenecen al campo de los medios, se caracterizan por un paradigma de comunicación que "no es dialógica (...) y es típicamente asimétrica", los segundos se caracterizan por la "reciprocidad constitutiva que lleva a un dialogismo inmediato". (P. 257)

La metodología aplicada por este autor se basó en el análisis de discursos, desde la perspectiva de Eliseo Verón y su "conjunto significante", que abarca

No apenas la materia lingüística sino (...) cualesquiera que sean las materias significantes en cuestión, por ejemplo, el lenguaje, el cuerpo, la imagen, etc. Un discurso nada más es, al final, sino una colocación de sentido en el espacio/tiempo. (2004.pp. 61-62)

Y dentro de ese conjunto significante, Vaca puso especial atención al llamado “dispositivo de enunciación", también llamado por Verón "contrato de lectura", que se 
refiere a la forma de decir, con sus distintas modalidades. En otras palabras, allí importa más el cómo que lo que se dice. Para Vaca Gutiérrez, ese fue un aspecto clave en la investigación, de cara a "establecer las modalidades de creación de vínculos, de aproximación, entre Radio Sutatenza y sus oyentes" (p.258) para lo cual el autor fue tras las marcas y estrategias de producción, evidenciadas en los discursos religioso, radiofónico y educativo.

En ese contexto destacaremos a continuación los siguientes recursos-tácticas, que serán enunciados aquí y ampliados en el capítulo III ( ACPO: Lecciones de radio popular para América Latina):

-Discurso religioso: Explica, en buena medida, por qué impactaron los mensajes entre las campesinas y campesinos-oyentes de Radio Sutatenza. Vaca subraya que el campesino, de una profunda raigambre religiosa, se caracterizaba por su conservadurismo y por su ingenuidad lo que, de alguna manera, se traducía en que "tenía resistencia a todo lo que significara cambio, transformación, progreso". (p. 262)

-Discurso radiofónico: Radio Sutatenza supo aprovechar los recursos del lenguaje de la radio: voz, sonido ambiente, efectos especiales, música y silencio.

-Discurso educativo: Vaca Gutiérrez concluye en su investigación que una de las claves del éxito de Radio Sutatenza consistió en haber entendido que la radio, por sí sola, como ocurre con los demás medios, no garantiza cambios entre sus receptores u oyentes, pero sí los motiva y los potencia.

Son, como se podrá advertir, propuestas de investigación que, por su propia naturaleza, se inscriben en el modelo crítico Latinoamericano, que nos ha permitido entender cómo opera el proceso de comunicación en contextos específicos. Sobre este aspecto nos detendremos a continuación.

\subsubsection{La investigación en comunicación popular}

En la investigación en comunicación en América Latina, con algunas contadas excepciones, se aplicaron hasta los años 70 recursos del positivismo, al basarse en mediciones y sistematizaciones que tenían como propósito producir un conocimiento "objetivo" de la realidad, para lo cual el investigador no se involucra como "agente de cambio social"' (Lozano, 2007, p. 4).

Es importante tener en cuenta que, en términos generales, hasta entonces se usaron "modelos conceptuales foráneos, procedentes más que todo de Estados Unidos de Norteamérica”. (Beltrán, 1985, p. 2). Ya a partir de la década de los 80 se hace evidente el cambio de tendencia hacia los enfoques críticos, en los cuales cobran relevancia aspectos como las particularidades del contexto; el análisis del impacto de la comunicación sobre el 
poder político y su incidencia en problemáticas como la desigualdad social; y el papel que cumplen los medios en el reforzamiento de la ideología imperante. A diferencia del positivismo, los investigadores del enfoque crítico no asumen posturas neutrales y, por el contrario, se comprometen con el cambio social. (Ib.)

De lo que se trató con estas indagaciones fue de dar cuenta de un proceso de comunicación popular, como el de Radio Sutatenza, que se anticipó varios años a la teoría, pues surgió en el marco de la defensa de hablar, de expresarse, en la medida en que "los recorridos de la comunicación popular latinoamericana hicieron eje en un silencio impuesto que debía ser roto". (Mata, 2011, p. 3) En ese orden de ideas, la propia María Cristina Mata la identifica con

Las experiencias de medios masivos gestionados por organizaciones populares o instituciones aliadas a sus causas -las radios educativas y populares, las televisiones obreras, el cine documental alternativo- (que) constituyeron en la década del 80, y de allí en adelante, acabadas muestras de ese proceso.(2011, p.4)

Así las cosas, hablar de este tema es referirse al conflicto derivado de la pugna por la construcción del poder, pues resulta inevitable tratarlo como "movimiento de resistencia, de impugnación y de la dominación estructural de nuestra sociedad”. (Martín-Barbero, 1983, p.5).

En clave de comunicación, es la disputa por el sentido; por influir en lo que también se ha llamado el "capital simbólico" de las sociedades lo que Michel de Certeau (1996, pp. 42-43), inscribe en la lucha cotidiana entre las tácticas (de los débiles) y las estrategias localizadas en los centros de poder hegemónico. En esa dirección, Mata observa cómo el camino hacia la "ruptura de silencio" ha estado lleno de imaginación y de propuestas creativas por hacerse escuchar aun en medio de condicionamientos de tinte mercantilista. Alude, por ejemplo, a la importancia que le concediera al rating un radialista popular como José Ignacio López Vigil, quien se pregunta :

¿Ganar audiencia es el objetivo? No, pero sin audiencia -sin mucha audiencia-no podremos lograr nuestro objetivo. ¿Que el rating no es la última palabra? Por supuesto que no. Pero sí la penúltima, porque en radio, si no te escuchan, no existes. (1993, p. 3)

Eso: existir, hacerse notar e incidir es lo que se ha buscado con propuestas como las de ACPO que, pese a los disensos, controversias y desencuentros, no solo no pasó 
inadvertida sino que influyó en forma notable en la manera como se ha asumido el proceso de comunicación radiofónica en buena parte de América Latina, en África y en Asia.

De ahí que al plantear el problema de investigación alrededor de las formas como se entiende y se asume el proceso de comunicación/educación en las Escuelas Digitales Campesinas, EDC, tengamos en cuenta que estamos en un campo de grandes tensiones y disputas. En un plano general, una de las más sonadas controversias está relacionada con el informe Macbride presentado en 1980 en la XXI Conferencia General de la Unesco, en Belgrano, que postuló el Nuevo Orden Mundial de la Información y la Comunicación ( NOMIC). La misma María Cristina Mata recuerda que pese a la importancia de haber puesto en el centro de las discusiones mundiales la preocupación por la desigualdad de unos flujos informativos centralizados y controlados ello no impidió cuestionar por qué "a los esfuerzos por diseñar proyectos contra-hegemónicos se les imponía una dimensión tecnoadministrativa que identificaba el acceso a medios y tecnologías con el acceso al poder ser y decir". (p.14) Es decir, no se tocaba el problema de fondo: "lograr una palabra propia sostenida en la igualdad económica, social y política." (Ib.) Es la "desconcertante paradoja" que significa acceder a tecnologías en medio del progresivo debilitamiento de lo público. (Martín-Barbero \& Rey, 1999, p.22)

Han pasado muchos años desde entonces y el desafío por democratizar la palabra se mantiene hoy más vivo que nunca. Se trata ahora de pensar las prácticas de comunicación popular "como puentes que permitan reconocer parentescos y establecer convergencias" y , también, hacer evidentes los desacuerdos o las contradicciones, así se expresen como "antagonismos irreductibles". (Ib., pp. 19-20) , como se postula desde el campo de comunicación/educación.

\subsubsection{Construcción de identidades}

"La comunicación en la educación: más allá de la escolarización" (1999) escrito por el comunicólogo argentino Jorge A. Huergo, ayuda a profundizar la manera como se asume la relación Comunicación/Educación que, como se ha señalado, es de gran importancia para la estrategia de Educación Fundamental Integral, con sus tres ingredientes centrales: aprendizajes, actitudes y valores. El autor llama la atención sobre la necesidad de confrontar la idea de que en todo proceso educativo, per se, está inmersa la comunicación. Al detenerse en las formas hegemónicas de la educación tradicional, Huergo advierte, como lo plantearan en su oportunidad autores como Paulo Freire, Mario Kaplún y Jesús Martín-Barbero, que ello solo condujo a desconocer el desorden o revoltura cultural inmerso en el acto de aprender, 
con un propósito político claramente identificado, pues buscaba tratar a los educandos como agentes pasivos y a la institución escolar como "la portadora y guardiana de lo 'culto'" . (Huergo, p.118). En esa misma dirección, señala que la escuela tradicional, "como proceso cultural, nos hace pagar el precio de la libertad, constituyéndose así en una gran paradoja de la modernidad (que nos prometía esa libertad) pues aunque se asegurara que sin comunicación no podía haber educación, lo cierto es que, en la práctica se ejercía una “comunicación” instrumental, es decir, no humanizada, que se ponía al servicio de esquemas verticales de enseñanza, entre ellos la memorización y la repetición literal acrítica, con perspectiva de "disciplinamiento (como ) estrategia de racionalización". (Ib. pp.118 y 119) Así, entre otros valores, se ha pretendido sacrificar activos sociales tan importantes, como los saberes ancestrales, porque "la escolarización hizo caer en desprestigio un conjunto de visiones y de tradiciones del mundo que estaban fuertemente ligadas al pasado de cada región, y que vivían en la memoria”. (Ib., p. 125)

La Comunicación/Educación inmersa en la "batalla cultural” o "campo de lucha por el significado" implica, en consecuencia, la obligación de educandos y educadores -cuyos papeles se intercambian permanentemente- de "reflejar una multiplicidad de valores, voces e intenciones" que conforman un capital simbólico determinado y permiten la construcción de identidades. (Ib., p.132). Es, como ya lo había propuesto Buenfil Burgos, en planteamientos retomados por Ernesto Laclau y Chantal Mouffe (2001), en el interjuego entre interpelaciones y reconocimientos, donde se materializa esa batalla. Sin embargo, Huergo advierte que para todo el proceso sea educativo no debe terminar ahí, es decir en ese interjuego, sino "en algún cambio en las prácticas socioculturales cotidianas”. ( 2003, p.5)

En otro de sus textos $(2006$, p.7) este autor sostiene que hablar de Comunicación/Educación es referirse a un campo complejo, problemático y conflictivo, que no se puede reducir a señalar que "comunicación y educación son lo mismo" que "comunicar es siempre educar" o "educar es siempre comunicar", porque -puntualiza- "el comunicador no necesariamente es un educador". Y subraya la necesidad de vacunarnos contra estos dos errores clásicos:

(...) la asimilación de la comunicación a los medios

(...) la confusión creada a partir del reduccionismo de la denominada "tecnología educativa", según el cual debemos prestar atención a las innovaciones tecnológicas, la informática, la "privatización" educativa, la educación a distancia, como formas concretas de relación entre comunicación y educación. 
Para alentar la discusión Huergo propone, como ya lo planteaba Freire en su Pedagogía del Oprimido (1970), volver a la etimología de comunicar, expresión que remite a otras como poner en común, compartir y comulgar ( estar en comunión con); y educar cuya desinencia "ducar" viene del verbo latino ducere, que significa 'conducir':

Educar significa conducir hacia afuera, "sacar desde adentro", al modo de "ex-presar", más que conducir hacia adentro o poner algo que está afuera dentro del hombre o de su mente. En este caso, se hace referencia a otra ruptura: la ruptura con el significado que privilegia el acto de transmitir, y su contrapartida: el acto de recibir e incorporar, lo que, de paso, pone en cuestión una perspectiva narrativa bancaria y también tecnicista de la educación. (Huergo, 2006, p. 9)

Así, la Comunicación/Educación se plantea de cara a contribuir a la conformación de la otredad, esto es, del otro visto como un ciudadano que participa de manera activa de la vida política, hacia la constitución de nuevas realidades. Como lo señala el profesor Carlos Valderrama, "es la apuesta por una nueva forma de vivir juntos, de interpelar a las organizaciones y de gestar la organización”. (2000, p.9) Para este autor, en los múltiples escenarios de la Comunicación/Educación se hace "necesario un proceso de resignificación de la escuela y del sentido de la educación”. (Ib.). Entre esos ámbitos menciona: educación para la recepción; comunicación en la educación y nuevas tecnologías, los cuales Ismar de Oliveira Soares (2000) complementa con los siguientes: -Gestión de comunicación en el espacio educativo; y -Reflexión epistemológica sobre la interrelación Comunicación/Educación.

En la misma dirección, de Oliveira Soares habla de la necesidad de reconceptualizar la relación entre educación y comunicación “orientándola hacia una educación ciudadana emancipadora, que se basa en la concepción de un nuevo sujeto, de una nueva temporalidad y de una nueva praxis”. (2000, pp. 27-47) Esa nueva temporalidad alude a la integración del “tiempo pedagógico y "el tiempo comunicativo", en el contexto de la era de la información, donde todo cambia de manera muy rápida. Son formas de descentralizar la palabra autorizada, que estaba en el texto impreso, con el fin de buscar "la transformación de las relaciones sociales internas del espacio escolar". (Ib.)

"Sobre esta perspectiva, la comunicación pasa a entenderse como relación, como un modo dialógico de interacción del actuar educomunicativo", dice Oliveira (Ib.). Por lo tanto, 
la comunicación y la educación no se conciben como áreas que deban tener su objeto de estudio disputado.

Y, en este contexto surge la siguiente pregunta: ¿hacia dónde y con cuáles propósitos se debe enfocar la educación? El investigador Francisco Gutiérrez observa que su papel debe estar en educar para la "incertidumbre", para "disfrutar la vida", para la "significación"; para la "convivencia entre los diferentes"; para la "apropiación de la historia y de la cultura". (1996, pp. 11-19)

Es en esa tarea que el recurso del diálogo se vuelve tan importante en la medida en que permite el conocimiento y el reconocimiento de imaginarios en el marco de la pasión por la comunicación que, en palabras de los investigadores Daniel Prieto Castillo y Francisco Gutiérrez activa la creatividad, la investigación y el intercambio de experiencias. (Ib.) Es un reconocimiento que permite, a su vez, participar de la lectura crítica de los medios tradicionales de comunicación.

Con esa mirada, Huergo asocia la Comunicación/Educación a la investigación participante, que permite el reconocimiento del otro, "del a quien de nuestra comunicación, para que el proceso no adquiera características bancarias". Son miradas que coinciden con las que han hecho los mismos como Gutiérrez y Prieto (1992, p. 25) para quienes la interrelación entre comunicación $\mathrm{y}$ educación fomenta el autoaprendizaje $\mathrm{y}$ el interaprendizaje, al asumir el conocimiento como una construcción colectiva.

Ese, como se verá en el curso de esta investigación, es un propósito que se ha planteado ACPO, al entender que las campesinas, campesinos, los afrodescendientes y las comunidades indígenas vinculados a las Escuelas Digitales Campesinas, son sujetos de aprendizaje que, como tales, asumen un papel protagónico, esto es, propositivo, analítico y crítico.

Así, desde su dimensión ético-política, la relación Comunicación/Educación parte del reconocimiento del otro, sin perder la propia naturaleza del individuo: " como yo cuento y quiero contar y ser contado, debo empezar por contar con el otro" (Martín-Barbero, 2017, p.7 ) y, por lo tanto, se compromete a fondo con el interaprendizaje, permeado por acciones inscritas en la crítica y en la autocrítica que, con frecuencia, llevan al autorespeto. He ahí una clave: aprendo a respetarme para respetar al otro. En consecuencia, la ética de la comunicación se pone al servicio de la "democratización de la democracia", por cuanto promueve la deliberación con un sentido "no instrumental de la política", es decir, no esconde veladas intenciones, sino el ánimo genuino de promover la convivencia ciudadana; como lo subraya el profesor Hoyos Vásquez (1995, p.70), “es posible encontrar fundamentos 
razonables de la política y de la justicia en las competencias de cooperación social del ciudadano, es decir, en sus virtudes éticas , fundamentalmente en su sentido de reciprocidad".

En un contexto más amplio, la Comunicación/Educación busca identificar la génesis del poder, en su empeño de construir sujetos críticos y socialmente responsables y comprometidos, pues como lo plantea Foucault (1993, p.27) "el poder no se aplica a los individuos, sino que transita a través de los individuos". También asociamos estas miradas a la propuesta de "biología del conocimiento" planteada por Humberto Maturana frente a la necesidad de construir una democracia mediante conversaciones que constituyan "un proyecto común de convivencia en la aceptación y respeto recíprocos" (Maturana, 1991, p.4) 25). En esta iniciativa, se asumen las diversas posturas ideológicas no como una amenaza sino como la posibilidad de abrirle paso a un proyecto común de nación, con un ejercicio encaminado a descubrir los errores que nos impiden llegar a buen puerto. "Si estamos en la pasión por la democracia podemos escuchar al otro y cooperar", dice el autor. (Maturana, 2001, p. 67)

Ya en clave de Comunicación/Educación buscamos integrar muchas formas de participación social y promover la construcción colectiva de los relatos, para activar la creatividad social que, como se verá más adelante, en la propuesta de ACPO, se expresa en formatos como el radioclip y las crónicas-relatos de vida. De esa manera, asume como gran motor la defensa y construcción de la dignidad, lo que demanda una apuesta constante por el mejoramiento de las condiciones sociales. "Se trata de un eterno proceso de construcción frente a las acechanzas de la humillación". (Prieto, 2006, p.6). Por lo tanto, promueve el ejercicio comunicativo con la intención expresa de compartir con el otro, sobre la base de una reglas de deliberación que ponen el énfasis en la argumentación dialógica: hablamos para entendernos con los otros, a fin de que el debate se convierta en una "guía para la acción". (Hoyos Vásquez, 1995, p. 69)

En palabras del sociólogo portugués Boaventura de Sousa Santos (2009) estamos ante el ejercicio de una "resistencia epistemológica", como condición para hacer efectiva la "resistencia política". En su "sociología de las emergencias", de Sousa Santos plantea la necesidad de profundizar la apuesta de la Investigación Acción Participativa, con el fin de promover otras maneras de entender y representar la realidad, lo que, para él, equivale a encarar "nuevas constelaciones de significado en lo que concierne al entendimiento y a la transformación del mundo", pues, "no puede haber justicia social global sin justicia social cognitiva”. Allí se inscribe la ecología de saberes (De Sousa Santos, 2009, p.12 ) como una perspectiva de las "Epistemologías del sur" asociada a la pedagogía de la liberación que 
planteara Paulo Freire a comienzos de los 70, la cual se ha concretado en América Latina en muchas experiencias de la llamada "Comunicación para el cambio social” y, como decíamos, en IAP, liderada por Orlando Fals Borda. Como tantas veces lo dijera el sociólogo colombiano, se trata de validar una investigación que le dé la verdadera dimensión al conocimiento popular, sin negar otro tipo de saberes, algunos de ellos provenientes del contexto académico. De ahí, de esa tarea de escuchar y validar lo que dice la gente, salen grandes lecciones y términos como el de sentipensante. Atribuido por el propio Fals Borda (2008) a un pescador de San Benito Abad, en la zona ribereña del San Jorge ( departamento de Sucre) la palabra sentipensante hace referencia a aquellos hombres y mujeres que saben unir la razón y el corazón para buscar verdades. También del trabajo de campo en esa región colombiana surgió el calificativo "hombre hicotea", para definir a aquellas personas "aguantadoras" o dueñas de una paciencia estratégica, que saben esperar su mejor momento para gozar la vida. "Somos hombres hicotea -dicen los pescadores del San Jorge- Sufrimos mucho, pero también gozamos y, al hacer la suma, va ganando la alegría, porque sabemos esperar", relató el investigador un poco antes de su muerte. (Ib.) Es, por lo tanto, un enfoque con alta incidencia social y política, en tanto busca potenciar "estrategias de cambio" que se deben traducir en el progreso de las comunidades. La propuesta de la IAP también se denomina "sistémica", esto es, encaminada a lograr interpretaciones globales, con sentido de complejidad. (Fals Borda,1999). Se trata de apelar a lo que la también socióloga colombiana María Teresa Uribe de Hincapié, citada por Jesús Martín-Barbero denomina “constelaciones de sentido" que, según lo indica, revelan las prácticas y acciones de los actores sociales “(...) y las búsquedas en la cultura, esa dimensión esquiva, huidiza, hecha de apariencia y representaciones, de imaginarios y máscaras que muestran y ocultan al mismo tiempo,..." (2004, P. 133) Ello ha conducido en países como el nuestro a las "ciudadanías mestizas", aquellas que han surgido no como producto de un orden formal o normativo impuesto, sino aun a pesar de las restricciones constitucionales o legales, por lo que se conoce tradicionalmente como "falta de voluntad política".

Desde una dimensión cultural, como lo plantearan Jesús Martín-Barbero; María Cristina Mata y Rosa María Alfaro, entre otros autores, se enmarca la comunicación en espacios simbólicos en los que se libran la disputa por los significados. Por lo tanto, desde esa perspectiva no solo es posible sino “ (...) indispensable que la diversidad de identidades nos pueda ser contada, narrada. Pues la relación de la narración con la identidad no es solo expresiva sino constitutiva: es en la diversidad de sus relatos que la identidad cultural se construye". (Martín-Barbero y Ochoa Gautier, 2005. pp 3-4) 
Al profundizar estas miradas, en la línea de la pedagogía liberadora de Paulo Freire, Boaventura de Sousa Santos recuerda que una es la historia si es contada por el cazador y otra si es contada por el leopardo. En sus palabras, "si se representa el mundo en el que vivimos como nuestro, podemos cambiar las cosas, podemos unirnos y organizar partidos, movimientos sociales" (2016, p. 7) Y, desde esa misma lógica, se entiende que uno sea el resultado del acto de conocer nuestra propia realidad, si los hechos se cuentan después y otro si se cuentan durante los procesos, por parte de los sujetos involucrados de manera directa en ellos. Hay, en todo caso, una profunda concepción ética, que se basa en entender que la batalla cultural, esto es, la disputa por la construcción de sentido, se inicia con "el nivel hermenéutico de la comunicación” (Hoyos Vásquez, 1995, p.76).

Por supuesto, la primera tarea consiste en desaprender aquello que se había impuesto como una verdad revelada, cuyas raíces se hunden en el eurocentrismo o epistemología del norte, tal y como la denominara de Sousa Santos. Aunque no lo pareciera, se trata de una vieja lucha, como lo demuestra el que un autor como Antonio Gramsci (1891-1937) ya se hubiera ocupado de la necesidad de entender cómo se dan los procesos hegemónicos. En efecto, Gramsci sostiene que es el mismo lenguaje el encargado de dotar a hombres y mujeres de su capacidad para concebir el mundo, las bases para construir el sentido común. (1984) Estamos, entonces, ante una batalla simbólica, que se libra en dos dimensiones claves, como lo son la fuerza y el sentido. "(Es) la apropiación de un sentido del poder en disputa por procesos de contrahegemonía que, de un lado y otro, envuelven sujetos y discursos por los que pasan la seducción y la complicidad”. (Martín-Barbero, 2003, p.11)

Como lo hiciera notar el profesor Hoyos Vásquez (1995, p.70), es ahí en el mundo de la vida, entendido como el escenario de la cotidianidad, con su universo de significaciones, tensiones y contradicciones, donde se da la oportunidad de construir valores asociados a la justicia, como rectitud, solidaridad y equidad. Para él, se trata de abrir la comunicación a otras culturas, con sus diferentes puntos de vista y formas de vida, " para apropiarse del contexto propio".

Hoyos Vásquez propone luchar por un nuevo ethos cultural, para comprender de manera crítica la ciencia y la tecnología. Y advierte que es en el proceso educativo donde se puede tejer ese ethos cultural:

Es allí, con un sentido deliberativo y no instrumental de la política, donde una ética que recoja lo mejor de la discusión contemporánea (...) tiene que poder incidir en la convivencia 
ciudadana y en la democratización de la democracia. Este es el significado de una ética, cuyo lugar prioritario sigue siendo el de los procesos educativos. (Hoyos: 1995, p.68)

En este contexto, concibe la ética como una "guía para la acción" (Ib., p 69), con la cual se exhorta a pensar y a avanzar por la vía de la argumentación y no del dogmatismo hacia una "formación moral de los ciudadanos".

Así mismo, subraya que en valores como la reciprocidad y la solidaridad se puede apuntalar un proyecto político que fomente las competencias de cooperación social del ciudadano.

Es lo que la filósofa española Adela Cortina (1997, pp.37-38) atribuye a una riqueza axiológica, "resultado de un quehacer, la ganancia de un proceso que empieza con la educación". Aquí la educación no es entendida solo como la formal, pues se asocia con todas las posibilidades de aprendizajes que tienen los sujetos, en el seno de su propia familia, el ambiente social y los medios de comunicación. Es, dice la investigadora, una tarea inaplazable, para evitar que aumente el número de excluidos de la vida social, "el número de los que ni se saben ni se sienten ciudadanos en ningún lugar: el número de los apátridas". (Ib., p 125). Es lo la autora denomina una "ética cívica de mínimos compartidos" que postula tratar a los otros como "fines en sí mismos” y, por consiguiente, no como instrumentos sino de manera dialógica, esto es, como interlocutores válidos. (2003. p. 31)

Surge, entonces, este cuestionamiento: ¿cuál es el papel específico que cumple la comunicación en esa tarea? Hoyos Vásquez propone: "No olvidemos que toda moral tiene que comenzar por la comprensión del otro". (p. 76) Y ello pasa, como se advirtió, por lo que él mismo denomina "nivel hermenéutico de la comunicación" (Ib.), para activar la comprensión de sentido, tanto de las expresiones lingüísticas como de "las situaciones conflictivas, de las propuestas de cooperación social, etc.”.

De ahí -según apunta- se debe pasar al proceso subsiguiente, identificado como la apertura de la comunicación a otras culturas (Ib., p. 76), es decir, a otras formas de concebir y de entender el mundo, para lo cual formula como principios esenciales de la deliberación pública el reconocimiento del otro y el derecho a la diferencia.

Como se puede notar, hay puntos de encuentro importantes aquí con Huergo, en la medida en que la relación Comunicación/Educación se considera clave en la búsqueda del nuevo ethos cultural. Los dos autores reconocen en sus posturas grandes incidencias políticas y sociales, por lo demás, deseadas para promover una eticidad que signifique "más justicia, más equidad y mayor solidaridad". Como se ha referenciado, en Huergo (1999, 
p.267) se trata de propiciar la construcción de identidades, mediante prácticas que implican "reflejar una multiplicidad de valores, voces e intenciones". Y en Hoyos Vásquez (p.86) se concreta la acción en la defensa de lo público, entendido como "un espacio social, una estructura social del mundo de la vida y de la sociedad civil, tejida por relaciones comunicativas que se concentran en torno a determinados problemas y tomas de posición ...".

En la misma línea de trabajo el periodista colombiano Javier Darío Restrepo (2008, p. 148) reconocido por su tarea en defensa de la ética en el seno de organizaciones como la Fundación Gabriel García Márquez para el Nuevo Periodismo Iberoamericano, subraya la necesidad de no abandonar nunca el "diálogo ético" que entiende como "el resultado de una exploración sobre la naturaleza humana". Para ese propósito, recalca, es indispensable el ejercicio de la autocrítica que, en el caso específico del periodismo, está en la naturaleza misma del oficio y debe incluir tanto la participación de toda la redacción, como de los lectores, oyentes o televidentes, pues, como él mismo lo dice:

Pesan en mí los años en que he sido defensor del lector, pero es un peso positivo porque puedo testimoniar que la influencia del lector es aire fresco para el periódico, es garantía contra el anquilosamiento y la rutina y es una permanente visión crítica, necesaria para un producto que debe renovarse día a día. (Restrepo: 2008, p.147)

Son miradas claves para enriquecer tanto el análisis como el trabajo concreto de las Escuelas Digitales Campesinas, cuya Educación Fundamental Integral postula -como se indicó- que "en la educación y en la comunicación se debe escuchar el llamado de la comunidad, no planeado desde un escritorio". (Pérez, 2017, audio podcast)

Es, también, una forma de profundizar "la búsqueda de conocimientos y de criterios de validez del conocimiento" (De Sousa: 2009, p. 12), entre las comunidades o colectivos que tradicionalmente han sido victimizadas, ignoradas o acalladas, es decir, vistas no como sujetos sino como "objetos" de las políticas globalizadoras impuestas desde el norte. (Ib.) La invitación es a entender que históricamente no solo colonizaron el territorio sino, lo más grave aún, colonizaron la palabra. Y sin el ejercicio de la palabra pública no existe el ciudadano como, en efecto, ha pasado durante tantos años. Todo porque, como lo afirma López Vigil, se ha negado el uso de la voz, no en pocas oportunidades mediante el ejercicio de la violencia. Por eso recalca: "somos hijos e hijas de pueblos con lenguas cortadas". (2015, p. 129) . Pero, aún así, estos pueblos también han sabido ser desobedientes... 
Es así como desde la comunicación participativa, el periodismo ciudadano y el periodismo literario, se han puesto en marcha experiencias exitosas que confirman la viabilidad práctica de este tipo de iniciativas. (Algunas de ellas fueron publicadas en el libro "Ser ciudadano en la radio" (2012)

\subsubsection{Experiencias de radio ciudadana}

La radio ciudadana ha abierto grandes posibilidades de generar espacios de participación que, a su vez, se ponen al servicio de la construcción de identidades culturales y políticas.

¿Pero por qué la denominación de ciudadana, y no la de comunitaria, popular, libre, alternativa, educativa o participativa...?

El radialista José Ignacio López Vigil (2008) propone el concepto de “ciudadanía global" para contribuir a la definición de lo que hacen las radios que trabajan por la democratización de la democracia. Según, lo señala, se trata de inscribir la denominación de este tipo de emisoras en una visión universalista, internacionalista, pues, según sus palabras,

las radios ciudadanas no se definen por el lugar donde están instalados sus equipos y sus cabinas. Ni por la edad de sus públicos. Ni por una visión nacionalista estrecha. Estas emisoras asumen un concepto amplio, revolucionario, indispensable, de ciudadanía global. (p.17)

López Vigil sustenta su propuesta de ciudadanía global a partir del cuestionamiento de los mapas políticos, muchos de ellos dibujados de manera arbitraria y autoritaria, para apuntarle a acciones prácticas que vayan más allá de las fronteras, con mayor razón, según argumenta, en el marco de la globalización, donde los nacionalismos se han vuelto algo relativo. "Quizás esto nos ayude a ampliar el concepto de ciudadanía”, recalca. (P.16).

Para contribuir a este debate, la investigadora Clemencia Rodríguez (2009) defiende el término de "medios ciudadanos" desde la democracia radical y sostiene que es el indicado, porque se trata de nombrar los procesos de cambio social y democratización que se viven allí. Señala que el concepto de "medios comunitarios" tiene el inconveniente de definirlos en función de quiénes los producen o a partir de la categoría asignada por el Estado para la asignación y clasificación de frecuencias. Y el de "alternativos" surge de "una relación reactiva frente a los medios dominantes $\mathrm{y}$, por lo tanto, la correspondiente aceptación de un estatus menor”. (P.17) 
Al sostener su propuesta desde las teorías de democracia radical y ciudadanía de Chantal Mouffe, dice:

Los ciudadanos son aquellas personas que asumen su ciudadanía mediante la participación en prácticas políticas cotidianas en tanto sujetos localizados cuya cotidianidad está cruzada por una serie de interacciones sociales y culturales. Tales prácticas están por tanto enmarcadas en las interacciones familiares, en las relaciones con vecinos, amigos, colegas y pares. (P.18)

Los medios ciudadanos apoyan esas tareas, al permitirles nombrar el mundo para poder intervenir en él con sus acciones políticas, pues "solo quienes estén en capacidad de narrar sus propias identidades y de nombrar el mundo en sus propios términos tendrán una presencia sólida como sujetos políticos”. (P.19)

Volviendo a López Vigil, este autor asegura que para hacer efectiva y eficaz la radio ciudadana se debe apelar a formatos que se salen de los lugares comunes, como el consultorio ("preguntas de quien no sabe a quien sabe" sobre temas como salud sexual y reproductiva; temas jurídicos y laborales; y de gastronomía...) ; el radioclip ( pequeños dramatizados en los que la propia comunidad representa su realidad) y los discoforos, para abrir la discusión social sobre la música de mal gusto. Así mismo, plantea el periodismo de intermediación que también denomina "quinto periodismo", el cual consiste en ejercer la ciudadanía desde los medios de comunicación, teniendo en cuenta que más que medios son mediaciones, como lo explicó Jesús Martín-Barbero. Concreta sus tareas en la fiscalización de los poderes públicos, "y a los privados, cuando violan los derechos humanos". “Ciudadanía es poder. Y periodismo de intermediación es ejercicio de ese poder”, puntualiza. (P. 192)

La tarea de observar cómo se pueden aplicar estos planteamientos en la práctica cotidiana de la radio remite a investigaciones como la denominada "Radio local, opinión pública y participación ciudadana", de los investigadores Alexánder Buendía Astudillo y Juan Carlos Pino Correa. (2008)

Allí se da cuenta del trabajo desarrollado con colectivos de comunicación en el departamento del Cauca, caracterizado por su diversidad geográfica, cultural, étnica y social, en el marco de un proyecto más amplio, denominado "Radios ciudadanas: espacios para la democracia”, promovido por el Ministerio de Cultura de Colombia. Para los autores, la radio debe entenderse, "más que un medio masivo de comunicación", como "un entramado de 
interrelaciones culturales, sociales estéticas y técnicas (...) y como "un fenómeno social y cultural, un modo de decir y de contar cosas, y un sistema tecnológico" (s.f..: El'Gazi, p. 17) Y al coincidir con Rosalía Winocur (1998, p. 130) dicen que tanto para la ejecución de su propuesta como para el trabajo de las comunidades, se partió de entender la ciudadanía como "un proceso que involucra 'cruces'y 'fracturas' en varios niveles de representación de la vida cotidiana - muchas veces contradictorios o antagónicos- en permanente 'negociación'y reconstrucción".

Al ponderar los resultados del trabajo, ejecutado entre marzo de 2005 y abril de 2006 en seis municipios y siete emisoras, "cinco de ellas comunitarias o de interés público y dos pertenecientes a pueblos indígenas", destacan que se generó "un importante impacto local que puede verse en lo social, lo cultural y lo comunicacional”. (Ib. p. 92)

Así mismo, subrayan que la participación ciudadana fue uno de los soportes fundamentales de la producción local y regional, lo que se tradujo en la concreción de valores como inclusión y respeto por la diferencia:

Hubo entonces pluralidad de voces y opiniones, lo que permitió a la postre la visibilización de nuevos actores sociales y culturales que tradicionalmente no se oían en las radios locales. En la producción radiofónica local se pasó del tradicional modelo bipolar del periodismo a la multiplicidad de fuentes y testimonios, que enriquecen los programas (...) (p. 94)

Y para que esa participación ciudadana tenga sentido, es decir, que no se quede en un ejercicio coyuntural sino que se asuma como una actitud permanente, concluye la investigación, es necesario promover la formación política de las comunidades. Así este proyecto de radio ciudadana podrá contar y "pensarse a futuro como una colectividad crítica, deliberante, incluyente y verdaderamente democrática" . ( P. 96)

Se confirma así que solo el trabajo directo con las comunidades permite concretar postulados como los que se plantean desde corrientes del pensamiento como el humanismo cívico y la democracia radical. Estos, como se ha señalado, con sus necesarios matices, han sido aspectos claves en el ejercicio de la Educación Fundamental Integral de ACPO, como los que se busca identificar en esta investigación.

Y “¿qué supone la participación de los públicos en la radio?”. Alrededor de esta pregunta-problema, las investigadoras Analía Brandolín y María Eugenia Robosh (2003) enmarcan su trabajo en la comunicación como fenómeno cultural que, como tal, "ya no refiere a un proceso lineal de emisión y recepción de mensajes sino a un intercambio de 
sentidos, porque en la comunicación se puede observar lo mismo que ocurre en la cultura (la producción social de sentido)”. (P.35)

Las autoras hacen referencia al concepto de hegemonía desarrollado por Gramsci que, destacan, permitió dimensionar la capacidad de los receptores para resistir la ideología de la élite dominante. Al recordar que la hegemonía depende de que la clase dominante tome en cuenta los intereses y necesidades de las clases dominadas para poder seguir dirigiendo la sociedad, hacen énfasis en que implica las "luchas por los significados". (Ib.)

Son postulados y matrices aplicadas por autores como Jesús Martín-Barbero (1987) para quien la comunicación se asimila a "un espacio simbólico" donde se dan los cruces y entrecruces de discursos como expresión de la "pluralidad de matrices culturales".

Y en el marco de las teorías del "contrato de lectura" de Verón y de "los campos sociales", de Bourdieu, las autoras recuerdan que no se puede analizar un texto sin tener en cuenta sus particulares condiciones "históricas de producción y consumo": "El texto adquiere su sentido en el encuentro con un conjunto de discursos bajo ciertas circunstancias; así el significado del texto se construye diferentemente de acuerdo a los discursos que le aporta el lector históricamente situado". (P. 38)

Por su parte la comunicóloga argentina María Cristina Mata, se refiere a la “comunicación popular” que identifica con

Las experiencias de medios masivos gestionados por organizaciones populares o instituciones aliadas a sus causas -las radios educativas y populares, las televisiones obreras, el cine documental alternativo- (que) constituyeron en la década del 80, y de allí en adelante, acabadas muestras de ese proceso. $(2011$, P. 4)

$\mathrm{Su}$ investigación denominada "Comunicación popular. Continuidades, transformaciones y desafíos" gira alrededor de las categorías comunicación popular, movimientos sociales, democratización y ciudadanía.

En el terreno específico de la construcción de ciudadanía, Mata (p.18) plantea la necesidad de buscar "nuevos caminos" hacia el ejercicio de prácticas que le apuesten a otras modalidades de interacción y producción de sentidos. Y al recordar la propuesta de Boaventura de Sousa Santos (2008, p.4) de empezar por imaginar un mundo diferente, subraya que ello implica deberes inaplazables, entre estos "cambiar las lógicas del poder; para lo cual las luchas democráticas son cruciales". Ello solo será posible -anota- si vamos a las raíces del problema, que parte de identificar la democracia con la mera formalidad 
electoral, en la cual se soslayan o minimizan valores como la diversidad, la pluralidad y la equidad, para encarar el reto de reconceptualizar la ciudadanía, asumirla y entenderla:

( ya no solo) remitida a derechos y deberes instituidos en normas constitucionales (...). La ciudadanía no nombra al conjunto de individuos poseedores de derechos y obligaciones, actores preconstituidos por las normativas existentes, sino una praxis: la capacidad de ser sujeto en todos los ámbitos en que se construye el poder y, por consiguiente, la participación pública en la elaboración de las reglas que, con validez de norma instituida o legitimada, tienen capacidad de ordenar la vida en sociedad. (P.18)

Con líneas de trabajo similares, el investigador australiano John Keane, citado por Lenin Martell (P.3), concluye que particularmente la radio se puede considerar esfera pública, "en las nuevas condiciones de globalización y desterritorialización de la cultura y la información". Pero, advierte, para ello es necesario concebirla en los múltiples cruces de los discursos del poder central con los de la vida privada, caracterizados por la diversidad y la heterogeneidad.

Es una búsqueda que no cesa y que Mata (Ib.) ubica en el "trazado del mapa de la ciudadanía": "Un nuevo territorio sonoro, gráfico, visual, escénico". Como podemos apreciar, aquí también hay grandes coincidencias con el humanismo cívico, en especial en su proyecto de "nueva ciudadanía" o "ciudadanía emergente", cuyo principal escenario de acción es la cultura, inscrito en el "mundo de la vida". (Ib., p.20)

Y desde esos postulados del humanismo cívico, la investigadora mexicana Paloma Mejía Lechuga indaga acerca de la estrategia para fomentar una cultura ambiental que se ponga al servicio de la construcción de ciudadanía,"orientada a la gestión del agua en el medio urbano, así como los componentes que la estructuran, usando la producción radiofónica como herramienta de comunicación ambiental". Con su trabajo "construcción de ecociudadanía a través de la radio, con enfoque en la gestión del agua en Xalapa ,Veracruz” (2015) la autora busca tener en cuenta aspectos inmersos en la Comunicación/Educación, que tienen como eje la producción radiofónica. Más que apostarle a la difusión de contenidos, Mejía destaca la importancia de usar los programas de radio en el marco de una estrategia que fomente y construya la gestión ciudadana, es decir, privilegia la activa participación de las comunidades, las cuales dejan de ser solo fuentes de información para actuar como corealizadoras de los programas. 
El diseño metodológico hecho por esta investigadora se apoya en la Investigación Acción Participativa (IAP) con el propósito de garantizar el protagonismo de las campesinas y campesinos durante todo el proceso de indagación y de análisis. La propia autora destaca "la flexibilidad y la agilidad de las técnicas" (P.37) como una de las ventajas más grandes de esa perspectiva. En esa dirección, afirma que "cuando la gente involucrada va sintiéndose parte del proceso de investigación, se tiende a romper la dicotomía entre el sujeto y el objeto". (Ib.)

Para esta investigación, es de suma importancia la radio, entendida como práctica significante.

El problema de investigación parte de estudios preliminares con los cuales se ha demostrado que la mera difusión de contenidos educativos no es suficiente para lograr transformaciones de fondo que impacten las realidades sociales y promuevan cambios efectivos. Como antecedente de estas indagaciones cobra especial importancia el debate que se plantea entre la "histórica dicotomía" campo-ciudad y/o urbano rural, "en lo cual lo rural lleva la peor parte", pues, como lo recuerda:

Se ha empleado el término rústico, con la misma etimología que rural, para referirse a lo opuesto de lo civilizado, de lo refinado. Se pone por un lado la importancia de la conservación de los recursos naturales, bosques, cuencas, etc., así como la producción de alimentos y servicios ambientales (en lo rural) y por el otro, el consumo, el derroche, la acumulación y el disfrute de los beneficios de la ciudad. (P.5)

Al retomar algunos de los postulados del humanismo cívico, plantea la necesidad de oponerse al modelo tradicional de información emisor-receptor, del cual surgen contenidos alejados de la realidad y de las necesidades de la población rural, para privilegiar el ejercicio de la ecociudadanía que, en palabras de Sauvé (2013), parte de reconocer,

los lazos estrechos que existen entre la sociedad y la naturaleza, una ciudadanía informada de las realidades socio-ecológicas, crítica, competente, creativa y comprometida, capaz, deseosa de participar en los debates públicos, en la búsqueda de soluciones y en la innovación ecosocial. (P.5)

En esa misma línea de acción, la comunicóloga Claudia Villamayor centró su investigación denominada "Las radios comunitarias, gestoras de procesos comunicacionales" (2014) en el conurbano bonaerense. Allí buscó "objetivar y analizar nociones, usos, estrategias y prácticas sociocuturales de radios comunitarias y alternativas", así como 
problematizar y sistematizar esas experiencias, "para construir nociones teóricas y metodologías de intervención”, a fin de promover políticas sociales hacia ese sector. Destaca la autora que los estudios sobre comunicación popular en América Latina abrieron una "grieta" para la creación de conocimiento, en la medida en que las teorizaciones no se han producido en abstracto sino como producto de prácticas específicas. En ese contexto, afirma que hablar de comunicación

implica modos de ser y de interactuar, modos de narrar y de narrarse, donde no solo cuenta lo que cada cual quiere decir, sino todo lo que se juega en esa interacción: las identidades, la interculturalidad, las historias, los cuerpos, las visiones del mundo, la proyección que se hace en torno a la sociedad y el Estado...(2014, p. 93)

Para la investigadora, comprender la comunicación no solo hace referencia a la producción de sentido, entendida como "trama de significación y construcción de subjetividades" sino a claros posicionamientos políticos y "modos de marcar la existencia, la estética y la circulación del poder”. (Ib.)

$\mathrm{Y}$ en su mirada sobre el movimiento radiofónico comunitario en América Latina se detiene en la experiencia de Radio Sutatenza, al destacarla por su "fuerte componente transformador":

Como se ve, la radio para la alfabetización ubica la paridad comunicación y educación en la raíz de un tipo de radio y un tipo estratégico de transformación nacido de la necesidad de un sector social excluido de las políticas nacionales del Estado colombiano. (Ib. p. 91)

Por ello, apunta Villamayor, hablar de radio comunitaria es aludir a "una perspectiva político-comunicativa y cultural de hacer radio, que se define como política y con objetivos políticos humanistas y laicos". (P. 92)

Así mismo, hace énfasis en las Radios Mineras de Bolivia, las cuales, también desde un enfoque educativo, le apostaron a propiciar la narración de su propio contexto, con sus respectivas realidades por parte de los propios mineros, quienes fueron capacitados en lenguaje y producción radiofónica, para que diseñaran y realizaran sus propios programas de radio. Ello les permitió "convocar a la movilización social para impedir la privatización y defender la nacionalización de un recurso público". (P. 91)

Y al hacer una revisión al estado del arte sobre comunicación popular en América Latina concluye que hay pocos trabajos "que apunten a objetivar nociones, metodologías 
estratégicas, problematizaciones teórico/metodológicas y propuestas nuevas y renovadoras del campo". (P. 99) Allí, justamente, se busca aportar con esta investigación.

\subsubsection{Lecciones de Radio Sutatenza}

Ya en el terreno específico de las investigaciones sobre Radio Sutatenza hay que señalar que desde su comienzo, en la década de los 60, han generado gran controversia. Una de las primeras fue publicada en 1961. De la autoría de Camilo Torres Restrepo y Berta Corredor, el estudio denominado "Las Escuelas Radiofónicas de Sutatenza-Colombia", de tipo sociográfico y descriptivo, concluyó que, si bien ACPO había producido cambios apreciables en la vida campesina, en especial frente a "su proceso técnico y cultural", era necesario reenfocar su campaña en favor de la reforma agraria, porque podría generar falsas expectativas. Según advirtieron los investigadores, "sin un plan y un equipo de expertos para orientar a los campesinos (...) podría surgir un descontento contra ACPO y el gobierno que podría, incluso, conducir a un estado revolucionario violento". (Villanueva: 1995, p. 99) Torres y Corredor plantearon que, en una etapa posterior, Radio Sutatenza debería dedicar sus esfuerzos a la "reforma absoluta" de las estructuras del campo. Estas propuestas dieron origen a un intercambio epistolar entre Camilo y directivos de Radio Sutatenza, el cual adquirió ribetes agrios, cuando Torres aseguró que el periódico El Campesino había emprendido "campañas anticomunistas". Por su parte el director general de ACPO, José Joaquín Salcedo, le contestó en una carta que todo obedecía a "consecuencias del entorno de Camilo, compuesto en su mayoría por 'enemigos del clero y de las obras de la iglesia', al tiempo que le anunció una acusación formal en su contra ante las autoridades eclesiásticas competentes. (González, 2012, p. 264)

Unos años después fue publicada la investigación "Los Medios de Comunicación Social al servicio del Desarrollo Rural. Análisis de eficiencia de "Acción Cultural PopularRadio Sutatenza (Colombia). (1971). A diferencia del primero, de corte sociográfico, el Informe Musto se apoyó en la aplicación de encuestas a la población beneficiaria, en seis regiones de Colombia; la realización de discusiones y entrevistas "con un número considerable de informantes", (p. 63) tanto colaboradores y empleados de ACPO como agentes externos vinculados de manera directa o indirecta a la vida de la organización, y en el análisis e interpretación de material documental. Fue liderado por el profesor Stefan A. Musto, y financiado por el Instituto Alemán de Desarrollo, por encargo del Ministerio de Cooperación Económica de la República Federal Alemana. Entonces Radio Sutatenza y su 
Acción Cultural Popular contaban ya con 20 años de existencia y se encontraban en uno de sus mejores momentos, a juzgar por sus propios resultados: Radio Sutatenza era la radioemisora más grande de Colombia; tenía por lo menos 550 mil alumnos radiofónicos; el periódico El Campesino era el segundo en circulación nacional, después de El Tiempo, con un tiraje semanal de 57 mil ejemplares y se consideraba "el más importante y conocido en las regiones rurales colombianas" ; contaba con un verdadero ejército de líderes, formados en sus propios institutos de Sutatenza, Boyacá y Caldas, Antioquia. A fines de 1968 se habían preparado para tal fin 5.631 estudiantes; sus Escuelas Radiofónicas -considerada la estrategia bandera- habían beneficiado, en el período comprendido entre 1963 y 1967, a más de 200 mil colombianos. (Pp.84-102)

Así las cosas, el llamado "Informe Musto" reconoció la enorme importancia de ACPO y su gran impacto en la población rural, al señalar que la tarea cumplida por la institución "en los últimos 20 años, fue todo menos insignificante" y contribuyó de manera importante al mejoramiento de las condiciones de vida de las campesinas y campesinos colombianos. (P. 201) No obstante, formuló varios reparos a la manera como venía funcionando $\mathrm{ACPO}$, entre los que figuran los siguientes: 1o. Cuestionó el papel y los objetivos de la institución, teniendo en cuenta que el país ya había cambiado mucho, pues en el momento en que se hizo la investigación ya contaba con más entidades públicas que se dedicaban a atender al campo,y con otros medios de comunicación al alcance de la población campesina. Se preguntó si, en esas condiciones, “¿corresponde ACPO a las necesidades efectivas de la actualidad?” (P.198). 20. Advirtió una desviación de los objetivos de ACPO, ya que en buena medida debido a su gran crecimiento, "produjo una estrategia organizacional que fue determinada en una medida considerable por estrategias tácticas"; es decir, aunque "no interrumpió nunca sus contactos inmediatos con el campesinado (...) esos contactos se desarrollaron muchas veces a la sombra de preocupaciones de tipo político y financiero" (P. 200) y 3o. Criticó la estructura de la organización "centralizada en sentido horizontal y vertical" y, en especial, la concentración en la toma de decisiones por parte de su director general, José Joaquín Salcedo, que se tradujo en "una cierta rigidez institucional (...) la cual influyó negativamente en la estrategia de adaptarse a los cambios fundamentales que tuvieron lugar en las áreas rurales colombianas". (Pp. 70-71)

En su momento, como ocurrió con el de Torres y Corredor, el informe Musto fue materia de discrepancias con las altas instancias de ACPO, a tal punto que en la publicación del mismo en 1971, las directivas de la institución incluyeron glosas como estas: 
Es evidente el interés de los investigadores en insistir sobre el absolutismo de Salcedo. Siempre aducen testimonios anónimos (...) La labor de Salcedo, sea "paternalista" o no, haya sido o no garantía de la continuidad y del crecimiento de la Institución y se interprete positiva o negativamente, solo podrá ser efectivamente juzgada cuando haya posibilidad de perspectiva histórica. (P. 72)

Como lo sugería el director general de ACPO, muchos otros trabajos se han ocupado de analizar con perspectiva histórica los hechos, realizaciones, aciertos y desaciertos de las Escuelas Radiofónicas. Uno de ellos es el del investigador y radialista argentino Carlos Malbrán (2010, p. 197 ) quien plantea herramientas de trabajo desde lo que él llama "la otra radio", aquellas emisoras que han nacido de las necesidades y de la acción de las propias comunidades, interesadas en proponer verdaderos modelos de comunicación, en contravía de propuestas eminentemente comerciales.

El trabajo de Malbrán resulta de particular importancia para nuestra investigación, ya que la metodología empleada la podemos inscribir en lo que Boaventura de Sousa Santos denomina “ecología de saberes", en clave de sus Epistemologías del Sur. Malbrán desarrolló su trabajo con docentes rurales, a lo largo de muchos años y varios encuentros lo que, según cuenta, le permitió pasar de capacitador a relator, "para narrar a unos las experiencias que a otros les habían dado resultado”. (Ib. P. 15) Destaca, así mismo, como ocurre en la auténtica realización radiofónica, la integración de muchas disciplinas, entre ellas "la literatura, la electrónica, el periodismo, la actuación, la oratoria, etcétera (...) “ en función de lo que conocemos como "la magia de la radio"

El autor subraya (p.197) que es allí, en las entrañas de los mismos pueblos de América, donde han surgido propuestas que han cumplido indispensables tareas de servicio público, pues "las emisoras emanadas desde el consenso popular, todas se han convertido en formidables herramientas de progreso y desarrollo y han llevado a cabo siempre diversas tareas relacionadas con la educación y la cultura de las comunidades".

Uno de los ejemplos que trae a colación es justamente el de Radio Sutatenza, cuya estrategia de combinación de medios, califica como "el programa de radial de educación de adultos más grande que ha conocido el mundo”. (P.207) Atribuye en buena medida el éxito de su estrategia a la total claridad que tuvieron sus directivos frente a que la primera función de la radio es entretener, lo que se reflejó en una programación amena y variada que se enfocó a hablarles a esas mujeres y hombres del campo muy azotados por la violencia y ávidos de transformar sus vidas a partir del conocimiento. Ahí estuvo el gran acierto, destaca 
Malbrán: en la activación de los diálogos comunitarios, “en los que se discutía la mejor forma de mejorar las condiciones de vida...” (P. 203). De ahí surgieron las propuestas para afrontar grandes problemas de Sutatenza, Boyacá, como el alcoholismo, la violencia intrafamiliar y el abandono del Estado en temas fundamentales como la prevención en salud y la educación y el tedio ocasionado por la prácticamente nula oferta cultural.

Concuerda, así, con otros autores, entre ellos Sandra Liliana Osses Rivera quien califica las tareas de Radio Sutatenza como "una experiencia paradigmática", en especial por no haber tratado a las campesinas y campesinos como agentes pasivos,

porque supera de cierta manera la concepción del oyente que imperaba en esa época, como receptor anónimo y pasivo del medio de comunicación, al llegar con un lenguaje sencillo y cercano a sectores de población como los campesinos que se encontraban hasta ese momento marginados del acceso a los medios de comunicación y los procesos de modernización en marcha, sin que esto haya significado una ruptura o reconversión del modelo comunicativo predominante. Sin embargo, Radio Sutatenza recibe reconocimiento como el primer intento de acercar un medio de comunicación a los oyentes, como la experiencia pionera de una comunicación que siendo masiva tuviera en cuenta las demandas de sectores siempre excluidos de los medios. (2015, p. 268)

Como lo dice la autora, no hubo una ruptura propiamente dicha con el modelo tradicional, pero sí una aproximación a uno inclusivo que, para la época, fue revolucionario, al empezar a contar con el otro como agente activo.

Por lo demás, es conveniente tener en cuenta que, ayer como hoy, la formación de lo que se denomina opinión pública "no se rige únicamente, ni de manera homogénea, por los estímulos provenientes de los medios masivos de información. "Tal visión carece de base empírica y no encuentra respaldo, tampoco, en las teorías contemporáneas de la comunicación”. ( Brunner, 1994, P.6)

Por su parte el investigador Alfonso Gumucio (2001) destaca que Radio Sutatenza, fue pionera en promover los ideales de lo que por entonces se llamó la "educación integral fundamental", un concepto que subraya la necesidad de ayudar a la gente a asumir la responsabilidad sobre su desarrollo, reconocer su potencial para progresar e identificar el valor de sus propios recursos. (P. 45)

Así mismo, Gumucio observa que "su enfoque integrado de los medios de comunicación y la educación fue tan exitoso que inspiró ampliamente otras experiencias similares en Asia, África y América Latina”. (P.44) 
También advierte que acabó siendo víctima del éxito que se evidenció en su primera etapa, en la que pudo demostrar las grandes bondades de una educación crítica, como medio “ para que los campesinos y pobladores rurales participen en condiciones de igualdad en el desarrollo...” En efecto, la propuesta original empezó a perder su sentido inicial, al pasar de un modelo basado en lo local a uno centralizado en Bogotá que, poco a poco, debilitó aunque no acabó- la participación directa de las campesinas y campesinos, su población objetivo. (P. 45)

Es claro que el modelo de las Escuelas Radiofónicas se caracterizó por su alta dosis de participación, pues para ACPO la formación de líderes tenía sentido en cuanto pudieran replicar su experiencia entre sus propias bases. Todo esto fue posible gracias a la educación y formación por radio a través de la escuela radiofónica, que contaba con un auxiliar inmediato, cuya tarea central era animar al grupo para su aprendizaje.

¿Por qué fue y es la radio el eje del proyecto de ACPO? Gumucio no duda en calificar este medio como el "más importante para el desarrollo y los cambios sociales", responsable en buena medida, de que América Latina haya ido a la delantera en experiencias de comunicación participativa. (P.5)

Así las cosas, la radio es considerada como la herramienta comunicacional más extendida en el mundo y el medio ideal para provocar cambios sociales, los cuales, en el caso de las Escuelas Radiofónicas, se basaron en la inclusión socioeducativa de las mujeres del campo. Tal y como lo documentó el investigador Luis Abrahán Sarmiento Moreno (2008) al hacer un recorrido por diferentes etapas de Radio Sutatenza y ACPO -entre 1947 y la década de los 70- cuando surge Radio Sutatenza "pensar en la educación de la mujer era una verdadera utopía”. Destaca, así mismo, la visión que tuvo ACPO de propiciar la inclusión de la mujer rural en el mundo educativo, al crear en 1956 el Instituto Femenino, para la formación de dirigentes y líderes campesinas, cuya motivación fue expresada por la propia organización en los siguientes términos: "la mujer campesina desempeña papel extraordinario en la vida cultural". Así mismo, hace énfasis en el carácter "revolucionario" de esa propuesta, al apuntar que

Aún no se ha reconocido suficientemente la tarea de promoción de la mujer que hizo ACPO, máxime cuando su acción se especializó en el sector campesino, que es el sector de mayor arraigo a las tradiciones y con mayores visos de machismo. El pensar en el liderazgo de las campesinas era una auténtica revolución... (p. 25) 
Como lo expresara el propio gestor de ACPO, José Joaquín Salcedo (1980) se trataba de cambios que le apostaban a "la liberación femenina, a la inauguración de nuevos comportamientos sociales, a la lucha contra el machismo, al surgimiento de un vigoroso liderazgo femenino en el sector rural”. (P. 16)

En la vida práctica, ello significó cambios de fondo en la manera de vivir, como se advierte en el siguiente relato sobre la campesina Teresa, publicado por el sociólogo y exdirector general de la organización, Hernando Bernal Alarcón:

Al llegar a su vereda, cuando iba camino de su casa, pensó que el mundo donde había vivido seguía igual, pero que ella había cambiado internamente. Algo raro había pasado. Su casa, a la que antes estaba acostumbrada, le pareció sucia, oscura y pequeña. Muchas veces, al recordarla en el Instituto, la había pensado así. Pero al llegar y verla en la realidad, le parecía menos agradable de lo que se había imaginado. Sin embargo, la consoló el cariño y la alegría con que la recibieron los suyos. Los meses siguientes fueron duros, porque sus padres y hermanos no comprendían por qué quería vivir limpia, por qué se preocupaba por cocinar mejor, por qué no soportaba que el cerdito anduviera suelto; y por qué quería que las gallinas tuvieran su propio gallinero. Además, todos reunidos escuchaban las clases radiales por la noche, y ella se preocupaba por enseñarles, no solo a sus hermanitos pequeños, sino también a su padre y a su madre, que nunca habían asistido a la escuela. ( 1975, p.145)

Ahí en efecto, como se podrá advertir, se estaba gestando una revolución de gran calado en Colombia, cuya protagonista fue la mujer, la misma que, hasta entonces, había estado aislada y marginada del sistema educativo por considerarse que su papel exclusivo estaba en los quehaceres domésticos. Fue una propuesta no exenta de grandes controversias que se profundizó con la puesta en marcha de una intensa campaña de procreación responsable, considerada la más importante de todas cuantas adelantó ACPO, gracias a su impacto social, al poner su énfasis en "un cambio mental y cultural de consecuencias irreversibles”. (Bernal, 1994, p.7). Hoy podemos decir que fue una iniciativa arriesgada, debido al contexto sociocultural del país, marcadamente conservador, pero, de manera alguna ingenua, pues como el propio Salcedo Guarín $(1974$, p.6) lo diría sin ambages, "no debería volver a nacer un solo niño que no sea consecuencia de la total responsabilidad de sus padres".

Si nos adentramos en lo que significó esta iniciativa, desde el punto de vista del ejercicio de la "ciudadanía rural", notaremos que la organización centró su atención en la educación de la mujer, como la mejor forma de impactar a la sociedad rural en su conjunto. 
Así lo destaca Sarmiento (p. 27): "La tarea de la ACPO implicaba entender que educar a un hombre es formar a un ciudadano, pero permitir que una mujer se educara integralmente era construir la célula de la sociedad, era educar la familia".

Este principio estuvo en total coherencia con la idea de una participación activa en el presente y en el futuro de la sociedad, al asumir a las campesinas y campesinos como "sujetos responsables de sus actos". Los directivos de ACPO sabían, muy bien, que ello implicaba en ese momento ir en contravía de lo que se consideraba políticamente correcto en el campo e, incluso, contradecir arraigados principios religiosos, según los cuales, " el saber y hablar sobre las cosas del sexo era pecado". Por eso, el pilar de la campaña estaba en la siguiente sentencia: "El pecado era no saber o ignorar sobre los asuntos del sexo y sus enormes consecuencias en la vida personal y, muy especialmente, en el desempeño social". (Ib., p. 8)

Esta fue una de las causas de una aguda polémica entre las directivas de ACPO y la jerarquía eclesiástica, que llevarían a la organización a suspender actividades entre 1989 y 1994. Pero queda claro que ese enfoque no obedeció al capricho o a una emotividad momentánea, sino a toda una concepción de la Educación Fundamental Integral, cuyo propósito era "la guerra contra la ignorancia", en la cual las mujeres, como se indicó, jugaron un papel clave. De hecho, según lo afirma Sarmiento, "muchas de las campañas de ACPO fueron pensadas y realizadas para mejorar las condiciones de la mujer campesina". (p.22) Y menciona como ejemplo las siguientes: "Las señoritas de la vereda organizan sus empresas"; "La industria familiar"; y "el jardín de la entrada de la casa y el jardín de la arboleda". Así mismo subraya que "en la programación de Radio Sutatenza (1969) se privilegió la educación de la mujer y encontramos, entre otros temas femeninos: La mujer orientadora de la vida en el hogar; sencillos conocimientos de puericultura; y fundamento primario de la sociedad”. (Ib.)

Podemos concluir entonces: no se puede concebir ni la acción cultural popular ni su EFI sin tener en cuenta el papel de la mujer...

Se confirma, así mismo, que Radio Sutatenza logró impactar y trascender las fronteras colombianas, no solo gracias a su potencia tecnológica sino, especialmente, debido a su potencia educativa, como ocurrió en los Andes colombo-venezolanos. Esta es una de las conclusiones de la investigación realizada por el historiador Luis Rubén Pérez Pinzón tras destacar que hasta la aparición del modelo de ACPO en 1947, 
Los obreros, jornaleros y campesinos, además de permanecer alejados de las instituciones educativas, ya que tenían que trabajar y subsistir, fueron gradualmente aislados de las redes de consumidores mediáticos, puesto que no se realizaban programas acordes con las peculiaridades y “malos gustos" de su “cultura popular"... (2015, p. 8)

Según el investigador, ese fue el punto de partida para la transformación que logró ACPO en su primera etapa, como lo destaca la UNESCO al calificar de "apreciables los resultados obtenidos por las Escuelas Radiofónicas “ (...) como consecuencia de la labor realizada para elevar el nivel de vida del campesino”. (P. 10) Así mismo, hace énfasis en la unión de esfuerzos de la Iglesia católica y de los sectores público y privado como razón de su crecimiento sostenido y su gran impacto. Por ejemplo, el Estado decidió que las radioestaciones que integraban la Cadena Sutatenza "contaran con licencia oficial para usar gratuitamente el espectro radioeléctrico nacional y plena autorización para emitir programas educativos y culturales financiados por el Estado".(P. 11)

Por lo demás, dice el autor, la propuesta de ACPO, específicamente su método de "Escuela Comunitaria" fue aplicada en Venezuela por Radio Occidente, gracias al trabajo de tutores-orientadores formados en los Institutos Campesinos de Sutatenza. Y puntualiza que ese fue el caso de la tutora Hilaria Gutiérrez Botello, quien

(...) al igual que su hermano, decidió partir de su natal Gramalote (Norte de Santander) hacia Sutatenza, para formarse como dirigente campesina (1963). Al regresar, fue representante parroquial de las escuelas existentes en las veredas cercanas, así como coordinadora y supervisora de las escuelas existentes en las parroquias ubicadas a lo largo de la frontera colombo-venezolana, ... (P.12)

Para Pérez Pinzón, se trató de "la primera estrategia de educación virtual o a distancia en los Andes colombo-venezolanos". (P.15)

Además de brindar información de gran importancia para el presente trabajo, esta investigación de carácter descriptivo confirma el potencial estratégico de propuestas como la de las Escuelas Digitales Campesinas que hoy buscan ampliar su radio de acción hacia las comunidades afrodescendientes e indígenas.

Hoy (2017), a 70 años de su fundación, los alcances del modelo ACPO-Radio Sutatenza aún son materia de controversia. Así lo demuestra el que varios investigadores hayan decidido analizarlos desde la matriz "colonialidad del poder", propuesta por autores como Walter Mignolo. Uno de estos trabajos denominado "La historia en reserva de Radio Sutatenza" (Mora, 2014) sostiene, por ejemplo, que las campesinas y campesinos de las 
Escuelas Radiofónicas no fueron tratados como sujetos. $\mathrm{Y}$ al referirse a una de las investigaciones de Bernal Alarcón dice que:

(...)concibe la idea del sujeto campesino como un sujeto vacío, carente de humanidad, casi como una mata, un humano que solo se desarrolla desde lo biológico. Ve en el analfabetismo el elemento que ocasiona los problemas de América Latina, por eso ve a ACPO como la forma de entrar al mundo desarrollado que solucionará el problema, para que las personas tengan una capacidad de integrarse a las nuevas formas de producción en este nuevo mundo del desarrollo. Bernal desaparece la historicidad de los sujetos, sus relaciones económicas anteriores, sus posibles desarrollos en la política, la literatura, la música, por ello Bernal se conecta directamente con el discurso de desarrollo. (Mora, 2014, p. 14)

Como puede apreciarse, el que aún subsistan polémicas como esta, confirma, como se consignó en el Informe Musto (1971, p.201), que "la tarea cumplida por ACPO (...) fue todo menos insignificante". Así mismo, reafirma la importancia de contar tanto la historia pasada como presente, de la mano y con las voces de los mismos sujetos que la viven: las campesinas y campesinos e integrantes de comunidades indígenas y afrodescendientes, estudiantes de las Escuelas Digitales, uno de los propósitos de esta investigación. Que sean ellos mismos y sus hechos quienes digan si fueron tratados como objetos o como sujetos. Podemos anticipar, como se plantea desde la perspectiva culturalista, que los receptores no son pasivos y que aquello que dicen o quieren imponer los mensajes o los discursos no es, necesariamente, lo mismo que leen o interpretan las audiencias. Desconocerlo sería aceptar que la comunicación obedece a un proceso lineal, no horizontal y que, como lo advirtiera Martín-Barbero,

Entre emisores-dominantes y receptores-dominados ( no había) ninguna seducción ni resistencia, solo la pasividad del consumo y la alienación descifrada en la inmanencia de un mensaje-texto por el que no pasaban los conflictos, ni la contradicciones y mucho menos las luchas. (1987, p. 238)

Con una mirada más amplia, siguiendo a Guillermo Mastrini (2011) esta lucha se inscribe en la defensa de los medios públicos, concebidos como aquellos cuya propiedad, no necesariamente estatal $-\mathrm{o}$ que a pesar de estar adscritos al Estado no trabajan de manera exclusiva al servicio de los gobiernos- se deben caracterizar por promover valores democráticos, entre éstos la inclusión y la deliberación pública, asociados al pluralismo y a la diversidad existentes en nuestras sociedades. Con ese mismo norte, tienen la tarea 
"fundamental de proveer a las sociedades modernas de una herramienta comunicacional que garantice el derecho a la comunicación de los pueblos”. (P. 8)

\subsection{I.A.P y Radio Sutatenza}

Entre los trabajos revisados - relacionados específicamente con la historia de Radio Sutatenza y su impacto en América Latina- tres asumen su base metodológica desde la Investigación Acción Participativa (I.A.P.) con el claro propósito de contar la historia con sus propios protagonistas, en este caso, las campesinas y campesinos beneficiarios de las Escuelas Radiofónicas. Son sentidos que se enmarcan en postulados como los de "democracia radical", en los que se valida el antagonismo o el conflicto como dinamizador social, que "lejos de poner en peligro la democracia (...) es de hecho su propia condición de existencia". (Mouffe, 2012 p. 116). No obstante, como lo señala el investigador español Tomás Villasante, en la ejecución de proyectos de investigación de tal naturaleza se corre el riesgo de caer en "la mitificación por lo popular". En efecto, Villasante subraya las bondades de la IAP, corriente de investigación en la cual ha participado de manera activa, en especial por su capacidad de activar un auténtico y horizontal diálogo social. Pero advierte:

Para superar las verdades parciales de cada sujeto, tanto de los populares como de los expertos y de los que ponen los recursos, tenemos que entrar en procesos auto-críticos y críticos, en donde las verdades colectivas que se vayan construyendo al menos sean creativas y operativas para el conjunto de los implicados, o los que se quieran implicar. (2006, p. 5)

Una de las propuestas encaminadas a lograr una mejor comprensión de la realidad desde la IAP con sentido autocrítico está en lo que el sociólogo portugués Boaventura de Sousa Santos llama "ecología de saberes" (2013) que, como se indicó arriba, es una perspectiva inscrita en las "Epistemologías del sur" asociada a la pedagogía de la liberación que planteara Paulo Freire a comienzos de los 70, la cual se ha concretado en América Latina en muchas experiencias de la llamada "Comunicación para el cambio social" y en la investigación implicativa liderada por Orlando Fals Borda. De Sousa Santos plantea la necesidad de poner en práctica lo que denomina "resistencia epistemológica", como condición para hacer efectiva la "resistencia política".

Al profundizar estas miradas, en la línea de la pedagogía liberadora de Paulo Freire, sostiene que esa es la manera de defender "la integración inclusiva" que significa la opción de los grupos tradicionalmente marginados o ignorados de representar el mundo como suyo, 
para poder afrontar y cambiar el estado de cosas. (2016, p. 2) Desde esa misma lógica, se entiende que uno sea el resultado del acto de conocer nuestra propia realidad, si los hechos se cuentan después y otro si se cuentan durante los procesos, por parte de los sujetos involucrados de manera directa en ellos.

En concordancia con lo que tantas veces dijera Fals Borda, se trata de validar una investigación que le dé la verdadera dimensión al conocimiento popular, sin negar otro tipo de saberes, algunos de ellos provenientes del contexto académico:

(...)el objetivo es generar un conocimiento liberador que parta del propio conocimiento popular y que explica su realidad globalmente (enfoque sistémico), con el fin de iniciar o consolidar una estrategia de cambio (procesos de transición), paralelamente a un crecimiento del poder político, destinados ambos a alcanzar transformaciones positivas para la comunidad a nivel local, y a niveles superiores, en cuanto que es capaz de conectarse con experiencias similares (redes). (Fals Borda: 1991. Pp. 7-19)

Ya desde una dimensión cultural, como lo plantearan Jesús Martín-Barbero; María Cristina Mata y Rosa María Alfaro, entre otros autores, no solo es posible sino necesario investigar "desde la articulación entre prácticas de comunicación y movimientos sociales"(Martín-Barbero, 1987, p.11).

\subsubsection{Hacia las nuevas ciudadanías}

Como se ha planteado, en el desarrollo de esta tesis interesa ver cómo las nuevas ciudadanías pueden impactar de manera positiva el trabajo desarrollado en las Escuelas Digitales Campesinas de ACPO. De ahí que nos detengamos a continuación en la evolución del concepto de ciudadanía, desde la polis griega hasta las concepciones modernas identificadas con las corrientes de la democracia radical y el humanismo cívico.

Esa evolución -que no se ha dado de manera lineal- se inicia, como decíamos, en la polis griega cuando, en el marco de la naciente democracia, fue identificado con el ejercicio de derechos y deberes en función de la toma de decisiones. Había entonces una condición básica: solo podían ser considerados como ciudadanos los hombres libres, es decir, quedaban por fuera de esa condición los esclavos, las mujeres y los extranjeros. La toma de decisiones se apoyaba en la deliberación entre iguales, a partir de la la clásica definición de Aristóteles del hombre como ser racional. En ese orden de ideas, los principios que guiaban el ejercicio ciudadano eran la igualdad, la libertad y la participación. 
Como lo plantea el mismo Aristóteles en "La Política", toda actividad humana debe estar enfocada hacia el bien. Destaca el "vivir en compañía", en el marco de la ley y de la justicia que, dice, “es una cosa política y civil; porque no es otra cosa sino regla y orden de la compañía civil, y este juicio es la determinación de lo que es justo”. (S.f).

Al analizar estos postulados aristotélicos, el filósofo español Alejandro Llano destaca que este era el fin de la polis:

La asociación con otros y la participación en la dirección valorativamente orientada de esa comunidad forman al mismo tiempo un medio para un fin y un fin (o bien) en sí mismo . Y la participación en la comunidad cuyo fin es el bien de todas las asociaciones particulares, y el logro de todos sus particulares bienes, es en sí misma un bien de una índole muy alta, precisamente porque es universal, ya que todo buen ciudadano debe saber y ser capaz de obedecer y mandar. (1999, p. 448)

En la Edad Media (siglos V a XV) se debilitaron los valores ciudadanos por cuenta del oscurantismo y del sistema feudal, los cuales vuelven a plantearse en el Renacimiento (S. XV y XVI) período en el que se sientan las bases de la ciudadanía moderna, desde el republicanismo cívico. Entonces se desarrollaron de manera puntual en el norte de Italia con la figura de las ciudades estado, que les permitían a los ciudadanos participar de manera activa en las decisiones del gobierno, pero aún era un ejercicio restringido a las élites, ya que estaban excluidos los obreros, las mujeres, los campesinos y los pequeños comerciantes.

Ya en la modernidad Rousseau pone el énfasis en la ciudadanía asociada a la formación educativa, que, según él, debía encaminarse a crear unas bases morales cuyo fin es la personalidad autónoma. En el denominado contrato social, los hombres deberían actuar como seres libres y autónomos, comprometidos con el bien común. La relación entre el ciudadano y el Estado se debía fundamentar en el estricto respeto de las leyes y en la convivencia, concebida como "la participación comprometida en el espacio público". (Reyes, 2009. pp. 77-94)

Por su parte Kant postulará el triunfo de la razón y del entendimiento humanos, como condición para superar la minoría de edad de hombres y mujeres que, a su vez, considera "la divisa de la Ilustración”. Es lo que denomina el rescate del entendimiento humano, como acicate de la razón y fundamento de la libertad. Kant Habla de la libertad "como supuesto necesario de las acciones". (Pérez, 2009) Es también una invitación a actuar como seres racionales, a romper tradiciones y lugares comunes. Pero el propio Kant advertía que ésa no es una tarea nada fácil: 
Tengo a mi disposición un libro que me presta su inteligencia, un cura de almas que me ofrece su conciencia, un médico que me prescribe las dietas, etc., etc., así que no necesito molestarme. Si puedo pagar no me hace falta pensar: ya habrá otros que tomen a su cargo, en mi nombre, tan fastidiosa tarea. (1981, pp. 25-27)

Advertirá que, en consecuencia, "solo son pocos, los que por esfuerzo del propio espíritu, logran salir de la minoría de edad, sin embargo, con seguro paso". (Ib.).

En este contexto, el filósofo alemán asocia los derechos de la ciudadanía con el respeto de los derechos humanos que, "no se contradicen, sino que se implican mutuamente". (Carrillo, 2010)

Como lo señala la investigadora Lucy Carrillo, Kant se ocupa de la idea de un derecho cosmopolita, "adelantándose al planteamiento de Arendt, en su solución a las dificultades que plantea el derecho a tener derechos". (Ib.)

Son postulados que se concretan, en buena medida, en las revoluciones americana, de 1776 y francesa, de 1789. La investigadora María Patricia Reyes destaca que "estos dos momentos van a significar un 'antes' y un 'después' en su historia, ya que establecen la igualdad entre los hombres, al consagrar el Estado de derecho, considerado por Bobbio (1992) como el Estado de los ciudadanos". (2011, p. 171). De ahí en adelante se puede hablar de la pugna por el ejercicio de una ciudadanía más integral, pues se incluyen los componentes civil, político y social, con desarrollos en los siglos XVIII, XIX y XX. Ya entonces "los derechos se conciben como de primera, segunda y tercera generación, respectivamente $(\mathrm{Ib}$.$) . Mientras los derechos civiles suponen la igualdad de todos ante la ley$ y se expresan en libertades como las de pensamiento y expresión, a la propiedad y a la religión, los políticos hacen referencia a la libertad de participar, elegir y ser elegido, y los sociales enmarcan el acceso a servicios como los de salud, educación y vivienda digna, entre otros.

Se trata de una lucha permanente que apunta en últimas a definir formas y acciones del "estar juntos y los unos con los otros", como lo expone Hannah Arendt, para quien "la política se basa en el hecho de la pluralidad de los hombres" (1997, p. 45). La propia Arendt observa que, en ese orden de ideas, el nivel político se define por la actitud de estar abierto y atento al mundo. $\mathrm{Y}$ en plena coincidencia con los planteamientos modernos del humanismo cívico (una de las perspectivas de análisis de esta tesis a la que haremos referencia de manera insistente más adelante) señala: "Donde quiera que los hombres coincidan se abre 
paso entre ellos un mundo y es en este 'espacio entre' donde tienen lugar todos los asuntos humanos" (Ib., pp. 57-58)

En este recorrido se puede identificar un principio que ha primado en la concepción de lo ciudadano y, en consecuencia, en el ejercicio de la ciudadanía: su anclaje a una serie de derechos y deberes que conceden los estados democráticos. "Un estatus que se otorga o se niega”. (Rodríguez, 2009, p. 18).

Ya al revisar tanto la historia como la praxis del concepto de ciudadanía en América Latina -el contexto en el que se desarrolla esta investigación- se observa la tendencia a identificarla con lo meramente formal $\mathrm{y}$, con mucha frecuencia, a restringida al acto de elegir, sin desconocer que en en el siglo XX "también se puede advertir el fortalecimiento de la etnicidad como característica predominante en los discursos de inclusión social en América Latina".(Herrera, et al, 2014, p.24)

En el siglo XXI, con sus inevitables avances y retrocesos, se evidencia la profundización del proceso de inclusión ciudadana, al reconocerse "a la ciudadanía y a la inclusión como procesos dinámicos, con determinaciones múltiples e interdependientes y se les confiere un lugar central para el mejoramiento de las condiciones humanas en el mundo". (Ib., p.24)

En ese marco, los primeros estudios relacionados con el concepto de ciudadanía se inscribieron, fundamentalmente, en estos tres enfoques o tradiciones de pensamiento: - El liberal, cuyo énfasis está en los derechos individuales a cargo del Estado; -El comunitarista, que asume su centro de análisis alrededor de la preponderancia del "bien común y la pertenencia de los individuos a una comunidad". (Ib. P. 31) y -El republicano cívico "que resalta la obligación individual de participar en los asuntos comunales". (Ib.) Ya las investigaciones contemporáneas "apuntan a creativas articulaciones de estas tradiciones".

Entre estas últimas están los estudios de la politóloga Chantal Mouffe -muchos de ellos realizados con el pensador argentino Ernesto Laclau- con su propuesta de democracia radical. Allí hay referentes muy importantes para esta investigación, en especial conceptos clave para que las comunidades aprendan a deliberar.

La democracia radical se puede entender como una respuesta a lo que Mouffe denomina "pospolítica", es decir, la pretensión de desdibujar la frontera política entre derecha e izquierda, tras acordar los partidos de centro derecha y centro izquierda de Europa que no había alternativa frente a la globalización neoliberal. (Mouffe, 2016). Ello se tradujo en la "drástica reducción" de la influencia de los ciudadanos sobre las decisiones políticas. Y, entonces, en la práctica, "fue puesto en cuestión lo que representa el corazón mismo de la 
idea democrática: el poder del pueblo". (Ib., p. 3) Se aceptaron, así, los dictados de la globalización financiera y capitalista. Y, en palabras de la investigadora,

al volverse borrosa la frontera izquierda/derecha por la reducción de la democracia a su dimensión liberal, desapareció el espacio donde podía tener lugar esa confrontación agonista entre adversarios. Y la aspiración democrática ya no encuentra canales de expresión en el marco de la política tradicional. El demos, el pueblo soberano, ha sido declarado una categoría zombi y ahora vivimos en sociedades posdemocráticas. (P. 4)

Hoy, por consiguiente, si lo que se busca es apostarle a la profundización de la democracia, se hace necesaria la constitución de una nueva voluntad colectiva, o lo que Mouffe califica como una sinergia entre la diversidad de movimientos sociales y fuerzas políticas.

Desde estos postulados, la investigadora asume que el antagonismo siempre estará presente en la vida política y que, por lo tanto, no hay otro camino diferente a contar con el otro, ya no en calidad de enemigo sino de adversario:

(uno) es el antagonismo propiamente dicho -que es el que tiene lugar entre enemigos, es decir, entre personas que no tienen un espacio simbólico común- y (otro) el agonismo (...) que no implica una relación entre enemigos sino entre "adversarios" (...) personas que son amigas porque comparten un espacio simbólico común, pero que también son enemigas porque quieren organizar ese espacio simbólico común de un modo diferente. (2012, p. 30)

Así las cosas, la democracia radical busca profundizar el pluralismo , entendido en el contexto actual como la manera de "radicalizar" lo que en el liberalismo individualista han sido simples enunciados o "buenas intenciones", en la medida en que ha asumido como su tarea prioritaria mantener la paz interior y las "libertades individuales" y privilegiar lo que Mouffe denomina "una política de consenso centrista", en la cual se asume que el antagonismo - connatural en las relaciones humanas- puede, o ser ignorado o erradicado. La vía que propone para afrontar ese problema es la recuperación de "la participación activa de la tradición republicana clásica para compatibilizarla con el pluralismo contemporáneo". (Barbosa, 2014, p. 70). Estamos hablando entonces de "nuevas ciudadanías" que implican reconocer problemas puntuales de "los nuevos movimientos sociales, los problemas de la ecología, la sexualidad, los problemas étnicos, de clase, de raza, de género, la pobreza, desigualdad, de exclusión.”(Ib. P. 71). Ello, en el marco del ejercicio de la política cuya 
finalidad es la conformación de un "nosotros", la lucha por la hegemonía, tarea imposible según Mouffe- sin un “ellos”.

$\mathrm{Y}$, en coincidencia con el humanismo cívico, el proyecto de la democracia radical plantea que las ciudadanías no se deben asociar ya con lo meramente legal, instrumental o procedimental, sino con la construcción de identidades políticas, íntimamente atadas a los contextos particulares.

Aquí es necesario precisar que el humanismo cívico (H.C.) es una perspectiva de la filosofía política de raíces aristotélicas que, según la investigadora Liliana Irizar, "queda consagrada en el discurso político a partir del Siglo XIV cuando la vida política pasa a ser revaluada en las ciudades-Estado del norte y centro de Italia, básicamente Florencia y Venecia”. (2008). Es una línea de pensamiento desde la cual han trabajado pensadores como Nicolás Maquiavelo; Juan Jacobo Rousseau, Benjamín Constant y Hannah Arendt.

Para el filósofo español Alejandro Llano, el H.C. enmarca propuestas para la acción con y sobre la vida comunitaria que "se ha vuelto a proponer en nuestros días como una opción superadora de la interpretación crudamente individualista y liberal de la democracia". (1999, p. 444). Parte de esta premisa fundamental: las personas son los sujetos radicales de la política. Llano sostiene, en esa dirección, que el ideal del humanismo cívico es la libre participación de los ciudadanos en la vida comunitaria y "como consecuencia de ello, en la política de una ciudad (o comunidad) a la que pertenecen como miembros responsables y activos". (Ib. p. 447)

Uno de los radios de acción de esta corriente se basa en el cuestionamiento al tecnosistema o tecnoestructura, entendido como los tres ejes estructurales que buscan dominar la esfera pública: "Estado, mercado y medios de comunicación”. (Irizar, sf.) Según advierten Irizar y González (2015, p. 44) estos ejes son insuficientes para dar cuenta de la complejidad que caracteriza a la sociedad actual. Agregan que -debido al dinamismo mecánico e impersonal con que han venido desplegando su actividad el Estado, los medios de información tradicionales y el mercado-, han transmitido la misma nota de impersonalidad tecnocrática a una ciudadanía organizada en torno a esos parámetros.

"La ciudadanía se convierte, así, en una noción abstracta e indiferenciada, que no confiere identidad alguna al individuo. De manera que el propio individuo pasa a ser considerado como una realidad abstracta y vacía”. (Ib.)

En oposición a esta mirada, el humanismo cívico se postula como filosofía "práctica, hacedora". El mismo Llano recalca: 
Entiendo por humanismo cívico la actitud que fomenta la responsabilidad y la participación de las personas y comunidades ciudadanas en la orientación y desarrollo de la vida política. Temple que equivale a potenciar las virtudes sociales como referente radical de todo incremento cualitativo de la dinámica pública. (1999, p.15)

Por su parte, los investigadores Irizar y González (2008, p.3) identifican estos tres pilares conceptuales y operativos del H.C.:

1. La promoción del protagonismo de los ciudadanos como agentes responsables de la configuración política de la sociedad.

2. La relevancia que concede a los diferentes tipos de comunidades.

3. El valor que confiere a la esfera pública como lugar privilegiado para el despliegue de las libertades sociales.

Así, el centro de análisis de esta corriente de pensamiento está en los cuestionamientos que le formula a la concepción tradicional de ciudadanía, por centrarse de manera excluyente en torno a lo político y lo económico, desde una mirada institucional.

Si la democracia "consiste en la libertad de participar en la vida pública y de manifestar libremente las propias opiniones dentro de la legalidad", la ciudadanía, tal como la entiende el humanismo cívico, debe identificarse con el libre protagonismo de los ciudadanos en la configuración de la sociedad. ( Irizar, 2009 p. 92) Dicho protagonismo se cristaliza, de manera especial, a través de proyectos con relevancia pública, no tanto de tipo político o económico, sino estrictamente "cívicos", o "ciudadanos", es decir, "orientados a la creación de sentido y de autorrealización de la propia identidad”. (Ib.) De ahí que el espacio propio para el desarrollo de la "nueva ciudadanía" o "ciudadanía emergente" sea la cultura, esto es, los ámbitos prepolíticos y preeconómicos que integran el "mundo de la vida". Desde esa línea de acción, postula la importancia del diálogo como recurso clave para buscar y abordar la verdad "desde los muchos aspectos que ella encierra", y, en ese marco

(...) son los ciudadanos los que asumen como un cometido natural, e incluso una necesidad, agruparse y hacer sentir su presencia en la vida sociopolítica con iniciativas de diferente índole, desde reclamar por el mal funcionamiento de los semáforos hasta pedir la revocatoria de un mandatario del gobierno o la reforma de un artículo de la Constitución. (Irizar y González, 2015, p.22) 
Así las cosas, el humanismo cívico le apuesta a lo que denomina "autonomías comunitarias" y a la conformación de "comunidades de amistad", en la búsqueda de trascender tanto el "individualismo como la oficialidad", para evitar que las iniciativas ciudadanas queden condenadas "a la ineficacia (...) y sean socavadas por intereses fragmentarios (Irizar, 2007, p.121)

Un ejercicio concreto de humanismo cívico lo encontramos en el texto "La diferencia entre hacer radio y ser parte de ella" (2015, p.53). Allí el radialista popular Guillermo Patiño relata cómo la emisora "Radio Semillas", del municipio Tibasosa (departamento de Boyacá) se convirtió en un "espacio vital", porque "aquí la radio permite vivir la ciudadanía, ejercerla de hecho y no con palabras..." . Esta experiencia de comunicación es un referente muy importante para este trabajo, porque confirma que sí es posible dejar de pensar en oyentes para hablar de realizadores o co realizadores de programas. Entonces el medio se vuelve un "escenario caliente", o punto de encuentro sin puertas para que "la gente tenga posibilidades de desarrollo y bienestar pero sobre todo donde se visibilice y dé cuenta de sus vivencias". (Ib.)

Con líneas de trabajo similares, Rosa María Alfaro postula que ya no podemos hablar de una sola forma de encarar la ciudadanía, pues

Hay procesos diferentes (...) con rutas de desarrollo a veces poco previstas. Se hace necesario re-conocer a esos ciudadanos concretos existentes, comprender la cultura política que han venido conformando, indagar sobre lo andado para desde allí abonar en propuestas participativas, educativas y de diálogo. Se trata de indagar en los nudos conflictivos de la construcción de ciudadanía para desde allí adecuar los métodos de trabajo y la educación ciudadana. (2000, p. 4)

Uno de esos nudos conflictivos lo ubicamos, por ejemplo, en las experiencias que dieron pie a la investigación denominada "Observatorios y veedurías: Experiencias de crítica mediática y construcción de ciudadanía”, de la comunicóloga María Patricia Téllez Garzón (2012). En el marco de un enfoque crítico, basado en el análisis de tres experiencias, el aporte fundamental de este trabajo está en la documentación y análisis de experiencias concretas de construcción de ciudadanías en América Latina. Dentro del contexto requerido, la autora expone la evolución del concepto de ciudadanía, desde los griegos, pasando por la visión estatutario-legalista que la ha vinculado con los deberes y derechos que se ejercen por estricto mandato constitucional y legal, hasta la concepción radical, en la que se define y asume desde una "nueva matriz sociopolítica", ya no anclada a lo legal sino relacionada con 
lo cívico-político, “ a partir de nuevas centralidades y demandas sociales”. En esa dirección, advierte con Arditi: Hoy la vemos como un escenario polifónico, donde se viven procesos de transformación y, además, se van a escuchar las voces de sus protagonistas, entre ellos los ciudadanos articulados en nuevas relaciones distintas a las establecidas en el pasado. (Téllez, 2012, p.170)

La investigadora coincide, así, con las perspectivas y matrices aplicadas desde el humanismo cívico y la democracia radical, que proponen la resignificación de la vida democrática, al entender el ejercicio ciudadano (Dagnino) como "estrategia política", esto es, expresada en prácticas concretas que no son definidas previamente como una condición universal dada". (Ib. p.171)

Subraya, en consecuencia, la evolución que ha tenido, tanto el concepto como el ejercicio, producto de las particularidades y dinámicas inmersas en las luchas-disputas que se han librado en América Latina, con diferentes instrumentos, anclados a sus respectivos contextos local y global. Hoy esas prácticas están permeadas por las TIC, escenario en el que cobra más importancia la comunicación, “ entendida como un campo de convergencia y como uno de los lugares de mayor relevancia política y sociocultural, donde es posible el intercambio y apropiación de sentidos y significados”. (Ib. p. 173)

En esa medida, al hacer explícita la coincidencia con otras autoras referentes para esta investigación, como Rosa María Alfaro y María Cristina Mata, apunta que tanto la ciudadanía como los medios y el ejercicio de los derechos son "piezas clave para conseguir la democratización de la sociedad". (P.176)

Desde los planteamientos de Wolton (2010), este enfoque se puede identificar con lo que este autor denomina "dimensión antropológica de la comunicación", cuyo foco está en promover procesos políticos encaminados a evitar la incomunicación entre los pueblos e individuos. Para él, la incomunicación no es mala per se, porque se refiere a la decisión que toma quien oye de no escuchar lo que no le interesa. Entonces, el reto está en abrir espacios de negociación con el otro.

Wolton propone privilegiar la convivencia en la comunicación y en el funcionamiento del espacio público, lo que exige "reflexionar también sobre la necesidad de gestionar al mismo tiempo las diferencias inherentes a nuestras sociedades y mantener un principio de unidad, todo ello bajo la perspectiva de una renovación de las características contemporáneas del vínculo social”. (P. 33) Entiende el vínculo social -caracterizado por su dinámica y fragilidad - como el "milagro" que significa conseguir la unidad entre individuos, grupos y 
comunidades y clases sociales "que no tienen nada en común". (Ib.). En la propuesta de Wolton, una palabra clave es "negociación" encaminada a construir la convivencia, la cual, dice, solo es posible en contextos democráticos que pueden asumir la tolerancia como condición estructural de todo proceso de comunicación. (P.25)

El investigador francés plantea, entonces, poner en el centro de la discusión la necesidad de mejorar la comunicación que califica como "el símbolo más interesante de la libertad del hombre (...) porque quien oye también tiene el poder de aceptar o no aceptar lo que le dicen".

Otro ejemplo concreto y práctico de este tipo de enfoques está en el proceso desarrollado con campesinas y campesinos de la provincia de Formosa (Argentina) cuyo objetivo principal consistió en promover la plena comunicación participativa. De la autoría de Claudia Villamayor (2006) está investigación da cuenta de la forma como se logró que ellas y ellos fueran protagonistas del programa de política pública denominado "Programa Social Agropecuario". La metodología aplicada fue la de diagnóstico participativo, para “objetivar, desde la perspectiva de los protagonistas". (P. 9) A partir de esa experiencia concreta, la investigadora subraya la necesidad de "abstraer menos y objetivar más", lo que se inscribe en entender la comunicación como "una dimensión experiencial capaz de ser reflexionada y 'leída' en una práctica concreta". Todo porque, como ella misma lo afirma,

El sentido producido entre las personas, organizaciones de prácticas concretadas, no hay que buscarlo en la abstracción de la razón pura, sino en el cuerpo de quien siente, y respira y habla y cuando habla nombra una decisión, una visión del mundo, una esperanza o un suicidio. (2006, p. 2)

Reconoce, eso sí, que garantizar que los sujetos sociales actúen como protagonistas de sus propias historias y relatos no es una tarea sencilla, pero tampoco imposible. Y tiene el propósito claro de "conocer el sentido del que se carga la vivencia de la comunicación, la vivencia de la organización y la vivencia de la participación”. (P. 4)

En el caso específico de las campesinas y campesinos de Formosa, según nos cuenta, gracias al ejercicio de comunicación participativa, se logró que la política pública se pusiera "al servicio de las personas concretas y sus proyectos y perspectivas. La misma es regulada por la visión del mundo de sus protagonistas y no de matrices foráneas que deciden por encima de ellas". (Pp.6-7)

Y nos da esta clave de acción, encaminada a conseguir no planificar la comunicación sino propiciar las condiciones para que la gente se comunique: 
(...) saber escuchar para poder contar lo que dicen las prácticas; saber sentir para poder expresar lo que ellas comunican por sí mismas y volverlas nociones, métodos y herramientas con identidad cultural e histórica y desde allí no romper la cadena que permita coordinar y gestionar procesos sociales que tenga a la comunicación como perspectiva y como dimensión, pero también como recurso estratégico para el diálogo ciudadano. ( P. 10)

Se trata de perspectivas y dimensiones que, bien aprovechadas, permitirán potenciar el diálogo social activo en las Escuelas Digitales Campesinas, en el marco de la Comunicación/Educación que se inauguró con la fundación de ACPO-Radio Sutatenza, en 1947. El propósito está claro: "formalizar nuevas prácticas políticas y de ejercicio de poder", mediante el ejercicio de la palabra pública”.

Son expresiones de ciudadanías íntimamente relacionadas con el mundo de la vida que, como hemos visto, para el filósofo estadounidense Michael Walzer, citado por Hoyos Vásquez, "se manifiesta como contexto universal de significaciones y fuente inagotable de las pretensiones de rectitud, corrección, equidad o justicia”. (Hoyos, 1995, p. 70)

Esta dimensión ética que demanda un arduo trabajo, porque estamos en el terreno paradójico de lo que Estanislao Zuleta señalara como tensiones entre el esencialismo y el circunstancialismo, según las cuales lo que hacen los otros “es una manifestación de su ser más profundo" mientras los errores nuestros son justificados como "fenómenos que se explican por circunstancias adversas, por alguna desgraciada coyuntura”. (1980, p.4)

En esa misma línea, para la democracia radical resulta fundamental entender unas ciudadanías que van más allá de las relaciones constitucionales o legales que supone el llamado "estado de derecho", uno de los pilares del liberalismo individualista, para privilegiar la construcción colectiva de saberes, encaminada a promover una auténtica democracia pluralista, donde cobren pleno sentido los conceptos de igualdad y libertad para todos, aunque para Chantal Mouffe no sean posibles "libertad e igualdad perfectas". He ahí una de las paradojas que señala: la tensión permanente entre esos dos valores claves para la construcción de una democracia que ella denomina "la lógica de la identidad y la lógica de la diferencia":

Esta tensión, que se presenta también como tensión entre nuestras identidades como individuos y como ciudadanos o entre los principios de libertad y de igualdad, constituye la mejor garantía de que el proyecto de democracia moderna está vivo y habitado de pluralismo. (Mouffe, 1999, p. 181.) 
¿Y Cuál es el papel que cumplen o deben cumplir los medios en la tarea de construir las nuevas ciudadanías? Rosa María Alfaro hace aportes significativos en su texto "Ciudadanos y culturas mediáticas: ocultos en la formalidad democrática" (2008, pp. 351391) en el que se ocupa de la relación entre ciudadanía, comunicación y cultura, desde las mediaciones. Advierte que "no es posible entender a la ciudadanía y a su cultura política por fuera del consumo massmediático". (P. 369) Al referenciar trabajos realizados por otros investigadores, entre ellos Jesús Martín-Barbero y Germán Rey, destaca el avance que se logró en América Latina al entender la relación indisoluble entre comunicación y cultura, lo cual contribuyó a la comprensión del proceso de comunicación, que -como se observó- pasa por dimensionar de qué está hecha la interacción y la circulación de significados. "Ello significó un detenimiento en los públicos como sujetos y no como una caja simple de resonancia de los medios". (P. 353)

Otros aportes significativos están en la profundización teórica -con hondas raíces en la praxis -alrededor de lo que se entiende por cultura política y por ciudadanía. Mientras la primera es identificada como "el lugar de formación de las subjetividades conformadas en relación al poder político democrático, sean afines entre sí o diferenciadas", (P. 354) la segunda parte de asumir al ciudadano como el sujeto de la democracia. Coincide así con esta afirmación de Sartori :

Hay democracia cuando existe una sociedad abierta en la que la relación entre gobernantes y gobernados es entendida en el sentido de que el Estado está al servicio de los ciudadanos y no los ciudadanos al servicio del Estado en la cual el gobierno existe para el pueblo y no el pueblo para el gobierno. (1994, pp. 20-23)

Por supuesto, algo que no desconoce Alfaro es la utopía del concepto, sin que ello signifique que las comunidades carezcan de posibilidades reales de acción en la búsqueda de las soluciones anheladas. Lo cierto es que no podemos sostener que exista una sola manera de encarar el ejercicio de la ciudadanía pues, dada su propia naturaleza, está íntimamente apegada al contexto en el que se desenvuelve.

Advierte entonces que es en el trabajo con la misma gente de carne y hueso como se asume y se dimensiona el quehacer político, al entender la cultura como " el modo particular en que una sociedad experimenta su convivencia y la forma en que se la imagina y representa". (P. 354) 
Así mismo, llama la atención sobre la necesidad de redefinir el papel de medios como la radio, en la medida en que hacen parte fundamental de la estrategia de representaciones sociales, a su vez dentro de un rol integral y central de la "definiciones hegemónicas", pues ahí, en ese terreno mediático se está jugando la posibilidad real de transformar el ejercicio de la política "y la democratizaciòn de nuestros países (...) para la generación de nuevas políticas comunicativas deliberativas e incluyentes". (P. 387) En ese sentido, una de sus preguntas centrales apunta hacia la forma como esos medios tradicionales configuran sus agendas o sus "ofertas comunicativas". Y desde allí, formula otras como estas que contribuyen a alimentar el debate sobre la relación ciudadanía-medios de comunicación:

¿Cómo representar estas sociedades en movimiento para que puedan realmente expresarse y avanzar? ¿Se trata de visibilizar la queja aislada y particular, solamente? ¿Cómo recomponer nuestra pasión por la democracia convirtiéndola en fortaleza y no solo en recurso movilizador del momento? ¿Cómo acercar el sentido de justicia al de participación?, ¿Cómo retrabajar juntos los vínculos sociales y nuevas nociones de comunidad que emancipen y liberen al individuo aprendiendo a vivir en solidaridad? ¿No tendría la radio que jugar un rol de tejedora de reflexiones y certezas, de organización de las dudas, de redefinición de lo que debe ser la política, de intercambio de palabras que configuren nuevas comunidades de interpretación e influencia? (P. 386)

En el marco de esas reflexiones, la investigadora plantea las siguientes tareas, que considera "urgentes":

i. Asumir el desafío cultural altamente significativo para la transformación política y la democratización de nuestros países y para la generación de nuevas políticas comunicativas deliberativas e incluyentes.

ii. Entender que los vínculos sociales y culturales están para ser fundados y convertirlos en capital político reconstructivo de la sociedad. (P. 388)

Para afrontar estos desafíos, enfatiza, es prioritario el papel de la comunicación/educación pues, según sus propias palabras, "no hay participación ciudadana válida si no se asienta en procesos de aprendizaje desde la comunicación”. (P. 386) Son aprendizajes que solo se pueden hacer efectivos si la sociedad se compromete con un proceso activo de transformación social; y son tareas que no se hacen solo con el discurso político, sino con la acción efectiva de la comunidades involucradas. 
Otras respuestas sobre la relación ciudadanías/medios de comunicación está en la investigación, realizada por los comunicólogos Mauro Cerbino y Francesca Belotti (2016), quienes dan cuenta de procesos de comunicación popular en emisoras comunitarias de Argentina y Ecuador, a manera de ejemplo de cómo se puede concretar la "ciudadanía comunicativa" en "medios populares, alternativos y comunitarios como herramientas de empoderamiento cívico". (P.50) La metodología aplicada se basó en dos estudios de caso, con un enfoque cualitativo, para "facilitar un diseño flexible e interactivo", (P. 51) que permitiera conseguir este objetivo fundamental: evidenciar cómo se da la articulación comunidades-medios, “enfocándonos en los vínculos recíprocos entre organización social, generación de contenidos y comunidades de referencia”. (Ib.) Los investigadores subrayan que este tipo de experiencias, caracterizadas por la participación directa de las comunidades en la producción de contenidos, se configura "como herramientas de intervención política y transformación social” y “ como espacios, procesos y al mismo tiempo productos mediáticos generados por y entre las interacciones - conflictivas o cooperativas- de una comunidad molecular que construye desde abajo un poder mediático alternativo al dominante”. (P.7).

Como se puede notar, la perspectiva de este trabajo tiene coincidencias importantes con el enfoque de nuestra investigación, en especial, por contar con una matriz de análisis similar, derivada de la pedagogía liberadora planteada por Paulo Freire, de la cual surgió el modelo de Comunicación/Educación, esto es, encaminado hacia la construcción colectiva de sentido.

Entre los principales hallazgos reportados, se pueden destacar los siguientes:

-El vínculo con el entorno social y territorial se traduce en una definición de la agenda fuertemente anclada a lo territorial, es decir a las cuestiones culturales, políticas y sociales cercanas.

-(...) los criterios de definición de la agenda reflejan la necesidad de plantear las demandas sociales de los ciudadanos en tanto sujetos de derecho.

-La realidad local en el caso de los medios comunitarios no es aprehendida como algo exterior, dado que en ella y por ella surge el gesto mediático como condición propia de una praxis social y cultural no instrumental. 
-(...)No son los intereses particulares -económicos o políticos- que subyacen a la elaboración de la agenda de los medios comerciales y públicos el criterio general que guía la agenda comunitaria, sino la convicción de que cualquier contenido puede ser mediatizado porque es producto de la experiencia vivida y, como tal, de interés colectivo. (P. 7)

A los obstáculos propios tanto de su funcionamiento como de la historia de los medios comunitarios, cabe añadir nuevos retos: la puesta en acto de plataformas locales, nacionales y regionales de lucha para la ejecución efectiva de las diversas leyes en cuanto a demandar la ampliación del espectro de oportunidades para el sector comunitario; y la profesionalización de una actividad que hasta ahora ha sido ejercida de manera voluntaria y con limitaciones debidas a la escasez de recursos que muchas veces han generado insoslayables problemas de sostenibilidad económica y de gestión. (Pp. 7 y 8) 


\subsection{CONCLUSIONES}

Debido a su propia naturaleza, investigaciones consultadas -con excepción de la liderada por Camilo Torres Restrepo Y Berta Corredor (1961) el "Informe Musto (1971), y las de la antropóloga argentina Rosalía Winocur, basadas en métodos mixtos- apelan a enfoques críticos. Como se puede advertir en el cuadro, los dos primeros estudios realizados sobre las Escuelas Radiofónicas, denominados “Escuelas Radiofónicas de Sutatenza” y "Los Medios de Comunicación Social al servicio del Desarrollo Rural. Análisis de eficiencia de Acción Cultural Popular- Radio Sutatenza”, aplican recursos del positivismo, al basarse en mediciones y sistematizaciones que tienen como propósito producir un conocimiento “objetivo" de la realidad (Lozano, 2007, p. 4).

Al evaluar los materiales seleccionados para el estado del arte, dada la naturaleza de esta investigación, se puso el énfasis en los estudios culturalistas, también enmarcados en la perspectiva crítica (32 trabajos), uno de cuyos aportes sobresalientes, como se evidencia en las categorías analíticas, consiste en tratar a las audiencias como sujetos activos que, como tales, participan de la producción social de sentido. (Ver anexo A).

La insistencia en investigar el devenir de Radio Sutatenza confirma la gran trascendencia que tuvo y tiene el experimento de las Escuelas Radiofónicas, y las lecciones que dejó para los procesos de Comunicación/Educación, no solo en América Latina sino en buena parte del mundo. No en vano ACPO se anticipó por lo menos diez años a los estudios sobre la comunicación para el desarrollo (Beltrán), y dejó grandes lecciones sobre las maneras de encarar iniciativas de Comunicación/Educación, dentro de las cuales destacamos las siguientes:

1a. Su principal innovación consistió en profundizar el modelo de comunicación que, como lo ha demostrado durante sus años de vigencia, solo se puede activar cuando la propia comunidad participa ya no solo como receptora pasiva sino como productora de mensajes. Ello fue lo que ocurrió con la figura del auxiliar inmediato, pues si bien los cursos ya estaban elaborados desde el punto de vista radiofónico, solo se podían completar mediante la interacción que provocaba este agente motivador que, como vimos, era un integrante de la misma comunidad, es decir, un par con un poco más de experiencia, amén de su formación, primero en el sistema tradicional de educación formal y luego en los Institutos Campesinos. Fue, como lo señala el investigador Hernando Vaca, una eficaz manera de "complementar la comunicación masiva con la comunicación interpersonal”. (2011, p. 261) 
2a. Para activar la utilidad social de la radio como práctica significante es necesario darse a la tarea de conocer muy bien las realidades, anhelos, expectativas y sueños de sus corealizadores, en este caso las campesinas y campesinos beneficiarios de las Escuelas Radiofónicas. Para esa tarea, el modelo de ACPO apeló a la combinación de medios: Radio Sutatenza, el periódico "El Campesino"; la editorial Andes, con sus publicaciones de libros y cartillas; los discos de acetato (Discoestudio); las cartas y la comunicación interpersonal. Se habló con las campesinas y campesinos y se les interpeló a partir del conocimiento de su esencia religiosa, política, cultural y afectiva. Los agentes de ACPO los conocieron muy bien, por una razón tan sencilla como profunda: no solo trabajaron para ellas y para ellos sino con ellas y con ellos.

3a. El impacto político inmerso en propuestas de esta naturaleza, es un ejemplo concreto de las dificultades, pero también de las oportunidades para hacer vigentes los principios de la democracia radical. Investigadores como Alfonso Gumucio, Carlos Malbrán y Hernando Bernal Alarcón, han concluido que en la medida en que la estrategia de combinación de medios, al servicio de la Educación Fundamental Integral, EFI, fue ganando en importancia, empezaron a aflorar sus propias tensiones internas y las amenazas de agentes influyentes de la sociedad que lucharon por asumir su control. Es cierto que el proceso declinó entre 1989 y 1994, pero también lo es que la sociedad colombiana, ávida de iniciativas de esta naturaleza, no ha renunciado a encontrar la manera de aprovechar el acervo de ACPO, como de hecho lo está haciendo en esta nueva etapa de las Escuelas Digitales Campesinas, EDC, en tiempos de las TIC.

4a. Hoy, como ayer, hay inmensos retos por asumir, pues el modelo democrático sigue en deuda con nuestros pueblos y, por lo tanto, con sus propios ciudadanos, quienes son los llamados a reconfigurarlo mediante la generación de "nuevas políticas deliberativas e incluyentes" (Alfaro, 2000). En esa tarea sí que resulta clave objetivar y profundizar el modelo de contar las historias con las propias voces de sus protagonistas, en cuya tarea cumple un papel fundamental la crónica y los relatos de vida y el género dramático, entre ellos el radioclip. Estos recursos narrativos han demostrado sus bondades en la tarea de motivar el diálogo social, en la medida en que incluyen, de principio a fin, el propio universo vocabular de las comunidades directamente implicadas en el proceso social. En el marco del objeto de estudio, estos géneros se identifican con maneras de contar con el otro, para validar y potenciar la sabiduría que hay en el mundo campesino, lo que implica adentrarse en la "trama cultural" que parte de conocer y reconocer las prácticas de Comunicación/Educación como espacio de lucha/disputa por la construcción y producción de 
sentido. (Huergo, 1999). Es, como se ha visto, el centro del debate al que se quiere contribuir con nuestra investigación.

Allí hay un aporte clave de este trabajo, pues su punto de partida y de llegada se basa en entender que una es la historia cuando se cuenta después y otra durante el propio proceso socio histórico. Ahí, justamente, está el énfasis: en contarla durante y con los actores de las EDC. 
Radio Sutatenza y Acción Cultural Popular en la era digital 


\section{CAPÍTULO II}

\section{CLAVES PARA UN ANÁLISIS}

¿Para qué escribe uno,

si no es para juntar sus pedazos?

Desde que entramos en la escuela o la iglesia, la educación nos descuartiza: nos enseña a divorciar el alma del cuerpo

y la razón del corazón.

Sabios doctores de Ética y Moral

han de ser los pescadores de la costa colombiana, que inventaron la palabra sentipensante para definir el lenguaje que dice la verdad.

Eduardo Galeano

( El libro de los abrazos) 


\subsection{Sumario}

En este capítulo haremos referencia a la dimensión metodológica de esta tesis, que se enmarca en la Investigación Acción Participativa (IAP). Argumentamos por qué apelamos a ese método y de qué manera asociamos la IAP con la Comunicación/Educación; con el método periodístico -parte esencial en el quehacer de las EDC- y con la ecología de saberes, propuesta por Boaventura de Sousa Santos. Así mismo, haremos precisiones sobre la manera como concebimos la relación entre participación e implicación y la forma como serán aplicados los instrumentos metodológicos, vale decir, las entrevistas semiestructuradas; los relatos de vida y los foros de discusión. Y en el último apartado, haremos precisiones claves para entender cómo se encarará el ejercicio de análisis sobre la producción de sentido en las EDC, desde los postulados de la Comunicación/Educación y del Contrato de Lectura, postulado por Eliseo Verón.

\subsection{Introducción}

Por la propia naturaleza de esta investigación que, como se ha señalado, busca darle preponderancia a la relación sujeto-sujeto, se aplicará la metodología de la Investigación Acción Participativa ( IAP), con un enfoque cualitativo encaminado hacia la producción colectiva de conocimiento.

Buscamos así garantizar el protagonismo de los actores sociales como productores y co-relatores de su propia historia, en la búsqueda de nuevas formas de entender el mundo con su entramado de significaciones. Es la manera de afrontar lo que el investigador argentino Héctor Schmucler identifica con las culpas heredadas del racionalismo, "que se empeña en formular leyes únicas para explicar el funcionamiento de fenómenos plurales”. (Bilyk, 2014, p. 13)

En concordancia con esa perspectiva metodológica, el diseño se enmarca en los postulados de la Comunicación/Educación; la Ecología de Saberes; el periodismo literario y las lógicas o "marcas" de la producción de sentido definidas por Eliseo Verón en el "contrato de lectura" . (2004)

Para la presente investigación ello significa apelar a prácticas de Comunicación/Educación, cuya apuesta central radica en un ejercicio siempre inacabado de interaprendizaje, con la mira puesta en la transformación colectiva de los modos de escribir, hablar y leer el mundo. (Prieto, 2006, p.27). Según el investigador Jorge Huergo, es un proceso que no está asociado tanto al acto clásico de conocer, en sí mismo, como al de 
reconocer, en el que juegan un papel fundamental las matrices y los formatos culturales, anclados al contexto específico donde se inscribe la lectura o relectura de los bienes culturales propuestos, lo que le da su carácter dialógico. (2001, p. 95) Así, en coincidencia con el método de análisis cultural que propusiera el antropólogo estadounidense Clifford Geertz en su "enfoque semiótico de la cultura" no interesará aquí la búsqueda de leyes sino de significados en contextos específicos. (2003, p.20)

Es una forma de encarar las realidades de las que participan los sujetos, para darle preponderancia a la "des-localización de los saberes" y al "desplazamiento de lo 'culto' por las culturas". (Huergo, 2017, P. 1) De ahí que el enfoque propuesto se enmarque en la construcción de memoria desde la propia mirada de las campesinas, campesinos, integrantes de comunidades afrodescendientes e indígenas que integran las Escuelas Digitales Campesinas de Acción Cultural Popular (ACPO). En palabras de Jesús Martín-Barbero (2010), ellos cuentan, es decir, son incluídos si participan directamente no solo de la historia sino de los relatos, y, de esa manera, se pone en juego la relación entre el reconocimiento y el derecho a la participación ciudadana.

Son, por consiguiente, actores principales de la producción de sentido, entendida como "trama de significación y construcción de subjetividades". (Villamayor, 2014, p.93). Es, entonces, una apuesta por el derecho a decir y a interactuar, donde se juegan "las identidades, la interculturalidad, las historias, los cuerpos, las visiones del mundo, la proyección que se hace en torno a la sociedad y el Estado...”(Ib.,p.93)

En consecuencia, esta investigación se enmarca en un proyecto que se ha venido consolidando en Latinoamérica, aunque no tan rápido como se quisiera, al amparo de una corriente de pensamiento que concibe tanto la educación como sus prácticas en clave de liberación/transformación de las formas de pensar, cuyo norte es la construcción de la dignidad. Y en esa tarea, como se ha indicado, es indispensable contar con el otro. Para el mismo Huergo es el ellos y el nosotros en calidad de integrantes activos de "una trama cultural de la que estamos hechos", pues como lo dice Freire en su Pedagogía del Oprimido (1970, p.8) “(...) nadie educa a nadie, así como tampoco nadie se educa a sí mismo, los hombres se educan en comunión, y el mundo es el mediador".

Por ahí pasa la apuesta central de esta tesis: un ejercicio de polifonía de voces y de saberes, que se inscribe en los principios de la democracia radical (Mouffe, 2012, p.31), con su propuesta de transformar el antagonismo (escenario de enemigos irreconciliables, dada la enorme distancia entre sus espacios simbólicos) en agonismo (escenario de adversarios, entendidos como aquellos con quienes se pueden construir acuerdos y hacer evidentes los 
disensos, gracias a que se mueven dentro del mismo espacio simbólico). Es desde ahí, y desde el humanismo cívico, que describiremos cómo se da la producción de sentido en las EDC.

\subsection{ACPO en clave de comunicación}

La realidad colombiana, inmersa en un conflicto armado de más de 50 años, ha dejado graves secuelas que se sienten con mayor rigor en el campo colombiano. Según el Tercer Censo Nacional Agropecuario (2014) en los últimos años se ha venido agudizando la migración del campo a la ciudad. Mientras en 1970 habitaban en el campo 9 millones de campesinas y campesinos (De un total nacional de 21 millones de habitantes) hoy son 11,3 millones (De un total nacional de 47 millones), incluidos ahora, además de las campesinas y los campesinos, indígenas, afrocolombianos, palenqueros, raizales y habitantes de 56 parques nacionales. En otras palabras: mientras en 1970 el 42,8\% de los colombianos vivía en el campo, hoy solo habita allí el $24 \%$. Los que más están saliendo de las zonas rurales son los jóvenes, por una razón fundamental: saben que sin educación no tienen futuro, y la educación rural, o es de muy baja calidad o sencillamente no existe, pues -según esa misma investigación- más del 72\% solo ha podido acceder al nivel de primaria. (Pérez, 2016, p.1)

Históricamente los programas de Acción Cultural Popular (ACPO) han tenido un gran impacto en la formación de la población campesina del país, a tal punto que su modelo ha servido de referente en otras latitudes de América Latina, África y Asia.

Y en esta nueva etapa, iniciada en firme en 2012, ACPO busca mantener vigente el modelo de Educación Fundamental Integral ( EFI) que aplicó con las escuelas radiofónicas de Radio Sutatenza, ahora mediante la utilización de las TIC, en sus Escuelas Digitales Campesinas (EDC).

Como se puede advertir, la estrategia de las EDC tiene un alto componente de comunicación y de periodismo, no solo en sus diferentes plataformas, como el periódico elcampesino.co, el programa de radio "Mundo Rural" y la web Escuelas Digitales Campesinas, sino en cursos como los diseñador para la "Red de Reporteros Rurales", de cara a la construcción y cualificación de las nuevas ciudadanías en los diversos escenarios de su población objetivo.

Ya desde el Plan Nacional de Desarrollo de Colombia 2006-2010 se contempló que mediante la inclusión de las campesinas y campesinos en la Sociedad de la Información y el conocimiento se debía generar un gran impacto en estos aspectos claves: 
Particularmente a través de las TIC, es posible mejorar el acceso a la información y al conocimiento, reducir costos de producción y de transacción en la economía, crear nuevos vínculos sociales y generar mayores posibilidades de competir a nivel regional y global. $(2007$, p.68)

¿Y cómo concibe ACPO la defensa y ejercicio del derecho fundamental a la comunicación y de qué manera promueve esos vínculos sociales? "Mundo Rural...Un espacio para hacer del campo un lugar digno para la vida de sus habitantes", se oye en el cabezote del programa radial de las Escuelas Digitales Campesinas. Es la expresión clara de lo que busca lograr ACPO con las campesinas y campesinos: que accedan a las TIC. Pero no de cualquier manera ni con cualquier propósito, sino para que ellas y ellos -dice la organización- avancen hacia la construcción de su propia dignidad, entendida como aquella que les permite a los seres humanos participar de la conversación pública de tú a tú. Es, como lo expresa Prieto Castillo (2011, p. 6) "estar de pie frente a los demás para hacer oír la propia voz y para sostener desde la propia mirada la escucha y el diálogo, (que) se entreteje a lo largo de años en clave comunicacional".

En esa dirección, se considera que no es suficiente con que la población campesina use las TIC como simple consumidora de contenidos, pues resulta fundamental su participación como productora de mensajes.

Así, la estrategia de Comunicación/Educación de ACPO que se enmarca en su Educación Fundamental Integral -uno de nuestros objetos de estudio- cobra sentido en el uso de distintos medios de comunicación al servicio de una interacción social que tiene como norte el establecimiento de nuevas pautas de comportamiento, cuyo fin, en palabras de su cofundador, es "la transformación de las mentalidades", para que las estudiantes y los estudiantes de las EDC actúen como sujetos protagonistas de su propio aprendizaje. En ese contexto es que se busca desplegar el método y los instrumentos metodológicos enunciados a continuación:

\subsection{IAP y ecología de saberes}

La ecología de saberes (De Sousa Santos, 2011) es una perspectiva de las "Epistemologías del sur" asociada a la pedagogía de la liberación que planteó Paulo Freire a comienzos de los 70, la cual se ha concretado en América Latina en muchas experiencias de la llamada "Comunicación para el cambio social” y en la Investigación Acción Participación ( IAP). De ahí, de esa tarea de escuchar y validar lo que dice la gente, salen grandes lecciones y términos como el de sentipensante (Moncayo, 2009, p.10). Como tantas veces lo dijera el 
sociólogo colombiano Orlando Fals Borda, se trata de validar una investigación que le dé la verdadera dimensión al conocimiento popular, sin negar otro tipo de saberes, algunos de ellos provenientes del contexto académico:

(...) la Investigación Acción Participativa (IAP), a la vez que hace hincapié en una rigurosa búsqueda de conocimientos, es un proceso abierto de vida y de trabajo, una vivencia, una progresiva evolución en dirección hacia una transformación total y estructural de la sociedad y de la cultura con objetivos sucesivos y parcialmente coincidentes. Es un proceso que requiere un compromiso, una postura ética y persistencia en todos los niveles. En fin, es una filosofía de vida en la misma medida que es un método. (Rahman y Fals Borda, p.213).

Y como filosofía, busca reinterpretar la realidad para cambiarla, desde el horizonte y propuestas de los actores sociales que es, también, el fin de la filosofía de la liberación: no apoyarse en la filosofía para interpretar la cotidianidad, sino partir "de la cotidianidad en dirección a la filosofía”. (Dussel, 1995, p. 85)

Con esos objetivos, la IAP privilegia el proceso de comunicación, por cuanto le apuesta a la indagación colectiva, en la búsqueda de aprendizajes que beneficien a la comunidad o a las comunidades. (Rocha, 2016). Aquí es tan importante el proceso comunicativo que, incluso, como lo señalan las investigadoras Rizo y Romeu ( 2008), "puede convertirse en el fin mismo de la Investigación-Acción" y "la tarea del investigador, así, puede ser el facilitar la interacción y comunicación entre sujetos aparentemente -según los síntomas detectados- separados.”

Para el caso específico de las Escuelas Digitales Campesinas nos interesa poner el énfasis en la forma como sus actores construyen las nuevas ciudadanías, y ver de qué manera usan diferentes medios de comunicación al servicio de "relaciones contrahegemónicas o alternativas”. (Rocha, p. 20 ) De ahí que el punto de partida de esta investigación haya sido el foro "Las voces de la ciudadanía en la radio del Siglo XXI", realizado el 20 de marzo de 2013 en la Universidad Sergio Arboleda, uno de cuyos ejes de discusión fue la historia y el presente de Radio Sutatenza, con la participación directa de algunos de sus protagonistas.

Así, los sujetos ofician como coinvestigadores de su propia realidad y, en esa tarea, participan de manera activa en el relato de la historia que viven, en el momento en que ésta ocurre pues, ¿quién mejor que ellos mismos para informar, analizar y proponer alternativas de solución frente a aquello que quieren cambiar? Es, en otras palabras, el ejercicio de la sociopraxis, la cual tiene lugar cuando los sujetos se dan a la tarea de evaluar o analizar las 
prácticas en las que están inmersos, para convenir vías de acción $\mathrm{y}$, por lo tanto, de transformación.

Se activa así la tarea de acción-reflexión-acción, la cual nunca debe acabar. Estamos hablando de "un proceso en el que las acciones son fundamentales para el logro de los propósitos colectivos, pero también la reflexión o la reflexividad colectiva”. (P. 16).

\subsubsection{Participación e implicación}

Nuestra investigación está inscrita en el siguiente principio: "estamos implicados en su construcción social", ya que, "sea por acción o por omisión, no podemos estar al margen de las redes en que convivimos". ( Villasante, 2000 p.12 ) Y la implicación ha de ser de todos quienes participan en el proceso.

El reto de fondo consiste participar de una "revolución epistemológica", que pasa por asumir los vicios -aunque también los aciertos- del modelo tradicional hegemónico, también llamado el "norte global", enmarcado en los saberes académicos profesionalizantes o científicos, en sus sentidos excluyentes. (De Sousa Santos, 2010). Es una apuesta por la "ecología de saberes" en la cual se enmarca el "pensamiento posabismal", esto es, una ruptura o cambios de fondo no solo en la forma de pensar sino, lo más importante, en la manera de actuar, (Ib, p. 46).

Ello no implica desconocer los alcances y aportes del conocimiento científico tradicional, pero sí la necesidad de asumir como válidas otras formas de conocer el mundo, mediante "la interacción e interdependencia entre conocimientos científicos y no científicos" (Ib.)

¿Y cuáles -se puede cuestionar- son las claves de esa revolución epistemológica también llamada “del Sur”?

La primera invitación que hacen autores como de Sousa Santos es a desaprender aquello que se ha repetido durante tantos años: que el único conocimiento válido es el que se desprende de aquellas prácticas de investigación enmarcadas en principios universales dictados desde "occidente", la base de la producción tradicional del conocimiento académico. Es una tarea que implica derribar preconcepciones que señalan como incontrovertible "la superioridad del logo centrismo occidental como única racionalidad capaz de ordenar el mundo". (Walsh, 2007, p. 103)

Para responder, en la práctica, a la pregunta planteada arriba, es conveniente también apelar a la cotidianidad de países como el nuestro que, al vaivén, de las "exigencias sociales", han decidido autodefinir su estructura jurídico-política como un "Estado social de derecho". 
En ese contexto salen a la palestra conceptos como el de "democracia participativa" "medios ciudadanos" o "diálogo social", muy asociados a los que se ha mencionado al comienzo: inclusión, participación, deliberación, interacción...Sin embargo, son palabras que, con frecuencia, se han vaciado de sentido, por obra y gracia de esa "colonización de la palabra”, dada, bien sea por la fuerza o mediante la sutileza de los discursos públicos que hablan de una bien velada participación, en realidad inmersa en el habitus lingüístico del que habla Bourdieu ( 2007). El mismo Villasante (2000, pp. 12-13) hace referencia, por ejemplo, a los famosos "círculos de calidad" de la Toyota que surgieron tras una huelga de trabajadores y poco a poco se fueron imponiendo en el mundo empresarial como una "alternativa participativa" pese a que, en la práctica, "se limita a algunos aspectos de las formas de producción"... "Y, según algunos autores, produce más cansancio y ansiedad...que el antiguo control del supervisor". (Ib.)

Son también muchos los ejemplos que se tienen en el contexto latinoamericano, como la pretendida "participación social" en las radios comerciales que, con muy contadas excepciones, se limita expresiones libreteadas, pues solo se admite hablar sobre el tema del día impuesto por el emisor.

Estas y otras realidades confirman la inconveniencia de identificar la ciudadanía con un estatuto inmerso de manera estricta en el ámbito jurídico y no con una mirada cívicopolítica, es decir, como "algo que debe construirse, no un estatus que se otorga o se niega": (Rodríguez, 2009, p.11). Allí surge la propuesta de la democracia radical de inscribir la categoría "ciudadanía" en un proyecto de naturaleza política que le apunta a la construcción de identidades, desde los propios anhelos y expectativas de las comunidades involucradas en procesos de participación. Se busca, como lo plantea el investigador César Rocha (2016) entender la participación como "una forma de construir sentido con otros, de hacer parte de un grupo, de permear o dejarse permear por las ideas de otros. (2016, p. 17).

Es una manera de defender la palabra pública, como bien fundamental y, por lo tanto, irrenunciable, en la medida en que ciudadaniza a quien la ejerce (López Vigil, 2015), al incluir a las ciudadanas y ciudadanos en formación en escenarios de deliberación, en la búsqueda de objetivos como los siguientes : construir o reconstruir su propio capital simbólico, lo que pasa por asumir el derecho de nominar, de relatar la forma como se percibe la realidad o "realidades". En palabras de Watzlawick, citado por Ignacio Ramonet: "De todas las ilusiones la más peligrosa consiste en pensar que no existe sino una sola realidad".(2002, p. 55) . Entonces, para que la participación sea efectiva, hay que contar para ser contado, en el sentido inclusivo del término (Martín-Barbero, 2017); avanzar a paso firme 
hacia el ejercicio del interaprendizaje que implica, a su vez, reconfigurar actitudes y valores que los propios actores identifiquen como un estorbo para su crecimiento en comunidad; y asumir de manera directa el manejo de un activo llamado información pública que, aunque no se nota siempre a primera vista, implica grandes consecuencias económicas, políticas, sociales y culturales.

\subsubsection{El método periodístico}

¿Puede el periodismo ser un aliado de las "Epistemologías del sur” y, por lo tanto, de la Ecología de saberes? En este acápite buscaremos contestar esa pregunta.

Con mucha frecuencia se suele identificar con periodismo o con periodístico aquello que, en el mejor de los casos, apenas sí podría clasificarse como un buen pastiche. (Pérez, 2016, p. 1) Estas reflexiones están encaminadas a sustentar por qué, a pesar de los cuestionamientos que se le formulan al mal periodismo o pseudoperiodismo, las herramientas de la investigación periodística pueden contribuir a cumplir los objetivos de este trabajo con las Escuelas Digitales Campesinas de ACPO.

Partimos de la siguiente convicción: sin análisis nunca se podrá hacer buen periodismo. Sí, la confusión ha llevado a pensar que todo el periodismo cotidiano es malo, porque la falta de investigación y de análisis hizo carrera. Pero memorables trabajos confirman que los valores esenciales del "oficio más hermoso del mundo" -precisión, rigor, honestidad, veracidad, independencia y responsabilidad...- no solo siguen vigentes sino que ahora, más que nunca, son indispensables.

En la historia reciente hay ejemplos en los trabajos realizados por Jesús Abad Colorado ("Mirar de la vida profunda"); Martín Caparrós (" El Hambre”); Leila Guerriero ("Una historia sencilla"); Alberto Salcedo Ramos ("El oro y la oscuridad") y Juan Villoro ("La ciudad es el cielo del metro"). O en los relatos radiofónicos de Ernesto Mccausland ( "Cuando Shakira no era Shakira"); Lorena Vega y el equipo de Radio Nacional de Colombia ("Memoria de un país que le apuesta a la paz") e Indalecio Castellanos ("Música para la infinita soledad del secuestro"). No solo son trabajos diferentes por su ejercicio de creatividad verbal, visual, sonora o escrita, sino por ocuparse de otras miradas, de otros enfoques, que cobran vida en las voces de sus propios protagonistas.

Es lo que también buscamos hacer en el marco del semillero "Radio y ciudadanía", con programas como "Mundo Rural, de las Escuelas Digitales Campesinas de ACPO"; “Desde la cárcel” y "En voz alta”, realizado este último con víctimas de la violencia, en alianza con la Fundación Víctimas Visibles, al propiciar los espacios para que la propia gente 
"eche su cuento".

En estas emisiones, que se apoyan en la estrategia transmedia con plataformas como Radio Virtual, sergiointeractivo.com, Mundo Rural y elcampesino.co, nos interesa, fundamentalmente, respaldar, desde la comunicación y el periodismo la tarea de inclusión de aquellos que, aunque han sido ignorados durante tantos años, o justamente por ello, se niegan a perder la palabra. (Ib., p. 5)

Este compromiso se hace aún más inaplazable en contextos como el colombiano, atravesado por su estela de violencia con sus inconmensurables secuelas, en el que "lo primero que pierde la víctima es la palabra, que resulta insuficiente para expresar el conocimiento al que se llega por la vía del dolor” . (Giraldo, 2010, p. 1 )

Se busca, así, potenciar valores asociados al ejercicio de la ciudadanía como: participación, interacción, deliberación y diálogo con el resto de la sociedad, con la mira puesta en la generación de identidad e identidades. (Pérez, 2016, p. 5)

Es, justamente, lo que pretende ACPO en esta nueva etapa, con la puesta en marcha de iniciativas como la Red de Reporteros Rurales (R3) cuyo punto de partida es el curso denominado "Comunidad, comunicación y periodismo". Así, la población campesina inmersa en las EDC se forma como reportero para que publique sus historias en Elcampesino.co y en el programa de radio EDC Mundo Rural. Como lo explica Kenny Lavacude "el propósito es abrirles espacios a los campesinos para que lleguen a los centros de poder, es decir, a las grandes ciudades, que es donde se toman las decisiones que tienen incidencia sobre su calidad de vida". (Pérez, 2016, audio podcast). Esta propuesta se enmarca en el el gran reto del prosumidor ( ver capítulo IV) y, por supuesto, de los medios, que consiste no solo en mostrar sino en aprender a relatar la realidad desde sus propios contextos. Es la forma de conseguir que los relatos de los propios actores sociales logren sintonizarse con sus anhelos y sentires. (Pérez, 2016)

En la misma dirección, ACPO puso en marcha la sección denominada "Las cartas del campo", tanto en elcampesino.co como en el programa de radio. Son espacios para que ellas y ellos hablen de sus sueños, anhelos, sentimientos, críticas, propuestas...Así, la correspondencia seguirá siendo un instrumento clave dentro de la Educación Fundamental Integral (EFI). (Pérez , 2017). De hecho, es la manera de recuperar un elemento de comunicación que tuvo un gran peso en la estrategia comunicativa de Radio Sutatenza, inmersa en el sistema combinado de medios, con el programa "El correo de Radio Sutatenza", dirigido por Ernesto Niño Mendoza y la sección "Correo y colaboración”, que se publicaba en el periódico El Campesino. Como lo indica uno de sus exdirectores, 
Para ACPO esta correspondencia era uno de los elementos más importantes de retroalimentación de su sistema de comunicación. Era una forma de superar la masificación propia de los medios de comunicación, y de crear una relación interpersonal con su audiencia. (Bernal, 2005, p. 17)

Hay quienes consideran que las cartas ya cumplieron su tarea y fueron útiles en otros tiempos, pero que hoy, en plena era digital, ya resultan anacrónicas. Claro, ello sería así, si nos remontamos al formato clásico. Lo cierto es que, lejos de ser un obstáculo, las redes sociales, son la muestra eficiente de la vigencia del intercambio epistolar. En efecto, al ciudadano le gusta opinar, participar, interactuar y deliberar porque solo así se siente humano. Es, en consecuencia, una forma de contribuir a la formación de ciudadanos. Una tarea que clama y reclama desde hace tantos años este país afectado por la guerra.

Ese compromiso, como lo expresara el reportero gráfico y también víctima de la violencia Jesús Abad Colorado, al lanzar su libro "mirar de la vida profunda" (2015), parte de entender que este país solo se puede construir y reconstruir con "los otros": los indígenas, las mujeres, las campesinas y campesinos, las comunidades negras, los estudiantes...Porque "los medios tradicionales viven más pendientes de la guerra que de la resistencia". (Pérez, 2016, p.5)

\subsubsection{Polifonía de voces en clave periodística}

Para el ejercicio propuesto es clave, además, tener en cuenta otro gran reto que se presenta en el periodismo de hoy, cuya columna vertebral sigue descansando en la investigación rigurosa, la cual demanda escuchar muchas voces; en especial voces genuinas que enriquezcan los relatos. (Pérez, 2016). La esencia de esta mirada no busca algo diferente a permitir que nuestra gente sea protagonista, no solo de su propia historia sino de sus propios relatos. Se trata, entonces, de validar las "prácticas cognitivas de las clases", es decir, la forma como ven el mundo y cómo aprenden de él quienes más lo han padecido, debido al ostracismo al que se les ha condenado históricamente . (De Sousa, 2009)

Como se recuerda, un trabajo hecho con enfoques y fines similares por la periodista bielorrusa Svetlana Alexievich le mereció el premio nobel de literatura en su versión de 2015. El jurado, al decidir por primera vez galardonar con el nobel a un periodista, exaltó su obra "polifónica" como "un monumento al valor y al sufrimiento de nuestro tiempo". Entre sus libros más conocidos están "La guerra no tiene rostro de mujer", "Los muchachos de zinc, "El fin del Homo sovieticus" y "Voces de Chernóbil". Mientras en este último se da a 
la tarea escuchar la voces de las víctimas del desastre nuclear, en el primero de los mencionados el tema de nuevo es la guerra, con relatos en voces de mujeres, porque "todo lo que sabemos de la guerra, lo sabemos por la 'voz masculina'. Todos somos prisioneros de las percepciones y sensaciones 'masculinas'. De las palabras 'masculinas'...Pero, según advierte, "la guerra la relatan las mujeres. Lloran. Su canto es como el llanto".(2015, P. 5) Y en "Los muchachos del zinc" hace una antología de relatos sobre la guerra entre Afganistán y la Unión Soviética. Como ella misma lo explica, al calificarse como "historiadora del alma", lo suyo no es la historia de la guerra sino "la historia de los sentimientos", pues su objetivo central es la búsqueda de lo más íntimo del ser humano:

Busco en la vida observaciones, detalles, matices. Mi interés en la vida no es el hecho en sí, la guerra en sí, ni Chernóbil en sí, ni el suicidio como tal. Lo que me interesa es lo que le ocurre al ser humano, lo que le sucede en nuestro tiempo. Cómo reaccionan y se comportan. Cuánto del hombre biológico hay en él, cuánto del hombre de su tiempo, cuánto hombre hay del hombre (Pérez, 2016, pp. 4-6).

Y ante las infaltables críticas de quienes aseguran que al apelar a los recuerdos y a la narrativa de las mujeres Svetlana Alexiévich no está ni haciendo historia ni literatura, ella apunta con contundencia: "Creo que en cada uno de nosotros hay un pedacito de historia. Uno posee media página; otro, dos o tres. Juntos escribimos el libro del tiempo. Cada uno cuenta a gritos su propia verdad". (2015, p. 19)

Son relatos en clave de resistencia y de existencia. Por lo tanto, juegan el papel reparador y reconciliador, en contextos donde ha primado el silencio y la invisibilidad. También se pueden asociar a una tarea que, con sus necesarias diferencias y matices, ha sido asumida con gran pasión y compromiso por los cultores de la corriente denominada "nuevo periodismo", hoy conocida como "periodismo literario", que según el periodista y escritor argentino Tomás Eloy Martínez, nació en América Latina, específicamente en Caracas, con la emblemática revista "Momento", de la que hizo parte Gabriel García Márquez.

En el marco de esa corriente, figuras como Guy Talesse, Truman Capote, Tom Wolfe, Norman Mailer, Joan Didion, Mark Kramer, y John McPhee han contado historias conmovedoras y de una gran trascendencia social, porque han tenido en cuenta no una sino muchas voces; no una, sino muchas perspectivas, dentro del rigor característico del periodista de raza, con herramientas como estas, contenidas en el libro "Los periodistas literarios" (Sims, 1984, pp.17-29): 
- Inmersión: Es, en palabras de Norman Sims (1984, pp.17-22), el tiempo dedicado al trabajo; pueden ser meses o años, porque se trata de "comprender", para relatar con buen criterio y con responsabilidad.

Como se lo dijera John Mcphee (1984, ib., p.18), uno de los grandes cultores de esta corriente investigativa en Estados Unidos: "descubrí que uno tiene que comprender una gran cantidad de cosas aunque solo sea para escribir un pequeño fragmento. Una cosa lleva a otra. Hay que meterse dentro del asunto para hacer que casen las piezas".

Con una perspectiva similar, la socióloga Maristella Svampa propone lo que denomina un camino intermedio entre el investigador militante y el experto académico, que identifica como "investigador anfibio". En sus propias palabras, es "una figura capaz de habitar y recorrer varios mundos, y de desarrollar, por ende, una mayor comprensión y reflexividad sobre las diferentes realidades sociales y sobre sí mismo". No es un enfoque encaminado desechar el espacio militante sino a motivar un "pensamiento innovador, reflexivo, instituyente, de vínculo con otras realidades":

(...) De lo que se trata es de buscar un lugar dentro de él, en tanto investigador-intelectual comprometido y a la vez crítico, esto es, capaz de producir un conocimiento que vaya más allá de la visión y el discurso de los actores y, al mismo tiempo, capaz de interpelar críticamente a quienes dice acompañar. (2007, p.12)

-Simbolismo: Va de la mano de la anterior, y busca descubrir el entramado cultural presente en los grupos sociales. Se trata, de nuevo, de apelar a la comprensión desde una lógica de lo complejo (lo que está tejido junto). "Para mí eso ha sido de una importancia tremenda. La revelación de los asuntos trascendentales del universo, el sentido de que detrás de la información hay estructuras profundas, ha sido central en todo lo que he escrito". (Sims, 2009, p.15)

Se trata, en otras palabras, de enfocar las energías de co-investigadores hacia uno de los puntos neurálgicos en las sociedades, como lo es "la lógica de la identidad", considerada por Ómar Rincón como “la estrategia más potente para la lucha a la política”. (2005, p. 49). Ahí, justamente, se reafirma la tarea del comunicador de conocer la cultura del otro y contribuir a la comunicación del otro con la sociedad. (Ib.)

-La voz, las voces: ¿Quiénes están inmersos en la historia o en las historias? ¿Con 
cuál voz se debe contar la historia? Para contar, es necesario contar con el otro. Ellas y ellos son los protagonistas de sus historias y ocupan un espacio destacado en los relatos, sin perder de vista que son seres humanos con sueños, con anhelos, con esperanzas; pero también con problemas, con carencias, con contradicciones y tensiones, muchas veces no solo con los demás sino aun con ellos mismos. De ahí optemos por hablar en plural, pues en la medida en que la palabra pública contribuye al ejercicio ciudadano permite compartir con otras y con otros. Así mismo, se recomienda ser cuidadosos con las maneras de aproximarnos a ellas y a ellos, pues, como lo dijera el cronista Alberto Salcedo Ramos

(...) el compromiso es con la historia, pero siempre debe haber respeto por el personaje y por su dignidad. Uno debe pensar no solo en él sino en su familia. Tenemos que aprender a ganarnos la confianza de las fuentes y a compartir con ellos. Si uno no ejerce la piedad, por lo menos la comprensión, uno no puede hacer periodismo. (2016, p. 60)

-Precisión: Este es otro de los grandes valores de la comunicación y el periodismo al servicio de procesos de transformación social. Esa es la gran tarea, como lo recalca Tomás Eloy Martínez, al definir el periodismo como "un instrumento para pensar, para crear, para ayudar al hombre en su eterno combate por una vida más digna y menos injusta". (2005, p.9) Desde esa misma mirada nos preguntamos, ¿cómo separar la comunicación y el periodismo de su función y de su trabajo social, si sus propias esencia y naturaleza descansan en el entendimiento con el otro que, muchas veces, somos nosotros? Es así como la exactitud se vuelve una especie de sello que le da valor y dimensión a nuestra tarea. "En cuanto mejor precisión, mejores resultados. Es el juego nuestro; jugamos a no inventar nada". (Castro Caycedo, 2018, p. 6) .Y como lo anota Claudia Villamayor (2006, p.10) para que esa función cumpla con su razón de ser, es aconsejable "abstraer menos y objetivar más con un oído en las prácticas socioculturales y el otro en la creatividad estética y política”. Es una construcción que demanda del investigador grandes habilidades para una observación peculiar porque es aquélla "generadora de problemas", es decir, de preguntas, como la concibiera el filósofo Karl Popper (Dader, 2002: 11) 


\subsection{Instrumentos}

Dentro del diseño metodológico planteado, enmarcamos los siguientes instrumentos:

\section{-Entrevistas semiestructuradas y relatos de vida:}

Son técnicas clave para esta investigación, en la medida en que permiten construir, tanto los discursos como el análisis, desde el universo vocabular de los actores de las Escuelas Digitales Campesinas, como lo postulan la IAP y la Comunicación/Educación. Por esa vía se busca acceder al conocimiento de lo social a través de lo individual. "Por eso se sustenta en la experiencia del individuo, no teniendo que ser este último una persona en particular ni especial, ya que solo basta con ser parte de la comunidad a la cual se estudia”.(Díaz, 1999, p. 2)

El escenario contemplado para la realización de las entrevistas fue, fundamentalmente, el espacio de radio "Mundo Rural", que se emite en la emisora online de la Universidad Sergio Arboleda "Radio Virtual" (hoy "La Sergio Radio"), se retransmite en 26 emisoras comunitarias en diversas regiones del país y se ubica en las plataformas digitales ACPO; Escuelas Digitales Campesinas y elcampesino.co.

Dentro de este ejercicio, el observador-investigador no se para en la distancia; se involucra en el proceso para producir conocimiento y sacar conclusiones con los sujetos o coinvestigadores de las EDC.

Es, entonces, un análisis colectivo enfocado hacia la indagación, alrededor de las siguientes preguntas: ¿Cómo perciben ellos mismos su propio proceso? ¿Cómo se reconocen como actores en las Escuelas Digitales Campesinas? ¿Cómo se activa el diálogo y cómo se da ese diálogo en las EDC? ¿Cómo se vive el aprendizaje colaborativo entre los estudiantes, entre ellos y los facilitadores y entre la comunidad de las EDC con el resto de la sociedad? ¿Cómo participan de la deliberación pública? ¿Cómo han evolucionado en los últimos años, según ellos mismos, los significados de ser campesino? ¿Cómo se vive el ejercicio de la ciudadanía en las EDC? ¿De qué manera las campesinas, los campesinos e integrantes de comunidades indígenas y afrodescendientes se involucran en las que denominamos“constelaciones de sentido y de significados? ¿Y ahora, como productores activos, qué significa para ellas y para ellos su ingreso a las plataformas digitales?

-Foros de intercambio de saberes: Para esta investigación se previeron tres foros, en los que estudiantes de las Escuelas Digitales Campesinas y de las antiguas Escuelas Radiofónicas de ACPO actuaron como protagonistas. Se buscó, de esa manera, propiciar la 
coparticipación, de cara a construir el análisis sobre la forma como ACPO interpela a sus estudiantes, la forma como ellos se reconocen en ese discurso y las respuestas-problemas que circulan en las EDC, otrora denominadas Escuelas Radiofónicas. Como lo señala Paulo Freire, el objetivo de este ejercicio " no es la incidencia final del pensamiento de un sujeto, sino la mediatización de la comunicación". (P. 2).

-Reportajes y crónicas. Son formas creativas de investigar y de narrar la realidad, que adquieren una especial importancia no solo para el propósito de socializar el conocimiento sino dentro del proceso de formación de los estudiantes de las EDC, que incluye la apropiación-uso las técnicas narrativas periodísticas, en el marco de las tareas de la Red de Reporteros Rurales (R3). Es, también, lo que podemos llamar una carrera hacia la formación de ciudadanas y ciudadanos que, como tales, buscan participar de manera activa de la conversación pública. Con sus diversas narrativas, el periodismo cumple la tarea de construir otras miradas sobre los acontecimientos que hacen parte del ejercicio de la ciudadanía. Y al vincularse a los nuevos movimientos sociales, contribuye a la transformación de la vida de la gente y, por lo tanto, plantea, desde las prácticas cotidianas, otras formas de hacer política. Esto supone también una forma nueva de hacer e investigar en periodismo, y es, por lo tanto, un gran desafío. (Osorio, 2013, p. 13)

\subsection{Producción de sentido en las EDC}

\subsubsection{Comunicación/Educación}

Como hemos señalado, un interés fundamental de esta investigación está en describir los principales aspectos que intervienen en la producción de sentido, que en lo político asociamos con los postulados de la Comunicación/Educación y desde lo que Chantal Mouffe y Ernesto Laclau denominan "democracia radical". Aunque a partir de esos enfoques no se plantea una identidad transversal o unificada, sí resulta pertinente identificar "puntos nodales" o marcas de lo que se considera "fijación parcial del sentido de lo social". (Laclau y Mouffe, 2001)

Así las cosas, para el análisis de la tarea que se viene adelantando en las EDC, se tendrán en cuenta estos principios de la Comunicación/Educación, planteados por el investigador Jorge Huergo (1999, pp. 128-130) en los siguientes términos:

1o. Toda práctica de Comunicación/Educación debe partir del otro (...) de las construcciones discursivas de que es objeto. Con una mirada similar, Daniel Prieto Castillo 
habla del "interaprendizaje y las comunidades de interaprendizaje" como condición básica de la educomunicación. (2006)

2o. Los educandos "cuentan", en cuanto relatan su realidad, hablan del mundo, lo dicen.

3o. Por oposición a la gran "conversación neoliberal", que entiende el diálogo como un modo de suspender y dilatar el conflicto, de lo que se trata en clave de Comunicación/Educación es de construir memoria, y ello pasa por la acumulación narrativa de voces diversas, como el mundo que habitamos. Hablamos con el otro " y no para o sobre el otro".

4o. La crítica y la autocrítica se identifican como ejercicios indispensables pues, al fin y al cabo, la práctica de Comunicación/Educación implica repensar la cultura mediática en un contexto más amplio que parte de "reconocer la cultura como campo donde se están jugando las hegemonías o donde se puede posibilitar o impedir la justicia y la autonomía”. (P. 147)

Dentro de este proceso de análisis, que implica la revisión tanto de documentos escritos como sonoros, es clave entender que la figura del auxiliar inmediato, que muchos investigadores coinciden en identificar como el principal elemento de innovación dentro del modelo de comunicación impulsado por ACPO, se mantiene hoy en las EDC, ahora con las denominaciones de tutor o facilitador. Hoy él o ella se encargan de acompañar el proceso de aprendizaje y de motivar a los estudiantes para que le saquen el mayor partido posible a todos los recursos que tienen a su disposición.

\subsubsection{El contrato de lectura}

Para complementar el ejercicio de análisis apelaremos al gran valor que tiene el uso del lenguaje con sus cadenas significantes y lo que Eliseo Verón denomina "contrato de lectura", es decir, las estrategias o modos de comunicación que se usan para estar en sintonía con los oyentes. (2004). Uno de los fundamentos de esta perspectiva analítica está en la convicción de que el impacto de los discursos no se puede entender solo desde las naturaleza y/o condiciones del emisor; es indispensable, además, escudriñarlos desde las lógicas de quien o quienes reciben el mensaje.

La razón de ser de esta iniciativa está en que la lectura de la producción de sentido como hecho sociocultural se considera una "actividad significante". Es así, porque "los procesos de producción de frases y los de su recepción, no son de la misma naturaleza". ( $\mathrm{Ib}$, p. 1). El planteamiento de Verón se centra, entonces, en la pregunta por el "funcionamiento 
social de los textos", en su afán de comprender no solo qué lee la gente sino, lo más importante aún, cómo lee y por qué, con frecuencia, no lee lo que le proponen los medios. Como lo señala el mismo autor, en este enfoque hay "vocación translingüística”, al incluir la semiótica y la teoría social. El investigador argentino Mariano Fernández encuentra coincidencias entre estos planteamientos y la "Teoría de los campos sociales" de Pierre Bourdieu, para quien en el "sistema total de relaciones" está la explicación sobre el sentido de las acciones "más personales y más transparentes" de los sujetos. (Fernández, 2009, p.5) La afirmación de Bourdieu (1998) coincide con esta propuesta de Verón (1993, p. 125): "No se puede describir ni explicar (...) un proceso significante sin explicar sus condiciones sociales productivas". Así las cosas, los autores plantean tener presente en el ejercicio analítico la tensión que subyace entre los usos oficiales o formales y las posibilidades del decir, condicionadas por el habitus lingüístico, a su vez constituido por lo "social incorporado" y tejido por aquellas relaciones de poder que son asumidas o internalizadas por los individuos.

\subsubsection{El análisis del discurso, la prosodia y el tono}

Aplicados estos criterios a los discursos hablados resulta de gran importancia detenerse en el tono, cuya teoría nos indica que en el lenguaje verbal suele contar más el cómo se dice que lo que se dice, pues cuando nos comunicamos a través de la radio, desaparece el lenguaje corporal y el tono de voz se vuelve determinante del impacto o efecto que logra en la comunicación. De ahí que nuestro interlocutor pueda interpretar, más de manera inconsciente que consciente, cuál es nuestro estado de ánimo y qué es lo que en realidad queremos decir, así nuestras palabras sugieran otra cosa. Por ejemplo: si saludamos al oyente con un "muy buenos días"; entonces, en forma literal quien escucha debería interpretar el que le habla es muy amable, porque le está deseando lo mejor para la jornada que comienza...¡Pero ojo y oído! Si el tono es desganado y pasivo, es decir, carente de entusiasmo, los oyentes interpretarán: "Este nos está deseando que nos vaya mal...”.

Estamos hablando aquí de lo que en el estudio de la gramática y de la lingüística se conoce como prosodia, esto es, el estudio de la pronunciación y de la acentuación de las palabras, a partir de recursos narrativos como los cambios de ritmo, la intensidad, la entonación o el estilo de habla. (Becerra, 2011, p. 105) . Es, como hemos indicado, la producción de sentido que se da en el juego de interacciones de los sujetos, donde está presente la disputa por los significados y, por lo tanto, así como hay espacio para la aceptación del mensaje, lo hay para la negación y para los malos entendidos. Por ejemplo, 
yo le puedo decir a mi interlocutor "Tu hijo es una belleza". Y él podría interpretar el calificativo "belleza" en su sentido irónico, como una persona indisciplinada o irrespetuosa, pese a que en realidad yo quería significar todo lo contrario: que es una persona colaboradora, atenta y servicial. Al final, será un tema que se aclare o, ¿por qué no?, que se enrede aún más en el juego de interacciones-interpelaciones.

Es solo un aspecto a tener en cuenta, en el afán por hacer un análisis integral, para cuyo propósito, un referente clave es la "teoría de la enunciación" de Verón (1985), según la cual se deben distinguir dos niveles en los discursos que son sometidos al trabajo analítico: “el enunciado y la enunciación”. Mientras el primero hace referencia al qué se dice en el texto o palabra, el segundo alude al cómo, esto es , a las "modalidades del decir", apegadas al contexto en el que se concreta la relación, esto es, la comunicación. Es allí, en el marco de la contextualización -la relación entre el texto y el contexto- donde cobran sentido los significados de las palabras, que a su vez impactan las identidades de quienes las intercambian. ( Becerra, 2011). Se explica así “ la manera en que la gente crea sentido en las interacciones". (Ib., p. 105)

Para el caso específico de las Escuelas Digitales Campesinas, se quiere identificar de qué manera se activa y se construyen los nexos comunicativos entre sus diferentes contenidos y los estudiantes de los diferentes cursos, pues como lo señala el propio autor de esta perspectiva metodológica, "por el funcionamiento de la enunciación, un discurso construye una cierta imagen de aquel que habla (el enunciador ), una cierta imagen de aquél a quien se habla (el destinatario) y en consecuencia, un nexo entre estos 'lugares'”. (Verón, 1985, p. 1) Como hemos dicho, dada la naturaleza de esta investigación, nos interesa poner el énfasis en el universo vocabular de los sujetos - campesinas y campesinos- que, según la propia propuesta de ACPO, deben oficiar como protagonistas de su propio aprendizaje. De ahí la decisión de apelar a la estrategia analítica propuesta por Eliseo Verón, que permitirá adentrarse en la "especificidad del soporte”, para ver de qué está hecha la relación entre los diferentes dispositivos de comunicación, denominados por ACPO "convergencia de medios". Buscaremos en consecuencia, aquellas "marcas o trazos" de producción de los discursos (Vaca, 2011), a fin de determinar cómo se reciben. Por consiguiente, apelaremos a ése y a otros instrumentos, con un común denominador: las voces directas de los sujetos de investigación. ¿Y qué significa, en el marco de las EDC, que sus propios actores centrales cuenten su historia? Es un ejercicio que para la investigadora Clemencia Rodríguez (2009, p.17) “implica sacar los lenguajes propios de su escondite habitual, para ponerlos en la esfera 
pública y ver cómo se comportan, cómo derrotan otros lenguajes o cómo son derrotados por ellos...".

Ya desde un plano eminentemente político, se hace referencia a relaciones intersubjetivas $\mathrm{y}$, por lo tanto, atravesadas por disensos y contradicciones, muchas veces insalvables, pero, al fin y al cabo, como lo sostienen Laclau y Mouffe (1999, pp.182 y 183) , "entretejidas en el lenguaje", razón por la que, al margen de la estructura discursiva no podemos concebir la construcción de ciudadanías, entendidas desde la democracia radical en el marco de "la pluralidad de las identidades políticas de los movimientos sociales". (Ib.)

En ese contexto, y para entender cómo puso en marcha su estrategia, es clave indagar acerca del modelo de Comunicación/Educación de las Escuelas Digitales Campesinas, que, como se indicó en el estado del arte, se ha basado, desde la época de las Escuelas Radiofónicas, en los siguientes elementos esenciales, por supuesto, hoy con importantes variantes de la mano de las TIC: El aprovechamiento del discurso religioso; la apropiación y buen uso del lenguaje radiofónico por parte de sus realizadores; el conocimiento permanente del oyente-alumno receptor, para adaptar el discurso a sus anhelos, expectativas y necesidades; el uso de agentes clave de interacción como el profesor-locutor, el auxiliar inmediato, el dirigente campesino y el párroco, y las cartas. Así mismo, como se indicó antes, fue muy importante la estrategia de combinación de medios, apoyada en la propia Radio Sutatenza, el periódico El Campesino; las cartillas; los discos de acetato y los libros.

Fue, entonces, un modelo interesante y, sobre todo, necesario para esos momentos del país, aunque no estuvo exento de problemas, algunos de los cuales contribuyeron a la crisis que llevó a ACPO a hacer una pausa entre 1989 y 2012.

Se trata ahora con esta investigación de ver cuáles de esos principios de la Educación Fundamental Integral se mantienen vigentes, cuáles han desaparecido o se han modificado, cuáles otros se han incorporado $y$, especialmente, de qué manera se ponen hoy al servicio de la producción de sentido y de la "nuevas ciudadanías" que nos proponen la democracia radical y el humanismo cívico.

\subsubsection{Técnicas participativas en las EDC}

En síntesis, para esta investigación nos interesa comprender las dinámicas y las lógicas de participación, así como reconstruir el escenario cultural que se genera allí, en el marco de estas tareas, identificadas por Rosa María Alfaro (2000) como esenciales en la agenda de investigación de América Latina: 
- Asumir el desafío cultural altamente significativo para la transformación política y la democratización de nuestros países y para la generación de nuevas políticas comunicativas deliberativas e incluyentes.

- Entender que los vínculos sociales y culturales están para ser fundados y convertirlos en capital político reconstructivo de la sociedad.

Así las cosas, las miradas colectivas a partir de múltiples propuestas de investigación, han fortalecido la idea de profundizar las estrategias de interacción, desde las herramientas que brindan la comunicación y el periodismo, en un activo y enriquecedor diálogo con otras disciplinas, como el que pretendemos lograr con este trabajo.

En todo caso, se busca que las mismas técnicas se adapten a las necesidades y expectativas de las campesinas, campesinos e integrantes de comunidades indígenas y afrodescendientes que participan del proceso de interaprendizaje y de inclusión digital: por ello y para ello, los facilitadores-alfabetizadores y los comunicadores ofician a la vez como motivadores, mediadores, co-realizadores y co investigadores. Se parte de un principio fundamental trazado por la propia ACPO desde los tiempos de Radio Sutatenza, según el cual la formación de líderes solo tiene sentido en cuanto pueda compartir su experiencia con sus propias bases. Al amparo de esta estrategia, como lo hiciera notar Hernando Bernal Alarcón (2013) desde la época de las Escuelas Radiofónicas se le concedió especial importancia a la figura del tutor o auxiliar inmediato -integrante de la misma comunidadcuya función principal es acompañar y animar al grupo en su tarea de aprendizaje. He ahí una de las pistas que nos ayudarán a jalar del ovillo.(Pérez, 2016)

Por supuesto, para el éxito de este ejercicio caen muy bien las recomendaciones hechas por Villasante, desde la Sociopraxis, en especial la autocrítica constante, y esta puntual: "Hay que insistir una vez más en que lo que hemos aprendido de todos estos movimientos sociales y autores críticos no es tanto una recolección de técnicas, sino la capacidad de readaptarlas a cada caso concreto" (Villasante, 2006, p. 13)

Parafraseando a Boaventura de Sousa Santos, son recursos encaminados a apelar a diversas formas de desobediencia creativa, para alentar y acompañar a la comunidades campesinas, indígenas y afrodescendientes a actuar como "sujetos epistemológicos", lo que siempre debieron ser, en oposición a la mirada de "objetos", con la que se les ha tratado históricamente. 
Radio Sutatenza y Acción Cultural Popular en la era digital 


\section{CAPÍTULO III}

\section{Radio Sutatenza:}

\section{Lecciones de radio popular para América Latina}

"La radio sería el más fabuloso aparato de comunicación imaginable de la vida pública (...) si supiera no solamente transmitir, sino también recibir, por tanto no solo oír al radioescucha, sino también hacerle hablar, y no aislarle, sino ponerse en comunicación con él”.

Bertold Brecht 


\subsection{Sumario}

Para contribuir al entendimiento sobre los alcances e impactos de Radio SutatenzaAcción Cultural Popular (ACPO) y su modelo de Educación Fundamental Integral (EFI), en este capítulo haremos un recorrido por el contexto histórico general en el que nacen las Escuelas Radiofónicas de ACPO; el contexto mediático, incluido el ingreso a las Tecnologías de la Información y la Comunicación (TIC); la forma como ACPO entiende y asume la defensa del derecho a la comunicación y el papel actual de ACPO alrededor de la la EFI como estrategia de inclusión digital y comunicativa. Todo ello en la búsqueda de respuestas frente a la siguiente pregunta de investigación: ¿Cómo se activa el diálogo y cómo se da ese diálogo en las EDC?

\subsection{Introducción}

Hablar de Radio Sutatenza y Acción Cultural Popular, ACPO, es, en buena medida, hablar de la historia de la radiodifusión popular en América Latina, pues gracias a su éxito aunque también debido a su fracaso temporal que la condujo a su cierre en 1989-surgieron propuestas de radio al servicio de la educación en la región y la aún activa Asociación Latinoamericana de Educación Radiofónica (ALER)

Acción Cultural Popular, que el 23 de agosto de 2017 cumplió 70 años de haber sido fundada en el bucólico pueblo Sutatenza (Boyacá) a solo 130 kilómetros de la capital colombiana, ofrece hoy una oportunidad histórica de análisis. Histórica no solo por la conmemoración de una estrategia -la Educación Fundamental Integral- enfocada hacia la inclusión socioeducativa de las campesinas y campesinos, sino por la reanudación de sus actividades desde finales de 2012, tras un aparente silencio de 24 años, ahora en el contexto de las Tecnologías de la Información y la Comunicación (TIC). Hoy, como ayer, el reto pasa por cumplir un objetivo clave: la inclusión de los habitantes rurales en el mundo digital.

Como se indicó, la historia de Radio Sutatenza - cuyo primer nombre fue Emisora Cultural del Valle de Tenza- comenzó el 23 de agosto de 1947, día en que llegó al municipio boyacense que le daría el nombre a la algunos años después cadena radial más 
potente de América Latina el sacerdote católico José Joaquín Salcedo Guarín, quien había sido trasladado de Tunja a manera de castigo, porque su superior jerárquico lo consideraba “ un revolucionario", pues ya desde su paso por el seminario estaba obsesionado con la radio, a tal punto que construyó un artesanal radiorreceptor que nunca abandonaba. Coherente con su gran vocación de radioaficionado y comunicador nato, al partir hacia Sutatenza el joven sacerdote no olvidó llevar un proyector de películas de $16 \mathrm{~mm}$ y su radiorreceptor de onda corta. Al llegar allí, en forma inmediata Salcedo empezó a hacer radio sin micrófono ni transmisor pues, según cuenta la historia, desde su primera misa prefirió el diálogo al sermón. Así de manera coloquial, invitó a los feligreses a dialogar sobre los principales problemas del pueblo, que apenas contaba con unos 130 habitantes en su área urbana y 8.000, incluido el sector rural. Entonces ese radialista sin radio, como diría José Ignacio López Vigil, concluyó con sus interlocutores que los problemas que más aquejaban a Sutatenza eran el analfabetismo y el alcoholismo. En realidad, como radioaficionado que era, ya llevaba en su cabeza la idea de poner los medios al servicio de la población campesina, aunque todavía no tenía claro cómo hacerlo. Un mes después comprobaría que, en efecto, el medio más eficaz para emprender la que llamó “cruzada contra la ignorancia” era la radio, pues su hermano, el también sacerdote Antonio José Salcedo, le envío un transmisor artesanal de 90 vatios el cual, después de muchos ensayos y ajustes, logró poner en funcionamiento. Ya en el primer ensayo de emisión, al escuchar la voz del padre José Joaquín, que salía de una especie de cajón de madera, la reacción de los campesinos de la vereda de Irzón -hacia donde se dirigió la primera transmisión- fue de un gran asombro y susto que, muy pronto, se convertiría en fascinación. (Bernal, 2005) Ahí estuvo la clave de lo que unos días después se conocería como Escuelas Radiofónicas de Radio Sutatenza, cuya estrategia socioeducativa se identificó como Educación Fundamental Integral (EFI).

La primera emisión formal fue protagonizada por músicos campesinos y se hizo el 16 de noviembre de 1947. Entonces nadie, ni el mismo José Joaquín Salcedo, pensó que unos años después esa incipiente emisora se convertiría no solo en la cadena radial más potente de Colombia , sino en el primer experimento exitoso basado en la combinación de medios, al servicio de la educación de las campesinos y los campesinos colombianos, ya que, además de las emisiones radiofónicas, con el propósito de aprovechar lo mejor de cada medio, contó con el periódico El Campesino, la editorial Andes y la Editora 2000 -encargadas de imprimir y divulgar libros y cartillas-; la biblioteca "El Campesino", y grabaciones prensadas en discos de acetato y cintas magnetofónicas, con las cuales se activó el Discoestudio.

Esta experiencia fue imitada en varios países de América Latina, entre estos 
Venezuela, Chile, Perú, Argentina, Bolivia y Ecuador. Así mismo, alentó proyectos socioeducativos similares en África y Asia.

\subsection{Contexto histórico}

En 1947 el presidente de Colombia era el conservador Mariano Ospina Pérez, quien promovió varias iniciativas con el aparente propósito de impulsar el campo colombiano, entre ellas el fortalecimiento de la Caja Agraria, que había sido fundada en 1931, y la creación de instituciones que beneficiaron en forma indirecta al agro, como TELECOM y el Instituto de Crédito Territorial (I.C.T.). Aparente, porque en el caso específico de la Caja Agraria, que fuera concebida como "banco en la ciudad y fomento en el campo", según su lema oficial, se dedicó, en realidad, a canalizar crédito subsidiado para terratenientes, muchos de los cuales nunca honraron sus compromisos (Kalmanovitz, 1991, p. 277). Esta situación contribuyó a su quiebra y liquidación en 1999.

Así mismo, Ospina se destacó por el aval que le brindó a la famosa Misión Currie, enviada por el Banco Mundial con el propósito central de "promover el desarrollo en el llamado Tercer Mundo para evitar que éste cayera en manos de la Unión Soviética o de alguno de sus satélites”. (Malagón y Pardo, 2009, p. 12) Gracias a su amplia trayectoria en la incipiente industria cafetera, impulsó el sector y administró la primera bonanza cafetera, ocasionada por el vertiginoso aumento del consumo interno y al repunte considerable del precio del grano en el mercado internacional.

Sin embargo, el país vivía ya una época de división y polarización política que se agudizó con el asesinato del caudillo liberal Jorge Eliécer Gaitán el 9 de abril de 1948, hecho que dio origen al famoso "Bogotazo". Allí se iniciaría el período conocido como "La Violencia”-1946-1958- que dejó un saldo de 300.000 muertos. (Tirado, 1991, p. 174)

Lo que el país conoció entonces como un agudo enfrentamiento entre liberales y conservadores, se enmarca en realidad en otra faceta de la lucha contra el comunismo internacional promovida por los Estados Unidos, que encontró en Colombia el terreno fértil, abonado por el bipartidismo.

Así se entiende que uno de los más importantes dirigentes conservadores de la época y presidente de Colombia entre agosto de 1950 y noviembre de 1951, Laureano Gómez, propalara la teoría del basilisco. Según decía, el basilisco era un monstruo mitológico de cuerpo gigantesco y torpe, el partido liberal, dirigido por una cabeza diminuta pero maligna, que era el comunismo internacional (Iragorri y Caballero, 2002, p.46). 
El asunto no se quedó en la mera representación simbólica, pues, como también lo señala Antonio Caballero, al vaivén de la lucha institucional contra el "comunismo", Colombia ha vivido inmersa en una férrea defensa de la propiedad que ha soportado lo que él llama "la estructura jerárquica de la sociedad colombiana", de la cual participan tanto liberales como conservadores. (Ib., p.45). Es decir, en buena medida el conflicto colombiano hunde sus raíces en la lucha por la propiedad de la tierra, en la cual los pequeños campesinos y campesinas han llevado la peor parte.

Así, lejos de hacerse la reforma agraria, Colombia ha avanzado de manera progresiva y sistemática hacia la contrarreforma agraria, fenómeno que se profundizó desde finales de los años 80, con la irrupción violenta del narcotráfico y el paramilitarismo. Hay quienes sostienen que por cuenta de esa contrarreforma, les fueron arrebatadas a la población campesina por lo menos seis millones de hectáreas. (Ávila, 2019, archivo de video). Lo cierto es que las mismas investigaciones oficiales confirman que la estructura de la propiedad rural en Colombia cada vez se concentra más. Según el Censo Nacional Agropecuario de 2014, el 70,9\% de las unidades de producción agropecuaria (UPA) menores de 5 hectáreas ocupan menos el 2,4\% del área censada. (C.N.A, 2015, p. 22) En contraste, el, 0.4\% de las UPA de 500 o más hectáreas corresponden al $65,1 \%$ de la tierra censada. (Ib.) Aquí es importante tener en cuenta que, según la denominación oficial, la UPA “puede estar formada por una parte de un predio, un predio completo, un conjunto de predios o partes de predios contiguos o separados en uno o más municipios, independientemente del tamaño, la tenencia de la tierra y el número de predios que la integran. Y Debe cumplir con las siguientes tres condiciones: 1) Produce bienes agrícolas, forestales, pecuarios, acuícolas y/o adelanta la captura de peces destinados al consumo y/o a la venta. 2) Tiene un único productor/a natural o jurídico que asume la responsabilidad y los riesgos de la actividad productiva. 3) Utiliza al menos un medio de producción como construcciones, maquinaria, equipo y/o mano de obra en los predios que la integran". ( C.N.A., 2015, p. 56). Al respecto, un análisis de la ONG Oxfam concluye que “ en 1960 el 29\% de Colombia era ocupado por fincas de más de 500 hectáreas, en 2002 la cifra subió a 46\% y en 2017 el número escaló al 66\%” . (Paz Cardona, 2018, p. 4) Se puede concluir, entonces, que el conflicto agrario es parte medular de una realidad, la cual, lejos de cambiar, se ha ido agudizando con los años, situación que ha debido afrontar ACPO desde su nacimiento en 1947. De ahí que desde las páginas de El Campesino y desde la misma Radio Sutatenza se insistiera con frecuencia en la necesidad de hacer la reforma agraria integral.

Si bien los objetivos de ACPO alrededor de la "cruzada contra la ignorancia" se 
fueron materializando con sus escuelas radiofónicas, en las cuales se impartieron cursos de formación básica, alfabeto, números, salud y economía y trabajo, el contexto socioeconómico general no le fue favorable, con excepción de la paz aparente que lograron dirigentes de los partidos tradicionales con el llamado Frente Nacional. En efecto, el período de La Violencia se aplacó mediante la firma del famoso acuerdo de Sitges (España) un pacto de alternancia del poder presidencial entre liberales y conservadores que se convino inicialmente a 12 años y luego se amplió a 16 años. Pero, a pesar de que la clase dirigente y la historia oficial lo denominaron "un acuerdo de paz", excluyó a muchos sectores de la vida nacional que no se identificaban con ninguno de los partidos tradicionales y gestó en la práctica otra nueva etapa de la violencia en Colombia que, según el Centro Nacional de Memoria Histórica (CNMH) causó -entre 1958 y julio de 2018- 267. 197 muertos y más de 82 mil desaparecidos. Al hacer énfasis en el alto número de desaparecidos, el director del CNMH, Gonzalo Sánchez, subraya que son dimensiones superiores a "todas las dictaduras sumadas del cono sur". (2018, p. 2)

Como lo hace notar el investigador Fernán González (1998, p.177) en Colombia se vive de manera intensa la lucha anticomunista durante un largo período, a tal punto que toda expresión por fuera del bipartidismo es "criminalizada y reprimida". Aunque esa fue una constante en la política de los presidentes de turno, uno de los períodos claves para entender nuestra historia contemporánea fue el que protagonizó el dictador Gustavo Rojas Pinilla, quien, aupado por dirigentes de los partidos Liberal y Conservador, dio un golpe de Estado el 13 de junio de 1953. El general Rojas, a quien se le reconoce por la ejecución de obras tan importantes como el aeropuerto internacional Eldorado de Bogotá, el Hospital Militar y el Instituto Nacional de Radio y Televisión (Inravisión, hoy RTVC) agudizó la represión contra toda manifestación comunista, a tal punto que el comunismo fue declarado ilegal. En el marco de esa campaña, en 1955 declaró por decreto como "zona de operaciones militares" el oriente del departamento del Tolima, que incluyó a los municipios de Villarrica, Icononzo, Cunday, Carmen de Apicalá y Melgar, entre otros. (Tirado, 1991, p.173) Ello dio pie al surgimiento del movimiento de autodefensa campesina y a una nueva etapa violenta, que se profundizó con la creación de las guerrillas Fuerzas Armadas Revolucionarias de Colombia (FARC) y el Ejército de Liberación Nacional (ELN) en 1964 y en 1965, respectivamente. La primera, de origen campesino, que en sus comienzos se conocería como Bloque Sur, reivindicaba entonces la necesidad de hacer efectiva una auténtica reforma agraria. Y la segunda, con clara influencia de la revolución cubana, de origen estudiantil y sindicalista, surgiría con la consigna de promover la defensa de los recursos naturales. 
Es importante observar que durante esta misma etapa Radio Sutatenza y su Acción Cultural Popular tuvieron una transformación importante, al fortalecer la participación de sus oyentes y luchar, a toda costa, por evitar ser absorbida, o por el Gobierno o por la jerarquía de la Iglesia Católica. Justo es reconocer que durante el gobierno de Rojas Pinilla se le dio un impulso importante a las actividades de ACPO, al reconocerla como "institución de utilidad común en 1955, lo que permitió ser eximida del pago de impuestos y facilitar el apoyo estatal". (Lopera, 2016, p.36) Sin embargo, en ese mismo período presidencial María Eugenia Rojas, hija del dictador, quiso adscribirla a una ONG presidida por ella, mientras la Conferencia Episcopal insistía en asumir su manejo y control, disputa que debió ser dirimida por el Consejo de Estado.

El exdirector general de ACPO Hernando Bernal Alarcón, recordaría muchos años después que, en efecto, esa pugna terminó en los tribunales correspondientes, que "restituyeron la autonomía a ACPO" pero la enfrentó definitivamente con la jerarquía eclesiástica. (2005, p.96)

Para Luis Alejandro Salas, ex director general de ACPO entre 1992 y 1996, es clave tener en cuenta que ese enfrentamiento no se dio con la iglesia como tal, si no con la jerarquía eclesiástica, es decir, con el Episcopado, pues "ACPO no es una fundación eclesiástica sino eclesial". Recuerda así que fueron las campesinas y campesinos quienes, desde el primer momento, oyeron el llamado de José Joaquín Salcedo, a tal punto que sin su apoyo hubiera sido imposible tanto su nacimiento como su consolidación:

(...) cuando iba a empezar lo que se denominó entonces la obra, entre comillas, porque era obra física y era obra también de la fundación que vendría a hacerse, pidió que lo apoyaran para construir un teatro...Y vino tanta gente y tantos obreros, que no había ni qué herramientas darles ni qué ponerlos a hacer. Entonces hubo la necesidad de planificar para que trabajaran por turnos. Y cuando les pidió apoyo económico, si ellos no tenían dinero sí tenían o una gallinita, un pollito. Muchos vendieron también sus terneros; traían o un pucho de lentejas o de garbanzos, para contribuir a la obra. Y de esta manera ayudar para que se hicieran las cuestiones físicas. Pero la tarea más importante era la espiritual, es decir, anímica, de aprendizaje, de educación, de Educación Fundamental Integral. (Pérez, 2017, audio podcast)

Queda claro, entonces, cuál fue el activo fundamental con el que contó ACPO desde su nacimiento. Pero lo cierto es que en la práctica, con este y otros conflictos el que siempre ha sido sacrificado es el desarrollo agrario del país, pues muy pronto le llegaría la cuenta de 
cobro a ACPO, con el progresivo cierre de sus fuentes de apoyo lo que que, a la postre, la obligó a suspender actividades a partir de 1989. En un contexto más amplio, historiadores como Marco Palacios (2013) subrayan que la lucha por la propiedad de la tierra, que ha dejado vastos sectores excluidos y marginados, ha impedido la construcción de la paz y afianzar una auténtica democracia en Colombia. Esta política de exclusión, sumada a lo que el historiador Fernán González (1998, p.163) denomina "precariedad de un ámbito público", explica en buena medida por qué en Colombia hay una tendencia muy marcada a resolver los conflictos con métodos privados y violentos, pues a los colombianos les cuesta mucho aceptar autorregulaciones y, mucho más, el control estatal.

De ahí que la sociedad colombiana haya postergado de manera indefinida la solución a problemas estructurales como la titulación de la propiedad rural y aún hoy, cerca de la mitad de los predios del campo no pueden acreditar una tenencia legal lo que, según Marcos Palacios (Ib., p. 239), "les conviene a los oligarcas que tienen poder político y tierra y, por lo tanto, la capacidad de hacer violencia. No les conviene que haya catastro porque su poder requiere que haya desorden catastral".

Como se ha visto, este contexto adverso no le impidió a ACPO poner su impronta en la tarea de inclusión socioeconómica de las campesinas y campesinos colombianos. Ahí están sus elocuentes resultados en esa primera etapa de trabajo -1947-1989- durante la cual consolidó un modelo de combinación de medios, que para esta investigación se ha denominado Acpoeducación. Como dijimos, este modelo fue aplicado con éxito en otros países de América Latina, Asia y África. Pero tanto las presiones que debió soportar, en especial de la jerarquía de la iglesia Católica y de los propios gobiernos, como sus propias contradicciones internas, materializadas en una política de administración bastante cerrada que llevó a su fundador y director general, José Joaquín Salcedo, a concentrar la toma de decisiones (Musto, 1971), profundizaron su crisis, la cual llegó a su punto álgido en 1989, cuando las frecuencias de Radio Sutatenza pasaron a manos de la cadena comercial Caracol Radio.

Esos episodios de apertura, consolidación y declive, que muchos investigadores han interpretado como un rotundo fracaso, fueron, en realidad, una etapa de siembras, de cosechas y de mucho aprendizaje. Y así lo ha demostrado con la reaparición de su organización administrativa en 2012 y su remozada estrategia de Educación Fundamental Integral, ahora alrededor de las Escuelas Digitales Campesinas (EDC) de la cual nos ocuparemos más adelante. 


\subsection{Contexto mediático}

En la mañana del 16 de noviembre de 1947 Radio Sutatenza emitió su primer programa, el cual "fue captado por los tres únicos receptores de batería existentes en Sutatenza, instalados en la vereda Irzón”, según se lee en una nota adherida al primer transmisor de 100 vatios.

Entonces muchos colombianos habitantes de las zonas urbanas ya estaban acostumbrados a entretenerse e informarse por emisoras comerciales de Bogotá, Tunja o Chiquinquirá, entre estas Radio Santa Fe, que barría en sintonía con programas como "La hora de los novios" o "Hacia una vida mejor"; y el "Radioperiódico El Pereque"; emisora "Nuevo Mundo" ( pionera en radionovelas tan exitosas como "El derecho de nacer") la cual se convertiría en la matriz de la Cadena Radial Colombiana (Caracol) en 1948; y la emisora "Nueva Granada", que daría origen en 1949 a Radio Cadena Nacional (RCN) entonces muy exitosa en programas musicales en vivo. Era el preámbulo de la época de oro de la radio espectáculo, con programas en vivo de música, teatro, variedades y de concurso.(Pareja, 1984)

Aunque no se puede negar el gran impacto cultural de la radio comercial, aún no había en Colombia una emisora cultural y popular propiamente dicha, pues aunque en 1940 el presidente Eduardo Santos había fundado la Radiodifusora Nacional de Colombia, desde la misma concepción de sus programas -que incluía franjas de música clásica, música colombiana, en especial del interior del país, y dramatizados- quedaba claro que el enfoque se dirigía fundamentalmente hacia la población urbana.

Por supuesto, tampoco se puede pasar por alto la "HJCK El Mundo en Bogotá", una emisora que nació en 1950 de la mano de dos de los personajes de la radiodifusión y la televisión más apreciados por los colombianos, como lo fueron Álvaro Castaño Castillo y su esposa, Gloria Valencia de Castaño. Como lo contó el propio Álvaro Castaño (2013), la HJCK abrió un escenario por el que desfilaron escritores, artistas, hombres de teatro, poetas, periodistas (...) "con el propósito de elevar el nivel cultural de Bogotá". Uno de los grandes mecenas de esa iniciativa -entre muchos otros- fue el recordado escritor y locutor Álvaro Mutis, quien grabó esta promoción que le daría identidad a la emisora: "Esta es la emisora HJCK, una emisora para la inmensa minoría”, célebre frase escrita por el propio Castaño. Impactante y exitosa, pero tampoco llegaba al campo.

Por el lado de la prensa escrita ya existían en nuestro país los periódicos de circulación nacional El Espectador, El Tiempo y El Siglo. Los dos primeros de origen liberal fueron fundados por don Fidel Cano Gutiérrez, en 1887 y en 1911, por don Alfonso 
Villegas, respectivamente, y El Siglo, creado en 1936 por los conservadores Laureano Gómez y José de La Vega. Son publicaciones que han tenido una gran influencia en la definición de la agenda pública nacional pero que en los años 40 prácticamente no llegaban al campo, porque la mayoría de su población era analfabeta funcional. Las cifras oficiales de la época indican que el índice de analfabetismo en el campo rondaba el 50\%, ya que los escasos recursos destinados a la educación se encaminaban fundamentalmente hacia el área urbana y los maestros se nombraban, en su inmensa mayoría, por recomendaciones políticas y no según su preparación académica. Como lo indican las investigadoras María Teresa Ramírez y Juana Patricia Reyes, "el porcentaje de maestros de enseñanza primaria oficial que no tenían grado llegaba al $82 \%$, mientras que ese porcentaje para la zona urbana era del 51\%”. (2005, p.96)

En este contexto mediático, resulta claro que Radio Sutatenza tenía el éxito asegurado entre la población campesina, gracias a que llenaba un vacío y a que no fue producto de la imposición de nadie, sino del diálogo concertado con su promotor, José Joaquín Salcedo Guarín. Los aportes de sus interlocutores, es decir, las mismas campesinas y campesinos, fueron tan importantes, que incidieron en la creación y puesta en marcha de la decisiva figura del auxiliar inmediato, un integrante de la misma comunidad que tenía más experiencia académica, lo que le permitía acompañar el proceso de aprendizaje en calidad de par y con gran conocimiento de causa. Así mismo, ellas y ellos fueron determinantes en el diseño general de las Escuelas Radiofónicas y en la elaboración de la parrilla de programación de Radio Sutatenza que, poco a poco, fue profundizando su enfoque variado y ameno, pues además de los cursos básicos apeló a formatos como el radioteatro; música selecta (de corte clásico); música popular, cultura general y noticias, entre otros. Hacia 1968, al inaugurarse Radio Sutatenza en Bogotá, con una potencia de 250 kw, se remozó la programación, con énfasis en la participación activa del oyente, "mediante mesas redondas, concursos y trasmisiones vivas". (Musto: 1971. P.89). A ello hay que sumarle la dinámica correspondencia que mantuvo con sus oyentes: en su vida activa ACPO respondió 1.229.552 cartas provenientes de los estudiantes y oyentes de las emisoras y de los lectores del periódico.

Fue así como Radio Sutatenza supo nutrirse del propio mundo campesino, para aprovechar de la mejor manera posible los recursos del lenguaje radiofónico -voces, música, sonido ambiente, silencio y efectos especiales-. Es decir, como lo advierte el investigador Hernando Vaca Gutiérrez (2011, p.264 ) entendió que no se trataba de dictar clases por radio, sino de promover una "enseñanza radiofónica" que, como tal, se respaldó en "el esfuerzo 
permanente por conocer al campesino como es él".

\subsection{ACPO y la defensa del derecho a la comunicación}

La lucha por la participación, por la inclusión y por el ejercicio del derecho fundamental a la comunicación en Colombia explica en buena medida la razón de ser de propuestas como la de Radio Sutatenza y su Acción Cultural Popular.

La batalla que iniciaran hacia 1947 los promotores de la radio educativa emblemática de América Latina es solo una de las tantas que debieron librar unos años después las llamadas radios comunitarias. Para ubicar la discusión, es importante tener en cuenta que este tipo de emisoras ha recibido distintas denominaciones los cuales, por momentos, tienden más a confundir que a aclarar lo que son o lo que pretenden ser. En esa dirección, la investigadora Clemencia Rodríguez (2009) recuerda algunos nombres que se han usado en diferentes contextos: medios alternativos, medios autónomos, medios participativos, medios radicales, ciudadanos, marginales, de contrainformación, paralelos, underground, populares, libres, disidentes, de resistencia, piratas, clandestinos, jóvenes, micromedios y, en un sentido más amplio, altercomunicación.

Es claro que la mayoría de estas denominaciones reflejan grandes tensiones derivadas de la inconformidad, tanto con las políticas institucionales como con el modelo comercial que, debido a su propia naturaleza, fueron dejando de lado valores asociados a la construcción ciudadana, entre estos diversidad, pluralidad, inclusión, participación, respeto por la diferencia y deliberación pública equitativa. Ahí se libran batallas inscritas en proyectos como el de la teología de la liberación, cuyo referente más importante es el Concilio Vaticano II (1962-1965), y la pedagogía liberadora impulsada por Paulo Freire desde los años 60 en Brasil, en Chile y luego en otros países de América Latina, gracias, en especial, al impacto de sus obras “Concientización y alfabetización” (1963) y "Pedagogía del oprimido (1967). Así mismo, en trabajos como los del italo-venezolano Antonio Pasquali, quien pone el énfasis en la dimensión humana del proceso comunicativo, al cuestionar los enfoques funcionalistas y positivistas que asumen la comunicación como un fenómeno puramente instrumental centrado en el devenir de los medios. En oposición a teóricos como Shanon y Weaver y McLuhan, Pasquali postula la necesidad de ver la comunicación con gran sentido crítico, desde dimensiones que van mucho más allá de la técnica o de los avances tecnológicos, al estar atravesada por complejas relaciones culturales inscritas en las ciencias y disciplinas antropológicas. (Pasquali,1990, p.42). En esa dirección, planteará que "lo esencial a comprender sigue siendo la comunicación misma y su contenido o mensaje y 
no el medio por el que ella circula". De allí se inspiraron muchas experiencias radiofónicas como las lideradas por Mario Kaplún, cuya esencia radica en comprender la comunicación como un "proceso de intercambio de experiencias, conocimientos y sentimientos". (2002, p. 58). En ese ámbito surgió el famoso informe Mcbride de 1980 que, tras reconocer los grandes vicios de los medios tradicionales, planteó, dentro de lo denominó el Nuevo Orden Mundial de la Información y la Comunicación (NOMIC) la necesidad de restringir los monopolios informativos, para promover la "diversidad de voces". Y subrayó como “derechos inherentes a la información: participar en la producción (y no solo en el consumo) de los flujos informativos". (De Moragas, 2011, p. 170 ).

En esos marcos teóricos, en coincidencia con estos y otros autores, si bien es clave no quedarse en el eterno debate alrededor de lo que hacen o dejan de hacer los medios comerciales, también lo es que las palabras ayudan a construir realidades y, por lo tanto, a constituir identidades. De ahí que para esta tesis se opte por la denominación de "medios ciudadanos", pues se identifica más con lo que se quiere lograr: poner el énfasis en "los procesos culturales y sociales que se desencadenan cuando las comunidades locales se apropian de las tecnologías de información y comunicación” (Rodríguez, 2009, p.18). Y, como publicamos en Ser ciudadano en la radio $(2015$, p. 93) las radios ciudadanas cuentan, entre otras, con las siguientes características básicas:

- Son radios culturales, educativas y para el desarrollo social. Por lo tanto, deben ser propositivas, que conozcan muy bien su contexto y que hablen con todos los actores sociales. -Deben ser plurales y, por lo tanto, reflejar la diversidad de voces y palabras que hay en la comunidad.

- Luchan por encontrar su propia identidad, es decir, por entender en esencia que deben estar al servicio de la misma gente, para que ella misma reconozca, interprete y cuente su propia realidad.

-En el marco de realidades como las que hemos vivido en Colombia, buscan apoyar a las víctimas para que construyan su propia narrativa, gracias a la reconquista del lenguaje, y para que tejan su propia memoria, que no es otra que la memoria de la sociedad.

- Asumen la comunicación como un proceso de circulación de sentidos que, como tal, trasciende a la misma radio. Así las cosas, la radio se vuelve un eficiente punto de encuentro por donde pasa la vida y, como tal, sirve para visibilizar anhelos, necesidades, dificultades y logros.

En ese contexto, uno de los propósitos fundamentales de ACPO con su estrategia de 
Educación Fundamental Integral ( EFI) es contribuir a la formación de "ciudadanos rurales". Habrá quien recuerde que ciudadanía nació de la palabra ciudad, cívitas para los romanos y polis para los griegos. Será necesario recordar, entonces, que la historia, que no es estática, obliga a revaluar los conceptos, para pensar y asumir hoy, en tiempos de globalización y de mundialización, en una ciudadanía planetaria que, en palabras de José Ignacio López Vigil, "trascienda las cambiantes y tantas veces indignantes fronteras que solo han servido para dividir a los pueblos". (2008, p. 17)

Se busca defender, entonces, el derecho fundamental de mujeres y hombres de nombrar no solo el propio mundo que habitan sino aquel que quieren construir para ellos y ellas mismas y para sus futuras generaciones, al coincidir con Borges (1972, p.4) en que "un idioma es una tradición, un modo de sentir la realidad, no un arbitrario repertorio de símbolos".

Se entiende así la comunicación como un derecho identificador de los estados democráticos o en vías de construir una democracia. Como proceso o como un conjunto de acciones, está inmersa en un campo de tensiones, de contradicciones o de conflictos que, por su propia naturaleza, lejos de invalidarla, la enriquecen y la ponen al servicio de la construcción de nuevos mundos, de nuevas perspectivas que la alimentan y confirman su verdadera razón de ser. Al fin y al cabo, es un "campo de batalla cultural", como la identificara hace algunos años el profesor Jesús Martín-Barbero. (2010) Porque la comunicación es, por encima de todo, un proceso humano y humanizante, pues, en palabras de Humberto Maturana (2010, p.5 ), "en tanto somos personas, podemos reflexionar y podemos darnos cuenta de si queremos o no queremos el mundo que estamos generando unos con otros. Podemos entonces, ser libres".

\subsubsection{Las radios ciudadanas en Colombia}

En el contexto que hemos esbozado es clave tener en cuenta que Radio Sutatenza demostró la importancia de ejercer el derecho a la comunicación con una perspectiva educativa y cultural que se tradujera en el mejoramiento de las condiciones de vida de la población campesina. Se puede afirmar también que aunque, en sentido estricto, Sutatenza no fue una radio ciudadana, sí abrió el camino para que se pudiera concretar lo que hoy se conoce como tal; de ahí que se le pueda calificar como la precursora del movimiento de radios ciudadanas en nuestro país.

A continuación haremos énfasis en los diferentes momentos clave de esa lucha que, como se ha advertido, está lejos de terminar y exhibe históricas y emblemáticas batallas, 
alrededor de la defensa de valores fundamentales para la vigencia de una ciudadanía de la comunicación, como la libertad de expresión y de participación.

Es importante tener en cuenta que centraremos el análisis en los avances de orden institucional que han permitido concretar el derecho, porque si bien en buena medida parte de las batallas se han librado por fuera de los cauces institucionales, se considera que los logros obtenidos en las diferentes instancias del Estado no han hecho sino corroborar su carácter legítimo, no solo al amparo de las normas domésticas sino de lo que se llamó Nuevo Orden Mundial de la Información y la Comunicación. Es claro que aunque el NOMIC fracasó como modelo global de política de información y comunicación, contribuyó a profundizar el debate mundial sobre la necesidad real de democratizar la palabra pública.

Sin embargo, en contravía de esos postulados, tanto por razones históricas como de la política pública, que han privilegiado la rentabilidad económica sobre la rentabilidad social, en América Latina, en general, han sido lentos los avances del modelo de medios comunitarios, en comparación con el gran auge del comercial.

En el caso colombiano la historia nos confirma que si bien es cierto la primera radioemisora en fundarse fue la estatal HJN (1929, gobierno del conservador Miguel Abadía Méndez) muy pronto el modelo comercial tomó la delantera, lo que se reflejó en datos tanto de orden cuantitativo como cualitativo. En 1934 había 17 emisoras y en 1939 ya se contaban 44. En esa década nacen, entre otras, La voz de la Víctor (1933); Emisoras Electra de Manizales (1936); La voz de Chapinero, Medellín Radio, Ecos de la montaña y la HKR de Cali. (Pérez, 2014, P. 10)

Como publicamos en la revista Interacción de Cedal (Pérez, 2017), aunque no es malo per se que se haya impuesto la dinámica comercial en un medio que empezaba a abrirse paso y, por consiguiente, todo estaba por aprenderse, sí es muy diciente que, de manera oficial, solo se haya abierto la posibilidad de fundar y entregar en concesión medios comunitarios con la Constitución de 1991, uno de cuyos principios fundamentales establece que "Colombia es un Estado social de derecho"(...) "democrática, participativa y pluralista". Y que cuatro años después (gobierno de Ernesto Samper Pizano) se hubiese iniciado el proceso de adjudicación de emisoras comunitarias. Es decir, las primeras emisoras comunitarias en Colombia fueron adjudicadas 67 años después de haberse fundado La voz de Barranquilla, la primera radioestación privada de Colombia.

Ahora bien, ¿cuáles batallas se pueden destacar dentro del proceso de materializar el funcionamiento de la radio comunitaria en Colombia? Habría que hacer primero una distinción entre lo que se considera legal, es decir, ajustado a la ley, y lo que es legítimo, o 
sea, aquello que es "razonable" o "ajustado al derecho". De allí se puede concluir que en un estado democrático las diversas expresiones ciudadanas deben contar con la especial protección del Estado, al ser una premisa "básica y elemental” de su ordenamiento jurídico, pues ¿cómo podría un ciudadano participar en forma libre del ejercicio democrático institucional, en especial elegir y ser elegido, si no tiene libertad de expresión?

Con esa misma perspectiva, muchos historiadores destacan que, en esencia, Colombia ha gozado de libertad de expresión, por lo menos en cuanto al formalismo normativo se refiere:

La tendencia a restringir legalmente(...) ha reaparecido bajo formas diversas una y otra vez, aunque en general, y en especial en los últimos 50 años, no ha logrado un impacto significativo. Por ello, las limitaciones y restricciones a la libertad de expresión que aparecen en estos años provienen menos del Estado que de la sociedad, de grupos políticos o sociales o personas privadas que presionan, intimidan o violentan a los periodistas. (Melo, 2004, p. 2)

Pese a lo que dice el historiador Jorge Orlando Melo, el Estado colombiano, sí ha restringido muchas veces, sea de manera abierta o soterrada, la libertad de expresión. Como lo hemos visto, una forma de censurar está en concentrar la propiedad de los medios; otra en la autocensura que provocan la presiones económicas, políticas o armadas (según datos documentados por la Fundación para la Libertad de Prensa, FLIP, a 2018 en Colombia ya habían sido asesinados 159 periodistas por razones relacionadas con su oficio) y otra que, por obvias razones, se evidencia menos, es la censura directa, como la que ocurrió, por ejemplo, entre finales de 2018 y comienzos de 2019, cuando un alto funcionario del gobierno, a la sazón director del sistema de medios públicos RTVC (Radio Televisión de Colombia) censuró el programa "Los puros criollos", emitido en el el canal público de T.V. Señal Colombia. Este atentado contra la libre expresión fue denunciado por FLIP y se desató justamente cuando el periodista Santiago Rivas, presentador del mencionado espacio, le formuló críticas al proyecto de Ley de modernización de las TIC. Fue tan grande el impacto de la denuncia -soportada con un audio en el que el director de RTVC ordena "matar la producción" de Los puros criollos-que el funcionario debió renunciar a su cargo.

Como vemos, en la práctica, los gobiernos han hecho muy pocos esfuerzos para cumplir la tarea del Estado como garante y promotor del derecho a la comunicación.

$\mathrm{Y}$ es en el marco de esa realidad que muchas comunidades han batallado para hacerse sentir, y oír. Un ejemplo está en la capital del país, donde desde el año 89 la 
comunidad de Usme (una de las 20 localidades de Bogotá) se las ingenió para hacerse escuchar por medio de altoparlantes. Algo similar ocurrió con habitantes de otros sectores populares como Kennedy, Suba, San Cristóbal, Mártires y Fontibón.

Así destacó el periódico El Tiempo la experiencia comunicativa de Usme en su edición del 4 de agosto de 1991:

Comunidad que se organiza es comunidad que progresa. Ahí está la clave para que prosperen proyectos como el de una emisora comunitaria que difunde información por altoparlantes en una zona de estratos bajos y que vive, desde hace 2 años, de una pauta publicitaria que no supera los diez mil pesos.

Pero como quiera que la necesidad de hacerse escuchar fue cada vez más sentida, vino la obvia reflexión: ¿Si el espectro electromagnético es un bien público, por qué no podemos acceder a emisoras abiertas? La respuesta se concretó en iniciativas como la de Vientos Estéreo, emisora que empezó a usar una frecuencia libre en el dial, aunque no oficialmente autorizada por el entonces Ministerio de Comunicaciones. Lo mismo pasó con otras emisoras en las localidades de Suba, Usme, Fontibón, Tunjuelito, Ciudad Bolívar y San Cristóbal. Y vino la reacción del Estado, con frecuentes operativos de la policía que, en algunos casos, incluyeron el decomiso de los equipos, como lo explica Carlos Acero, director de Vientos Estéreo:

Nos tocaba prácticamente ir de un sitio a otro; como nos venían monitoreando nos tocaba de barrio en barrio. La gente nos acogía en los salones comunales, ahí estábamos un tiempo y después rotábamos porque el Ministerio siempre estaba detrás de nosotros, siempre tratando de ubicarnos. (Pérez, 2015, p. 67)

Durante años, la reacción del gobierno se mantuvo en lo punitivo, es decir, no avanzó, como era su obligación, hacia la concreción de ese derecho fundamental de las comunidades. Pero la gente no se quedó quieta y optó por dos vías fundamentales para defender lo que siempre consideró legítimo: -Ejercer la palabra pública mediante el uso de un bien público y - Activar los mecanismos establecidos en la Constitución, en la Ley y en los tratados internacionales, para hacer valer lo que era suyo. Fue toda una estrategia de resistencia que se extendió por más de 20 años.

En lo jurídico cada vez parecían cerrarse más las puertas, pues el gobierno alegaba que, a pesar de estar consagrado el derecho a la libre expresión -del cual, como hemos 
observado, el ejecutivo debía ser garante y promotor- como el espectro electromagnético es un bien limitado, no podía otorgar frecuencias a todas las comunidades, menos en una ciudad como Bogotá, que contaba con una suficiente oferta de emisoras. Pero en lo político se fueron abriendo más las posibilidades, pues, poco a poco, más sectores de la sociedad entendieron lo que estaba en juego: no solo poder hablar en una radioemisora sino que las comunidades tuvieran el derecho a decidir sobre su propio destino. Uno de los espacios de discusión y sensibilización se abrió en 2003 en el Concejo de Bogotá, con la realización de un foro abierto para analizar por qué el gobierno se negaba a abrir licitación pública para adjudicar emisoras comunitarias en la capital. Entonces las comunidades acordaron promover la conformación de una mesa distrital que definiera las bases de la política de medios comunitarios.

Entre tanto, la batalla jurídica continuó, mediante la presentación de sucesivos derechos de petición ante el Ministerio de Comunicaciones -siete en total entre el 11 de mayo de 1995 y el 16 de mayo de 2002-. Las respuestas, siempre negativas, incluían razones de orden técnico ( "no se pueden adjudicar más frecuencias"); político ("Se les dará prioridad a los municipios que carecen del servicio") y sencillamente dilatorio ("En la actualidad se están definiendo las características técnicas de esos canales, por ello hasta que no se efectúe esta planificación no se podrá acceder a estos canales"). De ahí que las comunidades optaron por la acción de tutela que solo procede cuando se vulnera un derecho fundamental. Este también fue un camino espinoso, pues el Tribunal Administrativo de Cundinamarca negó la acción en primera instancia, el 13 de octubre de 2005, fallo que fue confirmado por el Consejo de Estado el 13 de diciembre de ese mismo año, con un argumento central: que los demandantes tenían otras vías judiciales, como "la acción de nulidad y restablecimiento del derecho". Lejos de desmotivarse, las organizaciones sociales siguieron actuando, pues aún quedaba el recurso de revisión ante la Corte Constitucional. En este empeño, contaron con el respaldo de las Ongs Dejusticia y Planeta Paz. Así, el 8 de junio de 2006, la Corte produjo la sentencia t 460, que marca un hito jurídico en la historia de la radio comunitaria en Colombia, al reconocer en forma expresa que

La libertad de fundar medios masivos de comunicación, especialmente cuando se concreta en la creación de emisoras comunitarias, es un derecho fundamental que potencia el desarrollo, la participación, el ejercicio del control político, el autogobierno, la creación de redes de solidaridad y la resolución pacífica de las controversias, (...) 
Tras esta decisión, el Ministerio insistió en dilatar el derecho que ya se les había reconocido a las comunidades, quienes debieron insistir con otro derecho de petición. Entonces el gobierno no tuvo una opción diferente a abrir licitación pública para adjudicar emisoras comunitarias, no solo en Bogotá sino en las capitales del país. En la capital colombiana fueron adjudicadas 7 emisoras, que aún pugnan por contar con reglas de juego más equitativas, pues deben funcionar con limitaciones como su potencia restringida a 50 vatios; el límite de 7 minutos por hora para la emisión de pauta publicitaria y excesivos costos por la utilización del espacio electromagnético y por derechos de ejecución pública (Sayco y Acimpro). Es la misma situación que se vive en el resto del país. (Pérez, 2015). Como lo relata el Sistema de Comunicación para la Paz, a 2013 fueron sancionadas, archivadas y canceladas 272 emisoras, y 300 licencias van por el mismo camino en diferentes pueblos de Colombia, “impidiendo así el derecho a la comunicación”. (Cueto, 2015)

$\mathrm{Y}$ es que el gobierno ha actuado de manera ambivalente, pues el mismo Ministerio que, como vimos, tanto se opuso a autorizar el funcionamiento legal de las emisoras comunitarias en las capitales, antes había promovido, al lado de entidades públicas como el Sena y Colcultura, la "Fiesta de la Palabra", un proyecto encaminado a capacitar a radialistas ciudadanos sobre la mejor manera de encarar la comunicación. Gracias a la iniciativa, se les propiciaba un espacio radial a los colectivos de comunicación para que pudieran ejercer su derecho y, de paso, aprender haciendo. En la misma dirección de capacitar a los radialistas comunitarios en todo el país, el Ministerio de Cultura diseñó y puso en marcha desde 1995 su "Programa Nacional de Radio Ciudadana". Sin embargo, todo empezó a cambiar, para mal, con la transformación del Mincomunicaciones en el Ministerio de Tecnologías de la Información y las Comunicaciones (Mintic) en 2009, al final del gobierno de Álvaro Uribe Vélez. Entonces se acabó la Dirección de Radio que tanto apoyo les había brindado a las emisoras comunitarias y el Mintic se convirtió en un mero administrador del espectro electromagnético. Una de las primeras disposiciones de la nueva entidad oficial fue aumentar en un $800 \%$ los costos por usar ese bien público, los cuales, a pesar de haberse moderado después un poco, siguen siendo muy altos, en comparación con el resto de América del Sur, pues incluso en muchos países no se cobra; es decir, aquí el gobierno ve el tema con ojos puramente economicistas, y la rentabilidad social pasó a un segundo plano. "Es como si el Ministerio de Salud solo se dedicara a administrar las licencias para las Instituciones Prestadoras de Servicios de Salud, IPS, y no a prevenir ni a combatir las enfermedades", advierte Mauricio Beltrán Quintero presidente de la Federación de Medios Comunitarios de Colombia. (Pérez, 2017, audio podcast) 
En la práctica, lo que ha ocurrido es una persecución sistemática contra las emisoras en manos de comunidades organizadas. Ante esa realidad, la lucha se mantiene porque, como se ha visto, muchas de las emisoras comunitarias del país -denominadas así según la clasificación gubernamental-, o han perdido sus frecuencias legales o están a punto de perderlas, lo que profundizará aún más el oligopolio informativo. En efecto, un estudio hecho por la Corporación Sipaz confirma que en Colombia hay una distribución inequitativa del espectro electromagnético, pues el $72 \%$ está asignado a la Radio Comercial; el 23\% a la Radio de Interés Público y solo el 3\% a la Radio Comunitaria. Y, en la práctica, más de 440 municipios no cuentan con emisora abierta. (2015)

Para Beltrán (Ib.) “ eso quiere decir que en manos de 45 millones de colombianos está el 3\% del espectro, mientras en manos del 1\% de la población está el 72\%”. (Ib.) Es un problema que se se asemeja mucho al de la concentración de la propiedad rural, sin cuya resolución será muy difícil construir la paz, como quedó claro durante los diálogos entre el gobierno y las FARC. Como se recuerda, dos de los puntos de discusión tuvieron que ver justamente con el conflicto agrario y con el de participación política, incluido el acceso a medios de comunicación. (Pérez, 2017)

Qué duda cabe que falta mucho por hacer, pero este ejemplo demuestra que es necesario y posible apostarle a la creatividad social, como gran movilizadora de propuestas, para que la sociedad asuma la comunicación como lo que es: un derecho fundamental. Al fin y al cabo, fue la movilización social la que permitió que nuestro país contara con una Ley de Víctimas; algo similar ocurrió en Argentina con la Ley de Medios -luego derogada por el gobierno de Macri- y en México con El Barzón que a partir de su consigna "debo no niego, pago lo justo", puso a temblar al sistema financiero internacional...

Esa creatividad sigue más viva que nunca y se refleja en el auge de emisoras ciudadanas online, tanto en Bogotá como en el resto del país. En la capital se han fundado cerca de 300, entre las cuales están Acpo Vive Radio Sutatenza, Campeones de la vida; Suba Alternativa; Manguala Stereo; 1Aimagen Radio; En sintonía con mi barrio; La banca del parque; La diez Radio; La voz de mi barrio 7...Y en otras regiones colombianas también se registran valiosas experiencias como la de Contacto 10 F.M y Voces de la 8, de Medellín; Radio Fantasma Alternativa de Cali; Radio Kronos o Redesónica, del movimiento cooperativo... 


\subsubsection{El papel de las TIC}

Los ejemplos mencionados demuestran que las TIC han abierto más posibilidades para que la gente se haga oír, para que presente y represente su propia realidad sin necesidad de que el Estado le tenga que ratificar ese derecho mediante la concesión de una licencia.

Sin embargo, el reto sigue vigente, pues, además de superar los problemas de conectividad, sobre los cuales el Estado colombiano busca avanzar con la nueva ley TIC 2019, aún sigue pendiente la democratización del espectro electromagnético. En efecto, el gobierno dice querer trabajar en temas como la reducción de la brecha digital, el acceso universal y la ampliación de la cobertura. Parece entender, entonces, que más colombianos conectados significa más ciudadanos comunicados. Pero lo cierto es que pese a las propuestas de organizaciones de la sociedad civil, como la Federación Colombiana de Medios Comunitarios, la nueva normatividad aprobada por el Congreso de la República no incluye la distribución equitativa del espectro, esto es, un 33\% para los medios comerciales; un 34\% para aquellos administrados por el gobierno y un 33\% para los medios ciudadanos.

Como lo advierte el investigador Fabio López de la Roche, director del Centro de Pensamiento en Comunicación y Ciudadanía de la Universidad Nacional de Colombia (2019), uno de los asuntos que prescribe la normatividad internacional es que este tipo de leyes, que tienen hondas repercusiones sociales, sean concertadas con sectores muy amplios, como productores audiovisuales independientes, comunidades, universidades públicas y privadas y escuelas de comunicación. Y, como lo podemos advertir, eso fue algo que no se hizo de manera concienzuda en el trámite de la nueva ley. Por ello, una tarea aún pendiente en Colombia consiste en reflexionar a fondo frente a la democratización de los medios masivos de comunicación y sobre el papel social de las TIC. En otros países de América Latina, como ha ocurrido en Argentina, ya comenzó el proceso pero en el caso colombiano, aunque se hace una crítica constante a los medios hegemónicos tradicionales, la tarea organizativa y las propuestas para dar una discusión seria y pluralista hacia una ley de medios no ha tenido la profundidad necesaria para que se activen las primeras iniciativas, las cuales se deben dar en escenarios del debate social, parlamentario, jurídico y, si es necesario, en las calles de Colombia por el derecho a la comunicación. (Pinilla, 2018)

Nos enfrentamos así al problema estructural que, para autores como Castells, tiene que ver con que, a pesar de los evidentes avances en la comunicación propiciados por las Tecnologías de la Información y la Comunicación, la propiedad de los canales tecnológicos sigue en cabeza de grandes conglomerados multinacionales, entre estos Movistar (Telefónica); Claro (América Móvil); Netflix; Amazon y HBO; Caracol (Grupo Prisa) y 
RCN (Organización Ardila Lulle). Según este mismo autor, es claro que el mercado dejará de lado las iniciativas ciudadanas que no sean rentables, para privilegiar y posicionar la convergencia entre fabricantes y operadores de aparatos tecnológicos. Es así, porque Los proveedores de internet hacen estudios de mercadeo en las redes para vender información a las grandes empresas que comercian con aparatos, escenario que critica el autor desde la vigilancia de la expresión de los usuarios. (Castells, 2009, p. 90).

Así mismo, se le debe demandar al Estado su compromiso de acompañar con políticas públicas los procesos de formación de quienes utilizan herramientas tecnológicas, pues hoy en día en muchos lugares de Colombia hay proyectos que plantean la conectividad a través de aparatos tecnológicos pero son pocos los que incluyen el aprendizaje para utilizarlos como herramientas sociales y pedagógicas. (Pérez y Pinilla, 2019).

Como señalamos, es en la confrontación con esa realidad, que el campo de la Comunicación/Educación postula la necesidad de volver la mirada hacia los sujetos, como protagonistas de procesos de transformación de la vida social, que pasan por la defensa del derecho a la comunicación. Vale decir que esta perspectiva epistemológica se nutre de experiencias específicas, entre éstas el proyecto de las Escuelas Digitales Campesinas, del que nos ocupamos in extenso en esta tesis; y el trabajo de los colectivos de Comunicaciones Comuna 10, de Medellín, y la Escuela Audiovisual Infantil, de Belén de los Andaquíes, en el departamento del Caquetá, entre muchas otros. Son sujetos que participan como actores comunicativos, en tareas específicas que le dan significado a los usos y prácticas de las nuevas tecnologías como herramientas educativas desde la categoría convergencia de medios, la cual entendemos no solo desde una perspectiva técnica, esto es, la integración en la web de los tradicionales mass media (radio, prensa y televisión) sino de manera especial como un proceso cultural que implica cambios profundos, tanto en las formas de emitir como de recibir informaciones. Es importante entender primero que las TIC fueron posibles mediante la convergencia entre la comunicación, la informática y la nanoelectrónica. "Estas tres industrias han unido el resultado de su trabajo ( las redes, el software y el hardware), originando la revolución digital” ( Rodríguez, 2002).

Es claro que la era digital facilita la tarea de publicar y posicionar un mismo contenido en diversas plataformas, a partir del cambio de paradigma propiciado por las herramientas 2.0, con las cuales se permite que los usuarios no solo consuman sino que puedan crear, compartir y transformar información, "modificando la idea de que Internet solo permitía obtener información". (Islas et all, 2019, p. 15). Pero más allá del aumento de los flujos informativos -que también son importantes en una democracia- nos interesa aquí 
poner el énfasis en las posibilidades concretas que se han abierto para que sectores tradicionalmente marginados de los medios, como las campesinas, los campesinos e integrantes de comunidades indígenas y afrodescendientes, puedan actuar como prosumidores, es decir, como sujetos gestores, realizadores y productores y distribuidores de contenidos. (Ver Capítulo IV). Todo ello, gracias a que, como lo hace notar Jenkins (2006), la convergencia, como proceso, "altera la lógica con la que operan las industrias mediáticas y con la que procesan la información y el entretenimiento los consumidores de medios (...) y tiene lugar en los mismos aparatos, en la misma franquicia, en el cerebro del consumidor y entre los mismos fans". (Pp. 26-27). Por consiguiente, al no depender de ningún mecanismo de distribución específico, la convergencia implica una "creciente interdependencia de los sistemas de comunicación", y propicia la cultura participativa de abajo hacia arriba. (P. 241)

En este, ya no tan nuevo contexto mediático, los antiguos oyentes ahora en calidad de productores-realizadores, deberán seguir librando la batalla por ganarse una escucha y por incidir no solo entre sus propios vecinos, sino en ámbitos cada vez más amplios. Y, así sea por los márgenes, ya lo están logrando con una poderosa herramienta que se llama comunicación plena que equivale a decir: todos tenemos la palabra, realidad de la que se desprende una pregunta obligada: ¿ Y cómo ejercemos esa palabra pública?

\subsubsection{Las Escuelas Radiofónicas de ACPO}

El experimento de las Escuelas Radiofónicas de ACPO, más conocido en su oportunidad por la marca Radio Sutatenza, se inscribe en esa eterna lucha por materializar un derecho humano fundamental que - por esas contradicciones naturales del mundo de la vidano es asumido como tal por la mayoría de nuestra población. En el caso analizado, la apuesta se ha hecho más intensa y, así mismo, más interesante, por tratarse del ejercicio de ese derecho básico entre la población campesina, la misma que históricamente ha estado más marginada y excluida.

Como se relató atrás, la historia se inicia en 1947 en el rural municipio de Sutatenza (Boyacá) cuando el entonces párroco José Joaquín Salcedo decidió hacer un ensayo con un rudimentario transmisor de radioaficionado de menos de 100 vatios de potencia.

Gracias al gran el impacto entre las campesinas y campesinos, nació así lo que desde sus comienzos se identificó como la Educación Fundamental Integral (EFI) inmersa en lo que se denominó “metodología de desarrollo” que, según Bernal Alarcón (1966, pp. 18- 20) tiene las siguientes características esenciales:

1a. Acción: Traspasa el límite de la erudición y se convierte en hechos. 
2a. Foco en la población adulta: Va dirigida fundamentalmente a los mayores de edad de las comunidades rurales. (Las niñas, niños y jóvenes no son excluidos, pero se promueve su asistencia a la educación formal)

3a. Voluntariedad. “(...) los alumnos que quieran matricularse en las Escuelas Radiofónicas son absolutamente libres tanto de hacerlo como de suspender su asistencia en el momento que quieran".

4a. Responsabilidad: Supone un proceso y un esfuerzo continuo de responsabilización por parte de quienes hacen parte de ella.

5a. Progresividad: "La persona (...) se siente impelida a profundizar y ampliar sus conocimientos"

6a. Combinación de medios de comunicación al servicio de la acción. (Radio, periódico, cartillas, correspondencia, institutos campesinos, biblioteca, Discoestudio, comunicación interpersonal, etc.)

7a. Urgencia. “(...) Debe llegar al mayor número de personas en el menor tiempo posible”

Con esas líneas de acción, la EFI se concretó en contenidos como alfabeto, números, salud, economía, espiritualidad e, incluso, presentación personal.

Once años después de su nacimiento Radio Sutatenza se instaló en la capital del país y, de manera estratégica, en Medellín, Cali, Barranquilla, Belencito y Magangué. Así empezó a consolidarse la que unos años después sería la cadena radial más potente de América Latina, hasta superar los 600 kilovatios en antena en 1978, cuya programación central estaba enfocada hacia la población campesinadel país. Es importante anotar aquí que este modelo tuvo una gran expansión debido a un cúmulo de factores, entre los que se pueden destacar: i)Su estrategia articulada en la EFI llenaba un vacío muy grande y de mucha importancia dado el contexto socioeconómico del país, pues aunque más del $57 \%$ de la población vivía en el campo (censo de población del 52), el analfabetismo rondaba el 40\%; ii) Supo potenciar el impacto al integrar diferentes medios como la radio, la prensa escrita (periódico El Campesino); las cartillas; los discos de acetato; y la correspondencia escrita. (Según Hernando Bernal Alarcón, uno de sus directores, se respondieron más de 1'200.000 cartas que escribieron los estudiantes y oyentes de las emisoras y los lectores de El Campesino) iii) Tanto el Estado colombiano, por medio del Ministerio de Educación, la Caja Agraria, el Instituto Colombiano Agropecuario (ICA) y la Acción Comunal, como el sector privado, específicamente la Federación Nacional de Cafeteros, fueron aliados del crecimiento de $\mathrm{ACPO}$, con el apoyo decidido al proceso de formación de tutores y promotores de las 
Escuelas Radiofónicas. (Bernal, 2012) iv) Tuvo donaciones internacionales y asistencia técnica "para el diseño, instalación y mantenimiento de su red de emisoras (...) de la empresa Philips y del gobierno holandés”, entre otros. (Bernal, 2012. P. 14)

Fue tan grande la incidencia que en sus 42 años de existencia capacitó a más de cuatro millones de campesinos, con un propósito central: contribuir a la inclusión de la población del campo, para integrarla a la corriente de la vida de la sociedad, para que pudiera jugar un "papel activo" en su propio desarrollo (Bernal, 1978)

Como hemos advertido, nos interesa poner el énfasis en la forma como se ejerció el derecho a la comunicación, en un país que pugnaba por instalarse en el Siglo XX teniendo en cuenta que , como bien lo anotara el historiador Jaime Jaramillo Uribe, los primeros pasos hacia la modernización de Colombia se dieron en el marco de "La Revolución en marcha" que lideró el presidente Alfonso López Pumarejo, entre 1934 y 1942. (Pérez, 2004). Lo cierto fue que la tarea de Sutatenza no estuvo exenta de grandes obstáculos, entre los que podemos mencionar: -Su gran dependencia e incidencia de la jerarquía eclesiástica que, así como contribuyó a su consolidación, fue decisiva en su declive; - La gran polémica que, hasta cierto punto minó su credibilidad, al impedir que los oyentes pudieran sintonizar su radioestación preferida, práctica que fue corregida hacia 1970. (Hasta entonces ACPO, que distribuía sus propios radiorreceptores por medio de los Almacenes Agrícolas de la Caja Agraria los entregaba sintonizados en Radio Sutatenza y no era posible mover el dial hacia otra emisora, salvo mediante un ajuste técnico hecho por un especialista en la materia).

-La falta de profundización en su modelo investigativo, que le impidió hacer las adaptaciones que reclamaba el contexto para mejorar el modelo de comunicación con su público objetivo y - Las evidentes presiones ejercidas por los medios comerciales, inconformes con la venta de pauta publicitaria por parte de una cadena radial de corte educativo y cultural que pese a haber recibido donaciones internacionales en equipos, no contaba con los suficientes recursos para hacer viable su operación.

Con ese norte, y para entender cómo puso en marcha su estrategia, profundizaremos a continuación en el modelo comunicativo inmerso en las escuelas radiofónicas, que se basó en los siguientes elementos esenciales: El aprovechamiento del discurso religioso; la apropiación y buen uso del lenguaje radiofónico por parte de sus realizadores; el conocimiento permanente del oyente-educando, para adaptar el discurso a sus anhelos, expectativas y necesidades; el uso de agentes clave de interacción como el profesor-locutor, el auxiliar inmediato, el dirigente campesino y el párroco, y las cartas. Así mismo, como ya 
se destacó, la estrategia de combinación e integración de medios, apoyada en la propia Radio Sutatenza, el periódico El Campesino; las cartillas; los discos de acetato y los libros.

Como lo indicamos, analizaremos a continuación cuál fue el papel que cumplió cada uno de estos elementos comunicativos:

-El aprovechamiento del discurso religioso: fue decisivo en cuanto al impacto se refiere, si se tiene en cuenta la gran tradición católica de la población campesina colombiana. Tal y como lo indica el investigador Hernando Vaca:

Así, los discursos, los productos, fueron escuchados y aceptados por sus alumnos, en su mayoría, porque en la enunciación, en las ofertas e interpelaciones, estaban las marcas del discurso religioso, de sus instituciones, de sus sujetos, de sus funciones y papeles. (2011. p 262)

-La apropiación y el buen uso del lenguaje radiofónico: Los realizadores de Radio Sutatenza entendieron que para impactar con su discurso debían usar características esenciales que integran la "personalidad de la radio", esto es, las voces; la música; y el sonido ambiente, enmarcadas en una forma de hablar sencilla, corta, directa y dialógica. Así, los programas se caracterizaban por esa cercanía con el oyente que le permite apropiarse o sentir como suya la emisora. Entonces, si bien los locutores se basaban en un libreto o guion, su forma de encarar el diálogo hacía que el radio-estudiante se sintiera interpelado en forma directa porque le hablaba "al oído".

-El uso de agentes clave de interacción, como el profesor-locutor, el auxiliar inmediato, el dirigente campesino y el párroco. Como se anotó, el profesor-locutor encaraba un discurso abierto a la interacción, en la medida en que se volvía un miembro más de la familia campesina. A su vez, el auxiliar inmediato cumplía la crucial tarea de hablarles y ayudar a sus propios pares, ya que

El principio era tan sencillo como contundente: resultaba más eficaz un campesino que educa otro campesino, a que cualquiera otra persona le viniera a decir lo que tenía qué hacer. Todo esto fue posible gracias a la educación y formación (...) a través de la escuela radiofónica, que contaba con un auxiliar inmediato, cuya tarea central era animar al grupo para su aprendizaje (Pérez ,2013, 17)

-Reuniones entre el auxiliar inmediato, el dirigente campesino y el párroco: Estos encuentros fueron muy importantes dentro de los propósitos educativos de ACPO, porque de 
allí se obtenía parte de la retroalimentación, necesaria para nutrir el proceso de comunicación, al hacerse una evaluación detallada sobre la forma como funcionaba la Escuela Radiofónica, en cuanto a la dinámica de las clases (formas y contenidos) y la calidad sonora de las emisiones, entre otros aspectos (Vaca, 2011)

-Las cartas: La activa correspondencia entre ACPO y sus oyentes fue uno de los principales instrumentos de interacción. Se puede afirmar, que , en buena medida, allí, y en el auxiliar inmediato, estuvo la médula de su estrategia comunicativa. Como lo explica Bernal Alarcón, cada día se recibían más de cien cartas, la mayoría de ellas referidas a inquietudes sobre los cursos, las cuales "debían ser respondidas personalmente a cada uno de los interesados". (2005)

Pero no se trataba solo de recibirlas y de contestarlas, pues constituyeron la base para todo un "banco de información" que les permitió a los realizadores de las Escuelas Radiofónicas ir adaptando sus discursos a las necesidades de los estudiantes.

Para ACPO esta correspondencia era uno de los elementos más importantes de retroalimentación de su sistema de comunicación. Era una forma de superar la masificación propia de los medios de comunicación, y de crear una relación interpersonal con su audiencia. Constituía una forma de monitoreo y control sobre los diferentes componentes del proceso educativo. (Ib, p. 17)

Tal y como ocurrió con las Escuelas Radiofónicas, ACPO le apuesta a lo que en ese entonces se llamaba combinación de medios, hoy denominada "convergencia de medios". Se enuncian a continuación, a manera de introducción, cómo se asumen y cómo se concretan las dinámicas y las lógicas de participación en las EDC, tema que será profundizado en el Capítulo IV:

-Plataforma Escuelas Digitales Campesinas: Además de ofrecer al acceso a los cursos y a los diferentes programas de radio, televisión y el campesino.co. permite la consulta de los libros publicados por la editorial Andes. Así mismo, facilita la interacción con los estudiantes, mediante la publicación de sus cartas, avisos clasificados, ferias y fiestas, turismo, recreación y deportes, al tiempo que les brinda información adicional sobre “innovación para la finca” y "prevención de riesgos". En cuanto a su enfoque educativo se refiere, "está basada en pedagogías propias de la educación no formal virtual rural". Le apuesta a hacer un uso óptimo de las TIC, “con el propósito de fortalecer el capital humano, social y cultural del campesinado" 
-Periódico elcampesino.co: Como complemento de Radio Sutatenza, el periódico impreso El Campesino se convirtió en uno de los principales instrumentos de Acción Cultural Popular. Fue tan importante para la estrategia de ACPO, que llegó a ser el segundo periódico de mayor circulación nacional, después de El Tiempo. Ahora en su versión digital busca apoyar esta nueva etapa de la Educación Fundamental Integral. Además de publicar noticias relacionadas con la actividad agraria del país, le hace un permanente seguimiento a las actividades de las EDC, facilita la consulta de programas emblemáticos de la antigua Radio Sutatenza como "La huerta casera" y la retransmisión del programa radial "Mundo Rural". Ahora ha asumido el reto de formar a los campesinos, campesinas e integrantes de comunidades afrodescendientes e indígenas para que produzcan contenidos a publicarse en el periódico, mediante un curso especializado en comunicación y periodismo y la conformación de la Red de Reporteros Rurales (R3).

-Programa de radio Mundo Rural: Desde su fundación en 2013 ya se han realizado más de 200 emisiones. Producido y realizado por estudiantes y profesores del semillero de investigación "Radio y ciudadanía", de la Escuela de Ciencias de la Comunicación de la Universidad Sergio Arboleda, hace parte de la estrategia de convergencia de medios de ACPO. Como ocurre con elcampesino.co, tiene el propósito central de mantener informados a los educandos de las EDC sobre la actualidad agraria del país, con una perspectiva analítica y pedagógica. Así mismo, sirve de escenario para promover y visibilizar las diferentes manifestaciones culturales del campo, como la música, los mitos y leyendas y la gastronomía, y respaldar el trabajo de las EDC. También promueve la participación directa de los oyentes o co realizadores, quienes dan testimonio de viva voz sobre sus experiencias de aprendizaje, y sus visiones, tanto del país como de su propio territorio. Se emite en vivo y en directo los viernes, en el horario de 9 a 10 de la mañana, en la emisora online Radio Virtual, de la Universidad Sergio Arboleda y es retransmitido por 26 emisoras comunitarias en igual número de regiones del país.

-Estrategia televisiva: ACPO también usa sus diferentes plataformas multimedia para posicionar sus contenidos en el formato audiovisual. Además de dar cuenta del trabajo de las EDC, se han ubicado videos sobre el folclor campesino; el proyecto de cafés especiales en el Valle de Tenza y voces y testimonios de los campesinos y campesinas, quienes nos cuentan por qué y cómo, a pesar de la difícil realidad que se vive, han decidido mantener sus vidas y 
sus sueños en el campo.

Como puede advertirse, aunque la experiencia de las EDC es incipiente ya reporta resultados interesantes, tanto de orden cualitativo como cuantitativo: en menos de 4 años ya cuenta con cuarenta escuelas en igual número de municipios y 8 departamentos del país. (Ver anexo C)

No se puede desconocer que en esta nueva etapa ACPO ha debido enfrentar dificultades, entre las cuales se destacan: - Los problemas de conectividad, pues en algunas regiones como Guainía y Guaviare el índice es del 00.3\%; éstos se han afrontado mediante la difusión de los cursos en memorias USB, y -La falta de recursos económicos, los cuales se han suplido mediante alianzas estratégicas con instituciones educativas, centros culturales y puntos Vive Digital que maneja el Ministerio de Tecnologías de la Información y las Comunicaciones. En la misma dirección, puso en marcha la campaña Milagro, con la cual ha buscado sensibilizar a los colombianos para que hagan aportes monetarios encaminados a fortalecer su estrategia educativa.

Hay que esperar a ver cómo madura este proyecto que aún no ha cumplido 10 años desde su reaparición. Lo cierto es que Los desafíos son muy grandes y empiezan por: i) No repetir los errores del pasado, en especial "evitar cierta rigidez institucional”, derivada de la autoridad de su fundador que, según la investigación adelantada por el Instituto Alemán de Desarrollo, fue un factor que jugó en contra de los necesarios cambios "que implica el proceso de desarrollo acelerado". (Musto,1971, p.73); ii) ii) Entender que el mundo cambió y que, en el caso particular de Colombia, una de las grandes apuestas desde la comunicación está en permitir que los campesinos y campesinos sean ahora "relatores de su propia historia"; que eso que tantas veces han dicho en privado haga parte de sus propio o discursos, con sus propias palabras públicas, con todas las implicaciones que tiene para la construcción y reconstrucción de su propia identidad... ( Rodríguez, 2009) Y iii) Activar la interlocución pública que tanto se les ha negado a nuestros campesinos y campesinas -los mismos que han puesto el mayor número de víctimas en el conflicto armado- para que sean ellos mismos los voceros de sus propias necesidades, expectativas y sueños.

\subsection{ACPO y la EFI como estrategia de inclusión digital}

Hoy como ayer, la Educación Fundamental Integral (EFI) es el eje del trabajo de Acción Cultural Popular. ACPO tiene claro que sus esfuerzos se deben concentrar en la formación de la "ciudadanía rural”, que implica propiciar la inclusión digital, social, política 
y económica de las campesinas, campesinos, afrodescendientes e indígenas.

La integración o convergencia de medios sigue siendo medular, ahora mediante el buen uso y apropiación de las Tecnologías de la Información y la Comunicación, TIC, en las cuales están presentes la radio, con su programa "Mundo Rural", los cursos en versión radial, las cartillas didácticas, el podcast y el periódico elcampesino.co, que,como lo indicamos, ha regresado después de 22 años de ausencia.

Hoy la EFI incluye la plataforma denominada "Escuelas Digitales Campesinas, EDC" que busca ofrecerle al campesino formación, información y recursos democráticos, con cursos como lo de "alfabetización digital", "liderazgo", "conocimiento del medio", “emprendimiento y asociación", "paz y convivencia" y "comunicación y periodismo". Además, divulga información actualizada para explotar su finca (tiempo, riesgos, compras, oportunidades, convocatorias para conseguir recursos y medios para cultivar la tierra) Así mismo, le apuesta al fomento del turismo rural.

Kenny Lavacude Parra, director general de ACPO,(Pérez, 2016, audio podcast), reconoce que tanto él como su equipo de trabajo están desarrollando una tarea quijotesca que, destaca, ya ha empezado a dar sus frutos, con la presencia de las EDC en 59 municipios de 8 departamentos del país y más de 18.000 beneficiarios. Siete mil de ellos reciben los cursos a través de medios digitales y los demás por medio de la radio, memorias USB y podcast. En buena medida el éxito obtenido hasta el momento tiene que ver con la naturaleza informal de los cursos, que pueden ser tomados de manera libre por campesinos, pueblos indígenas e integrantes de otras etnias. Un balance preliminar hecho por ACPO indica que el rango de edades de quienes se han beneficiado con esta nueva etapa de la Educación Fundamental Integral está entre los 14 y los 82 años, la mayoría entre 16 y 35 años. Se trata, en general de personas que viven cerca de los cascos urbanos, excepto los que toman los cursos mediante la convergencia de medios, que son pobladores rurales dispersos. Son personas en condición de pobreza, que pertenecen al estrato uno y al Sisbén 2 y 3. (El Sisbén es un sistema de beneficios administrado por el Estado colombiano, y permite identificar la población que está en situación de pobreza y de vulnerabilidad, para focalizar inversiones sociales. En teoría, debe cobijar a las personas más pobres).

La mayoría de ellas tienen estudios de primaria; menos del 15\% ya terminó el bachillerato y un grupo muy pequeño ha cursado carreras técnicas o universitarias. Otro aspecto clave a tener en cuenta es que entre los estudiantes el $55 \%$ corresponde a mujeres que, como lo subraya Lavacude, son las que jalonan al resto del grupo, a sus maridos, a sus hijos y a otros miembros de la familia. Así mismo, para ACPO es fundamental tener en 
cuenta la gran diversidad sociocultural de Colombia. Por ello, aunque se ofrezcan los mismos cursos, no se desarrollan con idénticos contenidos, por ejemplo, en La Guajira o en el Caquetá, porque son los mismos educandos quienes ofrecen valiosísima información sobre su propio entorno. "Esa riqueza ha hecho que la propuesta de las EDC sea más original, más inclusiva y, por lo tanto, con mayor impacto y acogida en las regiones colombianas, porque valoramos la diferencia", dice Lavacude. (Pérez, 2016, audio podcast)

\subsubsection{El campo cuenta}

Contar y ser contado resulta de particular importancia en el contexto actual de Colombia, que incluye la firma de acuerdos de paz con las FARC, la guerrilla más antigua de América Latina. Es un tema clave, dentro del propósito de construir memoria y hacer aportes concretos para la necesaria reparación simbólica, en un país que ha soportado más de 60 años de guerra.

Esta es una tarea que asumió ACPO aun antes de su fundación en 1947 y hoy sigue siendo medular en la era de las TIC. Por eso muchos de los cursos son reelaborados por los propios estudiantes de las EDC, en función no solo de lo que pasa sino de la manera como ellos perciben y asumen su propia realidad. Por ejemplo, una mirada a la primera unidad del curso sobre "conocimiento del medio" nos permite advertir que hay una sección recurrente denominada "manos a la obra", en una de cuyas actividades se les propone a los estudiantes: “Observe con detenimiento su vereda...Con sus propias palabras y de acuerdo a los conocimientos adquiridos en esta sección, describa en las líneas dispuestas a continuación las principales características de la tierra, el aire y el agua de su vereda"...

Algo similar ocurre en el programa de radio "Mundo Rural", donde los propios campesinos-estudiantes de las EDC han narrado historias como estas:

Juliana Ortiz (Pérez, 2016, audio podcast) estudiante de las EDC en San Vicente del Caguán, Caquetá. (Uno de los municipios que hizo parte de la zona de distensión, en el marco de los diálogos de paz entre el gobierno de Andrés Pastrana y la guerrilla de las FARC, entre enero de 1999 y febrero de 2002)

Tengo 17 años y vivo en San Vicente del Caguán. Mi familia es netamente campesina. Somos mi papá, mi mamá y cuatro hermanos, y yo he buscado que ellos también aprendan mucho.

Con los conocimientos que he adquirido yo les he ido explicando. Creo que las 
Escuelas Digitales son una alternativa para mejorar el campo, para mejorar la producción y colaborar con el medio ambiente y con el crecimiento del país.

Hasta el momento he adelantado tres cursos de las Escuelas. He adquirido muchos conocimientos y he aclarado dudas. He aprendido palabras técnicas y muchas cosas sobre el campo, y otras herramientas que ofrecen los cursos. Aprendí las formas que se pueden usar para manejar un grupo, como ir a la comunidad y buscar su bien; es decir, cómo trabajar con todos y en conjunto. Por ejemplo, tuve una experiencia muy bonita, que fue llevar asesoría técnica. Y fue un total éxito. Hubo total aceptación, la gente mostró interés, como que les gustó el tema. Ahí descubrí que puedo ser líder.

Para mí el el cambio ha sido drástico y súper bueno, porque en la medida en que yo aprendo, les puedo transmitir a las personas de mi comunidad, de mi región. Enseñarles de manera estratégica a tener el amor por el campo y a cambiar la manera de pensar...Nosotros somos estratégicos. Cada persona, cuando termina el oficio, pasa a colaborarles a los otros grupos que aún no han terminado. Manejamos mucho lo que es la amistad, la comprensión y la colaboración... Somos una familia estudiantil y de esa manera nos colaboramos todos. Las jornadas de trabajo las hacemos cada 15 días. Hacemos actividades que generen impacto social, que es el objetivo principal de la institución. Y contamos con el acompañamiento de un profesor del área de suelos agrícolas y ecología amazónica. Destinamos todo el día; y nos dividimos en grupos. Cada uno responde por las actividades que se le dejan.

Algo de lo que he llamado la atención es ver que a los campesinos sí se les puede tener en cuenta en un proceso de paz. Sí se puede, porque querer es poder. ¿Y qué hago con eso que he aprendido? Hablar de la paz y aprender a usar el diálogo para arreglar las diferencias que existen en la comunidad. Así lo hacemos en todos los grupos, como en las juntas en las que nos reunimos.

Sacramento Soriano (Pérez, 2016, audio podcast) campesina de Manta (Cundinamarca, en el centro de Colombia)

Yo me vinculé a las escuelas el año pasado...Estoy terminando el curso de alfabetización. Es muy bueno porque el horario es flexible. Ya pronto empieza otro grupo... Estamos interesados en que esto llegue a todos los hogares.

Creo que tengo el compromiso de invitar a los demás a que aprendan en las Escuelas. Les digo que no es muy difícil; la gente se anima cuando conoce la dinámica, y cuando saben que otros han podido. 
En mi caso, no me asusté, porque ya sabía algo de computadores. Me matriculé de una. El curso es muy fácil...

Yo quiero ser líder para colaborarles a otras personas a que aprendan. Yo soy pensionada, discapacitada, pues desde hace tres años casi no puedo mover las manos.

Pero además de estar en las Escuelas Digitales estoy terminando el bachillerato y quiero hacer trabajo social. Los cursos me entretienen...

...La idea es que aprendan a manejar el computador; yo les enseño a abrir el correo y la forma de acceder a los cursos.

Empezamos doce y quedamos ocho y ya algunos otros terminaron. Otros están empezando...

Al verme a mí, el resto de mi familia se ha entusiasmado. Mi hija ya tiene el diploma...Estamos interesados en aprender.

Esta experiencia me ha cambiado la vida, porque ahora tengo una forma de pensar diferente; soy positiva y tengo metas, como enseñarles a otros...

(Ver más entrevistas en el anexo

Como se puede notar en estos relatos, es claro que la palabra inclusión va mucho más allá de un lema, para entenderse y asumirse como un concepto transversal e integral. Entonces para la Educación Fundamental Integral no es suficiente con emitir y recibir información sino, además, que esa información se convierta en una oportunidad de desarrollo social y personal. Para Lavacude (Pérez, 2016, audio podcast), inclusión digital significa que las personas del campo, que siempre han estado más relegadas que las personas de la ciudad, en cuanto a las Tecnologías de la Información y la Comunicación se refiere, puedan aprender a usarlas y servirse de ellas para su propio desarrollo. En esa misma dirección, ACPO diseñó y puso en marcha un semillero periodístico que ya hace parte integral de las Escuelas Digitales Campesinas, entendido como un espacio de formación para no expertos, cuyo propósito fundamental consiste en promover la participación de los estudiantes de las EDC en los medios de ACPO, "dando así voz a las comunidades rurales, y permitir el goce de derechos esenciales para la ciudadanía rural”. (ACPO, 2016) De allí nació la Red de Reporteros Rurales (R3) para que ellos mismos redacten sus noticias, crónicas, reportajes, poemas o cuentos, que son publicados en el periódico El Campesino y en el programa de 
radio Mundo Rural. Son, entonces, ejercicios concretos para que las campesinas y campesinos e integrantes de comunidades indígenas y afrodescendientes sean relatores de su propia historia. ACPO les brinda los medios, ellos ponen el talento, la creatividad y, como lo dijera el cronista colombiano Juan José Hoyos, "la pasión de contar" (2010)...Es la historia que apenas ellas y ellos mismos empiezan a contar en la otrora Radio Sutatenza, hoy Escuelas Digitales Campesinas, en la era de las TIC. 
Radio Sutatenza y Acción Cultural Popular en la era digital 


\title{
Capítulo IV \\ Nuevas ciudadanías: \\ De audiencias pasivas a prosumidores
}

\begin{abstract}
"No solo los humanos, sino los pueblos, las naciones, el mundo, tienen un verano invencible dentro, que puede acabar con cualquier invierno si le damos la oportunidad y asumimos el riesgo".
\end{abstract}

Isabel Allende 


\subsection{Sumario}

Haremos a continuación reflexiones y propuestas encaminadas a fortalecer el proceso de construcción de las nuevas ciudadanías en las EDC que, desde la comunicación y el periodismo se expresan en tareas y ejercicios concretos del prosumidor. Buscamos establecer la manera como nuestros sujetos de investigación asumen en la práctica esa categoría, para ver las implicaciones que tiene la dimensión ética y el mundo de la vida en la construcción de sentido, y contribuir a la comprensión sobre lo que significa hoy "ser campesino" e identificar por qué desde ACPO se ha preferido la denominación "habitante rural". Es, entonces, un análisis colectivo enfocado hacia la indagación, alrededor de las siguientes preguntas: ¿De qué manera las campesinas, los campesinos e integrantes de comunidades indígenas y afrodescendientes se involucran o se pueden involucrar en las que denominamos “constelaciones de sentido y de significados? ¿Y ahora, como productores activos, qué significa para ellas y para ellos su ingreso a las plataformas digitales? ¿Cómo perciben ellos mismos su propio proceso? ¿Cómo se reconocen como actores en las Escuelas Digitales Campesinas? ¿Cómo se activa el diálogo y cómo se da ese diálogo en las EDC? ¿Cómo se vive el aprendizaje colaborativo entre los estudiantes, entre ellos y los facilitadores y entre la comunidad de las EDC con el resto de la sociedad? ¿Cómo participan de la deliberación pública?

\subsection{Introducción}

Como hemos indicado desde el primer capítulo, la propuesta de Comunicación/Educación formulada por ACPO desde su nacimiento en 1947 estuvo marcada por grandes tensiones, muchas de ellas insalvables en su oportunidad, hasta el punto de llevar a su declive y suspensión de actividades administrativas, entre 1989 y 1994, las cuales se reanudaron en 2012 con su propuesta de Escuelas Digitales Campesinas.

En el marco de las disputas, algunas históricas asociadas al control político y económico de la que llegó a ser la cadena radial más potente de América Latina, y otras a diversas matrices de análisis desde el mundo académico, se ha llegado considerar por algunos la Educación Fundamental Integral ( EFI) como uno de los tantos instrumentos que se usaron para imponer las políticas de "desarrollo" dictadas desde el norte, en el marco del "Plan Marshall”, según el cual hasta el modelo de desarrollo debía ser importado. Tanto es 
así, que hay quienes han querido ubicar la estrategia de ACPO en el marco de un trato y un tratamiento a los campesinos y campesinas como objetos de la comunicación, pues, según sostienen, los saberes impartidos por las Escuelas Radiofónicas "se trajeron de afuera y se impusieron, utilizando maneras formativas e innovadoras para la época como la radio". (Mora, 2014, p. 4)

Otros no compartimos dicha tesis o postulado, pues al evaluar en detalle la forma como operaban las Escuelas Radiofónicas, vemos que si bien en algunos casos los cursos impartidos ya estaban listos y había que "aprenderlos", ello no correspondía a la actitud deliberada de ACPO, sino al mismo contexto sociopolítico que fue dejando sus lecciones y aprendizajes paralelos. Ahora bien, si asumiéramos que las campesinas y campesinos fueron tratados como "objetos de comunicación", es necesario también preguntarnos si ellas y ellos se comportaron como tales. Si la respuesta fuera positiva, ello equivaldría a afirmar que los receptores no cumplen ningún papel en el proceso y, entonces, sería imposible hablar de comunicación desde una perspectiva culturalista. Así mismo, esa postura nos llevaría a sostener que los actores de las Escuelas Radiofónicas, o no pueden o no han podido acceder a lo que autores como Wolton (2010) denominan "incomunicación”, que ocurre cuando quien ve, oye o lee un mensaje decide o no escucharlo o desecharlo porque, o no lo interpela o no le interesa. Claro, nuestra postura no implica desconocer que el modelo de ACPO tuvo fallas, como ocurrió, en general, en América Latina con los flujos de comunicación.

En esa dirección, en cuanto al derecho a la comunicación se refiere, se puede argumentar que del dicho al hecho hay mucho trecho porque, en la práctica, ni las autoridades mundiales ni los gobiernos locales se han caracterizado por defenderlo, pero, nos preguntamos: ¿Esa, también, ha sido la actitud de los actores de las Escuelas Radiofónicas y ahora de las Escuelas Digitales Campesinas? Es decir: ¿ Han asumido una actitud pasiva y, en consecuencia, han renunciado a defender su derecho fundamental a comunicarse y, por lo tanto, a ejercer como prosumidores? Cabe preguntarse también si es viable aplicar en el marco de la Educación Fundamental Integral (EFI) algunos de los postulados de la democracia radical propuesta por Chantal Mouffe y Ernesto Laclau y del humanismo cívico, otra corriente de la filosofía política según la cual "el ciudadano es el sujeto radical de la política". Para centrar aún más la discusión en el contexto de las Escuelas Digitales Campesinas, y establecer más adelante (Capítulo V) cómo se da allí la producción de sentido, haremos referencia a lo que los actores de este proyecto de Comunicación/Educación 
entienden por ser campesino. Así, las reflexiones que se harán a continuación girarán alrededor de las anteriores y de las siguientes preguntas fundamentales:

¿Cómo se pueden construir las nuevas ciudadanías desde la comunicación y el periodismo? ¿Cómo se asume la categoría “ciudadanías”en las EDC?

¿De qué manera el mundo de la vida se pone al servicio de esa construcción de sentido? ¿En qué consiste y cuál es el impacto que tiene la dimensión ética en la construcción de sentido?

¿Qué significa ser campesino en las EDC?

\subsection{Democracia radical y nuevas ciudadanías}

Desde una perspectiva eminentemente política, el recorrido propuesto para esta investigación se inscribe en lo que Chantal Mouffe y Ernesto Laclau identifican como "democracia radical", un proyecto que le apuesta a la promoción y al ejercicio pleno de los ideales ilustrados de justicia distributiva, economía solidaria, libertad política y equidad cultural. (Tubino, 2006) Así mismo, nos apoyamos en los postulados del humanismo cívico, según los cuales el ciudadano debe ser el sujeto radical de la política.

Lo que se pretende en el marco de las EDC es incluir a las campesinas, campesinos, comunidades negras y comunidades indígenas en la era digital. En otras palabras, se busca que esos actores de la vida colombiana tengan también la capacidad de nominación, pues , como lo dijera Boaventura de Sousa Santos $(2009$, p.12) "no puede haber justicia social sin justicia cognitiva".

Desde esas miradas podemos indicar que según la propuesta de ACPO, aunque es un paso muy importante, no es suficiente con que la población campesina acceda a las TIC como simple consumidora de contenidos, pues resulta fundamental su participación como productora de mensajes, en medios como El Campesino.co y el programa de radio Mundo Rural. De ahí que entre los cursos ofrecidos esté el denominado "Comunidad, comunicación y periodismo", pues se considera de gran importancia para esta comunidad aprender a deliberar, un ejercicio que, según Norberto Bobbio, permite entender la democracia como un "poder visible", en la medida en que propicia la crítica libre, en el marco del derecho fundamental de expresión. (1986, p. 80)

Y como se observó en el capítulo I, desde el humanismo cívico se propone afrontar de manera práctica, en el ejercicio ciudadano del día a día, el llamado "tecnosistema", es decir, "los tres ejes de dominación" que tienden a bloquear las iniciativas ciudadanas desde el 
Estado, el mercado y los medios tradicionales de información.

Tanto la democracia radical como el humanismo cívico son perspectivas desde las que se propone corregir o, por lo menos, afrontar errores históricos de tal calado que hoy le siguen pasando grandes cuentas de cobro a nuestras sociedades. Fue lo que pasó en Colombia, por ejemplo, con el Frente Nacional. (Ver capítulo III). Más allá de lo puramente jurídico, ese pacto entre liberales y conservadores quiso imponer una mentalidad política que se puede calificar de perversa, porque, como se dijo, buscó invalidar otras formas de pensamiento. Ello se ha traducido en que, aún hoy, toda ideología divergente o emergente sea vista como "sospechosa" de estar aliada con el "narcoterrorismo" a tal punto que Luis Eduardo Garzón, quien fuera presidente de la Central Unitaria de Trabajadores (CUT) alcalde de Bogotá y ministro de Trabajo, hizo célebre esta frase: "En Colombia es más complicado y difícil montar un sindicato que una guerrilla". (2000, p.1)

Se comprueba así que la dirigencia política colombiana en general — salvo algunas excepciones - ha sido incapaz de buscar fórmulas de entendimiento que propicien una deliberación pública entre adversarios para ponerle fin al enfrentamiento armado entre enemigos. Claro, no es, en realidad una incapacidad en sentido estricto, sino una apuesta deliberada por mantener un statu quo que les reporta los anhelados réditos electorales a sectores dominantes. Obedece al pragmatismo político que lleva a Mouffe a postular que "ninguna cantidad de diálogo o de prédica moral logrará persuadir jamás a la clase dirigente de que renuncie a su poder. (Ib., p. 31)

Por eso la invitación es a luchar en el terreno práctico, es decir, con acciones simbólicas concretas, que pasan por ejercer la palabra pública, para participar de manera activa de la disputa por la construcción del sentido. Y en estas latitudes se ha demostrado que, a pesar de los obstáculos, es posible incidir en la vida pública. Para la muestra están los siguientes ejemplos:

A)La Constitución de 1886 fue modificada por una Asamblea Constituyente, gracias, entre otros hechos, a la presión ejercida por un grupo de universitarios que propuso la famosa "Séptima papeleta". Para el 11 de marzo de 1990 habían sido convocadas elecciones para decidir quiénes serían nuestros representantes en el Senado, la Cámara, asambleas departamentales y concejos municipales. Así mismo, serían escogidos nuevos alcaldes y, de manera simultánea, se haría una consulta del partido Liberal. La séptima papeleta propuesta por los universitarios diría: "Voto por Colombia. Sí a una Asamblea Constituyente". A pesar de la respuesta favorable de buena parte de la sociedad colombiana, el asunto se enredó porque no faltó quienes dijeran que esa iniciativa no tenía ningún sustento jurídico. Como la 
Registraduría se negó a imprimir el respectivo material, los estudiantes insistieron en que era sano que el pueblo se pronunciara en las urnas y, en respuesta, varios periódicos de circulación nacional imprimieron el texto mencionado, que los ciudadanos recortaron e introdujeron en las urnas. Lo que pasó en la práctica fue que, al parecer por razones de orden logístico, no se pudieron contabilizar todos los votos, pero ya se había provocado un gran golpe de opinión que el gobierno de entonces, liderado por Virgilio Barco Vargas, o no quiso o no pudo desconocer. El efecto práctico consistió en que el ejecutivo dictó el decreto 927 del 3 de mayo, con el cual le ordenó a la organización electoral contabilizar los votos que se depositaran en las elecciones presidenciales del 27 de mayo frente a la convocatoria de la constituyente. El resultado electoral fue contundente: 5' 236.863 en favor y 230.080 en contra.

Otro caso que tuvo un impacto decisivo en la vida pública del país lo protagonizaron también estudiantes, en esa oportunidad de universidades públicas agrupados en la Mesa Amplia Nacional Estudiantil (MANE) quienes en 2011 se opusieron a una reforma a la educación superior anunciada por el gobierno del presidente Juan Manuel Santos. Según el movimiento, lo que pretendía la administración Santos era profundizar el modelo privatizador de la educación. Como el gobierno se negó a escucharlos, los estudiantes protagonizaron una serie de manifestaciones públicas, ejercieron un gran activismo en las redes sociales y se declararon en paro indefinido. Y cuando alistaban otra gran marcha nacional y la "toma pacífica de Bogotá", el propio primer mandatario anunció el retiro del proyecto de ley.

B)Otro ejemplo que no puede faltar en el que, por razones obvias profundizaremos más, fue protagonizado por campesinas y campesinos durante el paro agrario nacional de 2013, que marcó un precedente en la historia reciente de Colombia, a juzgar por la unidad demostrada y por los resultados obtenidos. La movilización se inició el 19 de agosto y concluyó 20 días después, mediante la firma de acuerdos puntuales en materias como el aumento de \$1 billón en el presupuesto para inversiones en el sector agropecuario; la eliminación de algunos aranceles para importar agroquímicos; restricción a las importaciones de productos básicos, como arveja, tomate y leche en polvo y subsidios para quienes se comprometieron con la política de sustitución de cultivos ilícitos en el Catatumbo (Norte de Santander) una región muy afectada por el conflicto armado. Lo interesante de esta movilización estuvo, entre otros aspectos, en un eficaz ejercicio de comunicación mediante el cual los ciudadanos lograron oponerse con éxito al desplegado por la “institucionalidad" que representaba entonces el presidente Santos, cuyo fin era desprestigiar 
la protesta social. Como lo indica el sociólogo Medófilo Medina (2013), los medios tradicionales se apoyaron en la construcción de una matriz basada en el reduccionismo: "ruanas vs. capucha", con el claro propósito de señalar que el paro estaba "infiltrado" por la guerrilla, y sentenciar que "el país estaría situado ante la disyuntiva: vandalismo o autoridad, anarquía o acción militar” (Ib. p. 7), a fin de ocultar el telón de fondo: el abandono del campo y los síntomas de polarización política que vivió, y aún vive el país, entonces en tiempos de conversaciones en La Habana y hoy en el marco del posacuerdo con las FARC. Como lo dice, el propio Medina, claramente es preciso afirmar que la contradicción central que hoy vive el país está entre quienes quieren abrirle paso a la paz, y con ella a una auténtica modernidad democrática, y quienes quisieran prolongar la guerra sin término.

¿Y cómo respondieron los campesinos movilizados a los intentos de desprestigio? Con autenticidad y con humildad, otros de sus rasgos característicos, pues en no en pocas ocasiones pudimos verlos en televisión contestar con una sonora carcajada a la pregunta sobre esa supuesta infiltración de las FARC. Como nunca antes, gracias también al contexto mediático del que hoy hacen parte las TIC, que los campesinos también han venido aprendiendo a utilizar, supieron ampliar la convocatoria para sumar más y más colombianos a su causa. Y es que , como se puede ver en el video resumen, "los dirigentes colombianos se encuentran frente a una ciudadanía menos maleable, con más poder y decisión para autoconvocarse”. (Jiménez, 2013). Fue así como se evidenció un gran activismo de los jóvenes, algunos habitantes del campo y otros simpatizantes de los campesinos, tanto en las marchas como en las redes sociales, especialmente en Facebook, con mensajes como estos: “Compañeros: usemos las redes sociales, porque Radio Casa de Nariño no nos va a ayudar. Cada uno convoquemos por Facebook, a diez a veinte o más personas para mañana a las diez". (Tengamos en cuenta que en este contexto usaron la denominación Radio Casa de Nariño como un parónimo de Radio Cadena Nacional, RCN, uno de los dos canales privados de cobertura nacional e internacional)

Así mismo, la música típica jugó un papel importante con la utilización de canciones como "El campesino embejucao" ( que quiere decir, enojado) y "La cucharita", que hicieron célebre en el mundo el cantautor campesino Jorge Velosa y "Los carrangueros de Ráquira", con su presentación en el Madison Square Garden de Nueva york en 1981, una de cuyas estrofas dice: "La cucharita se me perdió, la cucharita se me perdió". Y los manifestantes la parodiaron así: "La cucharita se me perdió, la cucharita se me perdió, porque el gobierno me la robó". A ello le añadieron la presentación de bailes típicos, especialmente a cargo de los jóvenes, durante las mismas manifestaciones de protesta. Y ante la insistencia de las 
autoridades en señalar la "infiltración del paro", también apelaron a la solidaridad de la fuerza pública con mensajes como este: “Amigo soldado, usted es colombiano". En la medida en que la protesta fue avanzando sin solución aparente a la vista, buscaron y obtuvieron, además, mensajes de solidaridad de colombianos residentes en otros países, entre ellos Chile, Brasil, Emiratos Árabes Unidos, Australia, Bélgica, Portugal y Holanda, los cuales fueron divulgados en redes sociales. Así, lograron que más y más colombianos asumieran la validez de sus reclamos. A ello habría que sumarle, claro, el papayazo (que en Colombia quiere decir dar oportunidad para la burla) que dio el propio presidente, Juan Manuel Santos, cuando declaró , en pleno fragor del conflicto: "El tal paro agrario nacional no existe", cuyas reacciones de indignación, ya no solo de las campesinas y campesinos, sino aun de los citadinos, se volvieron virales. Dos días después de esta "metida de pata", que, como se indicó, contribuyó a inclinar la balanza de la opinión en favor de los campesinos, una comisión del gobierno, liderada por el entonces Vicepresidente, Angelino Garzón, se sentó a la mesa de conversaciones con los líderes del movimiento, hasta lograr un acuerdo final el 8 de septiembre.

Son hechos específicos que confirman que sí hay opciones para el ejercicio ciudadano, pero, casi siempre ocurre por los márgenes, o por excepción, pues marcados hechos de corrupción, como los denunciados casos de sobornos protagonizados por la multinacional Odebrecht o los sobrecostos de la Refinería de Cartagena — tasados por la Contraloría General de la República en $\$ 17$ billones, es decir, más de US\$4.000 millonesy la opinión generalizada en contra de la actividad política, que se suele identificar con lo torcido o clientelista, se traducen en un vaciamiento de sentido de lo político, una de cuyas expresiones más palpables es la apatía, reflejada en el abstencionismo electoral, que en el caso del famoso plebiscito por la paz realizado en octubre de 2016 alcanzó el 62.6\%, el más alto de los últimos 22 años.

Ante ese estado de cosas ¿qué sentido tendrían los postulados de la democracia radical y del humanismo cívico? Ómar Rincón propone: "necesitamos unas ciudadanías `más divertidas', 'más cotidianas' para construir la 'enunciación colectiva del mensaje'; una comunicación pública en la que la sociedad se reconozca y se confronte para crear un nuevo estatuto para la democracia". (2007, p. 7). Una, precisamente, que no niegue al diferente, que no demonice la diversidad, sino que la vea como una gran riqueza para construir otros mundos posibles. Y que asuma los conflictos desde su enorme potencial de contribuir al desarrollo de las sociedades, es decir, como una oportunidad de crecimiento, no como una amenaza, siempre y cuando se aprenda a gestionarlos, no a soslayarlos o a negarlos, como se 
ha hecho durante tantos años.

Esos postulados hacen parte del proyecto de la democracia radical, que, como lo indica Chantal Mouffe, le apuntan a transformar el antagonismo en agonismo, al "entender que no hay una sino muchas maneras de pensar, sentir y convivir y que, por lo mismo, no hay una sino muchas maneras válidas de entender los derechos humanos y de ejercer la ciudadanía”. (Tubino, 2006 p. 127)

\subsection{Comunicación y periodismo en clave de democracia radical}

$\mathrm{Si}$ "la democracia necesita otra forma de hablar". O, en palabras de Mouffe, "hay que democratizar la democracia”, es válido preguntarse para esa tarea, cuál es el papel que pueden jugar la comunicación y el periodismo. En este apartado, buscaremos algunas respuestas.

Como quedó enunciado arriba, una de las opciones planteadas está en retomar una clave muchas veces mencionada pero pocas veces aplicada con efectividad: aprender a deliberar.

Desde hace varios años hemos insistido, de la mano de autores como José Ignacio López Vigil, que la palabra pública ciudadaniza. Y, claro, no es cualquier tipo de palabra, sino a aquella emitida con sentido de la ética ( "una ética de mínimos"), de la responsabilidad y de la construcción social. De ahí que, más que emitir mensajes, sea necesario "aprender a hablar...Porque nos colonizaron la palabra" ( López, 2015, p.130)

Siguiendo a Mouffe, la democracia agonística identifica la esfera pública con espacios conflictivos de deliberación caracterizados por hacer evidentes la pluralidad y la diversidad. Pero no se trata, según esta propuesta, de quedarse en el conflicto, menos en el contexto colombiano, que ha convivido con él durante tantos años, sino de verlo "como punto de partida, pues el punto de llegada que anima la deliberación pública es el reconocimiento y la fecundación recíproca”. (Tubino, 2006, p. 4)

Es, sin duda, un proyecto ambicioso y necesario pese a que, para muchos, se podría quedar en otra de las tantas entelequias de los postulados democráticos pero, en fin de cuentas, parte de reconocer "la imposibilidad conceptual de una democracia en la que se materialicen la justicia y la armonía”. (Ib.). Así lo reconoce también el humanismo cívico, al señalar al "tecnosistema" como el responsable de bloquear las iniciativas ciudadanas.

Lo primero sea subrayar que la dificultad de hacer tangible el concepto de opinión pública, plantea un reto capital: garantizar desde nuestra posición, ya sea de comunicadores sociales-periodistas o de ciudadanos en ejercicio, que la opinión se alimente de una 
información respaldada en el rigor, la confrontación y contrastación de fuentes, el análisis, la organización y la interpretación honesta, pero, sobre todo, de la validez y reconocimiento de la opinión ciudadana. Así se entiende el protagonismo del propio ciudadano como sujeto radical de la vida política.

Ya desde la Ilustración filósofos como Locke y Kant, sostenían que el conocimiento procede solo de la experiencia y la observación guiadas por la razón. Esa vía era, según ellos, la más indicada para quien quiera pensar por sí mismo y salir de su minoría de edad intelectual.

Así las cosas, en palabras de Kant, se parte de la base de comprender que con una educación apropiada, la humanidad podía - y puede ser modificada — “cambiada su naturaleza para mejorar". No obstante, conviene advertir que la misma Mouffe, en sus estudios con Ernesto Laclau, ha señalado al racionalismo como una de las corrientes responsables de haber negado o desconocido el antagonismo de lo político, lo que, según ella,"ha tenido consecuencias muy serias para la política democrática". (P.28).

En todo caso, rescatamos de allí la necesidad de recuperar la dimensión educativa de la comunicación, en la medida en que esta última busca construir y circular sentidos entre diversos actores sociales en un contexto determinado. Se entiende aquí la comunicación "como un proceso; no una acción sino un conjunto de acciones en las que se ven comprometidos varios individuos que se relacionan entre sí y continuamente producen modificaciones producto de sus interacciones". (Rocha, 2003, p.3).

Tal y como lo hiciera notar Paulo Freire, el proceso educativo se asume, en relación con los medios de comunicación, como una "práctica de transformación" en la que los receptores se educan a sí mismos en la medida en que se encuentran con la realidad de la cual participan ellos y otros sujetos. (Alfaro, 2000).

Estos postulados se han enriquecido con reflexiones, teorías y prácticas de la comunicación desde la cultura. En palabras del profesor Martín-Barbero, se entiende, así, la comunicación a la vez como proceso social y como "campo de batalla cultural". (2003).

Son enfoques que ponen el énfasis en la persona humana como ser pensante, activo y proactivo, capaz de ir más allá de su papel como simple consumidor y pasar, incluso, a ser productor de contenidos o prosumidor, como lo propusieron Marshall Mcluhan y Barrintong Nevitt en 1972, concepto ratificado por Alvin Toffler en 1980. (Islas, 2008)

A la vez son formas prácticas de ciudadanías, llamadas a profundizarse con "los nuevos ambientes comunicativos que introducen las comunicaciones digitales móviles, estimulan la creatividad y la autonomía" (Ib, p.5) 
Desde una perspectiva puramente económica, los modelos tradicionales de comunicación y de periodismo, enmarcados en la separación tajante entre productores y consumidores, lo que han hecho es deshumanizar cada vez más el proceso, pues, como lo indica el economista chileno-alemán Manfred Max-Neef, esa mirada “ (...) lo que ha conseguido en la práctica es "destruir culturas para establecer economías" (...) El ejemplo está ahí, miren a Chile, miren el crecimiento, la economía está fantástica. Bueno, ¿y cómo está la gente? Pero de nuevo, ese es problema de la gente, no de la economía”. (1997, p. 101)

Algo similar ocurre con el caso mexicano, que se ha pretendido mostrar como modelo de las bondades de los tratados de libre comercio. El argumento que se esgrimía era el "impresionante" repunte que tuvo la inversión extranjera aparejado del crecimiento sostenido de la economía... Esa, en realidad, es una verdad a medias que esconde los negativos efectos del NAFTA sobre los ingresos y, por consiguiente, sobre el poder adquisitivo del grueso de la población. Chomsky (2002) reveló dos estudios sobre el impacto del NAFTA, realizados, uno por Human Rigths Watch y otro por el Instituto de Política Económica de Washington,

(...) ocultados tanto por el gobierno de Estados Unidos como por los medios comerciales de comunicación, los cuales confirman que tras la entrada en vigor del Tratado, los ingresos de los trabajadores asalariados cayeron un $24 \%$, mientras para los independientes tuvieron una disminución del $40 \%$ y el salario mínimo perdió el $50 \%$ de su poder adquisitivo (...)La actividad industrial disminuyó y el desarrollo se estancó o pudo haber retrocedido. Un pequeño sector se hizo extremadamente rico y los inversores extranjeros prosperaron. (Chomsky, 2002, p. 138)

Son razones de peso para plantear la necesidad de apelar al interjuego entre ciencia y sabiduría y enriquecer el ejercicio democrático de los pesos y contrapesos, en el que la comunicación, más allá de la información, juega un papel esencial. Se trata de profundizar el modelo inmerso en la Educación Fundamental Integral que, como hemos visto, apela al protagonismo del educando como motor de su propio desarrollo individual y social, en oposición a lo que Walter Lippman, periodista y teórico de la opinión pública y de la democracia de comienzos del siglo XX, considerado el padre de la teoría de la fabricación del consenso, señalaba como la tarea de una clase especializada, de "sabios" de la sociedad que tiene como misión central orientar al "rebaño desconcertado".(Chomsky, 2002)

La teoría es sencilla y, en apariencia, inobjetable: como la inmensa mayoría de los ciudadanos no se interesa porque no sabe cómo, porque no la dejan o porque no tiene tiempo 
para interesarse en los asuntos públicos, hay otros, casi siempre aquellos que tienen columnas de opinión o que son consultados por los periodistas como "fuentes autorizadas", (léase políticos de carrera, en especial los expresidentes de la República a quienes los medios siguen llamando "presidentes"; dirigentes gremiales y tecnócratas) encargados de cumplir la tarea de pensar, proponer e, incluso, decidir, por los demás.

Como lo advierte Chomsky, se parte de la convicción —errónea pero conveniente para el propósito de mantener el statu quo - según la cual "la gente es demasiado estúpida para comprender las cosas".

\subsubsection{El papel del prosumidor en la era digital}

Como acabamos de apreciar, el ejercicio de la palabra pública cumple la tarea clave de oponerse al modelo tradicional para ciudadanizar, al asumirse la comunicación como un bien esencial e irrenunciable, que también se puede ver como un campo de tensiones, en el cual resulta fundamental el papel del prosumidor. Como lo señalamos, esta palabra fue sugerida primero por Marchall Maclujan y Barrington Nevit, al advertir que los seres humanos, gracias a los avances tecnológicos, podríamos cumplir las tareas de productores y consumidores de contenidos en forma simultánea. Según lo indica el investigador Octavio Islas ( 2010), fue Alvin Toffler quien acuñó la palabra como tal, en su libro "La tercera ola", publicado en 1981. Por supuesto, de ahí en adelante los usos y prácticas han permitido la evolución del concepto, asociado a los desarrollos de la web 2.0, que han propiciado y están propiciando nuevos ambientes mediáticos, dentro de los cuales se proyectan escenarios como la blogosfera (los blogs, como comunidad o red social), "propicios para el activismo de las redes de prosumidores, las cuales han denunciado, por ejemplo, las prácticas inescrupulosas de algunas marcas, cuyo comportamiento no precisamente corresponde con lo dispuesto en sus códigos de ética". ( Islas, p. 53)

$\mathrm{Y}$ es que uno de los avances más importantes que introdujo la web 2.0 es la facilidad para posicionar contenidos propios y para buscar todo tipo de información, según las particulares necesidades del prosumidor, lo que, según el ex director general de Google, Erich Schimidt, “(...) revierte en una emancipación sin igual del ser humano...Es la atribución de poder al individuo para que haga lo que considere mejor con la información que desee" (Friedman, 2005, p. 169)

Así lo entendemos y hemos buscado aplicarlo en esta tesis: El prosumidor es un realizador, un gestor y productor de contenidos, en pleno ejercicio de su derecho a comunicarse, para relacionarse, incidir, proponer y construir con los otros el mundo que 
quiere vivir. Y para lograrlo, sabe que debe prepararse, pues no es suficiente con publicar contenidos porque la batalla de fondo consiste en escuchar a los demás y en ganarse una escucha. Como lo plantea la Comunicación/Educación, de esa manera, el educando participa, tanto del proceso de resignificación de la escuela como del sentido mismo de la educación y, por consiguiente, se educa para la emisión y para la recepción, es decir, para la comunicación. (Valderrama, 2000, p. 9).

En ese marco se puede entender la vigencia que han recobrado conceptos como el de "guerrilla semiológica" y el de público como amenaza para la todopoderosa televisión, postulados por Umberto Eco y otros autores en las décadas de los 60 y los 70.

Desde entonces el semiólogo y escritor italiano, al lado de Paolo Fabbri, Pier Paolo Giglioli y otros, hicieron notar que

(...) lo que decían los mensajes intencionadamente no era necesariamente lo que el público leía en ellos. (...)la publicidad de un Jaguar despertaba el deseo de un espectador acomodado y sentimientos de frustración en un desheredado. En definitiva, el mensaje apunta a producir determinados efectos pero puede chocar con situaciones locales, con otras disposiciones psicológicas, deseos, miedos y producir efectos bumerán. (2004, p.1).

Fue, por ejemplo, lo que pasó en Colombia con el referendo propuesto por el primer gobierno de Álvaro Uribe y negado de manera rotunda en las urnas en el 2003. En esa oportunidad el propio presidente se jugó a fondo su propia imagen y prestigio personales, mediante una intensa campaña en los medios comerciales, con énfasis en la televisión. Su mensaje fue directo y contundente: "No apoyar el referendo sería respaldar la corrupción y la politiquería”. Sin embargo, los electores voltearon esa argumentación para decir: "Apoyar el referendo sería darle luz verde a nuestro propio empobrecimiento; y eso no nos conviene". La respuesta fue igual de contundente: de las 14 preguntas de referendo, solo pasó aquélla que autorizaba la muerte política de los corruptos. Por supuesto, este resultado no se dio por generación espontánea, pues fue reforzado por una intensa campaña de información voz a voz, paralela a los medios comerciales.

Es una demostración más de las grandes posibilidades y del enorme espacio que se abre para ejercer una comunicación que obre efectos transformadores en la sociedad, con el propósito de evitar "ser instrumento de los instrumentos". De esa manera se podrá cambiar la realidad creada por una pomposa y artificial "postmodernidad", para que, en palabras de Eduardo Galeano, "la gente no sea manejada por el automóvil; ni comprada por el 
supermercado; ni mirada por el televisor ni programada por el ordenador". (2011, archivo de video).

Para ello, las principales respuestas las tiene el propio individuo que quiere oficiar como ciudadano. Él es el llamado - como lo anota Castoriadis - a romper el nudo gordiano de la política que ha mantenido a la economía de mercado como un valor absoluto y dominante:

Es la gran mayoría de los seres humanos la que debe convencerse de que su vida tiene que cambiar radicalmente de orientación y sacar las consecuencias. Mientras que los seres humanos continúen poniendo por encima de todo la adquisición de un nuevo televisor en color para el próximo año, no habrá nada qué hacer. (1997, p. 5).

La idea, entonces, es aplicar una perspectiva individualista bien entendida que va de la mano del ejercicio de una comunicación llena de sentido. Estamos hablando, claro está, de la dimensión comunitaria del individualismo que, aunque parece un contrasentido, nos está invitando a entender que nuestros sueños y expectativas como individuos solo los podemos concretar con los otros. Ahí empiezan a cobrar gran importancia acciones como saber escuchar; trabajar en equipo; aprender a vivir el "ahora" proyectado al futuro y saber ejercer un liderazgo no excluyente, que bien podríamos llamar coliderazgo. Es en el terreno simbólico en el que compartimos el mundo de la vida materializado en "la fiesta del lenguaje", como la llamara Daniel Prieto Castillo (2000). Sí, ahí se está jugando, en buena medida, nuestro presente y nuestro futuro como ciudadanos en formación o en ejercicio.

Es, por lo demás, una apuesta encaminada a conseguir que el individuo se haga consciente de su propia realidad y tome cartas en el asunto para transformarla. Como lo dijera Gibson citado por Prieto, "en una experiencia de primera mano uno se hace consciente de algo, en tanto que en una de segunda mano uno es hecho consciente". (Ib, p. 32)

Y como quiera que es imposible para un ser humano tener siempre experiencias de primera mano, conviene advertir que cuando es otro el que participa o se informa por nosotros para luego dar cuenta de lo que pasó, se está frente a lo que el propio Gibson llama "percepción de sustitutos". Nótese, entonces, cómo en esa dimensión — que es la que gobierna la mayoría de nuestras actitudes y comportamientos- el riesgo de informarse de manera parcial o de participar de manera restringida es muy alto.

Si por lo menos somos conscientes de esa limitación, ya estaremos dando un paso 
muy grande para validar, entender y ejercer la comunicación plena, capaz de darle una respuesta efectiva a los retos que plantean las prácticas de la ciudadanía. Por fortuna, los seres humanos ya cuentan con el activo cultural que les permite apropiarse de su propio contexto.

Es cierto que las dinámicas del mercado inmersas en la globalización económica han impuesto barreras para el ejercicio de valores democráticos, pero también lo es que tenemos el reto de advertir y superar lo que el sociólogo brasileño Renato Ortiz, citado por Luis Ignacio Sierra, llama "trampa de carácter ideológico, según la cual todo transcurre inexorablemente dependiendo de las leyes impuestas por el mercado y por la tecnología". Sí, dice Ortiz, "la globalización conlleva peligro pero también posibilidades". (2002, pp. 168170)

\subsubsection{Ciudadanías en las EDC}

Como lo anotamos, el ejercicio pleno del periodismo ciudadano y de la comunicación participativa se están encargando de demostrar que sí es posible que la gente de carne y hueso ejerza el poder de la palabra, el valor transformador y emancipador de la deliberación pública y el poder de la acción comunicativa.

Se trata de un poder que — en palabras de Hanna Arendt — se manifiesta cuando los hombres son capaces de actuar con la mira puesta en objetivos comunes y desaparece tan pronto como se dispersan de nuevo:

(...)El poder solo es realidad donde la palabra y acto no se han separado, donde las palabras no están vacías y los hechos no son brutales, donde las palabras no se emplean para velar intenciones, sino para descubrir realidades, y los actos no se usan para violar y destruir sino para establecer relaciones y crear nuevas realidades. (1993, p. 223)

Se busca, entonces, profundizar el debate, mediante la participación directa de los actores de las Escuelas Digitales Campesinas como productores de sus propios mensajes, para lo cual — como lo hemos indicado - hoy cuentan con iniciativas como la Red de Reporteros Rurales (R3) y las Cartas del Campo y medios propios como las emisoras ACPO vive Radio Sutatenza y Asoacpo Sutatenza Medellín.

¿Cómo constituir en ese contexto formas de poder que contribuyan a democratizar la democracia? ¿Cómo llevar a la práctica los postulados y valores de la democracia radical y del humanismo cívico? Como ya lo habíamos enunciado, una de las respuestas está en el reto 
de aprender a deliberar, para lo cual proponemos el siguiente decálogo:

$1^{\circ}$. Reconocer y respetar la diferencia: Se debe estar abierto a la diversidad cultural, a otras formas de pensamiento y a otros modos de vida buena.

$2^{\circ}$. Asumir que las reglas del juego de la discusión deben ser analizadas y acordadas entre nosotros y con los otros (Nuestros adversarios)

$3^{\circ}$. Validar al otro como interlocutor y no apelar nunca a los ataques personales.

$4^{\circ}$. Prepararse para la argumentación, que es la base de la deliberación.

$5^{\circ}$. Reconocer que estamos ante un espacio de conflicto, el cual debe asumirse como punto de partida. ("El punto de llegada es el reconocimiento y la fecundación recíproca").

$6^{\circ}$. Ejercer el sentido dialógico de la crítica social, es decir, una discusión pública basada en el respeto mutuo, sin exclusión social ni cultural.

$7^{\circ}$. Tener en cuenta que deliberar es buscar lo justo posible. (Para autores como Adela Cortina, referirse a lo justo es hablar en el terreno de lo práctico-político, en el que también cabe tratar asuntos como "lo correcto o lo racionalmente válido, pero no sobre lo verdadero, que quedaría para el ámbito teórico". (2011, pp. 29-30).

$8^{\circ}$. No perder de vista que le apuntamos a una cultura de consenso de mínimos éticos, que se debe expresar en hábitos y valores compartidos.

$9^{\circ}$. Ejercer la tolerancia que no significa dejar que todo pase, sino aprender a ponerse en los zapatos y en las lógicas del otro. Es, en palabras de Freire, "la virtud revolucionaria que consiste en convivir con quienes son diferentes para luchar contra quienes son antagónicos" (1994, p. 57)

10. Asumir que no le estamos apostando a la construcción de una ciudadanía, sino de ciudadanías, que cambian en función de la cotidianidad, de los contextos y de las necesidades.

Son enunciados encaminados a educar para la deliberación y para lo cual es necesario "contar con un conjunto de destrezas y de virtudes, que se a su vez se aprenden mediante el ejercicio de la deliberación, y que también se aprenden en la escuela", tanto en la educación formal como en la informal. (Cortina, 2011, p. 27)

Pensamos que estos postulados pueden enriquecer el ejercicio de convergencia de medios de las E.D.C. de ACPO, cuya tarea, aún incipiente, plantea preguntas como estas, aún sin respuestas concluyentes:

¿Cuáles de esas grandes tensiones inmersas en el modelo de la Educación Fundamental 
Integral, que subsisten desde la era de las Escuelas Radiofónicas de Radio Sutatenza, se deben contemplar y tramitar en un modelo de democracia radical como el propuesto en este trabajo? ¿Cuáles son los nuevos retos y las nuevas interpelaciones que el contexto político colombiano, en trance hacia el "pos acuerdo" con las FARC, caracterizado por una aguda polarización sociopolítica, le suma a este nuevo modelo de comunicación?

Lo cierto es que la deliberación pública —que se mueve en los terrenos de lo simbólico, en las diversas apropiaciones del lenguaje- está en el centro de lo que, tanto Gramsci como Mouffe, subrayaran como clave en la tarea de construir nuevas realidades, o lo que investigadores como Rey y Martín- Barbero califican como la "lucha de los pueblos por entrar a contar en las decisiones que los afectan, esto es, por el derecho a contar sus historias y descubrir/recrear en ellas (...) su identidad plural”. (1999, P. 11)

Entonces sí, bienvenidos los debates, siempre y cuando se libren en escenarios de libertad y equidad al servicio de transformaciones que pasan por otras formas de conocer, de pensar y de actuar.

\subsection{Significados de ser campesino}

Como lo hemos indicado, el contexto sociocultural cumple una función clave en las tareas del prosumidor. De ahí que nos interesemos a fondo por conocer quiénes son, cómo son y cómo actúan nuestros sujetos de investigación.

Con ese norte y con el propósito de entender con mayor precisión cómo se da la producción de sentido en las EDC, surgen estas preguntas: ¿Qué significa hoy ser campesino? Y ¿Cómo se concibe allí la “ciudadanía rural?

Solidaridad, humildad, laboriosidad, unidad, orgullo...Con estos calificativos se autodefinen muchas de las campesinas y otro tanto de los campesinos consultados para esta investigación. Y habría que agregarles otras: TESÓN y ARRAIGO, así con mayúsculas, pues constituyen valores que les han garantizado permanecer en el campo, a pesar de ser las principales víctimas del conflicto armado, al lado de las comunidades indígenas y de las poblaciones negras.

Debido al contexto casi siempre hostil en el que han debido vivir, muchos de ellos se caracterizan por su espíritu rebuscador pues, casi siempre "a la brava" han debido abrirse paso en regiones que, aunque no son las suyas, les han dado la oportunidad de subsistir. Fue, por ejemplo, lo que pasó con muchos campesinos caucanos, desplazados en forma violenta de su territorio por grupos armados que llegaron tras los grandes negocios derivados de la hoja de coca y de la minería ilegal. Un buena cantidad, emigró en los 80 hacia el Putumayo 
donde se vivía la famosa "bonanza cocalera". Unos pocos años después, por instrucciones del gobierno de los Estados Unidos, se inició la erradicación masiva de la hoja de coca con el nocivo glifosato. $\mathrm{Y}$ aunque algunos campesinos resistieron la embestida con recursos artesanales, como el riego con melaza de panela, muchos otros decidieron retornar a su Cauca a comienzos de los 90 "pero no como obreros de palma o como jornaleros de las chocolateras. Regresaron a sembrar coca. Y detrás —o quizás adelante- llegaron los narcotraficantes". (Molano, 2017, p. 38)

Claro ésa, por fortuna, no ha sido la realidad de todo el país pues, a pesar de todo, el campo colombiano sigue siendo un gran productor alimentos básicos, como lo advertimos en los siguientes testimonios, recogidos del programa radial Mundo Rural:

"Somos los que producimos comida, y los que siempre estamos dispuestos a colaborarles a las personas", dice Vicente García, de la zona rural de Tena (Cundinamarca). "Ser campesino es la riqueza más grande que tengo", afirma con decisión Pastor Valero, campesino de Otanche, municipio del occidente de Boyacá conocido por ser el corazón de la famosa "guerra de las esmeraldas". "Es maravilloso; es lo que que más me ha gustado...Hay libertad, hay felicidad, hay aire libre", complementa María Carmen Valero, de la misma población, mientras doña Odilia Marín, matrona caldense, quien dice sentirse orgullosa de sus 71 años de vida en el campo de Pensilvania, asegura a manera de sentencia pausada y franca: "también es cierto que a muchos les gusta el trago, piden préstamos y se les complica la vida". (Pérez, 2017, audio podcast)

Claro, hablar del campo colombiano y de lo que significa ser campesino es pisar terrenos complejos, pues no nos podemos referir a identidad sino a identidades llaneras, vallunas, montañeras, costeras, selváticas...Con diferentes delicias gastronómicas, como las hallacas nortesantandereanas, el tamal tolimense, el asado huilense, la bandeja paisa del Viejo Caldas y Antioquia, la bitufarra atlanticense, el sudado de pescado del Pacífico, el ajiaco bogotano...Y variadas propuestas musicales como el vallenato, la cumbia, la carranga, el joropo, el bambuco, el currulao, el torbellino, el rajaleñas...Son, como vemos, oímos o saboreamos, manifestaciones culturales variopintas como la propia geografía colombiana, las cuales tampoco han salido ilesas de la arremetida violenta. Como lo cuenta el propio Molano, no solo se ha hecho o se ha pretendido hacer el desplazamiento de todos aquellos que se niegan a obedecer a los guerreros, sino lo que podemos llamar un "desplazamiento simbólico": "Los alabaos y los arrullos ( cantos típicos del Pacífico) fueron reemplazados por los corridos norteños y por los vallenatos modernos; los tambores y las marimbas 
sucumbieron bajo el ruido de los altoparlantes". (Ib.)

Vemos, entonces, algo en común que ha dejado sus imborrables marcas en la esencia de las campesinas y campesinos colombianos: la lucha por la tenencia de la tierra, en la cual muchos han perecido, otros más han sido desplazados, pero otros ¡han resistido!. Y en esa resistencia también se han salvado expresiones culturales como las referenciadas por Molano, sin negar que el miedo ha hecho mella. Por eso la marimba de chonta sigue sonando, aún más fuerte y con mayor nitidez que antes, amén del trabajo musical desplegado por grupos, hoy tan emblemáticos en Colombia, como "Herencia de Timbiquí", ganador de una Gaviota de Plata en el Festival Internacional de la Canción de Viña del Mar, versión 2013, con su tema “Amanece". En letras como las de esta canción se hace evidente cómo los habitantes rurales han echado mano de la "potencia del silencio" (Guerrero, 2018) para hacer notar el horror de la guerra:

\author{
Amanece noche \\ amanece, que ya tengo frío noche amanece \\ Cuando el campesino deja su bohío \\ En la madrugada en medio del frío \\ Lo coge la noche de regreso al nido
}

Hay una tormenta de medio camino

Amanece noche amanece, que me estoy mojando noche amanece

Amanece noche amanece, que ya tengo frío noche amanece

Es claro que aquí no hay una denuncia explícita, pero sí una clara enunciación del dolor y una exhortación a la esperanza, desde una de las zonas donde se ha librado el conflicto armado colombiano con mayor intensidad, como lo es el occidente del departamento del Cauca. En efecto, quienes levantan sus voces para cantar han sufrido en carne propia la violencia, y devuelven así, canciones por plomo. Como lo advierte el periodista Arturo Guerrero, al referirse a este tipo de estrategias usadas también por comunicadores de zonas alejadas, víctimas de toda clase de abusos del poder, enunciar es

Hablar del milagro pero no del santo. En esos casos el milagro era desgracia: tierras apropiadas con la vista gorda de notarios, campesinos expulsados, masacres, "muñecos" echados al río para que bajaran al mar del olvido (...) Gracias a este trueque, el pueblo se informa con mayor profundidad. No mediante el estruendo de la foto del maleante, de su prontuario puntual. Más bien con el relato del cáncer que muele a mordiscos a toda la sociedad. $(2018$, p. 1) 
Es solo un ejemplo pues, en realidad, el país cuenta con una pléyade de artistas que se ha aferrado a su propio terruño para hacer escuchar sus voces esenciales y auténticas, entre los cuales podemos mencionar también a Hugo Candelario González; a José Antonio Torres, "Gualajo"; a Nidia Góngora y a los grupos "Chocquibtown”, "Ondatrópica", "Saboreo" y "La Revuelta"... La mayoría de ellos se han hecho notar en el festival "Petronio Álvarez", que se realiza cada año en Cali, la capital del Valle del Cauca. Inaugurado en 1997, hoy por hoy es reconocido como el más importante escenario para proyectar las músicas del Pacífico.

Claro, son voces que nos confirman que la población campesina ha sido diezmada, como lo evidencian las cifras del Censo Nacional Agropecuario 2014. Pero vale esta pregunta: ¿Cómo se explica que aún existan campesinas y campesinos en medio de los horrores del conflicto? El mismo Molano, sociólogo y periodista colombiano que se ha dedicado a contar la historia rural con "ojos de campesino" amén de sus travesías en las que se ha dedicado a conversar y a escuchar que, según sus propias palabras, significa "limpiar lo que me distancia del vecino", tiene estas claves : la difícil y "caprichosa topografía" que ha propiciado el uso de la mano de obra familiar, mientras la gran agricultura debe contratar labriegos asalariados: "Son secretos que hacen factible hoy en el país, a pesar de la acelerada concentración de la tierra, que el campesino no haya desaparecido". A ello se suma la decisión de los indígenas de atrincherarse en sus resguardos " y parar al terrateniente a costa de miles de muertos". (2011, p. 2)

Por supuesto, la misma guerra se ha encargado de profundizar la idiosincrasia raizal campesina, algunas de cuyas bondades ya se mencionaron. Queda claro que las prácticas cotidianas marcan una diferencia estratégica frente a los negociantes de tierras quienes, casi siempre, o son los mismos, o están asociados con los hombres de la guerra.

En efecto, como lo reafirma Molano, "la familia tiene una importancia decisiva" (Ib.), valor que hemos podido comprobar en el propio trabajo de las Escuelas Digitales Campesinas, cuyas dinámicas se caracterizan por ser colaborativas y por apoyarse en el principio cristiano de la solidaridad, a tal punto que las propios estudiantes asumen como clave compartir lo que aprenden.

Así lo explica, por ejemplo, Marco Fidel Zambrano, estudiante de Guayatá, Boyacá: "Trabajando unidos es mucho mejor para el agro y para los campesinos, ya que hemos estado muy abandonados". Y agrega: “ Cada sesión consta de unas tres horas, cada ocho días. Hay diálogo entre nosotros. Nos apoyamos para superar cualquier dificultad. Hay mucho compañerismo. Nos dedicamos a nuestro estudio y nos ayudamos mutuamente". (Pérez, 


\section{7, audio podcast)}

Y don Vicente García, de Tena (Cundinamarca) no duda en señalar que esa disposición para ayudar al otro hace parte de la propia esencia campesina: "Siempre estamos dispuestos a colaborarles a las personas. Si llega un vecino a pedir un favor y uno lo puede hacer, uno le sirve a la gente. Somos muy unidos...Esta semana, por ejemplo, dijeron: vamos a arreglar la carretera.Y todos los campesinos salimos a trabajar. Los campesinos somos más unidos que la gente de los pueblos...". (Pérez, 2017, audio podcast)

Por su parte Gladys Celis, madre de familia y quien a sus 61 años decidió inscribirse en la EDC de La Capilla (Boyacá), destaca cómo su decisión le ha traído beneficios familiares muy importantes. "Mi familia está muy feliz de ver que a mi edad yo me he interesado por participar y por aprender. Tan así que mis hijos se quieren venir de Bogotá, a trabajar conmigo y a apoyarme", dice. (Pérez, 2017, audio en podcast)

Situaciones como estas son las que le dan pie a Molano para afirmar que "el trabajo solidario (...) hace que la vereda sea un organismo social de gran cohesión”. (Ib.)

Recordamos que fue ese acendrado valor de los campesinos el que hizo posible el nacimiento de ACPO en 1947. Y es que el principio cristiano de ayudarle y tenderle la mano al otro fue el que se manifestó cuando José Joaquín Salcedo los convocó para que ayudaran a construir el teatro, la primera gran obra de la organización, y la respuesta no se hizo esperar, como lo revela el investigador Indalecio Rodríguez, citado por Bernal Alarcón:

(...) superó cualquier cálculo y demostró que en sus mentes había materia prima suficiente para dar un sí, cuando se les explicaba con claridad la nobleza de una buena causa y cuando se les demostraba que correspondía a un deseo auténticamente amigable cristiano, de ayudarles a superarse por sí mismos. (2005, p. 43)

Es un valor que hoy también se hace tangible, como quiera que la ha permitido ha ACPO consolidar su proyecto de Escuelas Digitales Campesinas con la campaña "Milagro", mediante el recaudo de $\$ 500$ millones desde su creación en 2015.

Otras investigaciones, como la realizada por Hernando Vaca Gutiérrez (2011) confirman que la religiosidad "deficiente, ingenua aunque sincera" (p. 262) , jugó y aún juega un papel preponderante en el proceso de la Educación Fundamental Integral y, en la práctica, ha sido muy bien aprovechada por ACPO, pues ha sabido incorporar a sus diferentes procesos interactivos e interpelaciones "las marcas del discurso religioso, de sus instituciones, de sus sujetos, de sus funciones y papeles". (Ib.) 
En cuanto al tesón y al arraigo se refiere, habría que recordar que buena parte del mundo agrario colombiano se ha hecho a punta de colonización, es decir, con grupos de campesinos que se han dado a la tarea de tumbar monte en zonas selváticas e inhóspitas, aunque, en su balance general, ello no se haya traducido en la democratización de la propiedad. El historiador Álvaro Tirado Mejía se refiere, por ejemplo, a la emblemática colonización antioqueña del siglo XIX, protagonizada por pequeños cultivadores que quisieron abrirse paso como propietarios pero, en su empeño siempre se enfrentaron a la voracidad de los terratenientes que detentaban el poder político y, por esa vía, "se hicieron adjudicar inmensas extensiones de terreno: La historia de la colonización es el relato de actos de violencia y un sinnúmero de pleitos (...) fue la acción de invasores idealizados como colonizadores" ( Tirado, 1978, p. 26)

En consecuencia, desde siempre esos pequeños campesinos, enfrentados a toda clase de inclemencias y arbitrariedades, aprendieron a mantenerse en su territorio y a defenderse con su principal activo llamado familia que, como se ha visto, supieron convertir en poderosa arma contra la competencia desleal de los latifundistas.

Es un arraigo que hoy se mantiene latente en la mayoría de ellos, como lo advertimos en el siguiente testimonio recogido por el semillero de investigación Radio y Ciudadanía:

Nací en el Carmen de Chucurí (departamento de Santander). Siempre he vivido en fincas; trabajé en el sur de Bolívar y salí de allí a trabajar en una finca de ganadería porque la situación era muy difícil. Solo estudié hasta segundo de primaria...Trabajé tres años de empleado y volví a la finca de mi papá, donde sembré yuca y plátano y también teníamos algo de ganado.Ya teníamos la finca bien organizada cuando llegó el Ejército y otros grupos armados y nos tocó salir desplazados para la ciudad...Fue muy duro, porque estábamos acostumbrados a trabajar con cultivos; me tocó regalarme para el Ejército, porque fue la única opción, pues necesitaba conseguir la Libreta Militar, porque nadie me daba trabajo. Dos años después me enteré de las ayudas para los desplazados; me han ayudado con $\$ 70$ mil anuales. El estado prácticamente no nos ayuda. Hoy sigo trabajando en parcelas, fincas, con ganado, con cerdos... (Pérez, 2017, audio podcast)

En ese mismo contexto, ¿cómo concibe ACPO la “ciudadanía rural”?. (Se retoman aquí algunas de las anotaciones publicadas en la revista Interacción, de Cedal) :

Participación y pertenencia activa, esto es, protagonismo en la toma de decisiones; pensamiento crítico y creativo; conocimiento de su propio entorno y de contextos más amplios que le permitan actuar en redes de interaprendizaje; aplicación y uso de técnicas y 
procesos apropiados para el aprovechamiento sostenible y responsable de la tierra...Son algunos de los valores y principios que guían la tarea de la Educación Fundamental Integral. En esa misma dirección, ACPO concibe la inclusión digital, articulada en su estrategia de integración de medios, como la capacidad de acceder información que se convierta en oportunidad de desarrollo personal y social. (Pérez, 2017)

Inclusión digital es eso: que las personas del campo, que siempre han estado más relegadas que las personas de la ciudad, en cuanto a las Tecnologías de la Información y la Comunicación, puedan ingresar a la sociedad de la información y servirse de ella para su desarrollo.(Pérez, 2016, audio podcast).

Es, entonces, un desarrollo personal que parte de hacerse consciente de la dignidad humana, para propiciar la formación de ciudadanos socialmente comprometidos, solidarios y justos, críticos y participativos, y responsables con el medio ambiente. En esa dirección, ACPO enmarca el concepto de ciudadanía rural en las tareas y transformaciones que se logran mediante la comunicación popular y la comunicación para el desarrollo y el cambio social.

\subsubsection{Los habitantes rurales de las EDC}

¿Son el campo de hoy y sus habitantes los mismos de hace 70 años? ¿La realidad rural colombiana, caracterizada en esos años por una fuerte presencia de grupos armados y por la agudización del conflicto, cambió, o no, de manera sustancial lo que significa vivir en el campo y ser campesino? ¿Si cambió, cómo son esos habitantes, razón de ser del trabajo de ACPO y de sus Escuelas Digitales Campesinas, EDC?

Compleja, diversa, dinámica y caracterizada por grandes y profundas transformaciones. Así se puede calificar hoy la realidad del campo colombiano, a 70 años de haberse fundado Acción Cultural Popular.

Hablar de los habitantes del campo hoy, ya no es referirse, necesariamente, solo a los productores de alimentos. Claro, los cultivadores siguen allí -aunque en una proporción considerablemente menor- pero muchos otros se dedican a actividades que no son, en sentido estricto, agropecuarias. El mismo Censo Nacional Agropecuario de 2014, confirmó que hay una tendencia creciente de los habitantes rurales a buscar otras fuentes de ingresos, al precisar que las Unidades Productivas no Agropecuarias (UPNA) ya "representaban el 18,6\% de las unidades de análisis del área rural dispersa censada". Y que el principal uso de esas 
unidades es la vivienda, es decir, muchos de ellos pueden afirmar: "vivo en el campo, pero no necesariamente cultivo ni produzco alimentos".

A conclusiones similares ha llegado ACPO en los últimos cinco años, en el marco de su trabajo con las EDC. En su plan estratégico, cuyo lema es "Sembramos educación y cosechamos bienestar en el campo" y, como producto de su interacción con los estudiantes y facilitadores de las EDC, se ha propuesto, en consecuencia, hablar y practicar una nueva Acción Cultural Popular para el Siglo XXI.

Y es que la organización sabe que, debido a la propia realidad colombiana y al contexto global, para bien o para mal, los habitantes rurales ya no son los mismos, aunque, con frecuencia, se mantenga el estereotipo del campesino, como lo relata el director general de ACPO, Kenny Lavacude:

(Hace unos años) hice el ejercicio de pedirle a 5 personas de diferente edad que me describieran un campesino. El resultado fue muy parecido. 4 imaginaron un hombre. Lo imaginaron de edad avanzada (entre 45 y 60 años), con botas de caucho, camisa de cuadros (excepto uno que imaginó al campesino con ruana iy sin camisa!), bluyín sucio y cachucha (excepto el de la ruana, que tenía sombrero de paño color café). Los cuatro tenían machete. La única mujer del ejercicio era igualmente de edad avanzada, usaba delantal de colores y estaba sentada vendiendo frutas y verduras. Un ejercicio parecido, pero con una muestra mayor, hice en el año 2012, y el resultado fue prácticamente el mismo. (2017, P. 1)

Claro, así siguen viendo muchos a quienes trabajan en la producción de alimentos, pese a que muchos de ellas y ellos se han visto forzados a desplazarse hacia las ciudades. Pero lo que se tiende a desconocer es buena parte de ellos ejercen hoy otras actividades. De ahí que, en la propuesta de ACPO, se busque tratar a los habitantes rurales, primero que todo, como seres humanos y no exclusivamente como productores. Es, por lo demás, una visión inclusiva que pretende verlos como son: blancos, mulatos, negros, indígenas, niños, jóvenes, adultos, adultos mayores...Algunos dedicados a la agricultura; otros a la ganadería y otros a la peluquería, al comercio, al estudio, a la celaduría o al trabajo en un punto Vive Digital.. Y muchos otros, con menor fortuna, al rebusque, como ocurre, por ejemplo, con los recolectores de café, que van y vienen: una temporada están aquí y otra allá. En fin : ¡ Son diferentes, diversos!. Y así prefiere tratarlos ACPO, en su empeño de contribuir a pagar las tres grandes deudas de la sociedad colombiana con el campo: la social, la económica y la educativa. Es el reconocimiento en la práctica de lo que Martín-Barbero (2003) denomina 
"el mestizaje" cultural, entendido no solo como un hecho racial sino como "la trama de modernidad y discontinuidades culturales, deformaciones sociales y estructuras del sentimiento, de memorias e imaginarios que revuelven lo indígena con lo rural, el folclor y lo popular con lo masivo". ( 2003, p. 28)

Es también la forma de encarar la "ciudadanía rural", en su sentido integral. Como lo recuerda Lavacude (Ib.), el artículo 52 de la Constitución Política de Colombia dice que "El ejercicio del deporte, sus manifestaciones recreativas, competitivas y autóctonas tienen como función la formación integral de las personas". Por ahí pasa el reto de la inclusión, pues "la risa, el baile o el paseo de olla quizá no se encuentren en la Constitución, pero forman parte de las acciones más propias de los seres humanos que el hecho de llevar un azadón al hombro". (Ib.,p. 1) 
Radio Sutatenza y Acción Cultural Popular en la era digital 


\section{CAPÍTULO V}

\section{Comunicación/Educación en las EDC}

La verdad está dentro, no nace de algo externo,

Hay en todos nosotros un recóndito centro

Donde íntima y plena la verdad nos habita.

Saber consiste más en abrirse un camino por donde pueda huir nuestra voz prisionera, que en abrir una puerta para los resplandores que imaginamos fuera.

Robert Browning 


\subsection{Sumario}

En este capítulo buscaremos aportar respuestas y proponer nuevas rutas de acción, alrededor de la siguiente pregunta: ¿Cuál es el papel que cumple la Comunicación/Educación, inmersa en la formación de los sujetos y en la lucha/disputa por la construcción de sentido, en los propósitos de ACPO de contribuir a la construcción de ciudadanías rurales? Con ese propósito serán descritas las dinámicas de producción de sentido y de participación que se viven en las Escuelas Digitales Campesinas (EDC). Tal y como fue planteado en el capítulo II, el ejercicio de análisis incluye categorías e instrumentos metodológicos fundamentados en las teorías asociadas a la Investigación Acción Participativa (IAP); en los postulados de Comunicación/Educación (Huergo-) ; en el contrato de lectura (Verón), y en la polifonía de voces, en el marco de la Acpoeducación.

\subsection{Introducción}

Entendemos la Acpoeducación como el trabajo concreto de ACPO, que se activa con los cursos de las EDC y se complementa con la estrategia de combinación de medios -hoy en la convergencia mediática- enfocado hacia la ciudadanía rural, como elemento clave de la inclusión de las campesinas y campesinos, comunidades indígenas y afrodescendientes en las TICs.

Es importante señalar que lo que ACPO califica como "aprovechamiento y empleo de los modernos medios de comunicación social" hace parte de la sexta característica de la Educación Fundamental Integral (EFI), el modelo socioeducativo que se aplicó en la etapa de las Escuelas Radiofónicas (1947-1994) y se mantiene vigente hoy, como base del trabajo de las EDC.

Con ese norte, haremos aquí primero algunas precisiones sobre el contrato de lectura y su relación con los postulados de la Comunicación/Educación, para centrar luego la discusión y el análisis alrededor de los elementos esenciales de la EFI, es decir, los cursos, la figura del auxiliar inmediato, hoy denominado facilitador, y las cartas, uno de los aspectos claves de la comunicación interpersonal. Y para aproximarnos a la forma como se entiende y como se aplica este último aspecto en tiempos de las TIC, describiremos y analizaremos el modelo el ecosistema comunicativo de ACPO, con sus diversas formas de inclusión, deliberación y participación.

Posteriormente, centraremos el análisis en la estrategia de convergencia de medios, con énfasis en aquellos que activan la Acpoeducación, y en el radioclip, un formato de 
reciente aplicación en la EFI que se considera clave por su demostrada potencia como dinamizador del diálogo social.

Y como punto de llegada, se incluyen trece relatos de vida de estudiantes, o de las Escuelas Radiofónicas o de las EDC, en el ejercicio de polifonía de voces, medular en esta investigación.

\subsection{El contrato de lectura}

Los postulados del "contrato de lectura" o "dispositivo de enunciación" (Verón, 2004) giran alrededor del valor especial que se le concede al uso del lenguaje con sus cadenas significantes, inmersas en las estrategias o modos de comunicación que se usan para estar en sintonía con los lectores, oyentes o, en una palabra, cibernautas.

Dado el enfoque de esta tesis, ponemos el énfasis en el universo vocabular de los sujetos, esto es, campesinas, campesinos e integrantes de comunidades indígenas y afrodescendientes que, según la propia propuesta de ACPO, son los protagonistas de su propio aprendizaje. Allí se fundamenta la decisión de apelar, como hemos visto en los anteriores capítulos, a categorías asociadas a la Comunicación/Educación y a la estrategia analítica que propone Eliseo Verón, más aún si se tiene en cuenta que nos permite adentrarnos en la "especificidad del soporte", para ver de qué está hecha la relación entre los diferentes dispositivos de comunicación, en lo que se han denominado Acpoeducación. Buscaremos, en consecuencia, aquellas "marcas o trazos" de producción de los discursos (Vaca, 2011), a fin de contribuir a determinar cómo se emiten y cómo se reciben los mensajes. Por consiguiente, habrá un común denominador: las voces directas de los sujetos de investigación. Para tal ejercicio resulta clave la siguiente pregunta-problema: i qué significa, en el marco de las EDC, que los propios actores centrales cuenten su historia? Es un ejercicio que para la investigadora Clemencia Rodríguez $(2009$, p. 17) “implica sacar los lenguajes propios de su escondite habitual, para ponerlos en la esfera pública y ver cómo se comportan...".

\subsubsection{Resultados y discusión}

En ese contexto, y para entender cómo se pone en marcha la estrategia, es clave indagar acerca del modelo inmerso en la Acpoeducación, que se ha basado, desde la época 
de las Escuelas Radiofónicas, en los siguientes elementos esenciales, por supuesto, hoy con importantes variantes de la mano de las TIC: -El aprovechamiento del discurso religioso; -la apropiación y buen uso del lenguaje radiofónico por parte de sus realizadores; -el conocimiento permanente del oyente-alumno receptor, para adaptar el discurso a sus anhelos, expectativas y necesidades; -el uso de agentes clave de interacción como el profesor-locutor, el auxiliar inmediato, el dirigente campesino y el párroco, y las cartas. Así mismo, como se observó, fue muy importante la estrategia de combinación de medios, apoyada en la propia Radio Sutatenza, el periódico El Campesino; las cartillas; los discos de acetato y los libros.

Se trata ahora con esta investigación de ver cuáles de esos principios de la Acpoeducación se mantienen vigentes, cuáles han desaparecido o se han modificado, cuáles otros se han incorporado $\mathrm{y}$, especialmente, de qué manera se ponen hoy al servicio de la producción de sentido y de las "nuevas ciudadanías" que propone la democracia radical, alrededor de las siguientes preguntas:

-¿Cuáles son las estrategias o modos de comunicación que se usan para estar en sintonía con los lectores/oyentes?

-¿De qué manera se activan y se construyen los nexos comunicativos?

-¿Cómo se usa y cómo se aprovecha el lenguaje radiofónico?

En la búsqueda de respuestas, y aun de nuevos interrogantes, haremos énfasis a continuación en los siguientes recursos, presentes en el modelo de comunicación/educación aplicado enlas EDC: 1. Las cartas y el auxiliar o facilitador ; 2. La convergencia de medios; 3. Los cursos y Comunicación/Educación; 4. El papel de la radio; 5. elcampesino.co; 6. La retroalimentación en tiempos de las TIC ; 7. El radioclip como dinamizador del diálogo social y 8. Lo que dicen los estudiantes.

Así las cosas, para el análisis se tomará como referencia los discursos que circulan en la "matriz" de las Escuelas Digitales Campesinas, expresada en los siguientes "puntos nodales" de su estrategia comunicativa en "convergencia de medios":

-Lo cursos de formación, dentro de los cuales serán tomados como ejemplo los de "Paz y convivencia" ; "participación comunitaria” y "Comunidad, comunicación y periodismo". Es importante tener en cuenta que no se han escogido al azar, sino en función de la incidencia que tienen dentro de los programas bandera de la denominada Educación Fundamental Integral, todos al al servicio de la formación y de producción de contenidos, en el marco de la La Red de Reporteros Rurales, con la cual se busca que las propias campesinas y 
campesinos relaten sus historias en el momento en que ocurren los hechos; el campesino.co y el programa de radio Mundo Rural. El enfoque que aplicamos apunta a ver de qué manera los cursos de formación de las campesinas y campesinos, se complementan con el uso de estos y otros medios, como parte esencial de la EFI.

Dentro de este proceso de análisis es clave entender que la figura del auxiliar inmediato, que muchos investigadores coinciden en identificar como el principal elemento de innovación del modelo de comunicación impulsado por ACPO, se mantiene hoy en las EDC, ahora con la denominación de facilitador. Hoy, él o ella, se encargan de acompañar el proceso de aprendizaje y de motivar a los estudiantes para que le saquen el mayor partido posible a todos los recursos que tienen a su disposición.

Para el cumplimiento de estos objetivos, es muy importante asumir que la estrategia comunicativa de ACPO, como se ha indicado, cobra sentido en el uso de los medios de comunicación al servicio de una interacción social que tiene como norte el establecimiento de nuevas pautas de comportamiento, cuyo fin es la transformación de las mentalidades, para que los campesinos y campesinas actúen como sujetos protagonistas de su propio aprendizaje.

Desde esta mirada se entiende la radio y los demás medios integrados a la plataforma de las EDC como "prácticas significantes" ( Mata, 1993) en la medida en que se ponen al servicio de la circulación de discursos que participan de la disputa por la producción de sentido.

Lo que se pretende en el marco de las EDC es que las campesinas y campesinos, como actores fundamentales de la vida colombiana, tengan también la capacidad de nominación, pues , como lo dijera Boaventura de Sousa Santos, solo "si se representa el mundo en el que vivimos como nuestro, podemos cambiar las cosas, (...”) (2016, p. 5).

Surge aquí la pregunta que planteamos al comienzo: ¿cuál es el papel que cumple la Comunicación/Educación, los propósitos de ACPO de contribuir a la formación de ciudadanos rurales?

Desde allí se quiere aportar a la discusión sobre lo que significa el ejercicio concreto de la Comunicación/Educación en un escenario tan importante para la vida colombiana y latinoamericana, debido a la incidencia que tuvieron las Escuelas Radiofónicas de ACPO -la antigua Radio Sutatenza- en el movimiento de radios populares con fines educativos, cuyos alcances y beneficios se buscan retomar ahora tras la reaparición de ACPO y su modelo de Escuelas Digitales Campesinas, desde agosto de 2012. 


\subsubsection{Las cartas y el auxiliar inmediato o facilitador}

Aún antes de su nacimiento, Radio Sutatenza fue concebida como un medio al servicio de la Comunicación/Educación. Aunque para esa época ni siquiera se hubiera proyectado la utilización de ese concepto, pues unos años después se hicieron los primeros avances, en el marco de las prácticas de la pedagogía liberadora impulsada por Paulo Freire, las Escuelas Radiofónicas ya venían trabajando en esa dirección. Ello confirma que las prácticas sociales no están supeditadas a la preexistencia de conceptos académicos.

Una rápida mirada a los principios y prácticas que enmarcaron la Acción Cultural Popular (ACPO) con su estrategia de Educación Fundamental Integral ( EFI) permite comprobar que el recurso del diálogo con las campesinas y campesinos estuvo presente desde el primer encuentro entre el entonces novel sacerdote José Joaquín Salcedo y los habitantes de Sutatenza. Fue así como durante su primera misa prefirió la charla al sermón, lo que le permitió conocer de primera mano que el problema que más aquejaba a la población era el analfabetismo, al lado de otros que también estaban conectados con la carencia o baja calidad del servicio educativo, como el alcoholismo y el machismo, causantes de altos índices de violencia intrafamiliar.

Ya una vez instalada la primera radioemisora de la que sería unos años después la cadena Radio Sutatenza, el reto siempre estuvo bien claro, porque salió de las conversaciones con sus propios beneficiarios, los campesinos del Valle de Tenza: poner la emisora al servicio del desarrollo social. Y se logró de tal manera que el investigador Luis Ramiro Beltrán (2005) la reconocería como la primera experiencia latinoamericana de comunicación para el cambio social.

Lo cierto es que los promotores de Radio Sutatenza entendieron desde el primer momento que la clave estaba en el actuar, para cambiar en la práctica pautas de comportamiento que las propias campesinas y campesinos entendían que les hacían daño. Entonces no fue gratuito que el mismo nombre empezara por acción, un vocablo que está en el corazón mismo de la comunicación, pues desde su etimología latina, communicare, “significa compartir algo, poner en común”. (Pérez, 2008) De allí se derivaría la EFI, que, según sus propios gestores, solo cobraría sentido si apuntaba a un desarrollo que partiera de la misma mentalidad porque, como lo repetía con insistencia José Joaquín Salcedo, “el subdesarrollo está en la mente del hombre”. Así, como también lo referiría algunos años después el famoso informe Musto (1971), el siguiente principio guiaría toda la estrategia: 
(...) la idea de que la educación y capacitación del individuo, la construcción de la personalidad, es la condición fundamental de todo desarrollo.

\subsection{Claves de la estrategia}

La estrategia de ACPO materializada en las Escuelas Radiofónicas giró alrededor de cinco contenidos básicos de la Educación Fundamental Integral, que en su esencia fue y es una apuesta inscrita en la llamada "Doctrina Social de la Iglesia Católica": alfabeto, número, salud, economía y trabajo más espiritualidad, las cuales se difundían con la ayuda de clases radiales, cartillas, libros de la biblioteca, cursos de extensión, y proyectos en el ámbito nacional e internacional.

Nos preguntamos entonces: en este contexto: ¿cómo entendió y cómo asumió ACPO la relación Comunicación/Educación? El investigador Hernando Vaca Gutiérrez ( 2011, p. 264) sostiene que la practicó como una "integración placentera" y, especialmente como una “integración estratégica para transformar las condiciones de vida del campesino". En efecto, como hemos señalado, la apuesta incluyó la combinación y el uso sistemático de los medios: Radio Sutatenza, el periódico El Campesino; los libros y las cartillas que imprimían la editorial Andes y la editora 2.000; los discos de acetato o "Discoestudio" y la comunicación interpersonal apoyada por las cartas y por la figura del auxiliar inmediato. Merecen especial atención estos dos últimos elementos de la estrategia, debido a su fuerte impacto en un modelo de la comunicación que, para la época fue revolucionario, aunque, como suele ocurrir con los cambios de fondo, solo se advirtió muchos años después. En efecto, la figura de los auxiliares inmediatos se puede calificar como un punto central de la Acpoeducación, en la medida en que se trataba de unos motivadores-acompañantes del proceso que, como integrantes de la misma comunidad, contaban con la ascendencia necesaria en el respectivo grupo para activar el diálogo con sus pares. Para entender mejor cómo cumplían su labor, hemos extraído el siguiente ejemplo del curso denominado "Las cuentas claras y el chocolate espeso":

-Locutor: ...Espero que usted me acompañe para que hagamos un buen equipo de trabajo para intercambiar ideas, es decir, para que usted me cuente qué problemas tiene con sus cuentas...(Entra música)

-Locutor: Me gustaría que usted, señora ama de casa o empleada y usted también, amigo campesino y trabajador, analizaran un momento para qué hacemos cuentas y cómo se deben 
llevar las cuentas (entra música)...

Aquí se puede notar cómo la música se utilizaba para abrir y para acompañar el espacio de reflexión- conversación, respaldadas por el auxiliar: “¿Sí escucharon?...Pensemos a ver para qué hacemos las cuentas"...

También es clave aquí detenerse en el tono que usa el locutor-profesor. Como publicamos en el libro "Cómo escribir para radio" al referirse al tono y al lenguaje coloquial: "Está demostrado que esta forma de encarar la comunicación en la radio es afectiva y efectiva, por cuanto involucra directamente al oyente en los hechos que son materia de información". (2015, p. 29)

Es "efectiva y afectiva", porque las audiencias no son tratadas como agentes pasivos sino como sujetos a quienes se les habla al oído y, por qué no, al corazón. Es una manera de privilegiar el cómo se dice sobre lo que se dice, para que el mensaje llegue y, en consecuencia, provoque un impacto comunicativo.

Entonces, el locutor-profesor sabe que no le está a hablando al aire, en sentido estricto, sino a la gente de carne y hueso, a quien trata como si tuviera cara a cara; por lo tanto, interpela a sus oyentes como se hace con un amigo:

"Me gustaría que usted, señora ama de casa o empleada...Y usted también, amigo campesino y trabajador, analizaran un momento...”.

Así, ya estaba abonado el terreno para que el auxiliar inmediato, quien como parte integral del grupo también era interpelado, empezara su tarea de motivador que consistía en preguntarle al grupo para que fluyera la reflexión colectiva. Claro, él también tenía mucho qué contestar y qué aportar, pero el diálogo no se quedaba en las cuatro paredes de la Escuela Radiofónica. Era complementado con los otros medios y con las cartas...Como dice la canción, “a veces llegan cartas"... Y la verdad es que a ACPO llegaron muchas, como parte esencial del proceso de comunicación/educación. Hernando Bernal Alarcón (2013), quien fuera varias veces director general de ACPO, entre 1986 y 1991, precisa que los 47 años de su primera etapa, se respondieron 1.229.552 cartas provenientes de los alumnos y oyentes de las emisoras y de los lectores del periódico. Y destaca que la correspondencia,

era uno de los elementos más importantes de retroalimentación de su sistema de comunicación. Era una forma de superar la masificación propia de los medios de comunicación, y de crear una relación interpersonal con su audiencia. (P .36) 
Sí, las cartas eran parte fundamental de las Escuelas Radiofónicas, pues por este medio se recibían las tareas y ejercicios que dejaban los profesores y, por lo tanto, "debían ser respondidas personalmente a cada uno de los interesados". (Ib.). Así, mismo, como elemento integral del proceso comunicativo, propiciaban la iniciativa de las campesinas y campesinos, quienes enviaban coplas, poemas, preguntas, sugerencias y críticas, formuladas tanto a la misma ACPO como a otras instituciones. Por ejemplo, don Jesús Arismendi C., escribió el 7 de febrero de 1970 desde Belén (Boyacá) para decir, entre otras cosas, que "de la alfabetización de nuestras veredas, pues muy poco se interesa la gente, pero en cuanto a las campañas de agua sí...”. (Musto, p.17). ACPO les concedió tanta importancia a cartas como esta, que decidió procesarlas y constituir un banco de información, "como parte de la motivación de los programas institucionales". (Ib.)

Ahí están, con sus ventajas y desventajas, los componentes centrales de la estrategia de interacción, en el marco de lo que se conoció entonces como la "combinación de medios", que buscaba y busca hoy llegar día a día a más campesinas y campesinos. (Ahora también a integrantes de comunidades afrodescendientes e indígenas)

Y es que éste ha sido el gran reto de ACPO: que sus líderes puedan compartir su experiencia entre sus propias bases. Ahí se puede ubicar la gran innovación de la Acpoeducación, es decir, no solo el haber puesto la radio al servicio de la educación, sino haberla complementado con una serie de mecanismos o elementos de apoyo educativo, entre los cuales el más sobresaliente fue la actividad de los miles de voluntarios de la cultura, deseosos de ayudar a los campesinos adultos a aprender por medio del simple seguimiento de las orientaciones que recibían del profesor que hablaba por la emisora. (Bernal, 2013).

En ese orden de ideas, aunque de manera incipiente, en esta nueva etapa ACPO revivió la correspondencia, mediante la inclusión de la sección denominada "Las cartas del campo", tanto en elcampesino.co, como en el programa de radio. (Ver Anexo B.)

\subsection{La Acpoeducación en la Educación Fundamental Integral}

Como hemos insistido, la combinación de medios fue un aspecto central de la estrategia de comunicación educativa promovida por ACPO. Ahora nuestro análisis girará alrededor del papel que busca cumplir hoy la convergencia de medios en las Escuelas Digitales Campesinas (EDC)

En esta nueva etapa que, como se ha indicado, empezó a finales de 2012, ACPO ha decidido retomar sus principios fundacionales; esto es, mantener la Educación Fundamental Integral como principio transversal de la formación de las campesinas, campesinos e 
integrantes de comunidades afrodescendientes e indígenas que hacen parte de las EDC. Ya no cuenta, por supuesto, con Radio Sutatenza, pero ahora dispone de las grandes posibilidades que brindan las Tecnologías de la Información y la Comunicación (TIC) con plataformas como www.escuelasdigitalescampesinas.org , www.elcampesino.co y el programa de radio Mundo Rural. Para ACPO es claro que hoy no puede haber inclusión social sin inclusión digital. Por eso, su estrategia va más allá de lo puramente instrumental, pues entiende que estamos ante nuevas formas de acceder al conocimiento, lo que, a su vez "provoca fenómenos sociales y culturales novedosos". (Huergo, 1999, p. 53). En esa misma dirección, como producto del diálogo con radialistas populares, quedó consignado en el libro Ser ciudadano en la radio que lo más importante de las tecnologías no es saberlas manejar en su integridad, sino aprender a aprovecharlas:

Las tecnologías no son fantasmas, son para nosotros, y deben estar al servicio de los intereses de la comunidad. No olvidemos que las primeras y las más importantes tecnologías que tenemos a nuestra disposición son nuestras propias cabezas, nuestro corazón y nuestra creatividad. No hay que dejarnos hechizar por ellas, porque corremos el riesgo de ponernos al servicio de una tecnología sin sentido. Y la tecnología debe estar a nuestro servicio. (Pérez, 2012, p.27)

Y Como lo sostiene el propio Huergo, al hacer referencia a las "alfabetizaciones posmodernas críticas" planteadas por Peter Mclaren,

hoy es posible redimensionar la praxis de la posmodernidad, (lo que significa que ): aprovecha las grietas y resistencias al sistema hegemónico, retoma al sujeto de liberación ( no solo teóricamente), parte de la acción y el decir de los otros desde los márgenes, y devuelve la alteridad a las voces que fueron y son acalladas, marginadas y despojadas de poder por los discursos dominantes. (P.167)

Con esa mirada, hoy como ayer, la estrategia de formación de ACPO se apoya en líderes comunitarios y facilitadores del proceso. Se busca, de esa manera, "garantizar el conocimiento suficiente de cada zona (...) así como el respeto y valoración de las culturas, pueblos y costumbres" (Pérez, 2017, audio podcast) para que la propia comunidad se apropie del proyecto. Por su propia naturaleza, el trabajo de las EDC se caracteriza por la participación y la inclusión, de tal forma que las comunidades intervengan de manera activa desde el mismo diagnóstico, el cual incluye la identificación de sus necesidades formativas y sociales. Es la forma de actuar en el "ecosistema comunicativo" (Martín-Barbero, 2004) en 
cuyo marco se han venido reconfigurando las identidades, esto es, "la fuerza y el sentido de los lazos sociales, y las posibilidades de convivencia en lo nacional y aun en lo local" (Martín-Barbero, 2010, pp. 8-9 ) . Todo, porque como lo señala el investigador Juan Carlos Amador (2012) estamos ante nuevas maneras, tanto de percibir como de contar la realidad; así mismo ante "nuevas formas de gestionar la participación; y la ruptura de la totalización mediante la creación interactiva" (Amador, 2012, p. 197), para que ahí, en el quehacer cotidiano, las campesinas y campesinos, así como los integrantes de comunidades afrodescendientes e indígenas potencien su capacidad de incidir en la vida pública. Y es que, como ya lo hacía notar Jenkins, citado por Amador, la cultura de convergencia mediática le ha abierto el espacio a nuevas culturas participativas, para que las experiencias sociales se conviertan "progresivamente en proyectos alternativos a la hegemonías políticas, cognitivas y estéticas que han encontrado en la web su principal superficie de control y reproducción". (Ib., p. 198). No se trata, entonces, de un asunto que solo tiene implicaciones tecnológicas sino, especialmente, un gran trasfondo cultural, en la medida en que los discursos, con sus lenguajes, saberes y prácticas, circulan en lo que McLuhan denomina "ecología de medios", esto es, la coexistencia de muchos medios que implican una ruptura con la escuela tradicional. En coincidencia plena con la Comunicación/Educación, hoy ya ni se enseña, ni se forma, ni se aprende solo; se interaprende. (Prieto, 2006, p. 26) El mismo Amador destaca, entonces, un rompimiento con el paradigma memorístico que imperó en la escuela moderna, para dar paso a propuestas como las del "aprendizaje significativo y el aprendizaje por descubrimiento". (Ib., p. 214)

Y ya en el plano operativo, según lo explica la propia organización, para la puesta en funcionamiento de cada EDC ha sido necesario activar alianzas público-privadas, como las suscritas con el Ministerio de las TIC y sus puntos "Vive Digital"; alcaldías municipales; instituciones educativas y parroquias, a fin de contar con la infraestructura mínima requerida. El balance que entrega su director, Kenny Lavacude Parra (Pérez, 2017, audio podcast), indica que las EDC ya llegan a 8 departamentos y a 48 municipios del país, donde se han beneficiado más de 18.000 campesinas y campesinos, incluidos indígenas $\mathrm{y}$ afrocolombianos. Siete mil de ellos reciben los cursos a través de medios digitales y los demás a través de la radio, cartillas, USBs y podcast. "La mayoría son mujeres, personas entre los 14 y los 82 años. Y esperamos seguir creciendo". (Ib.)

La oferta de cursos -11 en total hasta el momento- incluye los de alfabetización digital; conocimiento del medio; liderazgo; asociación y empresa y comunidad, comunicación y periodismo. Quienes tomen este último pueden integrarse a la Red de 
Reporteros Rurales, cuyas historias son publicadas en elcampesino.co. Según lo destaca Lavacude, "se busca que los campesinos lleguen a los centros de poder, es decir, a las ciudades, que es donde se toman las decisiones”. (Ib.) Se le apunta por esta vía, a combatir la pobreza estructural en las zonas rurales, es decir, ya no solo la monetaria sino la multidimensional que, como lo advierte Brunner, también está asociada a la privación de información, "una forma de marginalidad en relación con los movimientos de conformación y expresión de la opinión pública. Lo mismo puede decirse de los desbalances regionales existentes en la generación y distribución de la información”. (Brunner, 1994, p.3 )

En ese marco de acción, el reto se puede resumir así : propiciar y potenciar la inclusión de las campesinas, campesinos, indígenas y afrodescendientes para que se sirvan de los beneficios de la Tecnologías de la Información y la Comunicación. 


\subsubsection{Cursos y Comunicación/Educación}

¿De qué manera los contenidos de los cursos se pueden inscribir en la Comunicación /Educación?

Para entender la naturaleza de los cursos, en general, es fundamental indagar acerca de la manera como se preparan los facilitadores, también denominados por ACPO como “acompañantes del proceso". En la época de las Escuelas Radiofónicas, se crearon los Institutos Campesinos, con el propósito de propiciar la mejor formación de los auxiliares inmediatos, "que deseaban servir mejor a sus comunidades". (Bernal, 2013). Hoy, aunque no existen los institutos con dicho nombre, sí se crearon en 2018 los denominados "Centros modelo", en los municipios de Manta y Silvania (departamento de Cundinamarca), donde son formados los líderes que se encargan de multiplicar los conocimientos en sus comunidades veredales. Son entidades que servirán de referencia para las EDC en todo el país.

De esa manera, ACPO mantiene su visión de contribuir a la cualificación permanente de los tutores, para lo cual, a manera de complemento de la formación presencial, diseñó el “Manual del profesor". Así, en cada uno de los cursos, se hace un acompañamiento detallado, para que el docente cuente con mejores herramientas conceptuales y metodológicas. Se trata, entonces, como en aquella época, de "ampliar sus conocimientos y de conocer con mayor profundidad las prácticas que debían ayudar a transmitir" (Ib., p.32)

Del propio Manual extraemos las siguientes claves de acción del modelo ACPO:

-Acompañar el aprendizaje

-Partir del estudiante como centro del proceso: "Interesa que el aprendizaje se realice con base en lo que los educandos conocen de su entorno físico-espacial inmediato (la vereda, el municipio) y lo que puede observar en él”. (Acpo, s.f., curso conocimiento del medio, p. 4) -Formular preguntas : Se trata de promover la observación analítica y problematizadora de los estudiantes y reconocer sus propios conocimientos como punto de apoyo para el aprendizaje de nuevos conceptos. (Ib.)

-Promover el sentido de pertenencia: "El sentido de pertenencia ayuda a las personas a crear una imagen de su territorio y de quienes lo habitan. Esa idea se puede ejemplificar a través de un ejercicio sobre la imagen que cada quien tiene de su vereda". (Acpo, s.f., curso Conocimiento del Medio, p. 13) 


\subsubsection{Estructura general:}

Desde el comienzo de los cursos, en su versión radiofónica, los estudiantes se encuentran con un recurso comunicativo que los invita a ser partícipes del proceso de aprendizaje. Es así como el cabezote o presentación usa la misma cortina musical que se hizo célebre por identificar a Radio Sutatenza. Apela así a un recurso básico de la realización radiofónica: recordar, pues "solo se recuerda lo que pasa por el corazón, y nada pasa tanto por el corazón como la música". (Pérez, 2012, p. 24).

Tanto el texto como el tono empleado por el locutor, preparan a los estudiantes para el diálogo., como se puede ver a continuación:

"Estas son las Escuelas Digitales Campesinas de Acción Cultural Popular, ACPO...

Ustedes son nuestros invitados de honor...

¡Es hora de aprender!

Bienvenidos...”

Es un tono afectivo, que busca aprovechar la cercanía o identificación con el oyente: "ustedes son nuestros invitados de honor"...Esta estrategia se complementa con la propia estructura narrativa, inscrita en el género dramático . Incluye los personajes Pedro, Etelvina, Jassay, Ramón y Pacho, quienes se dan a la tarea de contar de manera coloquial. Así mismo, se cuida de hacer una ambientación, con todos los recursos que ofrece el lenguaje radiofónico, con el claro propósito de hacer vivir la magia de la radio. Además, al incluir el diálogo como columna vertebral de la emisión, acompañado con música, sonido ambiente y efectos especiales, apela al "contrato de lectura" . Por lo demás, el ambiente dialógico, esencial en todo proceso comunicativo, cumple la tarea de contar con el otro, a partir de lo que Jorge Huergo llama " su universo vocabular". Y para que el impacto sea aún mayor, incluye cuentos como "la fábula del león y los animales de la selva". Se trata, entonces, de hablar, o como habla, o como le gusta a la gente (habitus lingüístico), pues como lo dijera el célebre ensayista estadounidense Hayden White, citado por Tomás Eloy Martínez lo único que mujeres y hombres conservan en sus mentes, son los relatos. (Martínez, 1997, p. 8) Así mismo, es evidente que los cursos están concebidos con un lenguaje dialógico e inclusivo, como este:

-Ramón; ¿Alguna vez le ha sucedido que está listo para hacer algo que siempre ha querido, pero no sabe cómo hacerlo? Y después de pensarlo, ¿se da cuenta de que necesita un plan que 
le ayude a llevar a cabo las metas que se propone?

-Etelvina: Aquí tenemos algunas preguntas que le ayudarán a reflexionar, para decidir sobre si integrar una asociación o una empresa en la que se requiere el trabajo en equipo:

¿Considera que tiene capacidades para el trabajo con otras personas?

¿Confía en los demás?

¿Es capaz de solucionar problemas de manera pacífica?

¿Le gusta aportar ideas a proyectos colectivos?

¿Cuáles son sus planes para los próximos años?

Como se puede advertir, es una propuesta que busca entablar una conversación con el otro: queda claro, entonces, que el oyente-alumno debe cumplir un papel activo , para potenciar su propio aprendizaje, en concordancia con la formación de la "ciudadanía rural". Así se evidencia también en el curso de "Liderazgo":

Los y las protagonistas principales de las formas de vida democrática, sus actores o actoras, son los y las sujetos, que la "encarnan" en sus acciones (...) Esta idea tiene como condición la ciudadanía activa, la participación, la puesta en obra del sentido de pertenencia a una comunidad política. (s.f., p. 8)

Y para que quede ninguna duda sobre la perspectiva de Comunicación/Educación inmersa en los cursos, todos cuentan con una sección denominada "Manos a la obra", con la cual se busca que las campesinas y campesinos desarrollen actividades de manera autónoma, por supuesto, con el acompañamiento y apoyo del auxiliar inmediato o tutor, que, como hemos dicho, actúa como agente motivador, en el marco de la tarea de interaprender con los estudiantes de las EDC.

Veamos ahora lo que ocurre con el curso "Comunicación, periodismo y comunidad" :

\section{Jassay:}

\section{...Gracias querida Etevina:}

Para empezar con nuestro curso, los invitamos a responder las siguientes preguntas:

¿QQué es la comunicación y qué elementos hacen parte de un proceso de comunicación?

-¿Qué es el periodismo y cuál es su objetivo?

-¿Cuáles son los géneros periodísticos? 
¿¿Qué es la libertad de expresión y la libertad de prensa?

...Y también se suma a este equipo de trabajo Ramón...Adelante Ramoncito...

Ramón: Gracias Jassay:

Entremos en materia...¿Recuerdan esta famosa fábula de Esopo?...Hagamos memoria, hagamos memoria...

Había una vez un joven pastor que vivía en un pueblo muy tranquilo. Este tenía la fea costumbre de decir mentiras.

Una día estaba cerca al pueblo y alarmó a los habitantes tres o cuatro veces gritando:

-¡El lobo, el lobo, el loboooo! Pero cuando los vecinos llegaron a ayudarle, lo encontraron riéndose sin parar porque les había hecho una broma.

Días después el joven pastor volvió a gritar: -¡El lobo, el lobo! Nuevamente los campesinos salieron de sus casas para perseguir al animal pero en vez del animal se encontraron con el pastorcito que otra vez se burlaba de sus buenas intenciones.

Semanas después, cuando el pastor descansaba debajo de una árbol mientras cuidaba a sus ovejas, apareció un grande y feo lobo que comenzó a atacar a sus ovejas.

Lleno de miedo el joven pastor gritaba:

- Por favor, vengan y ayúdenme; el lobo está matando a las ovejas.

Pero ya nadie prestó atención a sus gritos y mucho menos pensaron en ayudarlo. Cuando el lobo vio que el pastor no podría defender a su rebaño y que nadie le ayudaría, hirió y destrozó a su antojo a todas las ovejas.

\section{Pedro:}

Muy bien Ramón...Esta famosa fábula nos permite identificar los diferentes aspectos que están presentes en el proceso de comunicación...

Vemos cómo el primero en intervenir es el pastorcito, a quien podemos identificar, en este caso, como el emisor del mensaje....

\section{Etelvina:}

También apreciamos que los vecinos del pueblo fueron los receptores del mensaje, lo 
interpretaron y actuaron, es decir, respondieron al llamado del pastorcito al salir en su ayuda.

\section{Ramón:}

...Y el canal en este caso fue directo, es decir, no se usó otro medio de comunicación diferente a la propia voz del pastorcito.

\section{Jassay:}

Es importante también tener en cuenta el código que se usó, como lo fue el idioma castellano...Y el contexto, es decir las circunstancias en que se emite el mensaje.

Pedro:

Podemos concluir que el proceso de comunicación se da, siempre y cuando haya una respuesta, como ocurrió aquí...Entonces, si solo se envía un mensaje sin que haya participación de quien lo recibe, podemos decir que todavía no hay comunicación.

\section{Etelvina:}

Así es, Pedrito porque para que haya comunicación debe haber participación...En otras palabras, o la comunicación es participativa o no es comunicación.

(Entra cabezote de salida)

...Se observa aquí cómo desde la iniciación del curso se interpela a los estudiantes, al exhortarlos a reflexionar sobre lo que es la comunicación y el periodismo. Ese es un principio medular de la Comunicación/Educación, presente desde que Paulo Freire hablara de la necesidad de oponerse a la educación bancaria tradicional, según la cual sería suficiente con depositar en la alumna o alumno una serie de conocimientos, para que los almacene y luego los repita en forma memorística. En esa misma dirección de activar una educación liberadora, gracias al tono dialógico, se tiene en cuenta el universo vocabular del alumno y se parte de la base de asumirlo como poseedor de conocimientos y de saberes, que se deben poner al servicio de su proceso de aprendizaje. Es, entonces, una forma de invitarlo a la acción. Así, al 
no ser tratado como un elemento pasivo, se apela también al universo emocional del estudiante, a quien se le propone "volver a pasar por el corazón”: “¿Se acuerdan de esta famosa fábula de Esopo?". Se observa, por lo demás, el uso de un recurso fundamental en el lenguaje radiofónico, como lo es echar mano de la narración, pues, como lo señala José Ignacio López Vigil, hay que decirle "no a los discursos, sí a los cuentos. Si lo que quiere es que la gente apague el radio, échele un discurso; si la quiere atenta y entusiasmada, échele un buen cuento". (Pérez, 2012, p. 25)

Por lo demás, de nuevo, se usan los diferentes elementos del lenguaje radiofónico: música, voces, sonido ambiente y efectos especiales, para enganchar a los oyenteseducandos. (Contrato de lectura).

En cuanto al curso denominado "Comunidad, comunicación y periodismo", se destaca la perspectiva que plantea con el proyecto de las EDC, ya en marcha, de conformar la Red de Reporteros Rurales (R3), para que los propios estudiantes cuenten de manera directa lo que pasa en su entorno inmediato, bajo esta premisa de Tostoi: "Pinta tu aldea y serás universal".

Así, en la última unidad, titulada "soy reportero rural", se invita a los estudiantes a integrar el semillero periodístico de las EDC, entendido como

un espacio de formación en periodismo, para no expertos, de y para una comunidad en particular, en este caso la rural. Tiene como propósito realizar lecturas de fenómenos sociales y producir trabajos periodísticos, a partir de ellos en pro de su región. (ACPO, documento anónimo, s.f., p. 3)

De esa manera, ACPO se propone fortalecer la lectura crítica y analítica sobre lo que pasa en las comunidades campesinas, indígenas y afrodescendendientes para promover "el crecimiento de la región y el mejoramiento de la calidad de vida de sus habitantes". (Ib.)

También es importante entender que el curso no se concibe como un módulo aislado, sino como parte integral de la convergencia de medios, que incluye el periódico digital elcampesino.co; cartillas impresas y el programa de radio "Mundo Rural", donde, los educandos ya han empezado a contar sus historias.

\subsubsection{El papel de la radio}

Hoy, como ayer, la radio cobra una gran lugar en la tarea de ACPO. Su programa 
oficial, producto de una alianza con el semillero "Radio y ciudadanía", de la Universidad Sergio Arboleda, es "Mundo Rural”, un magazine que se emite con una periodicidad semanal en la emisora online "Radio Virtual", se retransmite en 26 emisoras comunitarias localizadas en nueve departamentos del país y está ubicado en las plataformas escuelasdigitalescampesinas.org y elcampesino.co

El espacio radial de las EDC tiene la siguiente estructura básica:

1o.Cabezote.

2o. Canción de apertura (Música popular campesina o de gran impacto en el campo)

3o. Cortina general (De corte campesino)

4o. Saludo y bienvenida, a cargo del conductor.

5o. Anticipo informativo (Breves )

6o. Desarrollo de noticias que tienen incidencia en el agro.

7o. Sube canción de apertura

8o. Sección "Las cartas del campo"

9o. Canción.

10o. Sección "Municipio invitado" ( Se hace un recorrido por las diferentes regiones donde están las EDC)

11o. Canción.

12. Sección "Las cartas del campo"

12o. Análisis del tema de la semana.

13o. Sorpresa musical antes del cierre.

14o. Despedida.

Esta propuesta se ha hecho posible gracias a las TIC, como se relata en la siguiente crónica, publicada en elcampesino.co:

"Este es Mundo Rural. Un programa para hacer del campo un lugar digno para la vida de sus habitantes"...

"Es mi tierra yo me siento como un rey; un rey pobre, pero al fin y al cabo rey"... (Fragmento de la canción campesina "El rey pobre", de Jorge Velosa)

Tanto la presentación como esta bella canción carranguera nos han puesto en ambiente...Es viernes y a las nueve de la mañana, como ya es costumbre, están frente a los micrófonos de la emisora online Radio Virtual Joel, Héctor, Liliana, Federico y Juan 
Carlos...Está empezando Mundo Rural, el espacio de las Escuelas Digitales Campesinas de ACPO.

Invitados de honor: nuestras campesinas y campesinas estudiantes de las EDC.

En sus casi cuatro años de vida, este espacio ya emblemático de ACPO y su Educación Fundamental Integral, EFI, ha venido consolidando la participación directa de ellas y ellos, las mujeres y los hombres del campo que hoy nos demuestran que sí es posible ejercer la ciudadanía rural, mediante su inclusión digital.

Como co-realizadores de este espacio, adscrito al semillero Radio y Ciudadanía de la Universidad Sergio Arboleda, entendimos que, para que este programa cobre su pleno sentido, no lo podemos hacer para sino con nuestras campesinas y campesinos. De ahí que estemos empeñados en que personajes como don Marco Antonio Zambrano, de Guayatá ( Boyacá) doña Gladys Celis, de La Capilla (Boyacá); doña Deyssi Labrada de la vereda El Hormiguero (Cali) o la joven Juliana Ortíz, de San Vicente del Caguán (Caquetá) entre muchos otros, echen su propio cuento. Así se llama la sección: "Como usted cuenta, eche su cuento". Y allí hemos escuchados relatos como estos:

"Yo entendí que líder no es el que más manda, sino el que más comparte”. " De mí se burlaban porque decían que a los 58 años qué iba a aprender de computadores, pero seguí adelante y ahora me miran como alguien importante para la comunidad". "Para mí es muy bonito que mis hijos, que se fueron hace varios años para Bogotá, ahora quieren regresar aquí al campo, porque me ven muy entusiasmada estudiando". "Todo lo que aprendo lo comparto con mi familia...Y ahí estamos progresando todos".

Estas son solo algunas de las frases que han salido de nuestros invitados de honor, ante las cuales nosotros, es decir, quienes estamos en cabina: Liliana, Joel, Héctor, Federico y Juan Carlos, nos sentimos como facilitadores de las EDC.

Ya son casi sesenta programas en cuatro temporadas y el crecimiento ha sido vertiginoso. Empezamos al aire en nuestra emisora online Radio Virtual; unos meses después se sumó "Bacana Stereo", de Restrepo (Meta); luego fue "ACPO Vive Radio Sutatenza", emisora fundada por exestudiantes de ACPO que emite por internet desde Potosí, en la Localidad de Ciudad Bolívar (Bogotá); después vinieron "Riscales Stéreo", de Nuquí (Chocó) y "Ecos del Caguán”, de San Vicente (Caquetá)...Y el pasado viernes 7 de abril, un poco antes de empezar la emisión, nos llegó otra buena nueva: ¡Ya son 26 las emisoras aliadas en 9 departamentos del país!

Recordamos entonces que al iniciar esta aventura periodística mencionamos como objetivo principal "fortalecer el diálogo social" porque "la democracia necesita otra forma de 
hablar"( Y de actuar)...Sabíamos que no era y no es una tarea fácil porque, como dice la canción del maestro Jorge Velosa, "los sueños, sueños son”...Pero con todos ustedes, nuestras campesinas y campesinos, los estamos y los seguiremos haciendo realidad.

A partir de los lineamientos del contrato de lectura y de los postulados de la Comunicación/Educación, se puede señalar que si bien la radio ya no es el eje de la estrategia de la Educación Fundamental Integral, como lo fue en la era de Radio Sutatenza, sigue cumpliendo un papel clave en la convergencia de medios de ACPO.

Para el análisis es fundamental tener en cuenta los cambios sustanciales que se presentan en el modelo actual de las EDC frente al de las Escuelas Radiofónicas, tanto en las lógicas de producción como de recepción de los discursos. Así, no solo en la estructura de "Mundo Rural" sino en su puesta al aire, se advierte el interés por promover la participación directa de los estudiantes de las EDC, lo que se evidencia en las secciones "Como usted cuenta, eche su cuento" y "Las cartas del campo". Con la primera, se busca la construcción de historias de vida sobre lo que significa ACPO para sus propios estudiantes; es la memoria viva del proceso de formación, que implica escuchar diferentes tonos, matices y perspectivas. Así, se habla con el otro "y no para o sobre el otro". (Huergo, 1999) Y la segunda inaugurada recientemente- apunta a revivir la correspondencia, una de las estrategias medulares de la Educación Fundamental Integral. Como se ha recordado, en los tiempos de Radio Sutatenza, el intercambio epistolar fue sustancial dentro del modelo de comunicación. Hoy se trata de darle la importancia necesaria, sin desconocer que las TIC permiten la retroalimentación permanente del proceso, tanto en tiempo real como de manera asimétrica.

Así las cosas, es claro que el contrato de lectura, que Eliseo Verón define como la propuesta o propuestas de discurso o mensajes que el medio propone a sus oyentes, y que hace efectivo el nexo comunicativo, tiene hoy unas variantes interesantes, que se derivan de la participación activa de los estudiantes de las EDC como productores y consumidores ( prosumidores). Para Verón, "en el caso de las comunicaciones de masa es el medio el que propone el contrato". Pero en el caso estudiado aquí la propuesta de contrato ya no es exclusiva del medio sino, en general, de los actores de las EDC. De esa manera, las expectativas, motivaciones, intereses y contenidos no corresponden de manera exclusiva al "discurso del soporte por una parte, y sus lectores, por la otra", pues se han venido integrando a una sola parte, que se llama prosumidor.

En esa dirección, en las mencionadas secciones de Mundo Rural, ellas y ellos son los 
que proponen qué y cómo quieren hablar sobre los que les preocupa de su propio mundo. Entonces allí no hay una agenda predeterminada, pues interesa que ellas y ellos incidan en la construcción de su propia agenda local, regional o nacional.

De esa manera, se pasa de la concepción clásica de las audiencias como agentes pasivos a la de co-realizadores, porque, como se apuntó, Mundo Rural no se hace para sino con las campesinas, los campesinos, los afrodescendientes e indígenas de las EDC. En palabras del radialista Guillermo Patiño, así se marca una diferencia entre hacer radio y ser parte de ella, pues el foco ya no está en el oyente o en el receptor de contenidos sino en la construcción "de comunidades, públicos activos, que le aportan a los contenidos de la radio y que se sienten parte del proceso". (Pérez, 2015, p. 54) Por consiguiente, ahora el énfasis está en la construcción de ciudadanías, es decir, en la formación de identidades.

Desde esa concepción, "los educandos 'cuentan', en cuanto relatan su realidad, hablan del mundo, lo dicen”. (Huergo y Fernández, 1999, p. 129) Así, como ya lo planteaba Paulo Freire, se parte del universo vocabular de los propios estudiantes de las EDC o ex estudiantes de las Escuelas Radiofónicas, muchos de los cuales ofician como acompañantes, motivadores o asesores del proceso de formación actual.

Ya en cuanto a los recursos usados para impactar con sus mensajes o "producir efectos de reconocimiento", que Verón identifica con "las modalidades del decir" (Ib.), es evidente el uso del tono conversacional o dialógico. Según la teoría del lenguaje de la radio, uno de sus principios básicos para abrir y potenciar la conversación con el otro consiste en el buen buen uso del tono, referido a la forma como se estructura y como se emite el discurso. La recomendación es clara y directa: a la hora de enganchar a quien escucha, en radio cuenta más el cómo se dice que lo que se dice. "De allí viene la fuerza expresiva". (Pérez, 2015, p. 33). Claro, en el programa analizado, están más o menos presentes los demás elementos del lenguaje (sonido, magia, voces, silencio y música). Pero se destaca el interés de aprovechar este último, que está presente de principio a fin. Como lo subraya el investigador Hernando Vaca Gutiérrez, en las épocas de Radio Sutatenza la música “(...) fue un instrumento de interacción bien significativo (...) recuperó el espacio de la fiesta en el mundo campesino, despertó la alegría y la diversión, y apoyó el desarrollo de la competencia comunicativa" ( $\mathrm{p}$. 263). Hoy, como se dijo, sigue siendo medular, en la medida en que matiza, acompaña, hace más amena la radio al sacarle el mayor partido posible a su tarea de entretenimiento, facilita el posicionamiento de los mensajes y permite conocer y reconocer al mundo campesino desde su rica diversidad cultural, que es uno de los principales objetivos de Mundo Rural.

Por supuesto, hablar de la radio como componente de la EFI, significa referirse a un 
proceso que aunque exhibe avances importantes aún no es perfecto, pues demanda profundizar la participación de los estudiantes de las EDC, para que tengan la posibilidad de administrar y divulgar sus propios contenidos. Ello pasa por el mejoramiento continuo del trabajo de formación que, como se observó, es uno de los propósitos centrales de la Red de Reporteros Rurales (R3). Lo cierto es que a 2018 ya son 64 reporteros, cuyos contenidos vienen siendo publicados en elcampesino.co y en el programa de radio de las EDC. También es importante hablar de propuestas como la de ex estudiantes de ACPO que decidieron fundar sus propios medios, como ACPO Vive Radio Sutatenza y Asoacpo Sutatenza Medellín, que les ha permitido profundizar su papel de prosumidores, como se lee en los siguientes relatos:

\subsubsection{Acpo Vive Radio Sutatenza}

Hablar del papel de la radio y de la producción de sentido es preguntarse también por la forma como los discursos que circulan por allí han calado entre los estudiantes de ACPO.

Un ejemplo está en las diversas actividades desarrolladas hoy por los exestudiantes de las Escuelas Radiofónicas y por lo actuales estudiantes de las Escuelas Digitales Campesinas. Una de ellas se palpa en la emisora online "Acpo Vive. Radio Sutatenza”, fundada el 23 de agosto de 2015 por los líderes formados en Radio Sutatenza Erasmo Angarita Tovar; Angelmiro Babosa y Rosmira Henao Zarrazola, como lo cuenta cuenta el mismo Erasmo Angarita Tovar:

"Hoy estamos conectados con el mundo": Erasmo Angarita Tovar

Nacido en la zona rural de San Antonio (departamento del Tolima) Erasmo hizo parte de la última promoción de líderes de las Escuelas Radiofónicas, en 1993, y se considera "hijo de ACPO”, como quiera que su madre también se alfabetizó gracias a Radio Sutatenza. “Acpo Vive Radio Sutatenza” emite desde el barrio Potosí, en la emblemática localidad Ciudad Bolívar ( suroriente de la capital colombiana). Decimos emblemática, porque Ciudad Bolívar puede considerarse hoy en Colombia como un símbolo del desplazamiento forzado, tanto aquel generado por la amenaza de las armas, como aquel ocasionado por carencias económicas. Una investigación divulgada por la Universidad del Rosario, indica que el 26\% de los habitantes de esa localidad bogotana son desplazados:

Esta zona incluye una buena porción del área rural de Bogotá y muchos de sus habitantes todavía son campesinos. Debido a este aspecto semiurbano, grupos guerrilleros y paramilitares poseen áreas de control difíciles de detectar. La violencia es una de las características primordiales y 
es la localidad con mayor tasa de mortalidad y menor cobertura médica. (Universidad del Rosario, 2009)

Desde allí, desde el corazón de ciudad Bolívar, habla Erasmo. Según sus propias palabras, uno de los propósitos de "ACPO vive Radio Sutatenza" es replicar el modelo de la EFI:

Mi madre estudió en el año 53 con Radio Sutatenza, tenía 6 años; aprendió a leer con Radio Sutatenza. Yo terminé en el 93, fuí de la última promoción, es decir, hace 24 años por esta época yo estaba estudiando en ACPO. Estuve allí en Sutatenza, Boyacá, y me enamoré de ACPO.

Hoy hemos recibido el aval de ACPO para abrir la emisora "ACPO Vive Radio Sutatenza" y también tengo que agradecerle mucho a esta universidad (Sergio Arboleda) porque nos han ayudado a seguir adelante, mediante la capacitación.

Hoy el resultado es que estamos conectados con el mundo. Son entre 30 y 40 países, con quienes tenemos comunicación todos los días. Hablamos con exalumnos, gente que quiere conocer la obra. En un solo programa como "Despertar Campesino", f recibimos hasta 8.000 mensajes cada día.

Nosotros somos una emisora cristiana católica, pero le damos cabida a todas las creencias. Nos basamos en la EFI cristiana. Hacemos una radio moderna; nos guiamos por las EDC, el periódico El Campesino. También retomamos la sabiduría de los grandes de ACPO, como el doctor Luis Alejandro Salas y líderes comunitarios, como Mario Torres, quien es nuestro corresponsal en Nueva York...Y muchos más, que no dejan perder la esencia de las Escuelas Radiofónicas.

Acabamos de terminar una campaña que se llama "La ignorancia es un pecado"; la terminamos hace un poco más de un mes, y ahora entramos a la etapa "dignificación de la familia”. Buscamos compartir mensajes que dignifiquen a la persona. Somos escépticos frente al proceso de paz, pero queremos incentivar a las personas para que asuman que la paz empieza por la persona y por la familia.

Hoy en "ACPO Vive Radio Sutatenza” tenemos muchos jóvenes vinculados. Un grupo de niños también hace su propio programa los sábados. Los invitamos a todos a que vayan a nuestra emisora. No sé qué pasa con nosotros pero los que hacemos parte de ACPO nos amamos. La gente nos ha apoyado. En Europa abrimos una convocatoria, y tenemos como corresponsal en España a Eduardo Rebollo. También tenemos corresponsales en 
México, en Europa, en Canadá, en Honduras. Diariamente tenemos un programa de 5 a 8 de la mañana y, como les decía, entran 8000 mensajes en un solo programa...

\subsubsection{Asoacpo Sutatenza Medellín}

Esta es otra de las emisoras creadas por ex estudiantes de las antiguas Escuelas Radiofónicas, con el propósito de mantener vigente los principios y propósitos de la Educación Fundamental Integral (EFI), como nos lo cuenta su actual director, quien también nos habla sobre lo que significó su experiencia en Radio Sutatenza:

\section{“Como ocurrió con la antigua Radio Sutatenza, ésta va a ser esencialmente una radio educativa": Eseliano de Jesús Flórez Barrera.}

Yo me vinculé a las Escuelas Radiofónicas por medio del párroco de mi pueblo, en este caso de Valdivia (Antioquia) a través de un movimiento llamado Escuelas Radiofónicas. Comencé como alumno-auxiliar inmediato. Esta fue la parte primordial, el contacto más importante. Logré primero la vinculación a nivel local y luego a nivel nacional.

Hice un primer curso que se llamaba "curso para líder campesino", que tenía una duración de cuatro meses; luego hice un segundo curso que se llamaba "para líder local de la educación campesina". Hice actividades de liderazgo en mi comunidad, principalmente en mi vereda y en mi municipio y después me vinculé a otro curso de líder local. Y al haber aprobado esos conocimientos en el Instituto Campesino Masculino de Sutatenza, fui enviado a diferentes comunidades del país en calidad de práctico. Mi práctica la realicé en algunos municipios de la Diócesis de Cúcuta (Norte de Santander). Más tarde hice unos cursos más avanzados (curso para líder regional, primera etapa, y curso para líder regional, segunda etapa, con una duración de un año). Luego volví al campo, a las Diócesis de Pamplona, de Ocaña y de Cúcuta (Norte de Santander) y luego fui a las de de Santa Rosa de Osos y de Santa Fe de Antioquia (Antioquia)

Mi vida cambió tremendamente a través de estos programas. Tuve muchas motivaciones para innovar en la educación, para capacitarme y para servirle a los demás compañeros del campo. Aprendí a usar los diferentes medios educativos, especialmente el sistema de combinación de medios de ACPO, como eran las cartillas; el periódico El Campesino; los libros de la biblioteca; la correspondencia; los centros de capacitación en Sutatenza (Boyacá) y en Caldas (Antioquia); así como los promotores, coordinadores y un departamento de profesores muy capacitado, todo a partir de Radio Sutatenza. 
Ahora vemos el paso de las Escuelas Radiofónicas a las Escuelas Digitales. Antes era por Radio Sutatenza y hoy es a través de Internet. Es un programa esencial, especialmente para la formación de la juventud campesina de los barrios, pueblos y ciudades de Colombia. El problema es que el Internet en Colombia es muy malo todavía, la cobertura es muy baja. Esta experiencia la viví cuando comencé en el año 2015 en el departamento de Antioquia, a experimentar el programa de las EDC en cuatro municipios: Marinilla, El Santuario, Montebello y Santa Bárbara. Ponerlo en marcha ha sido muy difícil en algunos municipios, debido al problema de la cobertura. Actualmente seguimos con ese problema. Es el inconveniente que le veo a la plataforma de las EDC. Pero lo importante es que en medio de las dificultades seguimos adelante, y por eso decidimos fundar la emisora. Esta es una iniciativa de la Junta directiva de Asoacpo, capítulo Antioquia. Luis Eduardo Correa Zapata, a quien llamamos el papá de los líderes, es uno de los promotores. Él trabajó en Caldas (Antioquia) y ocupó diferentes posiciones dentro de ACPO. También tenemos a José Domingo López, exalumno, quien hoy vive en Marinilla.

Tenemos hasta el momento un balance muy positivo, tanto en la cobertura como en la programación de contenidos. Pero volvemos al asunto del Internet. Cuando internet está débil, la programación no llega con la calidad que se necesita. Es un proyecto que puede llegar a muchas partes de Colombia y el mundo, siempre y cuando se mejore la señal de Internet. Sin embargo, hay que destacar que llevamos tres meses y vemos a ciencia cierta que hay buenos resultados: tenemos buena audiencia tanto en Colombia como en el mundo.

Radio Sutatenza hizo una tarea muy importante con su Educación Fundamental Integral. Queremos retomar ese legado de la obra de monseñor José Joaquín Salcedo. Aquí en Medellín exfuncionarios y exempleados de ACPO seguimos trabajando con esos principios. Para eso queremos revivir la Radio Sutatenza, para seguir con el trabajo que hacían las Escuelas Radiofónicas.

Tener una emisora online significa para nosotros un cambio muy grande. Nuestros usuarios están muy animados, porque se está reviviendo Radio Sutatenza. Es una radio participativa, comunitaria y de servicio. Claro, son otros tiempos pero lo importante es que la gente está animada. En cuanto a la programación, pensamos encadenarnos con otras emisoras, como ACPO Vive Radio Sutatenza y Odismar Stereo 717, dirigida por don Odilio Martínez Carrillo. Y como ocurrió con la antigua Radio Sutatenza, ésta va a ser esencialmente una radio educativa.

Contamos con una programación inicial de 4 de la tarde a diez de la noche, que es un horario propicio para nuestra audiencia. Esta es una frecuencia amiga. Es totalmente cultural. 
Por la mañana nos vamos a encadenar con ACPO Vive, que será la emisora matriz. También con Odismar 717, y haremos enlaces con emisoras del Ejército Nacional.

También queremos que se vincule Mundo Rural, porque unidos somos más y más fuertes.

\subsection{4 elcampesino.co}

Desde su fundación, en 1958, el semanario El Campesino se concibió como un medio complementario de la educación radial. Buscaba, así mismo, "ilustrar a las audiencias campesinas con temas de opinión sobre la vida nacional". (Bernal, 2013). Como lo indica su último director, Gabriel Rodríguez (Pérez , 2017, audio podcast), fue clave en la Educación Fundamental Integral, en la medida en que activó una fluida correspondencia con las y los estudiantes de las Escuelas Radiofónicas, quienes debían escribir a El Campesino, para responder a las tareas y ejercicios que les dejaban sus profesores: "Las cartas eran parte del proceso de evaluación; quienes estaban en el curso básico, debían escribir su primera carta, ese era su primer ejercicio, y para los más avanzados, se usaban las separatas de El Campesino". (Audio podcast)

Fue una interacción que también le permitió a ACPO saber qué pensaban sus lectores no solo en el aspecto estrictamente académico sino en el ámbito cultural, pues, por lo general, las cartas "iban acompañadas (...) con coplas y comentarios de los campesinos sobre diferentes temas". (Bernal, 2005, p.30) Así mismo, fue la base de retroalimentación para saber si la propuesta de Comunicación/Educación respondía a las expectativas y necesidades de la EFI. Como lo habíamos indicado, permitió que ACPO activara un "monitoreo y control sobre los diferentes componentes del proceso educativo".

El periódico impreso circuló por última vez en 1994, con la promesa de regresar pronto. Y se revivió en versión digital en 2013, como parte integral de ACPO, con este postulado misional: "El Campesino espera así ser la voz del campo colombiano y es el único medio colombiano dedicado a informar exclusivamente sobre los temas rurales".

Hoy elcampesino.co registra un crecimiento exponencial, con cerca de 63.000 usuarios permanentes y 34.200 seguidores en Facebook (abril de 2017).

Como medio al servicio de la Educación Fundamental Integral, hace parte de las jornadas académicas de las EDC de tal forma que al iniciar cada clase los estudiantes leen uno de los artículos publicados en elcampesino.co .

Así mismo, se ocupa en hacerle seguimiento a las diversas actividades de las Escuelas Digitales Campesinas y, lo más importante, sirve de medio de expresión y de difusión de las 
propias campesinas y campesinos vinculados a la EFI, a partir de su Red de Reporteros Rurales ( R3) Por eso, incluye la sección de las EDC, donde publica en forma permanente los reportes que envían estudiantes y facilitadores desde las 8 regiones colombianas en las que hoy hacen presencia. Podemos mencionar, a título de ejemplo, artículos como los siguientes: "las digiaventuras de un facilitador auxiliar" ; “ 'Juanla', el nuevo estudiante de EDC en Buenaventura"; "Entre Cali y la zona rural de Trujillo: la travesía de un encuentro de aprendizaje".

Además, la publicación incluye las siguientes secciones: "Noticias"; “ 70 años de ACPO"; "Editorial"; "Espiritualidad"; "Lo más leído" y "Radio Sutatenza", en la que se ubica el podcast del programa radial "Mundo Rural".

Al retomar la senda que lo posicionó y lo identificó como un medio vocero del campo colombiano, elcampesino.co tiene hoy la tarea de contribuir a la comunicación entre las zonas rurales y los centros urbanos, donde se toman las grandes decisiones que tienen que ver con la vida de las campesinas, campesinos, afrodescendientes e indígenas, vinculados a Acción Cultural Popular (ACPO). Así lo podemos advertir en el siguiente cuadro sobre las fuentes de los artículos publicados, en el que se evidencia una participación diversa que, en la etapa reciente, se ha fortalecido con la Red de Reporteros Rurales (R3) y la sección "Las Cartas del Campo". Es la forma como la propia organización concibe la inclusión de esa comunidades - las más vulnerables del país- en la era digital. 
Fuentes de los artículos elcampesino.co (2017)

\begin{tabular}{|c|c|c|c|}
\hline Fuente & Febrero & Marzo & Abril \\
\hline Propios & 60 & 32 & 47 \\
\hline Facilitadores & 28 & 40 & 38 \\
\hline Practicante & 36 & 40 & 28 \\
\hline Voluntarios & 1 & 5 & 1 \\
\hline Campo de la Palabra & 28 & 31 & 29 \\
\hline Comité Editorial & 3 & 6 & 6 \\
\hline Kenny & 7 & 3 & 3 \\
\hline Mundo Rural & 3 & 4 & 4 \\
\hline TOTAL & 166 & 161 & 156 \\
\hline
\end{tabular}

Elaboración: equipo editorial elcampesino.co

\subsubsection{Retroalimentación en tiempos de las TIC}

Como hemos subrayado, a la manera de lo que unos años después Jesús MartínBarbero (1999) identificara como "ecosistema comunicativo", ACPO fundamenta su modelo en lo que podemos denominar un sistema participativo integral, en el que los saberes se “deslocalizan"; están aquí y allá,y se pueden identificar mediante un profundo cambio del modelo educativo tradicional. Por consiguiente, el maestro ya no es un "mero transmisor de saberes": 
(...) Se convierte en formulador de problemas, en provocador de interrogantes, en coordinador de equipos de trabajo, en sistematizador de experiencias y en memoria viva de todo lo que su sociedad necesita pasarle a la nueva generación. (P. 21)

En consecuencia, el "ecosistema comunicativo", permeado por el contexto cultural, incluye diversas formas de inclusión, deliberación, participación y retroalimentación, que sin negar la importancia de los medios tradicionales- asume y valida otras instancias de interacción, entre éstas la relación interpersonal que le ha dado tan buenos resultados al modelo de ACPO. Es lo que se hace evidente en sus diversos medios y en las distintas actividades paralelas, como el "Foro ACPO y Radio Sutatenza 70 años", en el que las campesinas y campesinos oficiaron como protagonistas.

Hoy, como ayer, la EFI se apoya en la retroalimentación de sus usuarios. Como vimos, en la época de las Escuelas Radiofónicas uno de los recursos más usados fueron las cartas. Y al inaugurarse esta nueva etapa, lo primero que hizo la organización fue consultar a las campesinas y campesinos, mediante grupos focales realizados en el Valle del Cauca, Chocó y Boyacá. Como lo explica Lavacude (Pérez, 2017, audio podcast) se les formuló la siguiente pregunta: ¿Qué debe hacer ACPO en el siglo XXI para responder a las necesidades educativas del campo? Entonces fueron consultados 300 campesinos, cuyas respuestas sirvieron de base para crear la plataforma "Mundo Rural", en la cual se ofrecieron los primeros cursos de esta nueva era. Y como la esencia participativa se mantiene, fueron las mismas campesinas y campesinos quienes, en la práctica, le cambiaron el nombre a la plataforma, a la que no llamaban "Mundo Rural” sino Escuela Virtual. De allí nació la denominación actual: "Escuelas Digitales Campesinas".

En la actualidad las redes sociales, en especial Facebook, son el principal instrumento para tomarle el pulso a los prosumidores, y gracias a herramientas como Google Analytics, ACPO sabe que la mayoría de lectores de elcampesino.co está entre los 25 y los 35 años, y que los contenidos que más impacto causan son aquellos que le dan su sello de identidad la publicación, como las diversas manifestaciones culturales, en especial la gastronomía campesina. (Ver gráficos)

Gracias a la sección "Lo más leído", tanto el Consejo Editorial de elcampesino.co como los realizadores del programa de radio cuentan con la información oportuna para la toma de decisiones. Esa es, sin embargo, solo una parte del proceso de retroalimentación, el cual se profundiza con la inclusión directa de los estudiantes, ya no solo como consumidores sino como productores de contenidos, lo que se evidencia tanto en "Mundo Rural" como en 
el periódico digital y en el esquema activo-participativo de los cursos.

Claro, hoy también sigue siendo fundamental la correspondencia $\mathrm{y}$, como quiera que los medios a disposición de lo internautas se han multiplicado, los retos para ACPO como organización son cada vez mayores, pues sabe que no solo debe recibir sino contestar...Volver a recibir, y volver a contestar...

\subsubsection{El radioclip como dinamizador del diálogo social}

Producción colectiva de sentido, diálogo entre las mismas comunidades y comunicación de las comunidades con el resto de la sociedad. Estos son algunos de los aspectos que se potencian mediante la práctica del radioclip, un formato corto que podemos considerar hijo de la radionovela, a su vez hija del radioteatro, ya incorporado a la Acpoeducación. (Pérez y Pinilla, 2019)

El término radioclip -antes conocido como radiodrama- fue acuñado por la organización "Radialistas Apasionados", al retomar la práctica exitosa del "videoclip", ese pequeño formato que se fue imponiendo en la televisión como eficaz fórmula para dar a conocer las producciones musicales.

En comparación con la propuesta televisiva, el radioclip gana en versatilidad, al incorporar toda clase de problemáticas sociales, en la medida de lo posible identificadas por los propios agentes que viven y, en no pocas ocasiones, padecen la realidad.

A diferencia del género informativo, no busca presentar sino representar la realidad. Es allí, tanto en el ejercicio de construcción de la historia como en su puesta en escena, donde la comunidad debe jugar un papel protagónico, mediante el ejercicio de un amplio diálogo de carácter horizontal.

Esa es, justamente, una de sus grandes bondades: poner a actuar a las comunidades, para representarse y representar su propio mundo, lo que pasa por un ejercicio de deliberación que fluye espontáneo, dinámico $\mathrm{y}$, por lo tanto, útil en proyectos de transformación social, pues, como lo destaca Ómar Rincón, "la ficción genera más reconocimiento y significa todo un reto de creatividad para sus realizadores más allá del tema de costos". (2015, p. 53)

Hoy, en la era digital, una de las grandes alternativas para posicionar contenidos está en distribuir los radioclips mediante la modalidad de podcast, en la web y en dispositivos móviles. Inserto en lo que se denomina radio por demanda o a la medida, el podcast permite 
que, apoyados por un computador y un micrófono, todas y todos nos podamos convertir "en productor y locutora y lanzar programas al aire, sin necesidad de frecuencias o permisos, sin necesidad de dinero".(García, 2010, p. 259) Esta opción, a la cual acude ACPO para divulgar su programa de radio Mundo Rural" cobra día a día más fuerza en el mundo, como lo demuestra su auge en países como Estados Unidos, donde a 2016 ya había 98 millones de oyentes, o que el The New York Times, considerado el primer periódico impreso del mundo, también haya lanzado un podcast informativo diario.

\subsubsection{Estructura}

El radioclip ofrece la gran ventaja de constituir una unidad narrativa en sí misma, es decir, el pequeño relato -que puede durar entre uno y cinco minutos- no queda en "continuará".

Se pueden identificar los siguientes elementos básicos:

$1^{\circ}$. Introducción o contexto. Allí se ubica al oyente en el entorno de la acción, bien sea mediante la figura del narrador, o a partir de los recursos que nos brinda el lenguaje radiofónico, esto es, sonido ambiente, efectos especiales, voces, música y silencio.

$2^{\circ}$. Desarrollo de la historia: Se activa mediante diálogos cortos y naturales que se logran con la cuidadosa redacción para el lenguaje hablado, en el cual no debe haber lugar ni para los giros idiomáticos o palabras rebuscadas ni para el lenguaje técnico sin su respectiva traducción. En palabras radiofónicas: el diálogo debe identificarse con la forma como habla la gente. Qué mejor entonces que sea la misma comunidad la que intervenga de manera directa en la confección de sus propios relatos. Y para ello resulta aconsejable lo que José Ignacio López Vigil (2014) denomina validación del texto, durante la cual interviene todo el equipo de trabajo, con el propósito de analizar si los diálogos están, o no, bien hechos, es decir, si se habla como habla la gente en su cotidianidad.

$3^{\circ}$. Contrapunteo o conflicto: Como ocurre con todo dramatizado, si la historia carece de conflicto, el interés será nulo. El conflicto, identificado en lo político como dinamizador de la vida social (Chantal Mouffe), es indispensable para que garantizar los clímax o puntos altos, claves para lograr el enganche o identificación con el oyente. Algunos ejemplos: problemas con el uso del agua, porque alguien decidió represarla para su uso exclusivo; otras disputas por el acceso a servicios como el de energía cuyas conexiones ilegales pueden poner en riesgo la misma vida de la gente; indignación por el robo de los recursos públicos; problemas de movilidad agravados con la invasión del espacio público...Conviene anotar que en algunos casos, aunque el conflicto no se evidencie en la misma historia, si 
corresponde a una problemática social aguda que, como tal, demanda soluciones urgentes, el interés de la comunidad está asegurado.

$4^{\mathrm{o}}$. Conclusión: Debe ser clara y contundente, no porque el cierre no admita discusión sino porque debe quedar bien claro que esa historia terminó ahí. El mejor indicador está en la reacción del oyente: si el cierre está mal hecho, se quedará con el sinsabor de algo que empezó pero no terminó; si se cerró de manera certera, se activará la necesaria reflexión alrededor de la problemática planteada, que es el telón de fondo del radioclip.

Eso sí: no es conveniente terminar en tono de moraleja, pues en radio resulta de poca utilidad o el sermón o la cantaleta. Como ya se ha dicho: si quiere a la gente aburrida y apagada, échele sermones o cantaleta; si la quiere viva y dispuesta, échele cuentos.

\subsubsection{Práctica de Comunicación/Educación}

Jorge Huergo subraya que una de las claves de la práctica de Comunicación/Educación está en contar con el otro. Su escenario es en el campo de la cultura, entendido como un espacio de lucha/disputa por la construcción de sentido. Sacarle el mayor partido posible a esa realidad es la apuesta central del radioclip.

Se busca, en otras palabras, a la forma potenciar el interaprendizaje, que significa aprender con el otro y del otro, porque "no hay habla posible sin el habla del otro". (Daniel Prieto Castillo, 2005, p. 24). Es, desde lo que otros autores como Tomás R. Villasante denominan sociopraxis, la cual incluye una alta dosis de implicación, en la que "el observador y el observado sienten que están aprendiendo juntos, cuando vibran en una tarea conjunta y creativa para ambos, aunque lo vivan de forma distinta". (2006, p. 4)

Es un asunto que cobra más importancia en clave política, más aún en un contexto como el latinoamericano, que amén de su precario sistema de escolarización, se ha caracterizado por una arraigada tradición oral, pues, en palabras de Huergo (Ib., p.165) "en general las mayorías populares latinoamericanas han tenido acceso a la modernidad sin haber atravesado un proceso de modernización económica y sin haber dejado del todo la cultura oral".

\subsubsection{El radioclip en las EDC}

Aunque aún de manera incipiente, las Escuelas Digitales Campesinas de ACPO han incorporado este formato a su estrategia de Educación Fundamental Integral.

Es una manera de recuperar uno de los elementos clave que ya había empleado en las antiguas Escuelas Radiofónicas, con sus radionovelas. En efecto, Radio Sutatenza apeló a 
dramatizados como "No serás un extraño", que giró alrededor de "la apasionante historia de un niño que quería ser médico: sus sueños, su amor, su vida..." Y "Manuela", "una novela costumbrista escrita por José Eugenio Díaz Castro en 1856”. Fueron producciones realizadas por su propio equipo de radioactores. Ahora, en el formato corto del radioclip los estudiantes de las EDC deben ser protagonistas de principio a fin.

Un primer ejercicio se hizo con estudiantes del semillero "Radio y ciudadanía" de la Universidad Sergio Arboleda, en el marco de una campaña de adaptación al cambio climático, que se promovió de manera intensa en el departamento de La Guajira -en el extremo norte de Colombia- el más azotado por la sequía. (Ver uno de los guiones en el anexo D).

Como se puede notar, el radioclip es una manera de apelar a la creatividad social, aquella que le apunta a la construcción colectiva de sentido, en aras de metas comunes y, para lograrlo, incluye una alta dosis de crítica y de autocrítica, requisito básico para ejercer la Comunicación/Educación. Es una de las nuevas apuestas de las EDC y su Educación Fundamental Integral.

\subsection{Hablan los estudiantes}

¿Cómo han recibido los estudiantes la propuesta de Acpoeducación? Ellos mismos lo cuentan en los siguientes relatos, que se han realizado para esta investigación con el apoyo del semillero "Radio y Ciudadanía", de la Universidad Sergio Arboleda. (Se incluyen también algunas tutoras y tutores, para tener una visión más integral del proceso)

\subsection{1 "La educación salva el país": Angelmiro Barbosa}

En el marco de esta investigación y con ocasión de los 70 años de ACPO, campesinas y campesinos se reunieron en la universidad Sergio Arboleda para rendir tributo al legado de la Educación Fundamental Integral. He aquí, entonces, un ejemplo de deliberación pública que, en este caso, apunta a mantener vivo el legado de Radio Sutatenza, y su paso de las Escuelas Radiofónicas a las Escuelas Digitales Campesinas, en el siguiente relato, publicado en elcampesino.co:

"Para mí el renacer de ACPO con sus Escuelas Digitales ha sido algo maravilloso; nosotras creíamos que los computadores eran para los niños y para los jóvenes, pero hemos comprobado que también son para los mayorcitos. Ahora he comprobado que me gusta interactuar con la gente del campo, para motivarlos y que se vinculen más y más a este 
programa".

Son palabras de Virgelma Barrera Sastoque, una líder nata, de Sutatenza, Boyacá, quien ha sido testigo directo, como estudiante o como espectadora, tanto de las Escuelas Radiofónicas como de las Escuelas Digitales Campesinas, EDC.

Ella fue una de las invitadas de honor al foro "ACPO y Radio Sutatenza 70 años", realizado el 27 de abril de 2017 en el auditorio principal de la Universidad Sergio Arboleda.

Ese día campesinas, campesinos, estudiantes y académicos se encontraron para evidenciar algo que ha vuelto a sentir el país desde 2012: que ACPO y su Educación Fundamental Integral siguen más vivos que nunca.

Estuvieron también Luis Alberto; Rosmira; Jessica; Paula; Rafael; José Israel; César; Erasmo, Hermes; Blanca Inés; Esperanza...Y muchos más...Todas y todos con algo en común: un pasado y un presente atravesado por la historia de Acción Cultural Popular.

“ACPO impactó porque llegaba con los mensajes reales, en los momentos reales y en forma directa a los campesinos; los temas tenían credibilidad porque se enfocaban hacia lo que le interesaba al campesino. Yo llegué a apoyar a los líderes que estaban en los municipios y después fui dirigente campesina, es decir, me capacité en los institutos; también fui líder de la educación campesina y líder regional...”, recordó Rosmira Henao Sarrazola.

Para otro estudiante de las Escuelas Radiofónicas, José Israel Cante Moreno, Radio Sutatenza y ACPO le cambiaron la vida, pues a sus 18 años no sabía leer ni escribir:

"Fui concejal en Mesitas del Colegio; fui dirigente campesino; me desplazaron en el año 76 por decir la verdad. Y hoy lo que quiero es que los medios nos hablen con la verdad. Era la verdad que siempre se dijo en El Campesino y en los libros y cartillas de ACPO. ACPO despertó a los campesinos y me siento orgulloso de participar en este foro. Es muy bonito saber que ACPO no ha muerto".

...Y sí, la fuerza de ACPO, que es la fuerza de nuestras campesinas y campesinos, se palpa hoy en estas cifras: ya son más de 18 mil estudiantes -la mayoría mujeres- en 48 municipios y 8 departamentos del país.

...Porque ahí, en el campo colombiano, se juega el presente y el futuro de la paz pues, como lo dice Angelmiro Barbosa, otro ex estudiante de Radio Sutatenza, "la educación es la clave; y con educación, especialmente de la juventud, sacamos adelante este país".

\subsubsection{Más voces (Audios podcast)}

\section{Rosmira Henao Zarrazola* (lideresa de ACPO):}




\section{"Radio Sutatenza me sirvió para levantar la cabeza y para descubrir las potencialidades que tenía como ser humano"}

Para contextualizar un poco geográficamente y entender la situación social por la que atravesaba en esa época, yo vivía en una vereda bastante retirada, en el municipio de Liborina (Antioquia). Esta vereda quedaba a más de 10 horas de camino del municipio más cercano. En ese entonces no había luz eléctrica, no había acueducto, no había escuelas.

Yo tenía alrededor de 13 años e iba a una escuela muy retirada, que quedaba a dos horas de camino. El máximo grado que existía en las escuelas rurales era segundo de primaria, pero como quería estar dentro del ámbito académico yo repetía y repetía el mismo segundo grado, hasta que me convertí en la monitoria de la profesora.

Un día mis padres me dijeron que ya no era prudente seguir repitiendo el grado, y que era muy riesgoso seguir caminando todos los días hacia la escuela, pues la situación era bastante peligrosa por aquel entonces. En ese momento, durante los días que me quedaba en casa, me preguntaba: ¿Qué hago? Creo que nací con un chip especial, pues siempre me estuve cuestionando lo mismo: ¿Qué hago?

Realmente en la región era escasísimo ver que una niña saliera a estudiar y tuviera que irse a un municipio lejano para poder ir a la escuela, pues la situación económica era muy limitada, y los papás no iban a correr con ese gasto.

Entonces yo empecé a escuchar la radio, que era el único medio de distracción que existía en mi casa, pero era muy controlado; tenía horarios establecidos y a mi papá encima. A él no le gustaba que nosotros escucháramos la radio, pues en ese entonces lo más famoso que existía eran las radionovelas, y él decía que eso no era algo para que escucharan los niños. La que más recuerdo es "Corín Tellado".

En todo caso, yo empecé a sintonizar diferentes estaciones radiales y llegué a Radio Sutatenza. Le puse mucha atención a la programación y encontré que en esta emisora transmitían clases: Curso básico de lectura y escritura, curso progresivo, y un curso un poco más avanzado, al nivel de la primaria académica.

Cuando mi papá se enteró, se enojó y me dijo que eso era una perdedera de tiempo. Pero, como bien saben, en el campo uno madruga bastante, tipo 4 de la mañana. $Y$ en el transcurso de levantarse, tomar un tinto y desayunar, como ocurría con mi papá, se acompaña de la radio. Él normalmente escuchaba la emisora "Voz de las Américas" de Medellín, pues allí transmitían mucha música campesina. Un día le dio por colocar Radio Sutatenza y se dio cuenta de que allí transmitían un programa llamado "Buenos días", donde 
daban orientaciones del campo: cuidado de los animales, de las plantaciones... Adicional a esto, la forma en que orientaban este programa, era muy cercano, con nombres propios.

Luego, con mi curiosidad de saber cómo era que se desarrollaban las escuelas radiofónicas, escuché que había un representante/auxiliar inmediato quien tenía cartillas, tiza, lápices, cuadernos, etc. En este punto dije: "Esto está interesante".

Yo era una niña, pero afortunadamente mi mamá fue quien me apoyó durante este proceso. Entonces con ella nos fuimos a buscar al representante de las escuelas radiofónicas para conocer un poco más acerca del tema. La condición para ser un auxiliar de estas escuelas era tener un conocimiento un poco más avanzado que del el grupo familiar o de la zona. Aquí dije: "Pues yo soy".

Reclamé las cartillas, los lápices, cuadernos, y todo el material que en la radio decían que daban. Cuando mi papá me vio con todo el material, pegó el grito en el cielo: ¡Ahora por qué locuras les dio! ¡Quién se las va aguantar!

Pero en menos de lo que canta un gallo, junto a mi mamá, organizamos un tablero y montamos una escuela comunitaria. Mi papá quedó a la expectativa, pero no se enojó.

A las 3 p.m. llegaba un grupo de niños y niñas, pues los jóvenes tenían que trabajar. A las 8 p.m, tenía clase con los adultos, con señores de 40 y 50 años que aún no sabían escribir. A este grupo en especial los motivé para que vieran la importancia de saber firmar y leer lo que firmaban.

El proceso con los adultos fue más complicado, pues debido a que todas sus vidas habían estado familiarizadas con el azadón, la pica y pala, el aprendizaje del uso del lápiz fue algo estresante para ellos. Algunas veces partían el lápiz y sudaban cuando realizaban las planas.

Pero la consecuencia de esto, puedo decir, fue que todos los adultos a quienes les impartí clases aprendieron a leer y escribir. Fue algo gratificante para mí.

Hubo una vez que logré reunir a toda la comunidad de la vereda. A esta reunión, asistió un señor que tenía una fama terrible dentro de toda la comunidad, pues era borracho, maltratador, agresivo y no tolerante. Tal era la inconformidad con la presencia de él, que mis propios papás me recriminaron el por qué había invitado a ese señor. En realidad, él era el único que me producía temor. Pero por cosas de la vida, era quien más participaba en las clases. Aunque no cambió su forma de ser, sí logré que les diera permiso a las hijas, quienes también habían sido maltratadas durante mucho tiempo, para que tuvieran una oportunidad distinta de vida.

En otra ocasión me enteré de que iba a asistir a la región el alcalde y el Comité de 
Cafeteros Departamental de Antioquia, y para nosotros era como si fuera el Presidente de la República. Persuadí a mi mamá para que me acompañara, hasta que lo logré. Nos fuimos temprano para la vereda donde iba a llegar el Comité, y después de que esta gente tan importante había hablado, yo alcé la mano y empecé a echarles el cuento: Yo no soy de esta vereda, vengo de tal vereda, donde no hay escuela, no tenemos acueducto, tenemos niños que van para primero, otros para segundo y un grupo para tercero. La sorpresa del presidente del Comité de Cafeteros fue tal, al ver que yo era una niña y la única que se atrevió a alzar la mano, que prometió en frente de todos que los proyectos en mi vereda iban a ser los primeros en ser construidos. En efecto, así fue.

Después de ver la repercusión en el desarrollo de la vereda, con el tema de la escuela, un polideportivo y el inicio de la construcción del acueducto, todo por labor de la mesa de acción comunal (que antes ni se sabía qué era eso) emprendí mi camino hacia Sutatenza (Boyacá). Me fui a estudiar un curso de dirigente campesina y regresé a seguir apoyando a las escuelas radiofónicas, pero ya no solo en mi vereda sino en todas las veredas del municipio.

Unos años después, gracias a una beca que me gané por mi trabajo con todas las veredas del municipio, viajé para realizar un curso de líder de educación campesina. Pero esto fue terrible, pues yo tenía 20 años y supuestamente era muy niña para hacer este tipo de trabajos -hasta para cobrar el subsidio que me daban, era un problema- pues en ese entonces, la mayoría de edad era a los 21.

Pero mi trabajo siguió siendo tan bueno, que me gané otra beca. Esta beca fue para hacer el curso de supervisora de educación campesina y dirigir el proceso de escuelas radiofónicas a nivel regional.

Unos años después me nombraron como asistente cultural en la central de servicios. Respondí muchas cartas. Después trabajé en centros de formación técnica del Comité de Cafeteros; trabajé en la dirección de una casa de formación; en una escuela agroecológica de formación para campesinos...

Radio Sutatenza me sirvió para levantar la cabeza y para descubrir las potencialidades que tenía como ser humano. Hoy mis hijas son profesionales y yo sigo vinculada a ACPO; tenemos un comité de ex estudiantes para apoyar a Kenny Lavacude (Director de ACPO) y a su equipo en diferentes actividades.

Puedo decir que Radio Sutatenza fue el servicio bandera de la institución, porque llegaba a los oídos de todos los habitantes del campo, pero se complementaba con los otros medios. El auxiliar inmediato no necesariamente era en que más sabía, pero sí el que tenía 
más liderazgo; era ante todo un motivador; sin esa motivación el grupo se disolvía. No solo lideraba en las escuelas radiofónicas sino entre su propia comunidad, en la vereda. ACPO impactó porque llegaba con los mensajes reales, en los momentos reales y en forma directa a los campesinos...Los temas tenían credibilidad porque se enfocaban en lo que le interesaba al campesino. Los líderes campesinos iban a las escuelas radiofónicas a acompañar a los auxiliares inmediatos.

*Este relato contó con el trabajo de campo de los estudiantes Jéssica Monsalve Y Esteven Riaño, del semillero Radio y Ciudadanía.

\section{Hermes Martínez: "Lo que soy se lo debo a ACPO"}

Yo empecé mi trabajo de abajo hacia arriba. Fui alumno de las Escuelas Radiofónicas, auxiliar, dirigente, líder, etc. Yo creo que lo que soy se lo debo a ACPO. Si yo no hubiera conocido a ACPO tal vez sería otra persona distinta; no sé dónde estaría.

En la segunda promoción del año 78 fui al Instituto Campesino de Caldas (Antioquia); allá hice el curso de dirigente campesino. En la segunda promoción del año 79 terminé el de líder. Trabajé como becario en varias zonas del país.

Puedo decir que en una reunión que tuvo monseñor Salcedo con nosotros en el año 88, nos hizo esta pregunta: "O ustedes, o las emisoras... Si no se salen ustedes, nos toca apagar las emisoras". Ahí sí nos puso a pensar...Y nosotros preferimos las emisoras. Para nosotros era más importante que las emisoras continuaran. Y le dijimos: "Nosotros nos hacemos a un lado".

Yo trabajé con ACPO hasta el primer semestre de 1988. Ese mismo año entré a trabajar en la alcaldía del municipio, como secretario general. Allí adquirí otra serie de conocimientos; fue algo totalmente distinto para mí; allá logré poner en práctica todo eso que había aprendido; lo que monseñor Salcedo y profesores como el Doctor Salas, el Doctor Eurípides Triana López nos enseñaron. Después fui concejal y allí en el concejo hicimos unos proyectos buenos para el sector rural.

Inclusive hicimos que las juntas de acción comunal compraran el famoso Discoestudio. Y con el Discoestudio se logró alfabetizar gran cantidad de personas. Yo tengo ese recuerdo del Discoestudio, porque aún lo conservo en mi casa.

En el año 90 se terminó ya el período en la alcaldía, y entré a trabajar al departamento de Cundinamarca (fui secretario asistente en la gobernación). Entonces me propusieron regresar al campo, y me nombraron inspector de policía de La Victoria, y duré 
diez años. Me llevé el Discoestudio y en las horas de la noche enseñábamos allá en el salón comunal del caserío. Hicimos grandes cosas; llevamos el acueducto, la energía eléctrica; la casa de la inspección; el puesto de salud y compramos la ambulancia para el puesto de salud. Incluso también dicté clases en el colegio departamental sobre desarrollo social. Fundamos el periódico y yo lo dirigí; se llamaba "La Palestra”. Escribíamos en el periódico; también escribí en la gaceta musical.

Entonces nos propusieron divulgar las actividades del pueblo, como los decretos municipales y lo que se hacía en las veredas. Hoy en día escribo en un medio educativo, en el colegio militar "Almirante Padilla", de Soacha (Cundinamarca). Allí dictamos clases con el Discoestudio a unos adultos del barrio San Mateo. Y ahí seguimos vinculados con ACPO. No nos queremos desligar todavía; y vamos a seguir luchando hasta que Dios lo disponga.

\section{"Estoy viviendo la mejor época del renacer de ACPO": Virgelma Barrera Sastoque, estudiante de las EDC en Sutatenza (Boyacá)}

Viví mi niñez y juventud con ACPO...Oíamos la radio y esas enseñanzas dirigidas a los campesinos, nos llegaban...Vi cómo llegaba mucha gente a Sutatenza a aprender.

Es muy diferente el ACPO de hoy debido a la tecnología, pero lo importante es que se mantiene el legado.

ACPO nació en el 47; yo nací en el 57. Viví la mejor época de ACPO, y hoy estoy viviendo la mejor época del renacer de ACPO...

Las EDC son maravillosas. Es una gran experiencia aprender, por ejemplo, sobre Asociación y Empresa, conocimientos básicos sobre el computador, la comunicación y periodismo rural...Ver la cara de las personas que ya somos mayores es emocionante. Y ver cómo se integran niños, jóvenes y adultos. Se demuestra que aprendemos, aunque jamás nos imaginamos que lo podíamos hacer. Antes solo se contestaba el celular y ya. Estamos muy contentos; es mucho lo que se puede hacer con el computador...

Yo me enteré del regreso de ACPO por las redes sociales. Yo trabajaba en la radio comunitaria y conozco al director de ACPO. Para mí fue una gran noticia el renacer de ACPO. Lo invitamos a un programa que teníamos y él nos explicó. Entonces, después de ver que hace muchos años se aprendía con la radio y con cartillas, hoy el sueño es que cada campesino tenga un computador...Esto es maravilloso, porque está creciendo a nivel nacional. Y vemos la alegría de los campesinos. Tengo testimonios de gentes de aquí asombradas por todo lo que hemos aprendido...

...También quiero comentarles que yo hago parte de la emisora "ACPO vive Radio 
Sutatenza", como corresponsal aquí en Sutatenza. Y que estamos muy contentos porque los 70 años se van a celebrar aquí donde nació ACPO.

\section{"Lo mejor es compartir con la comunidad": Juliana Ortiz}

El turno ahora es para Juliana Ortiz, estudiante de las EDC en San Vicente del Caguán. Esta pequeña y próspera región ganadera hizo parte de la famosa zona des distensión y sirvió de escenario para el fallido proceso de paz entre el gobierno de Andrés Pastrana Arango -1998-2002- y la guerrilla de las FARC. De 17 años, Juliana dice que lo mejor "ha sido compartir" con su comunidad:

En mi familia somos mi papá, mi mamá y cuatro hermanos. Es netamente campesina y yo he buscado que ellos también aprendan mucho. Con los conocimientos que he adquirido yo les he ido explicando. Las EDC son una alternativa para mejorar el campo, para mejorar la producción y colaborar con el medio ambiente y con el crecimiento del país.

En mi grupo de estudio tenemos entre 16 y 19 años. Me he sentido muy bien; he adelantado tres cursos hasta el momento; he adquirido muchísimos conocimientos y he aclarado dudas. He aprendido palabras técnicas y muchas cosas sobre el campo, y otras herramientas que ofrecen los cursos.

El cambio ha sido drástico y súper bueno, porque en la medida en que yo aprendo, les puedo transmitir a las personas de mi comunidad, de mi región. Enseñarles de manera estratégica a tener el amor por el campo y a cambiar la manera de pensar...

Las jornadas de trabajo las hacemos cada 15 días. Hacemos actividades que generen impacto social, que es el objetivo principal de la institución. Y contamos con el acompañamiento de un profesor del área de suelos agrícolas y ecología amazónica. Destinamos todo el día y nos dividimos en grupos. Cada uno responde por las actividades que se le dejan.

Nosotros somos estratégicos. Cada persona, cuando termina el oficio, pasa a colaborarles a los otros grupos que aún no han terminado. Manejamos mucho lo que es la amistad, la comprensión y la colaboración...Somos una familia estudiantil y de esa manera nos colaboramos todos.

De los cursos que he tomado el que más me ha impactado ha sido el de liderazgo. Aprendí las formas de cómo uno puede manejar un grupo, cómo ir a la comunidad y buscar su bien; cómo trabajar con todos y en conjunto. Tuve una experiencia muy bonita, que fue llevar asesoría técnica. Y fue un total éxito. Hubo total aceptación, la gente mostró interés, 
como que les gustó el tema. Ahí descubrí que puedo ser líder.

Yo veo que la paz en Colombia sí es posible; la veo por buen camino, porque se ha visto que los grupos que están en diálogo han estado cumpliendo...Como que sí se quiere tener la paz verdadera. Una de las partes más importantes son los campesinos, y se les ha tenido en cuenta. Sí se puede, porque querer es poder. ¿Qué hago? Hablar de la paz y aprender a usar el diálogo para arreglar las diferencias que existen en la comunidad. Así lo hacemos en todos los grupos, como en las juntas en las que nos reunimos.

\section{"Las EDC aportan mucho: aquí no se mira la edad sino las ganas de salir adelante":} Hortensio Palacios.

En Mundo Rural también nos desplazamos hacia Nuquí, en el corazón de la selva chocoana. Bañado por el océano Pacífico, este municipio es famoso por su belleza natural y por el espectáculo que año tras año -entre junio y octubre- ofrecen las ballenas jorobadas. A esa región del departamento del Chocó, caracterizada por ser la más biodiversa del mundo, también llegaron las Escuelas Digitales Campesinas de ACPO. La palabra es para Hortensio Palacios, uno de sus estudiantes:

Yo veía Internet como algo muy lejano, imposible; pero acepté el llamado e inicié con el curso de alfabetización digital. También he tomado el de conocimiento del medio, el de liderazgo y el de comunidad, comunicación y periodismo rural. La verdad, estoy muy satisfecho. Es muy bueno, pues tomamos los cursos con estudiantes de diferentes edades, y la pasamos muy bueno, porque compartimos mucho.

Esto me ha servido y me va a servir mucho para mi trabajo, ya que soy el director de la emisora comunitaria "Riscales Estéreo". He comprobado que las EDC aportan mucho, y lo mejor es que aquí no se mira la edad, sino las ganas de salir adelante. El miedo ya quedó atrás.

Hay quienes dicen que "loro viejo no aprende a hablar", pero yo tengo 50 años y ya me gradué. Eso es lo que les quiero transmitir a mis oyentes; les aconsejo que es muy bueno prepararse. Esta interlocución con las comunidades es muy importante. Además, fue muy bonito y motivante que la rectora me pusiera de ejemplo ante los demás.

Yo hago parte de una red de liderazgo que se llama "Prolíder", con la cual buscamos que los jóvenes se motiven y se vinculen a las EDC. 


\section{“Quiero ser líder para ayudarles a otras personas a que aprendan": Sacramento} Soriano, campesina de Manta, Cundinamarca (Valle de Tenza)

Me vinculé el año pasado...Estoy terminando el curso de alfabetización. Es muy bueno porque el horario es flexible. Ya pronto empieza otro grupo. Estamos interesados en que esto llegue a todos los hogares. Por eso yo invito a todo el que puedo; les digo que no es muy difícil...La gente se anima cuando conoce la dinámica, y saben que otros han podido.

En mi caso, no me asusté, porque ya sabía algo de computadores. Me matriculé de una y, la verdad, el curso es muy fácil.

Yo quiero ser líder, para colaborarles a otras personas a que aprendan. Yo soy pensionada, discapacitada; estoy terminando el bachillerato y quiero hacer trabajo social. Los cursos me entretienen. La idea es que aprendan a manejar el computador: Yo les enseño a abrir el correo y la forma de acceder a los cursos.

Creo que estos cursos me han cambiado la vida porque ahora tengo una forma de pensar diferente; soy positiva y tengo metas, como enseñarles a otros...

\section{Mauricio Ramos: "Líder no es el que más manda, es el que más comparte”, estudiante de las EDC en Dagua, Valle del Cauca.}

Yo soy cogestor social. Debo visitar familias vulnerables, es decir, afectadas por la violencia. Entonces, lo que voy aprendiendo lo comparto con ellos. Es muy bonito, porque hay muchas personas que nunca en su vida habían cogido un mouse, y uno ya ve el progreso...

En mi casa somos mi papá, mi mamá, mi abuela y cuatro hermanos.

Me siento muy bien en las EDC porque son cursos muy favorables para la comunidad campesina. Yo ya había manejado un computador, pero sabía muy poco. Acabo de terminar el curso de alfabetización digital. Es muy agradable porque el tutor nos brinda mucha confianza.

Aquí en Dagua somos 50 personas (adultos entre los 40 y los 60 años). Trabajamos los miércoles.

Creo que la clave para aprender es tenerse confianza y hacer las prácticas; en mi caso, he hecho los cursos en una sala de internet. Ya terminé el de alfabetización digital y ahora estoy en el de liderazgo. He aprendido que para ser líder hay que ganarse la confianza de las demás personas, ser sociable y tener muy buena comunicación para saberles llegar. Y que líder no es el que más manda, es el que más comparte. 
"Antes se sentían aisladas; ahora están saliendo adelante":Angie Marcela Alba, tutora de Guachetá (Cundinamarca)

Guachetá está cerca de Capellanía, en el norte de Cundinamarca, y hace parte del Valle de Ubaté. Aquí se trabaja mucho en la minería y en la ganadería.

He tenido una experiencia muy bonita con las EDC. Estoy trabajando con un grupo de 35 mujeres. La alfabetización digital promueve el desarrollo tecnológico y rural: hacemos talleres prácticos, para que tengan un aprendizaje útil. Muchas de ellas no tienen un computador en la casa. Ahora manejan internet, tienen visitas a personas. Para ellas es una gran experiencia. No sabían que podían consultar cualquier cosa, que podían hacer compras...

En el grupo hay adultas sobre los 25 años y una señora de 61 años. Y adolescentes, de los 13 a los 18 años.

Es más complicado con las personas de mayor edad, pero demostramos que se puede, Les da miedo. Se trata de darles ánimo. Hay muchas madres que tienen tiempos libres y no saben cómo aprovecharlo...Esta es una buena opción.

La mayoría son madres que tienen que trabajar muy duro. A esto le dedican dos horas; ya pueden investigar cosas que no sabían, incluso remedios caseros. Se les ve el interés, trabajan muy activamente.Ya tienen como un espacio de paz, donde pueden socializar sus ideas y compartir con otras personas.

Me ha parecido que es una experiencia muy enriquecedora... Me gusta ver el avance de ellas. Ellas antes se sentían como aisladas; ahora están saliendo adelante.

\section{"Ha sido muy importante que hablen ellos, porque nunca se habían sentado a analizar realmente ni qué eran, ni lo que tenían en conjunto": Orlando Rendón (Facilitador en Antioquia)}

Aquí en Antioquia empezamos el proceso el 25 de enero de este año (2017) ...Tenemos 179 campesinos. Los cursos son bastante dinámicos; una de las grandes dificultades ha sido la conectividad, pero hemos venido superando ese inconveniente. Los campesinos se han venido familiarizando. A ellos les ha gustado mucho el curso de conocimiento del medio.

Estamos trabajando con adultos de diferentes edades en diez municipios de 
Antioquia...Todos son campesinos. Así se le está brindando bienestar. Son cursos innovadores; están aprendiendo a manejar el computador para, por ejemplo, llevar mejor sus cuentas en las unidades productivas.

A través del curso aprenden a conocer su contexto, su propia finca, la tierra, sus recursos...Ha sido muy importante que hablen ellos. Ellos nunca se habían sentado a analizar realmente ni qué eran ni lo que tenían en conjunto. Así tienen muchos fundamentos para hacer una especie de monografía de su terruño, de su finca y de su vereda en comunidad.

Toda mi vida la he trabajado en el campo. Los fines de ACPO y los fines de las Escuelas Campesinas son muy afines a lo que hacemos. Los cursos les dan la posibilidad a los campesinos de desenvolverse mejor.

Nosotros nos reunimos a hablar con ellos. Primero, tienen interacción con el docente, quien es un motivador. Lo que más les llama la atención es la aplicación práctica en su propia finca. Hay un curso que es el de adaptación al cambio climático, es muy útil...También estamos esperando mucho el de cultura de paz.

La meta es tener 800 y más estudiantes para este año. Debemos aprovechar la oportunidad que tenemos todos los campesinos.

"Me siento orgulloso de haber aprendido todo lo que aprendí, porque a los 18 años no sabía ni leer ni escribir": José Israel Cante Moreno.

Fui estudiante de Sutatenza. Fui concejal en Mesitas del Colegio, dirigente campesino y líder rural. Fui desplazado en el año 76. Aprendí que no debo ser transgénico ni comer productos transgénicos.

Lo que quiero es que los medios nos hablen con la verdad; era la verdad que siempre se dijo en El Campesino y en los libros y cartillas de ACPO. Me siento orgulloso de haber aprendido todo lo que aprendí, porque a los 18 años no sabía leer ni escribir. Hoy soy odontólogo. ACPO despertó a los campesinos. Me siento orgulloso de participar en este foro. Es muy bonito saber que ACPO no ha muerto...

\section{César Rodríguez: "Radio Sutatenza es un referente mundial".}

Mi relación con Radio Sutatenza fue particular. Tuve la oportunidad de estudiar en la educación tradicional, pero también seguía los cursos de ACPO para complementar mis estudios.Quiero destacar la onda corta de Radio Sutatenza, que le permitía llegar a otras partes del mundo. Se recibían cartas de personas de Japón, Australia, Francia. Hoy Radio 
Sutatenza es un referente mundial.

\section{"Vivo con mucho cariño el regreso de ACPO: Luis alberto Celis.}

También me beneficié con ACPO, mediante la utilización de sus diferentes medios. Fui auxiliar inmediato y líder campesino (estudié en los Institutos campesinos). Participé en la elaboración proyectos educativos formales en el occidente de Boyacá. Hoy en día estoy vinculado a las Escuelas Digitales Campesinas, como alumno en Antioquia, en el occidente. Vivo con mucho cariño el regreso. No vivo de la educación, pero hoy presto servicio social en educación. Como ex alumnos estamos dispuestos a seguir apoyando a ACPO. Yo he tomado varios cursos y también he compartido con alumnos de otros programas, con el fin de que se certifiquen.

\section{"Interactúo con el grupo. Yo aprendo de ellos y ellos aprenden de mí": Alberto Medina, facilitador de las Escuelas Digitales Campesinas en el Caquetá.}

San Vicente del Caguán es un municipio ganadero del amazónico departamento del Caquetá ( sur del país) que ganó notoriedad por ser el centro de la zona de distensión que estableció el entonces presidente de Colombia, Andrés Pastrana Arango, para adelantar diálogos de paz con la guerrilla de las FARC. Se considera una de las regiones más abandonadas del país, ante la marcada ausencia del Estado. De allí nos llega este testimonio de quien se iniciara como auxiliar voluntario y hoy, a sus 18 años, es el facilitador más joven de las EDC:

Esta experiencia me causa mucho orgullo contarla...Yo fui beneficiario de las Escuelas Digitales Campesinas durante el primer año en que llegó el programa al Caquetá, que fue en el 2015. Inicié mi formación, y tuve la oportunidad de crecer. Nosotros como estudiantes íbamos a nuestras comunidades a promover las EDC. Compartíamos todos nuestros conocimientos con muchos campesinos. Yo me destaqué como un estudiante que me esforzaba por ser líder de mi comunidad.

Cuando uno está interesado en salir adelante, y le pone empeño, se encuentran los resultados. Yo siempre lo que quise fue ayudar a los campesinos, porque yo me crié en el campo, y conozco bien los problemas que se viven allí. Ese era mi anhelo, y ahora tengo la 
oportunidad de llevar este programa. Yo aprendí gracias a las EDC; es algo que me motivó y que me motiva para salir adelante; y es cierto que sacrifiqué muchas cosas para llegar hoy donde estoy.

De verdad que es tan bueno trabajar aquí...Soy el más joven del grupo; entonces tengo ese reto, pero me ha ido muy bien, pues todo depende de cómo trato a las personas; el acercamiento siempre es respetuoso y el resultado ha sido muy bueno.

En las EDC de acá se educan personas adultas, ya que es un colegio para formar líderes; son 22 estudiantes. Aquí hay una buena zona verde. Las clases son muy dinámicas. Una de las tareas consiste en conocer las diferentes experiencias, porque vienen estudiantes de los 18 municipios del departamento.

La vida me ha cambiado mucho. Primero, por lo que uno aprende cada día. Uno conoce el contexto de cada persona e interactúa con el grupo; yo aprendo de ellos y ellos aprenden de mí. Lo cierto es que mis conocimientos de tecnología se los debo a este programa .

Una experiencia inolvidable la viví cuando estaba empezando y llegué por primera vez a una comunidad. Yo iba a encabezar la reunión, llegué temprano y me senté a esperar a que se acomodaran todos. Ellos seguían esperando a que llegara la persona que iba a hablarles sobre el programa. Hasta que empezaron a decir: "Y por qué no llega"...Ya se iban a ir. Yo en ese tiempo tenía 16 años. Y cuando les dije que era yo el que les iba a presentar el programa de las EDC, quedaron sorprendidos.

Yo me proyecto a diez años ejerciendo mi carrera profesional, que es la de ingeniería agrónoma. Espero empezar el próximo año.Yo quiero seguir aquí en el campo y ayudar. Estos son lugares muy abandonados, les falta mucho desarrollo y quiero aportar al bienestar campesino.

Los invito a todos a participar. De verdad que este programa contribuye mucho al buen desarrollo de esta región. Qué bueno que día a día se involucren más, y que vivan esta experiencia; que aprovechen cada curso de los que ofrece la plataforma. Mi invitación es a siempre seguir adelante...

Ahí están algunos de los testimonios de los propios protagonistas. Es claro que esta nueva etapa de ACPO es aún incipiente y que las EDC se enfrentan a un contexto completamente diferente, atravesado por la presencia de las TIC. También, que la radio sigue jugando un papel destacado en el campo, en especial gracias a la tradición oral de sus habitantes, pero, como ocurrió en la era de las Escuelas Radiofónicas, las y los estudiantes 
demandan otros medios y para ello cuentan, como hemos señalado, con elcampesino.co, con las cartillas impresas y con instrumentos de distribución como las USBs y el podcast, entre muchas otras posibilidades que les abren las TIC.

Y en cuanto se refiere a la tarea de la Acpoeducación propiamente dicha, es clave el aprendizaje colaborativo, a partir tanto de la figura del tutor o tutora, como de los propios estudiantes, quienes tienen el reto de sacarle el mayor partido posible a las herramientas que les brinda la tecnología, sin perder de vista que lo más importante es el para qué la utilizamos. Por ejemplo, gracias al podcast o archivo sonoro, inscrito en lo que hoy se denomina "radio por demanda" o "a la carta", todos podemos actuar con gran facilidad como productores de contenidos. Así, de manera directa, se puede incidir en la sociedad, mediante un ejercicio que demanda valor y valores. Como lo sugiere Tomás Eloy Martínez, es conveniente tener en cuenta, primero, que debemos ser fieles a nosotros mismos, a lo que somos y a lo que queremos ser: "Lo que escribo ( o lo que digo) es lo que soy, y si no soy fiel a mi mismo no puedo ser fiel a quienes me lean". (1997, p. 12)

Es la palabra que se pronuncia y se emite con el ánimo genuino de dialogar y, por lo tanto, de transformar esa sociedad de la que también hacemos parte. 
Radio Sutatenza y Acción Cultural Popular en la era digital 


\section{CAPÍTULO VI}

\section{CONCLUSIONES}

“(...)descubrimos que las preguntas rompen los silencios cuando las transformamos en acción colectiva y esa fuerza nos convierte en un solo cuerpo, un territorio que siente, que crea, que tiene memoria...".

Soraya Bayuelo 


\subsection{EI diálogo, clave en las nuevas ciudadanías de las EDC}

En la descripción y análisis de tareas concretas ejercidas por los actores de las Escuelas Digitales Campesinas (EDC), que potencian el ejercicio de la Comunicación/Educación por parte de sujetos insertos en procesos de construcción de significados, hacia la conformación de lo público, se inscribe el principal aporte de esta tesis. En consecuencia, son los propios estudiantes quienes, como "significadores críticos", cuentan su propia historia mientras ésta ocurre, no después, una perspectiva que Boaventura de Sousa Santos (2010) denomina "sociología de las emergencias", entendida como una ampliación simbólica, tanto de los saberes, como de las prácticas y de los agentes sociales que intervienen en ellas.

La pregunta que ha guiado nuestras reflexiones está inmersa en otras forma de pensar y de narrar las realidades sociales, esto es, ya no desde la objetividad positivista sino desde la forma como los propios sujetos experimentan y construyen o aportan a la construcción del sentido común. De ahí que esta investigación se haya desarrollado en el propio entorno social y simbólico de los habitantes rurales vinculados a las EDC.

Desde allí hacemos un ejercicio de creación de memoria histórica, mediante el cual se promueven las ciudadanías activas, hacia la conformación de la otredad, que pasa por reconocer, validar y potenciar otros horizontes narrativos con sus genuinas formas de expresión, esto es, oral, escrita, visual,corporal y musical, entre muchas otras.

Se evidencia aquí, entonces, un claro posicionamiento político, al comprenderse la comunicación como un proceso clave en los "modos de marcar la existencia, la estética y la circulación del poder". (Villamayor, 2014, p.93)

Con ese norte, a lo largo de esta tesis hemos planteado la necesidad de cualificar el ejercicio de las ciudadanías, apuesta que, como se ha descrito, incluye las diferentes estrategias y modalidades de producción de sentido activas en las EDC, con sus diferentes canales y medios.

Es lo que Acción Cultural Popular denomina “ciudadanía rural”, que entiende desde la comunicación para el cambio social como la construcción de un auténtico diálogo con el que se busca contribuir a profundizar la democratización de la comunicación, para que los campesinos e integrantes de comunidades indígenas y afrodescendientes actúen como sujetos comunicativos y, por lo tanto, como "actores y agentes de su propio desarrollo humano y 
social”. (ACPO, 2017) Hoy, en la era digital, estos postulados cobran un valor especial, si tenemos en cuenta que desde su nacimiento, en 1947, una de las tareas centrales de las Escuelas Radiofónicas fue combatir el analfabetismo, reto que se mantiene vigente hoy con las EDC, ahora con el énfasis en la alfabetización digital, para afrontar y contribuir al propósito de cerrar la brecha que separa al país urbano del rural. Claro, así se propicia la inclusión, que va mucho más allá del uso de aparatos para asociarse con la activa participación en la gran conversación que les permita a los actores de las EDC insertarse en la batalla político-simbólica, hacia la configuración e incidencia en las agendas públicas, para defender el orden social que quieren vivir. En esa dirección, como lo contempla la primera característica de la EFI, se busca que los estudiantes vayan más allá de la erudición y le den preponderancia a los hechos que ocurren en su cotidianidad.

Si bien es cierto hay muchos caminos para concretar ese objetivo, uno de los identificados está en las prácticas inscritas en los postulados de lo que hemos denominado Acpoeducación, que se desprende de la sexta característica de la EFI, para aprovechar y sacarle el mayor partido posible a la experiencia de ACPO-Radio Sutatenza, considerada por muchos investigadores como la pionera en el ejercicio de la comunicación para el desarrollo y el cambio social en América Latina.

Como lo indicamos en el capítulo $\mathrm{V}$, entendemos la Acpoeducación como la estrategia de Comunicación/Educación, que se despliega a partir de los cursos de formación en la combinación organizada y sistemática de medios, entre ellos el periódico elcampesino.co; el programa de radio "Mundo Rural"; las emisoras fundadas por los ex estudiantes; los libros ; las cartillas; el Discoestudio; los programas de formación para facilitadores y tutores y las cartas, entre otros. Es el sello característico de una experiencia que tuvo y aún tiene un impacto notable entre las poblaciones con mayores problemas de representación e inclusión en Colombia, como lo son las campesinas, campesinos, indígenas $\mathrm{y}$ afrodescendientes $\mathrm{y}$, en general, los habitantes rurales, el foco de atención de las EDC, en las cuales juega un papel destacado la participación de la mujer. De hecho, de manera estratégica, desde su primera etapa la organización decidió centrarse en la educación de la mujer, para impactar al conjunto de la sociedad rural.

Por consiguiente, son ellas y ellos los protagonistas del proceso y, como tales, se asumen como sujetos de interaprendizaje, entendido este último concepto como las posibilidades de "aprender del otro (...) Aprender con el otro. Y, elemento sustantivo en esa relación: la comunicación”. (Prieto, 2005, p. 24). En ese marco de acción, ACPO le concedió, y le concede aún, una especial importancia a la comunicación interpersonal, como 
elemento esencial de transformación, en la cual juegan un papel clave la figura del "auxiliar inmediato" y la correspondencia, hoy llamados facilitador o tutor y "las cartas del campo", respectivamente.

Es por ello (y para ello), en su afán de construir la realidad no para sino con el otro, que el modelo de ACPO-Radio Sutatenza ha apelado a la conversación, un "ganar-o-ganar" que trasciende la comprensión de un solo individuo y deviene participación en la que no estamos jugando contra los demás sino con ellos. (Bohm, 1997). Así, a partir del lenguaje, la comunidad participa de "nuevos mundos", pues, como lo expresa Humberto Maturana,

El lenguaje tiene que ver con las coordinaciones de seres. Mientras más rico es el ámbito de los haceres y las coordinaciones de seres, más rico es el lenguaje. Lo que hace uno al conversar es moverse en un flujo de coordinaciones de seres y emociones. O sea, generamos mundos. $(2013$, p. 1)

Esos mundos, como lo propone Bohm, solo pueden generarse si se activa el diálogo, a partir de la capacidad manifiesta y efectiva de las personas de escucharse sin tratar de imponerse nada. De esa forma, se promueve lo que podríamos llamar el "descubrimiento" de significados compartidos, (...) “el aglutinante, el cemento que sostiene los vínculos entre las personas y entre las sociedades". (P. 3).

Durante el recorrido de esta tesis pusimos el énfasis en ese aspecto, porque es el que permite confirmar la importancia de los medios como práctica significante.

Es una perspectiva que también han planteado autores como el antropólogo estadounidense Clifford Geertz, para quien "todo el quid de un enfoque semiótico de la cultura consiste en ayudarnos a lograr el acceso al mundo conceptual en el cual viven otros sujetos, de suerte que podamos, en el sentido amplio del término, dialogar con ellos". (2003, p. 35)

Es un diálogo que, insistimos, se vive con las voces directas emitidas desde los territorios y sobre las propias realidades cotidianas de los actores sociales, en su empeño por interpelar, por incidir, por reconocerse y por ser reconocidos, en un ejercicio de tolerancia que Freire define como la virtud revolucionaria que consiste en entenderse con los diferentes para poder "luchar mejor contra los antagónicos". (1994, p. 19) Como lo indica el investigador Boris Delgado, "lo interesante es que esa cotidianidad reflexiva está constituyendo al mismo tiempo saberes en torno a la escucha de los territorios". (2018, p. 4). Se trata de un despliegue de sensibilidades expresadas en agendas políticas y comunitarias capaces, en el caso específico de Colombia, de permitir la sintonía “con prácticas creativas y 
estéticas (...) que nos están enseñando otras formas de encontrarnos”. (Ib. p. 5) Y es que "encontrarnos" o "estar juntos" se ha vuelto un imperativo en el marco de la batalla por la existencia, de manera especial en zonas tan afectadas por la violencia como "Los Montes de María”, región del Caribe colombiano que abarca parte de los departamentos de Bolívar y Sucre. Allí esa táctica ha sido la eficaz forma de espantar el miedo que han querido imponer los actores de la guerra pues, como lo cuenta Soyara Bayuelo Castellar, fundadora y directora del Colectivo de Comunicaciones Montes de María Línea 21,

descubrimos que las preguntas rompen los silencios cuando las transformamos en acción colectiva y esa fuerza nos convierte en un solo cuerpo, un territorio que siente, que crea, que tiene memoria, que es capaz de abrirle paso a la vida aunque nuestras propias vidas sean solo cifras en rojo, porque no estamos dispuestos a perder lo que nunca pudieron arrebatarnos: nuestra dignidad. (2019, audio podcast)

De ahí, de esa acción colectiva, viene la fuerza cultural, pues, como lo advierte García Márquez, toda cultura de verdad es popular: nace y crece de la periferia hacia el centro y de abajo hacia arriba (2018)

Podemos hablar así, desde las perspectivas del humanismo cívico y la democracia radical, de un recorrido hacia la búsqueda de nuevas formas de concebir y de ejercer la política que, en oposición a la que se ha ejercido de manera tradicional en Colombia, ya no esté hecha para borrar sino para promover la construcción de identidades; no se conciba para anular posibilidades sino para abrir más espacios de interacción/participación y, por lo tanto, permita "interpretar creadoramente lo que somos y lo que puede ser el país". (Ospina, 2018, p. 1) . Como lo hace notar el investigador Jorge Iván Bonilla (2002) estamos aquí ante la pregunta por la visibilidad, en el marco de las luchas "por ampliar la esfera pública de la democracia", que se relaciona con el derecho a ejercer la palabra pública. (P. 83). Es importante subrayar que para concretar esa tarea, como lo propone la democracia radical, entendemos que los sujetos se constituyen de manera permanente en los juegos del lenguaje.

En ese marco de acción, el gran objetivo consiste en propiciar un proceso de ciudadanización y de reconstrucción del tejido social en un país afectado por el conflicto armado, en la medida en que, como lo señala Freire en la Pedagogía del oprimido: "Los hombres no se hacen en el silencio, sino en la palabra, en el trabajo, en la acción, en la reflexión”. (1970, p.71)

Como lo hemos indicado, en lo político uno de los puntos de convergencia de esta 
estrategia de Comunicación/Educación -que desde su génesis se entiende también como una propuesta de intervención política- es la ciudadanía rural. En ese contexto es clave entender que los habitantes rurales ya no son los mismos de hace 70 años, cuando nació Radio Sutatenza. Tal y como se describió en el capítulo IV, sería un error hablar hoy solo de campesinos a secas, pues las EDC trabajan hoy, en general, con habitantes rurales, no solo con productores de alimentos y, por lo tanto, ni el ejercicio de la comunicación ni la construcción de ciudadanía se pueden concebir al margen de esa gran diversidad cultural existente en el campo colombiano.

Es claro que el campo evidencia cambios desde cuando nació ACPO, en 1947, tras haber estado en el corazón el conflicto armado durante más de 50 años (una realidad que hoy se prolonga con las nuevas manifestaciones de la guerra, que ha vuelto a provocar más muertes y más desplazamiento, como lo confirma un reciente informe de la organización Save the children). Por consiguiente, la transformación de la organización también es evidente. Para empezar, ya no solo trabaja con campesinas y campesinos, entendidos como los clásicos productores de alimentos sino con los habitantes rurales -incluidos miembros de comunidades afrodescendientes e indígenas- muchos de ellos dedicados a la producción agropecuaria, pero también a otras actividades afines al comercio, a la industria o a quehaceres domésticos acordes con sus particulares necesidades familiares. Así mismo, aunque en esta etapa ACPO como institución oficial es manejada por la jerarquía eclesiástica de la Iglesia Católica, que integra y preside el Consejo Superior, hemos podido evidenciar notables cambios en los procesos de producción de contenidos que incluyen a los actores de las EDC como protagonistas del proceso de comunicación. En ese orden de ideas, si bien es cierto que tanto ayer, en la etapa de las Escuelas Radiofónicas, como hoy con las Escuelas Digitales Campesinas, ACPO se basa en los mismos principios cristianos de la Educación Fundamental Integral, es claro que el contexto cambió de manera radical, en especial debido a la presencia de las TIC, lo que implica otras lógicas de interacción/participación/inclusión/deliberación. Observamos, entonces, un cambio sustancial, si tenemos en cuenta que en la antigua Radio Sutatenza los campesinos eran consultados sobre el tipo de programas que querían escuchar, pero no participaban de manera directa de los procesos de deliberación y decisión, pues eran representados por los respectivos párrocos (Vaca, 2011, p. 267) Y, hoy, como lo evidenciamos, en muchos casos, actúan como prosumidores. Al leer este nuevo contexto ACPO decidió que los cursos ofrecidos por las EDC no estén concebidos para ser aprendidos y repetidos, sino para ser readaptados por los propios estudiantes en función de su propio mundo, con sus propias 
realidades, para lo cual resulta clave la formulación de preguntas, como se contempla de manera explícita en el "Manual del profesor". (Ver Cap. V)

Entonces podemos confirmar que para las EDC la ciudadanía no es teoría, es acción, "una experiencia que debe ser producida desde las estéticas y relatos que habita la gente, no desde los códigos de la máquina mediática y la máquina del desarrollo”. (Rincón, 2008. p. 3)

Es un enfoque que cobra mayor relevancia entre la población de esta investigación, conformada por comunidades que, como señalamos, han padecido con mayor rigor "la crisis de representación" de la que hablan Jesús Martín-Barbero y Germán Rey. (2000, p. 23). En esa mismas realidades descansan la plena validez del reclamo "que los movimientos étnicos, raciales, regionales de género, hacen del derecho al reconocimiento de su diferencia (...) Cada región, cada localidad, cada grupo reclama el derecho a su memoria". (Ib. pp. 23 y 25)

Y como se refirió arriba, en lo político, la propuesta desarrollada en este trabajo se apoya en el siguiente principio, defendido por el humanismo cívico (H.C.) y por la democracia radical: Los ciudadanos son la razón de ser de la política. Como tales, desde los postulados del H.C., buscan actuar como "comunidades de amistad" que aprenden juntas, comparten , replican el conocimiento y deliberan para incidir en la vida pública. Como lo proponen Irizar y González, (...) son los ciudadanos los que asumen como un cometido natural, e incluso como una necesidad, agruparse y hacer sentir su presencia en la vida sociopolítica con iniciativas de diferente índole... (2015, p. 22)

Es el reto que implica el que sea la gente de carne y hueso la que se exprese, para narrar su propio mundo, porque, al fin y al cabo, para eso se hizo la palabra: para presentar y representar la forma de sentir y de palpar la realidad; (Borges). Y así, como lo advierte Buenfil Burgos, se marca la "historicidad del ser", pues tanto lo que dice como las formas de decirlo son producto de las relaciones de poder, porque el lenguaje no es neutro ni inocuo. ( 2013, p. 9).

Insistimos: en esta tesis hemos hablado de las realidades que viven los actores sociales quienes, en su gran mayoría, no hacen sino muchas veces padecen la política tradicional, con todas sus componendas y vicios. Por eso son indispensables nuevos escenarios para la acción pública, que el escritor William Ospina concibe como la intervención directa de la comunidad, tanto "en el tono de la participación (como) en los debates de la modernidad", lo que implica

(...) darle un lugar distinto a los ciudadanos en la transformación de la realidad, romper para siempre con esa lógica triste y mezquina de los directorios y de las clientelas, donde las personas 
valen como cifras pero no como interlocutores, como formuladores de propuestas y como inventores de soluciones. $(2018$, p. 8$)$

Tal y como se destacó, ayer como hoy, para el éxito de ese ejercicio, ACPO cuenta con activos tan importantes como el gran valor que aún tiene el círculo familiar en el campo, factor clave de unidad y de cohesión social que permite potenciar la formación de los educandos de las EDC. Con la mira puesta en ese objetivo, en esta tesis hemos postulado nuevos formatos como el radioclip, y las diversas posibilidades que abre el podcast, encaminados a dinamizar aún más el diálogo social. (Ver capítulo V).

\subsubsection{Estudiantes como significadores críticos}

Desde la óptica planteada, en esta investigación hemos formulado preguntasproblemas como estas: ¿Cómo se activa y cómo se da el diálogo en las EDC? ¿Cuál es el papel que cumple la figura del auxiliar inmediato ( facilitador o tutor) en el proceso dialógico que se vive en las EDC? ¿Cómo perciben los estudiantes de las EDC su propio proceso? ¿Cómo se reconocen como actores en las Escuelas Digitales Campesinas? ¿Cómo se vive el aprendizaje colaborativo entre los estudiantes, entre ellos y los facilitadores y entre la comunidad de las EDC con el resto de la sociedad?

Como señalamos, los hechos confirman que en el auxiliar inmediato, estuvo y está el principal elemento dinamizador-motivador del diálogo en la Educación Fundamental Integral de ACPO. (Ver Capítulo V). Allí la comunicación, entendida como relación, juega un papel clave y explica, en buena medida, el impacto de la estrategia pues, como lo leímos atrás, “ACPO (...) llegaba con los mensajes reales, en los momentos reales y en forma directa a los campesinos" .El auxiliar inmediato (tutor o facilitador) era ante todo un motivador. "Sin esa motivación el grupo se disolvía". (Monsalve, 2018, audio podcast).

Estamos, entonces, ante un elemento clave en el proceso de comunicación, como lo es el universo emocional, que permite poner los sentimientos al servicio de la producción de sentido.

Hoy, en la era digital, el auxiliar inmediato sigue siendo muy importante y los hoy denominados tutores o facilitadores tienen claro que su tarea cobra sentido en la apertura de espacios de interacción, que contribuyen tanto a la formación como a la producción de significados en las EDC. Un ejemplo está en la tarea que cumple en el departamento del Caquetá -una de las zonas de Colombia históricamente más afectadas por la violencia- el facilitador Alberto Medina, de 18 años. Como lo relata él mismo, sus conocimientos en 
tecnología se los debe a su proceso con ACPO. Tras iniciarse como estudiante de las EDC a los 16 años, muy pronto llegaría a ser auxiliar voluntario y hoy es el facilitador más joven de las EDC. Su testimonio es directo: "Interactúo con el grupo; yo aprendo de ellos y ellos aprenden de mí". (Pérez, 2017, audio podcast). Es la forma de llevar a la práctica la "urgencia", contenida así en la característica No. 7 de la EFI: llegar al mayor número de personas en el menor tiempo posible. Se reafirma así la importancia de la comunicación educativa que, como ocurrió ayer con las Escuelas Radiofónicas, hoy les brinda a los estudiantes una nueva proyección personal y profesional.

Es, insistimos, el diálogo, que se activa cuando la palabra se pronuncia para mover a la acción y a la reflexión. (Freire, 1972), pues, según el mismo Freire, la palabra llena de praxis y de verdad, transforma el mundo.

Como decíamos, en ese contexto se da la colaboración no solo dentro del mismo grupo sino con el resto de la comunidad; es una constante en el proceso de la EFI. Y es lo que se observa en casos como los de la estudiante Sacramento Soriano, quien afirma: "Yo soy pensionada, y con una discapacidad; estoy terminando el bachillerato y quiero hacer trabajo social. (...) La idea es que aprendan a manejar el computador: Yo les enseño a abrir el correo y la forma de acceder a los cursos". (Pérez, 2017, audio podcast)

Una experiencia similar es la que narra Alba Vásquez, voluntaria de ACPO en Silvania (Cundinamarca): "Yo duré como ocho meses en silla de ruedas y durante tres años no pude trabajar. Y de pronto el nuevo alcalde me llamó y me puso a trabajar en una oficina, donde empecé a trabajar con gran dificultad, pues me tocaba agarrarme de las sillas y de las paredes. Así empecé, hasta que volví a recorrer todo el municipio, casa por casa. Luego empecé a hacer labor social aquí en la vereda. En agradecimiento a esa oportunidad de trabajo yo decía: Tengo que hacer algo bonito. Un día me llamaron de ACPO y me dijeron que como yo era líder, me querían capacitar para que les enseñara a otros. Me interesó y me gustó mucho. Desde que inicié, le pedí a mi hijo que me colocara internet acá, mi hermana me trajo el computador y ahí he aprendido muchísimo. Me he dedicado a esto, y ha sido algo muy bonito. (...) Y ahorita me dedico a trabajar con los niños de esta vereda y con los abuelitos".

Por su parte, Mauricio Ramos, estudiante en la EDC en Dagua (Valle del Cauca) destaca: "Entonces, lo que voy aprendiendo lo comparto con ellos. Es muy bonito, porque hay muchas personas que nunca en su vida habían cogido un mouse, y uno ya ve el progreso..." (Pérez, 2017, audio podcast)

Y para que no quede ninguna duda sobre el aprendizaje colaborativo, que implica la 
reelaboración de los contenidos de los cursos, Orlando Rendón, facilitador en Antioquia, relata que "ellos nunca se habían sentado a analizar realmente ni qué eran ni lo que tenían en conjunto. Así tienen muchos fundamentos para hacer una especie de monografía de su terruño, de su finca y de su vereda en comunidad. (Pérez, 2016, audio podcast)

Como vemos, los estudiantes actúan como sujetos activos del proceso educativo, en la medida en que incorporan algún nuevo contenido valorativo conductual, conceptual...(Buenfil Burgos, 1992). Es, también, una de las formas de acceder al reconocimiento que, como se ha señalado en este trabajo, hace posible la formación de subjetividades y la producción de sentido, esto es, de las identidades sociales. Porque, como también lo hemos indicado, el interjuego entre interpelaciones y reconocimientos“ se enlaza con una práctica de interpelación y una modificación o la reafirmación fundamentada de una práctica concreta”. (Martínez, 2017, p. 169).

Reconocimiento es respeto, que se basa en validar al otro como interlocutor; implica valorar las distinciones y las identidades - de ellos y de nosotros- lo que nos lleva a dudar, y a ejercer la autocrítica para evaluar nuestro propia forma de pensar, de cara a construir nuevas realidades con los otros, pues en la comunicación no se trata de imponer sino de crear algo en común. Por lo demás, cuando en calidad de ciudadano participo de la deliberación con quienes manejan otras perspectivas, desde otros horizontes o puntos de vista, contribuyo a la construcción de mi propia vida, tanto individual como colectiva. Y en ese sentido, me ciudadanizo con la palabra pública, al acceder a lo que Dussel llama "lógica de la alteridad", que comienza con el cara a cara y "significa enfrentarse al Otro como otro". ( 1995, p. 128). Por esa vía podemos destacar y potenciar los valores y aportes de otras culturas que, en realidad, también hacen parte de nuestras culturas. Entonces el reconocimiento es lo opuesto a la violencia con sus diversas manifestaciones, entre estas negación o desposesión de derechos, discriminación, maltrato, violación, exclusión, racismo, indignidad, injuria, humillación, xenofobia... Por lo tanto, se enmarca en una relación constitutiva de la subjetividad, pues "uno se convierte en sujeto individual en virtud de reconocer a otro sujeto y ser reconocido por él” (Fraser, 1997, pp. 17-18). En otras palabras, el acto de reconocerse y ser reconocido es lo propio de la ciudadanía, pues se traduce en inclusión y, por consiguiente, en el acceso al derecho a ser visto y a ser oído, porque quien no es reconocido no existe como sujeto político. (Martín-Barbero, 2015, p.24). De ahí, como lo expresara Freire, lo importante que resulta que el educando se reconozca conociendo los objetos. Así, en la medida en que descubre que puede conocer, asiste a "la inmersión de los significados en cuyo proceso se va tornando también significador crítico" (1994, P. 66) Y, 
como lo señalamos, ser "significador crítico" es también tener y ejercer la capacidad de nominación, tanto de lo material como de lo inmaterial, es decir, participar de manera activa de las mediaciones simbólicas, lo cual resulta clave para la tarea de transformar la realidad social, que es, según lo subraya Jorge Huergo, el verdadero fin del proceso educativo: no solo el interjuego entre interpelaciones y reconocimientos sino el cambio en las prácticas socioculturales cotidianas, es decir, "en los modos de hacer y de ser, en los saberes, en la formas de pensar, de posicionarnos...”. (2003, p.5).

En efecto, cuando nombramos la realidad con palabras y significados específicos la reconocemos e identificamos para tomar una posición concreta frente a la misma, es decir, para actuar, deliberar, proponer y, si es necesario, tomar medidas preventivas. (Cortina, 2018, archivo de audio). Esa es la razón, por ejemplo, para que las autoridades meteorológicas hayan optado por darles nombres concretos a los huracanes, tormentas o borrascas. Y, como pregunta Cortina, si ello pasa con los fenómenos naturales, ¿no debería hacerse algo similar con los problemas sociales?

La pregunta es: ¿Es que no hay borrascas sociales que son más peligrosas que las borrascas atmosféricas? ¿No puede ocurrir que haya una borrasca tan peligrosa como el rechazo a los pobres, el rechazo a los desvalidos, el rechazo a los mal situados? Yo creía que necesitábamos una palabra para identificar ese rechazo a los pobres, para reconocerla.Y por eso tomé mi diccionario del griego y busqué la palabra pobre. Construí la palabra "aporofobia", que vendría de "aporos", que es el pobre, el sin recursos, como decimos en la situación aporética, de alguien que no tiene salida. (2018, audio en archivo)

Es lo que también hemos visto en esta tesis, por ejemplo, con las palabras "ciudadanía rural" que, para ACPO, van mucho más allá de un estatuto constitucional o legal -por lo demás inexistente en nuestra Carta Política- para identificarse con acciones cotidianas relacionadas con la risa, con la música, con el baile... Son tareas que también asumen nuestros habitantes rurales con narrativas que se activan como formas simbólicas de resistencia, para enunciar sin denunciar y echar mano de "la potencia del silencio", como lo advierte el periodista Arturo Guerrero. (Ver capítulo IV)

Se confirma así una de las ideas fuerza de este trabajo: que la radio va más allá de la radio, y que, como lo plantea la teoría del "contrato de lectura" de Verón, en el cual nos detendremos más adelante, son los propios actores del proceso de formación los encargados de apropiarse o de rechazar los mensajes que circulan por allí. Entonces nada mejor que sean los propios estudiantes quienes produzcan los contenidos, pues en la medida en que los 
discursos son elaborados colectivamente, se potencia la construcción del sentido de lo social, "a partir de la experiencia propia, donde intervienen la memoria social, política y cultural". (2015, p.31)

Estamos, entonces, ante una apuesta por la construcción de las identidades culturales y políticas, uno de los aspectos clave en la constitución de las ciudadanías, que cobra sentido en los relatos de los propios actores sociales, sin la interferencia del Estado, "pues la relación de la narración con la identidad no es solo expresiva sino constitutiva". (Martín-Barbero y Ochoa Gautier, 2005. pp 3-4) .

Desde el campo de la Comunicación/Educación este proceso se identifica con la formación que trasciende la escolarización, para insertarse en los diferentes escenarios que conforman el mundo de la vida, en los que se ejercen las nuevas ciudadanías, esto es, en los diferentes contextos de deliberación-disputa por el significado que también, en lo político, asociamos a los postulados del humanismo cívico y la democracia radical. Desde este último enfoque, hay democracia cuando sectores que no participaban de la gestión de la cosa pública, ahora empiezan a participar, tanto de su propia concepción de organización política como de la forma de gestionar los conflictos. (Laclau, 2009). Ese es el telón de fondo de lo que hemos planteado aquí: la ampliación de la democracia, como única alternativa y garantía posible para luchar por ella, concretar las esferas de los derechos civiles, políticos y sociales y hacer viable la justicia social.

Son perspectivas que confirman también la importancia de propuestas como las formuladas por el investigador Ismar de Oliveira Soares (2000, pp. 27-47) encaminadas a reconceptualizar la relación entre educación y comunicación, hacia "una educación ciudadana emancipadora, que se basa en la concepción de un nuevo sujeto, de una nueva temporalidad y de una nueva praxis", acorde con la era digital, que está transformando la forma como nos relacionamos, los sentidos que generamos e intercambiamos, "y hasta los imaginarios o valoraciones que los ciudadanos hacen de esta nueva estructura de las relaciones humanas" (Rey, 2015, p.36)

Ahí es donde cobra más importancia la propuesta de las "nuevas ciudadanías", enfocada a humanizar la relación sujetos-sujetos y sujetos-Estado, en la que juega un papel clave lo que se conoce como "capital simbólico".

\subsection{Capital simbólico}

El sociólogo francés Pierre Bourdieu (1994) sostiene que más allá de una definición concreta, el capital simbólico debe asociarse con el resultado de un conjunto de acciones 
ejercidas por agentes sociales que buscan legitimidad, incidencia y reconocimiento. Para Bourdieu, la distribución del capital (económico, social, cultural y simbólico) determina la estructura del espacio social y las oportunidades de vida de los agentes sociales. (1994, p. 116). Como lo destaca el investigador José Manuel Fernández, en Bourdieu "prestigio, carisma y encanto" son formas de capital simbólico. "Frecuentemente, equipara el capital simbólico con el carisma y la legitimidad en sentido weberiano". (Ib, p. 38). Vale decir aquí que Weber relaciona la legitimidad con conceptos como dominación, que asocia a su vez con la probabilidad de encontrar obediencia; poder, identificado con la probabilidad de imponer la voluntad dentro de una relación social, esta última a su vez definida por él como la reciprocidad entre dos o más individuos. El mismo Weber le concede una especial importancia a la influencia de las relaciones sociales y de los fenómenos culturales que, dice, "es mucho mayor que lo que a primera vista parece". Y menciona como ejemplo la dominación que se ejerce en la escuela "mediante la cual se imponen las formas del lenguaje oral y escrito que valen como ortodoxas". (1964, p. 699)

En ese orden de ideas, podemos señalar que el principal capital simbólico de Acción Cultural Popular es Radio Sutatenza, nombre que ha dejado marcas y huellas no solo en Colombia, sino en América Latina, África y Asia, hacia donde se extendió el modelo de las Escuelas Radiofónicas.

Como lo hemos recordado, en Suramérica inspiró trabajos similares en Chile, con la Fundación Radio Escuela para el Desarrollo Rural, Freder; la Asociación Cultural Loyola en Sucre, Bolivia; el Instituto Cultural Popular (Incupo) en Reconquista (Argentina); Las Escuelas Radiofónicas Populares de Ecuador, (ERPE); Radio Occidente en Tovar (Venezuela); las Escuelas Radiofónicas de Nicaragua y Radio Onda Azul, en Puno, Perú. (Ban.República, 2012)

Así mismo, este movimiento radialista educativo dio origen en 1972 en Sutatenza ( departamento de Boyacá) a la Asociación Latinoamericana de Educación Radiofónica ( ALER) "como resultado del Segundo Seminario de Directores de Escuelas Radiofónicas de América Latina convocado por ACPO, con sede primero en Argentina y luego en Quito, Ecuador”. (Ib.). Hoy, 47 años después de su creación, ALER sigue trabajando por la defensa del derecho a la comunicación. Como vemos, gracias a su prestigio, carisma y encanto, las marcas y huellas de Radio Sutatenza no solo no se han perdido sino que hoy se mantienen más visibles que nunca, a 70 años de su fundación.

En realidad, Radio Sutatenza nunca dejó de actuar; es cierto que su organización administrativa cesó actividades, primero en 1989, cuando se concretó la venta de sus 
frecuencias a la cadena comercial Caracol Radio; luego, en 1990, con la venta de la Editorial Andes y el cierre del semanario El Campesino y finalmente en 1994, al cesar sus actividades los Institutos Campesinos. Pero ello no implicó que las tareas medulares de la EFI dejaran de existir, pues no solo mantuvo vigente su espíritu formativo en otras latitudes, sino que muchos de sus estudiantes y beneficiarios indirectos siguieron y siguen trabajando, motu proprio, en pro de la inclusión, de la participación y de la promoción de valores democráticos inmersos en la Comunicación/Educación. A manera de ejemplo, recordamos los testimonios de líderes y lideresas como Rosmira Henao Zarrazola, Luis Alberto Celis y Hermes Martínez, quienes nunca han dejado de trabajar como promotores de la EFI, mediante la utilización de recursos tan emblemáticos y útiles como el Discoestudio. Y los casos muy significativos que hemos mencionado de Erasmo Angarita Tovar, Angelmiro Barbosa y los demás ex estudiantes de ACPO que fundaron en 2016 y hoy mantienen al aire la emisora online ACPO Vive Radio Sutatenza. Así mismo, el de la Asociación de Exalumnos de ACPO (Asoacpo) que inauguró este año (2018) la emisora online “Asoacpo Sutatenza Medellín”.

Se comprueba así, en la práctica, esto es, en los quehaceres concretos de quienes hacen parte de la Acpoeducación -como gestores, voluntarios, estudiantes, lideresas y líderes o como productores de sus propios mensajes- que esta realidad es el resultado más palpable de una obra que nació de las entrañas de la Iglesia Católica, pero no entendida ésta como la jerarquía, en cabeza de la Conferencia Episcopal Colombiana, sino como los entusiastas feligreses que atendieron el llamado del entonces novel sacerdote José Joaquín Salcedo Guarín. Al fin y al cabo, esas campesinas y esos campesinos fueron, y son hoy, los verdaderos gestores, promotores y replicadores de la obra que marcaría un antes y un después en la educación rural, tanto en Colombia como en buena parte del mundo. En efecto, fueron ellas y ellos quienes con su aporte económico y espiritual hicieron posible que la propuesta de comunicación educativa de ACPO hubiera llegado tan lejos. O, nos preguntamos: ¿Qué hubiera pasado si José Joaquín Salcedo no hubiera encontrado el decidido apoyo de las campesinas y campesinos de Sutatenza? Y ¿Qué pasaría hoy si el aparato de organización de ACPO no contara con la receptividad y el respaldo que le brindan sus estudiantes, voluntarios y auxiliares en los 11 departamentos donde ya hace presencia? Claro, la organización administrativa ha sido y es importante para potenciar múltiples acciones en beneficio de su población objetivo. De hecho, como lo indicamos en el Capítulo IV, ACPO ha sabido aprovechar, en el buen sentido del término, la religiosidad de las campesinas y campesinos, al incorporar el discurso religioso como parte fundamental de sus procesos 
interactivos e interpelaciones, e insertar la acción humana dentro de un contexto religioso y "proveer las bases para el ejercicio de un criterio moral". (Bernal, 1978, p. 126). Es lo que confirmamos, por ejemplo, con la exitosa estrategia de movilizar a millares de voluntarios en favor de la EFI y la actitud solidaria y colaborativa constante que se manifiesta dentro y aun fuera de las EDC, para compartir y replicar lo aprendido. Es, así mismo, un elemento clave para convocar a los educandos, como ocurre hoy con la programación de ACPO Vive Radio Sutatenza, que se reconoce y asume su trabajo en el marco de la "EFI cristiana". Ignorar este aspecto sería desconocer de tajo principios y valores que, para Habermas, llenan a las sociedades de "reservas de fundación de sentido e identidad" (Habermas, 2008, P. 5). Pues, como se ha demostrado, las tradiciones religiosas no solo aportan riqueza motivacional sino "también cognitiva en la esfera pública de una sociedad civil comprometida y activa. Es tiempo de sumar esfuerzos, no de restar. (Cortina, 2011, p. 48)

Es claro, entonces, que sin esos valores y principios de las campesinas, campesinos y hoy también los integrantes de comunidades indígenas y afrodescendientes, ACPO perdería su razón de ser. De hecho, muy pronto José Joaquín Salcedo entendió que para estructurar una programación eficaz e impactante de Radio Sutatenza debía contar con ellas y ellos para conocer muy bien a sus oyentes: sus gustos, sus intereses, sus prácticas cotidianas, sus necesidades y anhelos, como se publicó en el libro "La audiencia campesina de Radio Sutatenza". (Gómez y Gutiérrez, 1970). Para el investigador Hernando Vaca Gutiérrez, estos fueron los primeros estudios de recepción que se hicieron en América Latina, a tal punto, que "podríamos decir que los prolegómenos de los estudios de recepción están en Radio Sutatenza, 40 años antes de que Jesús Martín-Barbero nos llamara la atención sobre el papel de los receptores, en su libro "De los medios a las mediaciones". (2018, archivo de video)

En ese orden de ideas, apoyados en las reflexiones de la filósofa española Adela Cortina, podemos afirmar que en el caso estudiado la formación ciudadana que se apoya o se promueve desde la comunicación, se construye en múltiples escenarios de la vida social, entre ellos la familia, la iglesia, la escuela, las relaciones interpersonales y demás medios de comunicación social, "entre otras razones, porque su compromiso fundamental no es el que les liga a la burocracia, sino a las personas concretas, a las personas de carne y hueso, cuyo beneficio da sentido a cualquier actividad e institución social”. (1998, p. 4) Así lo concibió ACPO desde la época de las Escuelas Radiofónicas al advertir que su modelo de uso combinado de medios de comunicación no se debía entender tampoco "como una alternativa excluyente de la educación convencional". (Bernal, 1978, p.219).

En ese contexto se ha vivido la construcción de ciudadanías que se expresa en los 
ámbitos específicos en que se mueven los actores de las Escuelas Digitales Campesinas, y ahora también en iniciativas como la Red de Reporteros Rurales (R3) para que sigan siendo ellas y ellos los relatores de sus propias historias.

En el escenario específico de las EDC, con este trabajo se ha buscado entender las luchas que se libran en el campo de la cultura, "en el que se reflejan la multiplicidad de valores, voces e intenciones" que conforman su capital simbólico y permiten la construcción de identidades. (Huergo, 1999, p.132). Es entonces, dice Huergo,

Una pedagogía expresada desde los márgenes que redimensiona la praxis en la posmodernidad: aprovecha las grietas y resistencias del sistema hegemónico, retoma el sujeto de liberación (no solo teóricamente), parte de la acción (...) y devuelve la alteridad a las voces que fueron y son acalladas, marginadas y despojadas de poder por los discursos dominantes. (Ib., p. 167)

Ello da pie para afirmar, sin desconocer las falencias de la Acpoeducación, que, en la medida en que los estudiantes de las Escuelas Digitales Campesinas interpretan, reelaboran los contenidos en función de su propio contexto y hacen públicos sus pareceres y sentires, se hacen partícipes de la deliberación pública encaminada a incidir en la definición de políticas que sean reguladas por su propia visión del mundo y no por representantes del Estado o por matrices foráneas que deciden por encima de ellos. (Villamayor, pp. 6-7).

Son formas específicas de intervenir en la constitución de las nuevas ciudadanías que, como lo reafirma el investigador Carlos Valderrama, se relacionan con la construcción de identidades, la sociabilidad, el sentido ético, el fortalecimiento de la convivencia y el sentido de participación, los cuales "se dan en la medida en que interactuamos con otros". (2000, p. 9).

\subsection{El contrato de lectura en la era digital}

Y para establecer cuáles son los elementos fundamentales que intervienen en la producción de sentido en las EDC, en esta tesis ha cumplido un papel clave la teoría del contrato de lectura, también denominada por Eliseo Verón "dispositivo de enunciación". Desde esa perspectiva, no solo cuentan las intenciones de quien emite sino, de manera especial, la forma cómo se recibe el mensaje, teniendo en cuenta que "el sentido no opera según una causalidad lineal” (1986, p.15) . ¿Por qué es aceptado? ¿ Por qué es rechazado? ¿Cuáles son las formas de relación que determinan ese proceso comunicativo? ¿Cómo se producen las interacciones, las cuales no siempre se dan en forma inmediata y simétrica? 
En estos planteamientos juegan un papel esencial tanto los agentes inmersos en el proceso de aprendizaje como los recursos narrativos (discurso religioso; auxiliar inmediato; cartas; combinación de medios, etc.) y el contexto en el que se da la interacción. De ahí que hayamos hecho énfasis en las implicaciones, es decir, en las formas como las campesinas, los campesinos e integrantes de comunidades indígenas y afrodescendientes se involucran en esa "constelaciones de sentido y de significados" en la era digital, tarea fundamental si consultamos el gran objetivo de las EDC de promover el pleno ejercicio de la "ciudadanía rural”. Como lo subraya la investigadora María Cristina Mata:

Por ello es que, reconociendo el indiscutible poder del emisor -aunque más no sea como aquél que tiene la iniciativa para el intercambio- debamos advertir en su discurso la presencia activa de los receptores porque ellos están presentes como término de su producción, como el otro que habla en lo que yo digo. (1985, p. 43)

¿Y ahora, como productores activos, qué significa para ellas y para ellos su ingreso a las plataformas digitales? Son muchos y variados los impactos, aunque es clave primero tener en cuenta que el problema de fondo no es el acceso a las tecnologías en sí mismo, sino algo mucho más complejo llamado comunicación. Estamos aquí ante lo el comunicólogo italo-venezolano Antonio Pasquali identificara en su clásica obra de 1970 "Comprender la comunicación" como la dimensión humana del proceso comunicativo, en un enfoque que partió de cuestionar las perspectivas funcionalistas y positivistas que habían imperado hasta entonces. Desde este horizonte, más allá de los avances tecnológicos y de los medios usados, la clave está en las relaciones que tejen las personas, y los sentidos que producen, a partir de algo complejo y cambiante, como lo es el lenguaje. Muchos años después autores como el francés Dominique Wolton (2018) insisten en la necesidad de poner el énfasis en las características sociales y culturales de la comunicación, tras concluir que, en efecto, el problema esencial nunca es la técnica sino los hombres, porque la técnica depende de la lucha política y del proyecto político que disputan los hombres. En palabras de Hoyos Vásquez (1995) se trata de librar la lucha hacia un nuevos ethos cultural, que, en el marco del proceso educativo, permita ver de manera crítica la ciencia y la tecnología y avanzar hacia "la democratización de la democracia". (P. 68)

En esa disputa cobra especial relevancia la forma no solo de acceder sino de generar conocimientos y saberes los cuales, en la era digital, al propiciarse nuevos modos de percepción y de lenguajes, esto es de estéticas y de narrativas, se deslocalizan y, por lo tanto, 
modifican las condiciones, "tanto del estatuto cognitivo como institucional de las condiciones del saber". (Martín-Barbero, 2015, p. 27).

Como lo podemos apreciar, es una batalla clave, en la medida en que las TIC son un "polo de identificación colectiva" y, como tales, devienen "matriz de representaciones sociales, de designación, de finalidades de la acción y de establecimiento de afectos". (Cabrera, 2006, p. 161).

En esa dirección, el centro de las discusiones planteadas aquí está en las distintas formas de activar y mejorar la comunicación en el seno de las EDC, a fin de construir la relación y ponerla al servicio de la convivencia. (Ib.) En la era del big data, debemos asumir, así, el reto de "ganar la política, el activismo, la posibilidad de actuar colectivamente para protegernos".(Rincón, 2016, p. 34) En ese sentido, coincidimos con especialistas como Catalina Botero y Pedro Vaca (Ruiz, 2019, audio podcast) quienes sostienen que, pese a ser un derecho fundamental en las sociedades democráticas desde siempre, la libertad de expresión se volvió realmente importante con la llegada de internet, lo que le abrió paso al ejercicio de la "ciudadanía digital”. En palabras de Hannah Arendt (2018) es parte de la pugna permanente que se ha librado desde hace muchos años por la vigencia de los derechos civiles que, sin embargo, no son, en sí mismos, la sustancia de la libertad, cuya esencia está, según la misma autora, en la admisión de los ciudadanos en el ámbito público y su participación activa en los asuntos públicos.

En el entorno digital, hemos identificado, entre otros, los siguientes recursos, caracterizados por su especial potencia para el ejercicio de Comunicación/Educación al servicio de la Educación Fundamental Integral:

-Narrativas transmedia: Varios autores, entre ellos Jenkins y Scolari se han ocupado de investigar este concepto, que definen como la expansión de historias-contenidos por diversos canales; como tales, implican nuevas formas de interacción, codificación y decodificación, "así como habilidades para interactuar y tomar decisiones en el mundo de la vida". (Amador, 2014, p. 1). El ecosistema comunicativo de ACPO no es ajeno a esta tarea, no solo en la medida en que despliega sus contenidos en diversas plataformas (periódico digital, radio, video, redes sociales e impresos) sino en tanto sus cursos, entre ellos el de alfabetización digital, les han abierto el camino a sus estudiantes para que usen y se apropien del universo ilimitado que significa acceder a Internet y sacarle así el mejor partido posible a las nuevas formas de estar en el mundo que implica la era digital.

-Inteligencia colectiva: Al ver con perspectiva histórica el proceso de ACPO encontramos que uno de sus grandes activos ha estado en el uso y apropiación de la 
inteligencia colectiva, considerada por el filósofo y sociólogo tunecino Pierre Lévy, la fuente del desarrollo humano que, como tal, "es practicada por los seres humanos desde que disponen de lenguaje y cultura (...). Ahora, en la era digital, "es una inteligencia repartida en todas partes, valorizada constantemente, coordinada en tiempo real, que conduce a una movilización efectiva de las competencias". (Amador, 2012, p. 2)

Se trata de una gran puerta que, como indicamos, favorece la movilización de los saberes y, por lo tanto, contribuye a la democratización de la deliberación pública, en la medida en que propicia el reconocimiento de comunidades que, como las campesinas, indígenas y afrodescendientes, en palabras del mismo Lévy, "a menudo han sido despreciadas, ignoradas, inutilizadas y/o humilladas”. (2004, p. 19)

Así, en la búsqueda del sentido enmarcado en la relación tecnologías digitales/medios/ comunicación, estamos ante tres dimensiones que favorecen la propuesta de comunidades de interaprendizaje de ACPO: "otros modos de asumir la realidad; nuevas formas de gestionar la participación y la ruptura de la totalización mediante la creación interactiva". (Amador, Ib., p.3)

Hoy, entonces, ACPO, que como planteamos va más allá de la organización institucional, se mueve en esos nuevos escenarios que le brindan mayores posibilidades de éxito en la tarea de construir sus propios relatos, en un contexto que, incluso, está cambiando la noción de lo popular, para asociarlo ya no solo con lo conocido y consumido por el "pueblo" sino por la construcción colectiva en lo que McLujan denomina ecología de medios, es decir, esa trama compleja de mensajes "los cuales fluyen múltiples, efímeros y cambiantes, a través de los entornos visual y digital" e impactan los contextos y los ambientes culturales. (Ib., p.4). Se evidencia, así, la heterogeneidad que se despliega en las TIC como institución de lo imaginario social, desde las cuales entreteje la realidad (o realidades) que Daniel Cabrera identifica como "económico-funcional institucional y simbólica". (2006, p. 159)

Voces propias en medios propios: "Para un nuevo modo y acceso al conocimiento es necesario un nuevo modo de mediación”, advierte Pierre Lévy. Es, se puede afirmar, la mediación ideal para el tipo de procesos sociales como el que estamos analizando, en la medida en que cada actor se puede convertir en productor de discursos y de relatos, que circulan en diversas plataformas. Para ello, según Habermas, aunque es necesario aprender a manejar las redes de manera civilizada, y a pesar de los problemas de fondo que se han planteado por el excesivo énfasis en el mercantilismo, no se puede negar, que la red ya ha abierto millones de nichos subculturales: 
Pensemos no solo en los blogs de científicos que intensifican su labor académica por este medio, sino también, por ejemplo, en los pacientes que sufren una enfermedad rara y se ponen en contacto con otra persona en su misma situación de continente a continente para ayudarse mutuamente con sus consejos y su experiencia. Se trata, sin duda, de grandes beneficios de la comunicación, que no sirven solo para aumentar la velocidad de las transacciones bursátiles y de los especuladores. (Habermas, 2018, p.5)

Lévy lo dice con estas palabras: "Así no solamente todo el mundo se convierte en autor sino también en prescriptor, organizador de la memoria colectiva, documentalista, crítico. En suma todo el mundo se vuelve mediador”. (2007, p.4) Es, como se ha visto, lo que ya se evidencia con el caso de la emisoras online "ACPO Vive Radio Sutatenza", "Asoacpo Sutatenza Medellín” y “Odismar 715 Estéreo". que nacieron y se mantienen gracias al mismo trabajo de los estudiantes, ya sea de las Escuelas Radiofónicas o de las EDC; con la vigencia del Discoestudio, como recurso para capacitar a comunidades que no tienen acceso a la educación formal; con el radioclip y el podcast, claves en la tarea de hablar desde el universo vocabular de los actores sociales y con la Red de Reporteros Rurales (R3). Siguiendo a Fuenzalida, (1996) se puede afirmar que, en la medida en que los propios sujetos relatan sus historias como ocurre en estos casos, se educan tanto para la emisión como para la recepción $\mathrm{y}$, por esa vía, se fortalece su participación activa en el proceso de construcción de significados y la producción de sentido, es decir, se cualifica el ejercicio ciudadano. Y en estas tareas, como lo destaca el investigador Raúl Hernando Osorio,

el periodismo cumple un papel esencial al construir con su narrativa de los acontecimientos el ejercicio de la ciudadanía, estando, así, vinculado a los nuevos movimientos sociales, que están transformando desde abajo la vida de la gente y la forma de hacer política. Esto supone también una forma nueva de hacer e investigar en periodismo. Es, por tanto, un gran desafío. (2013, p. 13)

Así mismo, como lo indicamos en el capítulo V, tanto la experiencia de las emisoras online como la del programa de radio "Mundo Rural", señalan unas variantes de lo que Eliseo Verón denomina "El contrato de lectura", en la medida en que los propios actores de las EDC pueden actuar como productores y consumidores (prosumidores). Claro, es un modelo que se debe profundizar, pero ya se observa la apropiación y uso de elementos que demuestran su plena viabilidad práctica, pues 
Son condiciones sociales de producción de sentido inscritas en las luchas por la hegemonía entendida en su complejidad desde sus dimensiones política, cultural y de concepción del mundodonde cobran su pleno valor los discursos que "articulan el sentido de una sociedad". (MartínBarbero, 2003)

Son, diríamos, más que sentido, sentidos que se disputan y se construyen, en el marco de la cultura, permeada por lo que Williams (2000) denomina prácticas dominantes, residuales o emergentes. Aquí lo residual alude a lo negado o reprimido por la cultura imperante, como algunas identidades étnicas o religiosas, que, sin embargo, existen y, con frecuencia, llegan a fusionarse o, por lo menos, a impactar lo emergente, como se puede evidenciar hoy en los escenarios digitales.

\subsection{Retos}

Como lo hemos planteado, aún son muchos los retos que debe enfrentar la Acpoeducación, entre los cuales subrayamos los siguientes:

1o. No perder de vista la necesidad de seguirse educando en la cultura del diálogo, que, aunque no es una tarea sencilla, tiene como gran aliciente y recompensa contribuir a la transformación del pensamiento colectivo.

2o. Abrir y abrirse cada vez más espacios de participación-deliberación para que los estudiantes de las EDC sigan siendo relatores de su propia historia; que eso que tantas veces han dicho en privado y que, a pesar de tener incidencia social no ha podido trascender, haga parte de sus discursos, de sus propias palabras públicas, con todas las implicaciones que tiene en la construcción de sus identidades.

3o. Apelar a la creación de más medios de comunicación por parte de los mismos actores de las EDC, en calidad de prosumidores, experiencias que ya se muestran como viables, gracias al trabajo de las emisoras ACPO Vive Radio Sutatenza, Asoacpo Sutatenza Medellín, "Odismar 715 Estéreo" y a otras diversas y creativas formas de difusiónparticipación-interacción de los contenidos que promueven la dignificación de las campesinas, campesinos, comunidades afro e indígenas, como sigue ocurriendo hoy con el Discoestudio.

4o. En esa tarea de activar y profundizar la interlocución pública que tanto se les ha negado a las minorías - las mismas que han puesto el mayor número de víctimas en el conflicto armado en Colombia- concretar la participación de representantes de las Escuelas 
Digitales Campesinas en el Consejo Editorial de plataformas como elcampesino.co y Mundo Rural Radio. Así mismo, es importante que, una vez terminado el proceso de formación en la $\mathrm{R} 3$, sean los propios estudiantes de las EDC quienes conduzcan y realicen sus propios programas de radio. (Como vimos, los podcast o archivos sonoros son una buena alternativa)

5o. Remozar las narrativas, como vimos íntimamente conectadas con los nuevos contextos en los que se mueven los actores de las EDC, de cara a potenciar géneros como el dramático (por ejemplo el radioclip o la radionovela versión 2020), pues, como lo planteamos, la ficción tiene un gran impacto en la tarea de generar reconocimiento.

6o. En cuanto a la organización se refiere, no repetir los errores del pasado, en especial "evitar cierta rigidez institucional", derivada de la autoridad de su fundador que, según la investigación adelantada en su oportunidad por el Instituto Alemán de Desarrollo, fue un factor que jugó en contra de los necesarios cambios "que implica el proceso de desarrollo acelerado". (Musto, 1971).

7o. Seguir incidiendo ante las diferentes instancias estatales para que se hagan efectivas mejoras sustanciales, tanto en la conectividad como en la ejecución de políticas públicas que acompañen el proceso de la formación para el uso de herramientas tecnológicas, a fin de superar las dificultades que se presentan con el acceso la plataforma de las Escuelas Digitales Campesinas y con la estrategia de convergencia de medios que se deriva del uso de las TIC. Ello sin perder de vista que el problema central está en seguir recuperando la comunicación, como condición para hacer viable el fortalecimiento de lo público, el cual se construye a partir de las articulaciones entre el interés común, el espacio ciudadano y la interacción comunicativa. (Rey, 1998)

Son propuestas para que se sigan tejiendo las nuevas narrativas del campo colombiano. Para que ellas y ellos cuenten, han aprendido y están aprendiendo a contar sus historias. Insistimos: es una realidad que se debe profundizar día a día, para concretar el proyecto de la Comunicación/Educación, en concordancia con el Humanismo Cívico y la Democracia Radical, de formar ciudadanas y ciudadanos, es decir, sujetos políticos socialmente responsables, útiles y transformadores de sus propias realidades. 
Radio Sutatenza y Acción Cultural Popular en la era digital 


\section{REFERENCIAS}

- Acción Cultural Popular, ACPO ( 2016). Plan estratégico 2017-2021. Sembramos educación, cosechamos bienestar en el campo. Recuperado de

- http://www.fundacionacpo.org/wp-content/uploads/2017/07/PlanEstrat\%C3\%A9gico-11-julio.pdf

- Acción Cultural Popular, ACPO. (Anónimo) Llega el nuevo curso de comunicación y periodismo rural. Recuperado de http:/www.fundacionacpo.org/llega-nuevo-curso$\underline{\text { comunicacion-periodismo-rural/ }}$

- Acción Cultural Popular, ACPO. (Anónimo) Aula Rural. Escuela Virtual Campesina. Manual del profesor. Curso conocimiento del medio.

- Alexiévich, Svetlana (2015) La guerra no tiene rostro de mujer. Editorial Debate. Barcelona .

- Alexiévich, Svetlana (2015). Svetlana Alexievich, premio nobel de literatura. Recuperado de: http://revistaliterariaazularte.blogspot.com.co/2015/12/el-culturalsvetlana-aleksievich-premio.html

- Alfaro, R.M. ( 2008) Ciudadanos y culturas mediáticas: ocultos en la formalidad democrática. Recuperado de https://dialnet.unirioja.es/servlet/autor?codigo=1233275

- Alfaro, R. M. (2000). Culturas populares y comunicación participativa: en la ruta de las redefiniciones, Razón y Palabra, núm. 18. Recuperado de http://www.razonypalabra.org.mx/anteriores/n18/18ralfaro.html

- Amador, J.C. (2012). Transmediaciones, nativos digitales y educación. Bogotá. Recuperado de: http://comunicacionyeducacion.sociales.uba.ar/files/2012/12/GT22_AmadorJ.pdf

- Arendt, H. (2018) La libertad de ser libres. Madrid. Editorial Taurus.

- Arendt, H. (2005) La condición humana. Barcelona. Editorial Paidós.

- Arendt, H. (1997) ¿Qué es la política? Barcelona. Editorial Paidós.

- Astudillo, A. et al (2008) Radio local, opinión pública y participación ciudadana. 
Recuperado de:

https://revistas.javeriana.edu.co/index.php/signoypensamiento/article/view/4580

- Avella, C (2008). Modelo de conexión rural-urbano: estrategia de conectividad a través de centros poblados rurales para el desarrollo rural integrado. Bogotá. Universidad Javeriana.

- Ávila, A. [Ariel Ávila]. $(2018,11,14)$ La clase política colombiana. [Archivo de video]. Recuperado de https://www.youtube.com/watch?v=ZyaMn8Y8Nr4

- Banco de la República (2012). Radio Sutatenza: una revolución cultural en el campo colombiano (1947-1994). En: Boletín cultural y bibliográfico. Volumen 46 No. 82. Recuperado de http://www.banrepcultural.org/radio-sutatenza-boletin-cultural

- Barbosa, S. (2014) Los desafíos del Pluralismo y la Ciudadanía Democrática. Recuperado de: https://periodicos.ufpel.edu.br/ojs2/index.php/rsulacp/article/view/3879

- Bassi, R. \& Britton, D. . (2008). Orlando Fals Borda-Sentipensante. (Archivo de video). Recuperado de: https://www.youtube.com/watch?v=LbJWqetRuMo

- Bayuelo, S. (2019) Hay cosas peores que la muerte. Recuperado de: https://www.semana.com/opinion/articulo/lideres-sociales-en-los-montes-de-mariacolumna-de-soraya-bayuelo/616408

- Becerra, M. (2011) El papel de la prosodia y el contexto en la comprensión y producción de dos formas de ironía en español. Recuperado de: https://repositorio.uam.es/bitstream/handle/10486/7700/42850 becerra_valdemoro m aria isabel.pdf? sequence $=1$

- Belotti, F. y Cerbino, M. ( 2016) Medios comunitarios como ejercicio de ciudadanía comunicativa: experiencias desde Argentina y Ecuador. Ed. Comunicar Spanish. Recuperado de: http://search.proquest.com/docview/1781328096/fulltext/4C43A3045F04A1CPQ/2/C omunicar?accountid $=48417 \#$

- Beltrán, L.R. (2005) La Comunicación para el desarrollo en Latinoamérica: un recuento de medio siglo. Buenos Aires. Recuperado de : 
http://red.pucp.edu.pe/ridei/wp-content/uploads/biblioteca/160310.pdf

- Beltrán, M. ( 2017, 26, 05.) Mundo Rural [Audio podcast]. Recuperado de http://www.elcampesino.co/radio-mundo-rural-beneficios-del-acuerdo-paz-agro/

- Bernal, H. (2013) ACPO Radio Sutatenza, precursores de una utopía. Bogotá. UNAD.

- Bernal, H. (2012) Radio Sutatenza: un modelo colombiano de industria cultural y educativa. Boletín Cultural y Bibliográfico. Vol 86. No. 82. Bogotá. Banco de la República.

- Bernal, H. (2005) Radio Sutatenza: de la realidad a la utopía. Bogotá. Ed. Fund. Cultural Javeriana.

- Bernal, H. (1975) Educación Fundamental Integral: Teoría y Aplicación en el caso de Acción Cultural Popular. Bogotá. Ed. Andes.

- Bernal, H. Réquiem por Sutatenza, Recuperado de: http://gumilla.org/biblioteca/bases/biblo/texto/COM199174 110-115.pdf

- Bernal, H. (1966) Educación Fundamental Integral y medios de comunicación social. en: América Latina: La revolución de la esperanza. Bogotá. Publicaciones Violeta Inc.

- Bilyk, P. (2014). La Nación en el cambio de época: democracia y nuevas ciudadanías. La Plata. Universidad Nacional de La Plata.

- Bilyk, P. (2015) Totalidades y paradigma indiciario. Recuperado de: http:/oaji.net/articles/2015/2719-1450553126.pdf

- Bobbio, N. (1986). El futuro de la democracia. México. Fondo de Cultura Económica.

- Bohm, D (1997) Sobre el diálogo. Editorial Kairos. Barcelona

- Bonilla, J. (2002) ¿De la plaza pública a los medios? Apuntes sobre medios de comunicación y esfera pública. Revista Signo y Pensamiento No. 41, Vol. XXI.

- Borges, J.L. (1972) El oro de los tigres.. Ediciones Ñeperuis. Buenos Aires.

- Bourdieu, P: (2007). El sentido práctico. Siglo XXI Editores. Buenos Aires.

- Bourdieu, P. (1997) Sobre la televisión. Editorial Anagrama. Barcelona.

- Bourdieu, P. (1994) Raisons pratiques: Sur la théorie de l'action. París: Seuil.

- Brandolín, A y Rosbosh, M.E. (2003) Transformaciones “al aire”. Radio, medios y poder”. Río Cuarto. Universidad Nacional de Río Cuarto. 
- Brunner, J.J. (1994) Comunicación y política en la sociedad democrática. Seminario "Políticos y Comunicadores: Interacción y Compromisos". Recuperado de: http://200.6.99.248/ bru487cl/files/ComPol\%25SocDEM_1994_DEF.pdf

- Buenfil, R.N. (2013) Eclecticismo y transversalidad en la investigación educativa. Entrevista, por Daniel Saur. Revista Propuesta Educativa. No. 39. Recuperado de: http://www.propuestaeducativa.flacso.org.ar/archivos/entrevistas/39.pdf

- Caballero, A. (2002) Patadas de ahorcado. Caballero se desahoga. Bogotá. Editorial Planeta.

- Castaño, A. (2013) . Álvaro Mutis, una voz inolvidable en la radio del país. Bogotá. Recuperado de: http://www.eltiempo.com/archivo/documento/CMS-13020785

- Castells, M. (2009). Comunicación y poder. Madrid: Alianza Editorial, S.A.

- Castoriadis, C. (2002). La cuestión de la autonomía social e individual. En Pánico en la globalización. Editorial Fica. Bogotá.

- Castro, G. (1999). La caja de herramientas del narrador. En revista Folios. Universidad de Antioquia. Medellín.

- Centro de Memoria Histórica (2018) 262.197 muertos dejó el conflicto armado. Recuperado de: http://www.centrodememoriahistorica.gov.co/noticias/noticias$\underline{\mathrm{cmh} / 262-197-m u e r t o s-d e j o-e l-c o n f l i c t o-a r m a d o}$

- Centro de Memoria Histórica (2018) En Colombia 82.998 personas fueron desaparecidas forzadamente. Recuperado de: http://www.centrodememoriahistorica.gov.co/noticias/noticias-cmh/en-colombia-82998-personas-fueron-desaparecidas-forzadamente

- Cervantes y Cruz Cruz, Pamplona. Editorial EUNSA.La Rue, F. (2013). Entrevista de D. Pastrana. Recuperado de http://seniales.blogspot.com/2013/06/frank-la-rue-las$\underline{\text { radios-comunitarias.html }}$

- Cortina, A. [TEDxUPValència].(2018, 03, 13) Aporofobia, el miedo a las personas pobres. [Archivo de video]. Recuperado de https://www.youtube.com/watch?v=ZODPxP68zT0

- Cortina, A. (1998). Ciudadanos del mundo: hacia una teoría de la ciudadanía. Madrid. Alianza Editorial.

- Cortina, A. (1998). Ética de las profesiones. Recuperado de https://elpais.com/diario/1998/02/20/opinion/887929205 850215.html 
- Cortina, A. (2011) Ciudadanía democrática: ética, política y religión. XIX Conferencias Aranguren. Recuperado

de: http://isegoria.revistas.csic.es/index.php/isegoria/article/view/718/720

- Chomsky, N. (2002) En: Un mundo libre de guerra.. Foro Social Mundial. Portoalegre, $\quad$ Brasil. $\quad$ Recuperado de https://www.rebelion.org/hemeroteca/chomsky/chom270802.htm

- Cueto, A. (2015) Origen de la radio comunitaria en Colombia. Recuperado de: http://sipaz.net/panorama-de-la-radio-comunitaria-en-colombia/

- Dader, J. (2002). Periodismo de precisión. Editorial Síntesis. Madrid.

- DANE. (2015). Tercer Censo Nacional Agropecuario. Recuperado de https://www.dane.gov.co/files/CensoAgropecuario/avanceCNA/Boletin\%20tecnico$\% 202$ sep.pdf

- Delgado, B. (2018) Carta pública al escritor Héctor Abad Faciolince. Recuperado de https://www.revistaarcadia.com/agenda/articulo/profesor-de-pasto-le-escribe-carta-ahector-abad-faciolince/69536

- De Oliveira, I. (1998) La Comunicación/Educación como nuevo campo del conocimiento y el perfil de su profesional. Recuperado de http://books.openedition.org/sdh/185?lang=es

- De Moragas, M., y otros. (2005). El informe MacBride 25 años después. Contexto y contenido de un debate inacabado. Recuperado de http://www.cac.cat/pfw_files/cma/recerca/qytuaderns_cac/Q21incom_ES.pdf

- De Moragas, M. (2011). Interpretar la comunicación. Estudios sobre medios en América y Europa. Editorial Gedisa. Barcelona.

- De Sousa, B. (2014) Epistemologías del Sur (Perspectivas) Madrid. Ediciones Akal S.A.

- De Sousa, B. (2010) Descolonizar el saber, reinventar el poder. Montevideo. Ediciones Trilce.

- De Sousa, B. (2009) Pensar el estado y la sociedad : desafíos actuales. - 1a ed. Buenos Aires : Waldhuter Editores.

- De Sousa, B. (2011) Epistemologías del sur . Maracaibo. En: Revista Internacional de Filosofía Iberoamericana y Teoría Social. Recuperado de http://www.boaventuradesousasantos.pt/media/EpistemologiasDelSur_Utopia $\% 20 \mathrm{y} \%$ 20Praxis\%20Latinoamericana_2011.pdf 
- De Sousa, B (2016). Entrevista con Boaventura de Sousa Santos. Recuperado de: http://www.democraciaenlared.com/2016/03/entrevista-boaventura-de-souza$\underline{\text { santos.html }}$

- Díaz, N. (1999) El relato de una vida: apuntes teóricos-metodológicos en comunicación. Recuperado de: http://www.revistalatinacs.org/a1999coc/33vanancy.html

- Dijk, T. (2003) Ideología y discurso. Editorial Ariel. Madrid.

- Dussel, E. (1995) Introducción a la filosofía de la liberación. Bogotá. Editorial Nueva América.

- Duque, D. (2014) Comunicación, información y cultura: Impacto de medios masivos, estrategias comunicativas. Información y sociedad (opinión pública, redes sociales, entre otros. Recuperado de (http://www.colciencias.gov.co/noticias/postconflictodesaf-o-para-la-investigaci-n-en-las-ciencias-sociales-y-humanas)

- Eco, H. (2002) La fuerza de la cultura podrá evitar el choque de civilizaciones. L'Expresso/El Espectador.

- Eco, Umberto. (2004) El público le hace mal a la televisión. En: La Nación. Recuperado de: http://www.lanacion.com.ar/596242-el-publico-le-hace-mal-a-latelevisio.

- Escuelas Digitales Campesinas. Documento de trabajo. Recuperado de www.escuelasdigitalescampesinas.org

- Fals Borda, O. 1991. Algunos ingredientes básicos. En Acción y Conocimiento. Como romper el monopolio con investigación-acción participativa. Bogotá. CINEP.

- Fals, O (1999). Orígenes universales y retos actuales de la IAP. Bogotá. Revista Análisis Político No. 38. Pp. 71-88.

- Fals, O. (Ricobassilon) [Ag. 17. 2008] Orlando Fals Borda-sentipensante. [Archivo de video] Recuperado de https://www.youtube.com/watch?v=LbJWqetRuMo

- Favela, J. (2010) Las relaciones entre el medio cultural y el sistema de enseñanza: El pensamiento de Pierre Bourdieu y Jean-Claude Passeron. México. Recuperado de: http://www.redalyc.org/pdf/270/27018883008.pdf

- Fernández, M. (2009) Bourdieu, Giddens, Habermas: reflexiones sobre el discurso y la producción de sentido en la teoría social. Cuaderno de H. Ideas. Universidad Nacional de La Plata. Recuperado de: File: /// Users/tallercreativobingbang1/Downloads/1390-7250-1PB.pdf 
- Foucault, M (1976) Vigilar y castigar. México Siglo XXI.

- Fraser, Nancy. (1997).Iustitia Interrupta. Reflexiones críticas desde la posición postsocialista .Santa Fé de Bogotá: Siglo del Hombre Editores-Universidad de los Andes.

- Freire, P. (1994) Pedagogía de la esperanza. Santiago. Siglo XXI Editores.

- Freire, P. (1970) Pedagogía del Oprimido. Santiago. Siglo XXI Editores. Santiago.

- Galeano, E. [Cadireta] $(2011,06,10)$ Utopía. [Archivo de video] recuperado de https://www.youtube.com/watch?v=1Nxafgc9Z48

- Galeano, E. (2001) En entrevista con Mauricio Beltrán Quintero. Bogotá. Fundación Colombia Multicolor.

- García, G. (2018). La cultura en 15 reflexiones de Gabriel García Márquez. Recuperado de https://centrogabo.org/gabo/contemosgabo/la-cultura-en-15-reflexiones-de-gabriel-garcia-marquez

- García, S (2010) Manual urgente para radialistas analfatécnicos. Quito. Unesco y Radialistas.net.

- Garzón, L.E: (2000) El sindicalismo se sacude. Recuperado de http://www.eltiempo.com/archivo/documento/MAM-1289855

- Geertz, C. (2003)“La interpretación de las culturas” (2003) España. Editorial Gedisa.

- Giraldo, D. (2010) Reconocimiento Fundación Víctimas Visibles. Recuperado de: http://fundacionvictimasvisibles.org/reconocimientos/58reconocimiemtomexico

- González, F. (2012) La correspondencia de Camilo Torres y Radio Sutatenza, 1962. En: Boletín Cultural y Bibliográfico. Vol 46. No. 82. Bogotá. Banco de la República.

- González, F. (1998) En “Las violencias: inclusión creciente. Centro de Estudios Sociales. Bogotá. Universidad Nacional de Colombia.

- González, et al (2001) Semilleros de investigación. Recuperado de: http://aprendeenlinea.udea.edu.co/revistas/index.php/biogenesis/articl e/view/326660

- Guerrero, A. (2018) La potencia del silencio. Recuperado de 
- www.elespectador.com/opinion/la-potencia-del-silencio-columna$735466+\& \mathrm{~cd}=2 \& \mathrm{hl}=\mathrm{es} \& \mathrm{ct}=\mathrm{clnk} \& \mathrm{gl}=\mathrm{co}$

- Gumucio, A. (2001) Haciendo olas. Historias de comunicación participativa para el cambio social. Nueva York. Fundación Rockefeller.

- Gumucio, A. (2011). Informar no es comunicar. Revista Signo y Pensamiento. No. 58

- Gramsci, A. (2003) Citado por Jesús Martín-Barbero en "Nuestras formas de estar en el mundo. Bogotá. Revista Número No. 37.

- Gramsci,A. (1984) Antología, selección, traducción y notas de M.Sacristán. Ed. Siglo XXI. Guzmán G. y Alonso A. (2007) La investigación participativa en agroecología: una herramienta para el desarrollo sustentable. Revista Ecosistemas. Recuperado de: https://www.revistaecosistemas.net/index.php/ecosistemas/article/vie wFile/135/132

- Gutiérrez, F. (1996) La mediación pedagógica y la tecnología educativa, en: Tecnología Educacional, Vol. 25 (132/ 133), Río de Janeiro, sept/dic.

- Habermas, J. (2008): «La voz pública de la religión. Recuperado de: http://www.elboomeran.com/nuevo-contenido/44/la-voz-publica-de-la-religionjurgen-habermas/

- Habermas, J. (2018) Entrevista: Jürguen Habermas: ¡Por Dios, nada de gobernantes filósofos! Recuperado de: https://elpais.com/elpais/2018/04/25/eps/1524679056_056165.html

- Habermas, J. (2014) Historia y crítica de la opinión pública. Editorial Gustavo Gili.

- Herrera, A, et al (2014) Construcción de ciudadanía e inclusión social. Bogotá. Universidad Nacional de Colombia (Vicerrectoría de Investigación). Recuperado de: http://investigacion.unal.edu.co/fileadmin/recursos/siun/img/agendas _conocimiento/06-construccion-ciudadania-inclusion-social.pdf

- Hoyos, J.J. (2009) La pasión de contar. El periodismo narrativo en Colombia. 1638-2000. Medellín. Editorial Universidad de Antioquia. Coedición con Hombre Nuevo Editores. Recuperado de: http://red.pucp.edu.pe/ridei/wp- 
content/uploads/biblioteca/160310.pdf

- Hoyos, G. (1995) . Ética comunicativa y educación para la democracia. Revista Iberoamericana de Educación. Bogotá. OEI. Recuperado de: La investigación- acción participativa. Inicios y desarrollos. Consejo de Educación de Adultos de América Latina.U.N. Colombia

- Ramírez, M.T. et al.(2006) La ehttp://sitios.itesm.mx/va/dide2/enc_innov/doctos/Eticacomunicativa _educacion_democracia.pd

- Huergo, J. (2017) Desbordes y conflictos entre la cultura escolar y la cultura mediática. Revista Nómadas. Recuperado de : http://nomadas.ucentral.edu.co/index.php/en/component/content/articl e?id=506:desbordes-y-conflictos-entre-la-cultura-escolar-y-lacultura-mediatica

- Huergo, J. (2006). Comunicación y Educación: aproximaciones. Recuperado de: http://comeduc.blogspot.com/2006/04/jorge-huergocomunicacin-y-educacin.html

- Huergo, J. (2003) Lo que articula lo educativo en las prácticas socioculturales. Instituto de Cultura Popular (Incupo) Recuperado de:

- https://perio.unlp.edu.ar/catedras/system/files/huergo-jorge_lo-quearticula-lo-educativo.pdf

- Huergo, J. (1999). La comunicación en la educación: más allá de la escolarización. En: Comunicación, Humanismo y Nuevas Tecnologías en el Espacio Escolar. Bogotá. Universidad Pedagógica Nacional.

- Iragorri, J.C. (2002) Patadas de ahorcado. Bogotá. Editorial Aguilar.

- Irizar, L. y González, J. ( 2015) Vivir e irradiar el Humanismo Cívico desde las emisoras comunitarias. Universidad Sergio Arboleda. Bogotá. E. Planeta.

- Irizar, L.B. (2009).Humanismo cívico: Una invitación a repensar la democracia. Bogotá. Konrad Adenauer Stiftung. Corporación Pensamiento Siglo XXI. Universidad Sergio Arboleda.

- Irizar, L.B. (2007) Humanismo Cívico. Recuperado de: www.usergioarboleda.edu.co/civilizar/revista13/Humanismo\%20civi 
co.pdf

- Islas, O. (2008). La sociedad de la ubicuidad, los prosumidores y un modelo de comunicación para comprender la complejidad de las comunicaciones digitales. En. Razón y Palabra. No.65. Recuperado de: http://www.razonypalabra.org.mx/N/n65/varia/oislas.html

- Islas, O. (2010) Internet 2.0: el territorio digital de los prosumidores. Recuperado de:https://dialnet.unirioja.es/servlet/articulo? codigo=3739971

- Islas, et all (2019). De prosumidores a observadores: una tendencia creciente en internet. Recuperado de:

https://docs.google.com/document/d/1M9nDZZPmn4 1QR MXrZpa qsL4NiebhGeCvxdhrMy9rU/edit.

- Jenkings, H. (2008) Convergence Culture. La cultura de la convergencia de los medios de comunicación. Barcelona. Ed. Paidós.

- Jiménez, E. (Multimedia Naranja) [Sep. 2 2013] Todos somos campesinos. Resumen paro agrario 2013. Recuperado de: https://www.youtube.com/watch?v=axFyZf7cX6g

- Kant, Immanuel (2003) ¿Qué es la Ilustración?. Bogotá. Editorial FICA.

- Kaplún, M. (2002). Una pedagogía de la comunicación. La Habana Editorial Caminos.

- Kalmanovitz, S. (1991). El desarrollo histórico del campo colombiano. En Colombia hoy. Bogotá. Siglo XXI Editores.

- Keane, J. (1997). Transformaciones estructurales de la esfera pública. México. En revista Estudios Sociológicos. Enero-abril.

- Lachance, L. (2001) Humanismo político. Individuo y Estado en Tomás de Aquino; Tr. J.

- Laclau, E. y Mouffe, Ch. (2001). Hegemonía y estrategia socialista.Madrid. Siglo XXI Editores.

- Laclau, E. (2009) [Sergiotej2]. (2009, 06, 17) Laclau sobre el concepto de democracia radical. [Archivo de video].Recuperado de .https://www.youtube.com/watch?v=4uq-1SvR7fw

- Lavacude, K. (2017) ACPO y el papel de la comunicación en el desarrollo rural de Colombia. Recuperado de: 
- http://www.elcampesino.co/acpo-papel-la-comunicacion-desarrollorural-colombia/

- Llano, A. (1999) El humanismo cívico y sus raíces aristotélicas. Navarra. Servicio de publicaciones de la Universidad de Navarra. Recuperado de: http://scriptor.typepad.com/files/pdf.pdf

- Lévy, Pierre (2004). Inteligencia colectiva. Por una antropología del ciberespacio. Washington. Organización Panamericana de la Salud.

- Liberman, J. (1997) Hablando con Cornelius Castoriadis. Recuperado de:

- http://decrecimientoybuenvivir.files.wordpress.com/2011/01/corneliu $\underline{\text { s-castoriadis decrecimiento.pdf }}$

- Lopera, J. (2016) Paternidad o procreación responsable: Iglesia católica, Acción Cultural Popular y control de la natalidad en Colombia (1964-1978). En bdigital. Recuperado de: https://webcache.googleusercontent.com/search?q=cache:WzWz_a4 UOY0J:https://revistas.unal.edu.co/index.php/hisysoc/article/view/55 $450 / 58680+\& \mathrm{~cd}=1 \& \mathrm{hl}=\mathrm{es} \& \mathrm{ct}=\mathrm{clnk} \& \mathrm{gl}=\mathrm{co}$

- López, J. I. (2008). Ciudadana Radio. El poder del periodismo de intermediación. Caracas. Ministerio de Información de Venezuela.

- López, J.I. (2015). Radio y construcción de ciudadanía. En: Revista Civilizar.Ciencias de la Comunicación. No. 02.Bogotá. Universidad Sergio Arboleda.

- López V., J.I. (1993) Comunicación popular en tiempos liberales. en Envío No 134, U. Centro Americana, Nicaragua

- López, J.I. (2014). Género dramático: 10 pasos para hacer un radioclip. Recuperado de:

- https://radialistas.net/media/uploads/descargas/guia-1_dramatizadosradioclips.pdf

- Lozano, J.C. (2007). Teoría e investigación de la comunicación de masas. México. Ed. Pearson Educación.

- Machuca Castillo, Gabriela (2006). El periodismo de investigación y la teoría crítica de la ciencia de Karl Popper. En www.saladeprensa.org. Bogotá.

- Malagón, et al (2009) Laureano Gómez, la Misión Currie y el 
proyecto de reforma constitucional de 1952. Revista Criterio Jurídico. Universidad Javeriana. Recuperado de:

- http://revistas.javerianacali.edu.co/index.php/criteriojuridico/article/vi ewFile/330/884

- Malbrán, C. (2013) La radio como herramienta Pedagógica. Buenos Aires. Ed. Corregidor.

- Martín-Barbero, J. (1983) Comunicación popular y los modelos transnacionales. En revista Chasqui. No. 8. Quito. Ciespal.

- Martín-Barbero, J. (1999) La educación en el ecosistema comunicativo. Bogotá. En revista Comunicar No. 13.

- Martín-Barbero, J. (2003) Nuestros modos de estar en el mundo. Bogotá. Revista Número No. 37 Recuperado de: www.revistacomunicar.com/index.php $\% 3$ Fcontenido $\% 3$ Ddetalles $\% 2$ 6numero\%3D13\%26articulo\%3D13-1999$03+\& \mathrm{~cd}=1 \& \mathrm{hl}=\mathrm{es} \& \mathrm{ct}=\mathrm{clnk} \& \mathrm{gl}=\mathrm{co}$

- Martín-Barbero J. \& Ochoa, A. (2005) Políticas de multiculturalidad y desubicaciones de lo popular. En libro: Cultura, política y sociedad Perspectivas latinoamericanas. Daniel Mato. CLACSO, Consejo Latinoamericano de Ciencias Sociales, Ciudad Autónoma de Buenos Aires, Argentina. 2005. pp. 181-197

- Martín-Barbero, J. (2010). De los medios a las mediaciones. Comunicación, cultura, hegemonía. Barcelona. Universidad Autónoma Metropolitana, Azcapotzalco.

- Martín-Barbero, J. ( S.f.) La nueva centralidad de la cultura en la sociedad. Recuperado de:

- http://www.oei.es/cultura2/barbero.htm

- Martín-Barbero, J. (2005). Los modos de leer. Bogotá. Centro de Competencia en Comunicación para América Latina.

- Martín-Barbero, J. (2015). ¿Desde dónde pensamos la comunicación hoy? Chasqui. Revista Latinoamericana de Comunicación. No.128, abril-julio.Quito. Ciespal.

- Martín-Barbero, J. (2017) “A los medios les hace falta país”. Recuperado de:

- http://www.semana.com/cultura/articulo/redes-sociales-y-su- 
influencia-en-colombia-jesus-martin-barbero/517343

- Martínez, T. E. ( s.f) Los hechos de la vida. Recuperado de: https://perio.unlp.edu.ar/catedras/system/files/decalogo-tomaseloy.pdf

- Martínez, T.E. (1999) Defensa de la utopía. Recuperado de: http://www.fnpi.org/es/fnpi/defensa-de-la-utop\%C3\%ADa-portom $\% \mathrm{C} 3 \% \mathrm{~A} 1$ s-eloy-mart $\% \mathrm{C} 3 \% \mathrm{ADnez}$

- Mastrini, G. (2011) Medios públicos y derecho a la comunicación: una aproximación desde América Latina. Recuperado de: http://www.portalcomunicacion.com/lecciones.asp?aut=76

- Mata, M.C. (1993). La Radio: una relación comunicativa. En revista "Diálogos de la comunicación". Felafacs.

- Mata, M.C. (2011) Comunicación popular. Continuidades, transformaciones y desafíos. En Revista Oficios Terrestres . Vol. 1 No. 16 Recuperado de:

- http://perio.unlp.edu.ar/ojs/index.php/oficiosterrestres/article/view/98 2

- Mata, M.C. (1985) Nociones para pensar la comunicación. Centro de Comunicación la Crujía. Recuperado de: http://www.agro.unc.edu.ar/ extrural/Mata.pdf

- Maturana, H. (2001) Emociones y lenguaje en educación y en política. Santiago. Editorial Dolmen.

- Maturana, H. (2010) Discurso al recibir el doctorado honoris causa, de la Universidad de Málaga. Recuperado de: https://www.uma.es/media/files/Discurso_Honoris_Maturana.pdf

- Max- Neef, Manfred. (1997) Desarrollo sin sentido. Recuperado de

- http://ecologia.unibague.edu.co/Msinsentido.pdf

- Medina, M (2013). El paro nacional agrario: cuando el mundo del trabajo se levantó. Recuperado de:

- http://www.razonpublica.com/index.php/politica-y-gobierno-temas27/7053-el-paro-nacional-agrario-cuando-el-mundo-del-trabajo-selevanto.html

- Mejía, P. (2015) Construcción de ecociudadanía a través de la radio, con enfoque en la gestión del agua en Xalapa, Veracruz. Tesis 
doctoral. Documento inédito.

- Melo, J. (2004) La libertad de prensa en Colombia: su pasado y sus perspectivas actuales. Recuperado de:

- http://www.banrepcultural.org/un-papel-a-toda-prueba/la-libertad-deprensa

- Miralles, A.M. (2002). Periodismo, opinión pública y agenda ciudadana. Bogotá. Editorial Norma.

- Moncayo, V. (2009) (Comp.) Una sociología sentipensante para América Latina. Bogotá. Siglo del Hombre Editores y CLACSO.

- Mosalve, J. et al (Productores) $(2018,13,05)$ Conoce ACPO aliado estratégico de la Universidad Sergio Arboleda. [Audio podcast].Recuperado de: https://soundcloud.com/user-658053125$\underline{718647821 / \text { conoce-acpo-aliado-estrategico-de-la-universidad-sergio- }}$ arboleda

- Montoya, A (2010) Logros y desafíos de la educomunicación desde la razón y la radio popular en estas últimas tres décadas.Bogotá. En: Revista Interacción de Cedal. No. 51

- Monzón, C. (2001) Opinión e imagen pública, una sociedad "bajo control". Bogotá. En revista Palabra Clave. Universidad de la Sabana.

- Mora, A. (2014) La historia en reserva de Radio Sutatenza. Colombia Parte I. Recuperado de: http://congreso.pucp.edu.pe/alaic2014/wpcontent/uploads/2014/11/GT12-Aura-Isabel-Mora.pdf

- Morín, E. (2000) Los siete saberes necesarios para la educación del futuro. Bogotá. Editorial Magisterio.

- Mouffe, Ch. (2016). El momento populista. Recuperado de

- https://elpais.com/elpais/2016/06/06/opinion/1465228236_594864.ht $\mathrm{ml}$

- Mouffe, Ch. (2007) El retorno de lo político. Buenos Aires. Fondo de Cultura Económica.

- Mouffe, Ch (2003). La paradoja democrática. Barcelona. Editorial Gedisa.

- Musto, S et al.(1971). Los Medios de Comunicación Social al servicio del Desarrollo Rural. Bogotá. Editorial Andes.

- Olmedo, S. (2011). Comprender la comunicación, de Antonio 
Pasquali. Revista electrónica Razón y Palabra. No. 75. Recuperado de:

- http://www.razonypalabra.org.mx/N/N75/monotematico_75/27_Olm edo_M75.pdf

- Osses, L. ( 2015) Cincuenta años de radio comunitaria en Colombia: Análisis sociohistórico (1945-1995). Recuperado de: http://www.scielo.org.co/pdf/recig/v13n16/v13n16a13.pdf

- Osses, L. (2002) Nuevos sentidos de lo comunitario: La radio comunitaria en Colombia. Recuperado de: http://conocimientoabierto.flacso.edu.mx/medios/tesis/osses_sl.pdf

- Osorio, H. (2013). Investigación. comprensión de la teoría del periodismo. Recuperado de https://bjr.sbpjor.org.br/bjr/article/view/494/471

- Ospina, W (2018) La paz del pueblo ausente. Recuperado de:

- www.elespectador.com/noticias/politica/la-paz-del-pueblo-ausentepor-william-ospina-articulo-743599

- Palacios, M. (2013). Conversatorio con Marcos Palacio. En Revista Historia y Memoria, No.6. Tunja. Universidad Pedagógica y Tecnológica de Colombia.

- Pareja, R. (1984). Historia de la radio en Colombia. 1929-1980. Bogotá. Servicio Colombiano de Comunicación Social.

- Pasquali, A. (1990.) Comprender la comunicación. (4a. ed.). Caracas. Monte Ávila Latinoamericana.

- Paz, A. (2018) Un millón de hogares campesinos tienen menos tierra que una vaca. Recuperado de: http://sostenibilidad.semana.com/impacto/articulo/concentracion-dela-tierra-en-colombia-el-1-por-ciento-de-las-fincas-mas-grandesocupan-el-81-por-ciento-de-la-tierra/40882

- Pérez, L.R. (2015) Tecnología educativa radiofónica en la frontera colombo-venezolana a mediados del siglo XX. Anuario Colombiano de Historia Social y de la Cultura. Recuperado de:

- http://search.proquest.com/docview/1707542772/D94F59DADC84E $\mathrm{B} 8 \mathrm{PQ} / 1$ ?accountid $=48417$

- Pérez, J.C., et al (2019) Apocalípticos e integrados en medio de la 
conectividad. Documento inédito. Bogotá.

- Pérez, J.C., et al (2019) El podcast y el radioclip: Lecciones de radio Sutatenza para fortalecer la Comunicación/Educación en entornos virtuales. Documento inédito. Bogotá

- Pérez, J.C. (2017) De las Escuelas Radiofónicas a las Escuelas Digitales Campesinas: El regreso de ACPO y la experiencia de Radio Sutatenza en la era de las TIC. En revista Interacción, de Cedal No. 59. Recuperado de: http://www.cedal.org.co/es/revista-interaccion/el-regreso-de-acpo-yla-experiencia-de-radio-sutatenza-en-la-era-de-las-tic

- Pérez, J.C. (2012) Ser ciudadano en la radio. Experiencias exitosas de comunicación y periodismo para la construcción de ciudadanía. Bogotá. Universidad Sergio Arboleda

- Pérez, J.C. (2015). El milagro de las EDC. Recuperado de:

- http://www.elcampesino.co/el-milagro-de-las-edc/

- Pérez, J.C. (Editor) (2015) Sonoridades Bogotanas Oportunidades para el ejercicio de la ciudadanía en las emisoras comunitarias de Bogotá . Bogotá. Documento inédito.

- Pérez, J.C. (2014). El ejercicio de la ciudadanía en la convergencia de medios, a partir de la experiencia de Radio Virtual. Bogotá. Universidad Sergio Arboleda. Documento inédito.

- Pérez, J.C. (2015) Cómo escribir para radio. Bogotá. Universidad Sergio Arboleda. Recuperado de http://antezanacc.com/docs/Como_escribir_para_radio.pdf

- Pérez, J.C. (2016) Modelo de las Escuelas Digitales Campesinas en el Encuentro Nacional de Semilleros de Investigación. Recuperado de:

- http://www.elcampesino.co/modelo-las-escuelas-digitalescampesinas-encuentro-nacional-semilleros-investigacion/

- Pérez, J.C. (2016). Experiencias de movilización social por el derecho a la comunicación en Colombia. Recuperado de: http://perio.unlp.edu.ar/ojs/index.php/actas/article/view/3614/2972

- Pérez, J.C. et al. Una mirada desde el humanismo cívico. El ejercicio de la ciudadanía en las emisoras comunitarias de Bogotá. Recuperado de: https://www.javeriana.edu.co/unesco/pdf/agendas- 
comunicacion2.pdf

- Pérez, J.C. (Productor) $(2017,29,05)$. Mundo Rural. Foro 70 años de ACPO [Audio podcast].

Recuperado de: http://www.elcampesino.co/radio-mundo-rural-foro70-anos-acpo-precios-del-cacao-ley-tierras/

- Pérez, J.C. (Productor) (2016, 18, 03). Mundo Rural entrevista a Marco Antonio Zambrano[Audio podcast]. Recuperado de http://www.fundacionacpo.org/mundo-rural-radio/

- Pérez, J.C. (Productor) (2016, 01, 04). Mundo Rural entrevista a Orlando Rendón[Audio podcast]. Recuperado de: http://www.fundacionacpo.org/mundo-rural-radio/

- Pérez, J. (Productor) (2016, 08, 04). Mundo Rural entrevista a Gladys Celis [Audio podcast].

Recuperado de http:/www.fundacionacpo.org/mundo-rural-radio/

- Pérez, J.C. (Productor) (2016, 29, 04). Mundo Rural entrevista a Juliana Ortiz [Audio podcast]. Recuperado de http://www.fundacionacpo.org/mundo-rural-radio/

- Pérez, JC. (Productor) $(2016,11,11)$ Mundo Rural. Entrevista a Kenny Lavacude [Audio podcast] Recuperado de: http://www.fundacionacpo.org/mundo-rural-radio/

- Pérez, J.C. (Productor) (2017, 08, 09). Mundo Rural entrevista a Alberto Medina[Audio podcast]. Recuperado de:

http://www.elcampesino.co/radio-mundo-rural-futuro-del-agroproceso-paz/

- Pérez, J.C. (Productor) (2016, 18, 11). Mundo Rural entrevista a Angie Marcela Alba y otras[Audio podcast]. Recuperado de: http://escuelasdigitalescampesinas.org/es/programa-radio

- Pérez, J.C. (Productor) (2016, 27, 05) Mundo Rural entrevista a Kenny Lavacude [Audio podcast] Recuperado de $\underline{\text { http://escuelasdigitalescampesinas.org/es/programa-radio }}$

- Pinilla, F. (2018) Acción colectiva por el derecho a la comunicación (Pp. 191-208). En: "Retos a la comunicación en el posacuerdo”. Ed. Universidad Nacional de Colombia. Bogotá. 
- Popper, Karl (1982) La lógica de la investigación científica. Ed. Tecnos S.A. Madrid.

- Prieto, D. ( 1992) La mediación pedagógica en el espacio de la educación universitaria. En:Revista TyCE / TyCE 25. Recuperado de: http://investigacion.ilce.edu.mx/stx.asp?id=2611\&db=\&ver=

- Prieto, D. (1994 ) La vida cotidiana en la pedagogía radiofónica. Quito. Ed. Oclacc

- Prieto, D. (2006,) El interaprendizaje como clave de la educomunicación. Revista Mediaciones. Recuperado de:

- http://biblioteca.uniminuto.edu/ojs/index.php/med/article/view/307

- Prieto Castillo, D. ((2000). La fiesta del lenguaje. México. Ediciones Coyoacán S.A

- Rahman, M.A. y Fals, O. (1991). La situación actual de las perspectivas de la investigación-acción participativa en el mundo. En Salazar, M.C. Educación primaria y secundaria en Colombia en el siglo XX. Bogotá. Ban. República.

- Ramonet, I. (2002). Cómo nos venden la moto. Barcelona. Ed. Icaria.

- Restrepo, J.D. (2008) La niebla y la brújula. Bogotá. Editorial Debate.

- Rey, G. (2013) La televisión más allá de la amnesia. Recuperado de:https://www.javeriana.edu.co/unesco/pdf/television_construccion publico2.pdf

- Rey, G. y Martín-Barbero, J. (1999) Los ejercicios del ver. Hegemonía audiovisual y ficción televisiva. Barcelona. Editorial Gedisa.

- Rey, G. (1998). Balsas y medusas. Visibilidad comunicativa y narrativas políticas. Bogotá: Cerec; Fundación Social; Fescol.

- Rincón, O. (2015) La creación de ciudadanías celebrities en las culturas bastardas. Recuperado de: https://www.javeriana.edu.co/unesco/pdf/television_construccion_pu blico2.pdf

- Rincón, O. (2005) Comunicar entre lo techno y lo retro: activismo y estéticas en experimento. Recuperado de 
https://revistas.javeriana.edu.co/index.php/signoypensamiento/article/ view/4653

- Rincón, O (2016). Los datos: la cancha donde se juega la democracia. Revista Chasqui No. 131. Ciespal. Quito.

- Rincón, O. (2008). Lo que le vamos quitando a la guerra. Medios ciudadanos en contextos de conflicto armado en Colombia. Bogotá. Centro de Competencia en Comunicación para América Latina.

- Rincón, O. (2007). Ya no es posible el silencio. Bogotá. Fescol. Bogotá.

- Rizo, M. y Rumeo, V. (2008) Investigación-Acción-Participativa y comunicación intercultural. Relato de una experiencia de investigación con estudiantes de dos universidades de la ciudad de México. Recuperado de:

- http://www.razonypalabra.org.mx/N/n65/varia/vromeu_mrizo.html

- Rocha, C. (2003). La comunicación en el conflicto escolar. Bogotá. Revista Mediaciones No.1. Uniminuto.

- Rocha, C. (2016). La Investigación Acción Participativa. Una apuesta por la comunicación y la transformación social. Bogotá. Uniminuto.

- Rodríguez, C. (2009) De medios alternativos a medios ciudadanos. Revista Folios 21 y 22. Facultad de Comunicaciones. Medellín. Universidad de Antioquia.

- Roveda, A. (Coord.). (2012) Fundamentación conceptual del módulo en procesos comunicativos. Bogotá. Afacom.

- Ruiz, Y. (Productora) (2019, 02, 05) La libertad de opinión en el debate político: entrevista con Catalina Botero y Pedro Vaca. [Audio en podcast] Recuperado de: https://www.facebook.com/rcnradio/videos/2299805783387301/UzpfSTY1MzcxNiQ 4MToxMDE1NjIwMzE1MTEwMTQ4Mg/

- Sarmiento, L.A. ( 2008) Acción Cultural Popular: un aporte a la educación de la mujer campesina en Colombia. (2008). Revista Praxis No. 4. Santa Marta.

- Sartori, G. (2003). ¿Qué es la democracia? México. Ed. Taurus Pensamiento.

- Sauvé, L. (2013) Saberes por construir y competencias por desarrollar 
en la dinámica de los debates socio-ecológicos. La Paz (Bol.) En: Revista Íntegra Educativa. (online) V.6. No. 3.

- Sierra, L.I. (2002) Globalización, multiculturalismo y comunicación. En “Comunicación, cultura y globalización. Bogotá. Centro Editorial Javeriano.

- Sims, N. (1984). Los periodistas literarios o el arte del reportaje personal. Bogotá. El Áncora Editores. Bogotá.

- Sims, N. 2009). Los periodistas literarios (Prólogo). Recuperado de:

- http://tintadelacalle.blogspot.com.co/2009/08/los-periodistasliterarios-norman-sims.html

- Svampa, M. (2008) Reflexiones sobre la sociología crítica en América Latina y el compromiso intelectual.. En Cambio de Época. Movimientos sociales y poder político. Siglo XXI y Clacso. Buenos Aires.Téllez, M.P. ( 2011) Observatorios y veedurías: Experiencias de Crítica Mediática y de construcción de ciudadanía. Revista Signo y Pensamiento. Universidad Javeriana. Recuperado de:

- http://revistas.javeriana.edu.co/index.php/signoypensamiento/article/v iew/2418/1701

- Téllez, M.P. (2012) Observatorios y veedurías: Experiencias de Crítica Mediática y de construcción de ciudadanía. Recuperado de: https://revistas.javeriana.edu.co/index.php/signoypensamiento/article/ view/2418

- Tirado, A. (1991) Colombia: Siglo y medio de bipartidismo. En “Colombia Hoy”.Bogotá .Siglo XXI Editores.

- Torres, C y Corredor, B. (1961). Las Escuelas Radiofónicas de Sutatenza-Colombia. Bogotá. Oficina Internacional de Investigaciones Sociales de Feres.

- Tubino, F. (2006) La democracia radical en contextos comunitaristas. En: Miradas que construyen (Pp. 125-146). Lima. Fondo Editorial. Universidad Católica del Perú.

- Universidad del Rosario (2009) (Anónimo) Localidad de Ciudad Bolívar Recuperado de: http://www.urosario.edu.co/Universidad-CienciaDesarrollo/ur/Fasciculos-Anteriores/Tomo-IV-2009/Fasciculo- 
3/ur/Localidad-de-Ciudad-Bolivar/

- Uribe, M.T. (Citada por Martín-Barbero, 2006) Nuestra excéntrica y heterogénea modernidad. En revista Estudios Políticos

- Urquieta, M. (1991). Amor y democracia. Conversando con Humberto Maturana. Recuperado de: http://www.paginadigital.com/articulos/2002rest/2002sept/cartas/mat 2-9.html

- Vaca, H.(2011) Procesos interactivos mediáticos de Radio Sutatenza con los campesinos de Colombia (1947-1989) . Bogotá. Revista Signo y Pensamiento. Recuperado de:http://revistas.javeriana.edu.co/index.php/signoypensamiento/articl e/view/2497/1767

- Vaca, H. ( Universidad Autónoma de Occidente) [Ab. 25. 2018] Procesos interactivosmediáticos de Radio Sutatenza con los campesinos de Colombia (1947-1989) [Archivo de video] Recuperado de: https://www.youtube.com/watch?v=bLJg0wILG7I

- Valderrama, C. (2000) Ciudadanía y comunicación. Saberes, opiniones y haceres escolares.Bogotá. Siglo del Hombre Editores, Universidad Central.

- Vargas, K. (2016). ACPO y el papel de la comunicación en el desarrollo rural de Colombia. Recuperado de:

- http://www.elcampesino.co/acpo-papel-la-comunicacion-desarrollorural-colombia/

- Verón, E. (2004), Fragmentos de un tejido. Editorial Gedisa. Barcelona.

- Verón, E.(1985) El análisis del “contrato de lectura”. Recuperado de http://www.catedras.fsoc.uba.ar/delcoto/textos/veron eliseo analisis del contrato de lectura.pdf

- Verón y Sigal (1986). Perón o muerte, los fundamentos discursivos del fenómeno peronista. Buenos Aires. Ed. Legasa.

- Verón, E. (1993) La semiosis social. Fragmento de una teoría de la discursividad. Ed. Gedisa. Barcelona.

- Villamayor, C. (2014). Las radios comunitarias, gestoras de procesos comunicacionales, 2011a 2014 .Bogotá. En Revista Mediaciones. Uniminuto. 
- Villamayor, C. ( 2006). La comunicación como perspectiva y como dimensión de los procesos sociales. Una experiencia de participación en las políticas públicas. PSA Formosa. La plata. En: UNIrevistaVol. 1, No. 3.

- Villanueva, O (1995). Camilo: Acción y utopía. Bogotá. Facultad de Ciencias Humanas. Universidad Nacional de Colombia.

- Villasante, T. (2006). La socio-praxis: un acoplamiento de las metodologías implicativas. Metodologías de investigación social. Introducción a los oficios. Recuperado de: http://contactoradio.com.co/wp-content/uploads/2014/03/La-sociopraxis.pdf

- Villasante, T, et al (2000) La investigación social participativa. Construyendo ciudadanía.Madrid. Ediciones el viejo topo.

- XBalamUV (productor) (2014, 20, 02). Diálogos Agroecológicos.-Tomás Villasante. [Archivo de video.] Recuperado de: www.youtube.com/watch?v=EFJ81xDeIyE

- Watzlawick, P. (2002). En: “Cómo nos venden la moto”. Editorial Fica. Bogotá. 2002.

- Walsh, Catherine. (2007) ¿Son posibles unas ciencias sociales/ culturales otras? Reflexiones en torno a las epistemologías decoloniales. En Revista Nómadas. No. 26. Universidad Central de Colombia. Bogotá.

- Weber, M. (1964) Economía y sociedad. F.C.E. (Segunda Ed.). México.

- Williams, R (2000) Marxismo y literatura. Ediciones Península. Barcelona.

- Winocur, R. (2007) La Participación en la Radio: Una Posibilidad Negociada de Ampliación del Espacio Público. Recuperado de: http://www.razonypalabra.org.mx/anteriores/n55/rwinocur.html

- Wolton, D. (2010) Informar no es comunicar. Ed. Gedisa. Barcelona.

- Zuleta, E. (1980) Elogio de la dificultad. Recuperado de http://www.utp.edu.co/rectoria/documentos/el-elogio-de-ladificultad.pdf 
Radio Sutatenza y Acción Cultural Popular en la era digital 